\title{
ABSTRACTS OF WORKING PAPERS IN ECONOMICS
}

This section contains abstracts and complete bibliographic information for current working papers. listed alphabetically by primary author. Brief entries appear for secondary authors, cross-referenced to the primary author. For more recent as well as historical information, consult the AWPE DATABASE, available on magnetic media from Cambridge University Press.

(Call 212-924-3900)

Abowd, John M.

PD January 1992. TI A Test of Negotiation and Incentive Compensation Models Using Longitudinal French Enterprise Data. AU Abowd, John M.: Kramarz, Francis. AA Abowd: Cornell University, INSEE, HEC. National Bureau of Economic Research. Kramarz: INSEE. SR Unite de Recherche Document de Travail ENSAE/INSEE: 9205; INSEE, Unite de Recherche, 18 Bd. Adolphe Pinard, 75675 Paris cedex 14. FRANCE. PG 21. PR no charge. JE J41, J31. KW Labor Contracts. Wage Determinants.

AB In this paper we model the determinants of firm level wages and employment explicitly allowing for firm and worker heterogeneity. Our firms have three types of workers (cadres. skilled and unskilled) and may explicitly choose from among three distinct contracting regimes (strong form efficiency, labor demand/right to manage, and incentive contracting). We apply the model to a representative sample of 1.097 French enterprises for the period 1978 to 1987 . We find that firms with enterprise level agreements appear to implement incentive contracts. This is significant because in France a firm level agreement is voluntary. On the other hand, firms without accords appear to operate on their labor demand curves. External wage rates, which we estimate for each group of workers within each firm. appear not to influence employment decisions in the manner predicted by efficient contracts regardless of the accord status of the firm.

\section{Acemoglu, Daron}

PD August 1992. TI Hedging and Nominal Contracts. AA London School of Economics. SR Centre for Economic Performance discussion Paper: 88; The Centre for Economic Performance. The London School of Economics and Political Science. Houghton Street, London WC2A 2AE. ENGLAND. PG 17. PR no charge. JE E31, C79, L14. KW Hedging. Nominal Contracts. History Dependence.

AB Why would two risk-averse agents write a nominal contract? A possible answer is that for an agent who is subject to risks caused by price variability. a nominal contract that offers hedging against these risks may be optimal. This paper argues that nominal contracts may have a role in efficiently allocating risks that are associated with changes in the price level. These risks may be fundamental to the economy or caused by imperfections. Alternatively they may be caused by the fact that other nominal contracts are written in the economy. As an additional nominal contract is preferred by an agent who has already written a nominal contract, multiple contracting equilibria may exist and nominal contracts can arise as equilibrium phenomena. Therefore this paper identifies advantages to writing nominal contracts in order to efficiently allocate risk but it also points out that under certain restrictions nominal contracts can also lead to inefficient equilibria.

\section{Agenor, Pierre-Richard}

PD August 1992. TI Inflation and Monetary Reform. AU Agenor, Pierre-Richard; Lennblad, Anna. AA International Monetary Fund. SR International Monetary Fund Working Paper: 92/60; International Monetary Fund, Washington, DC 20431. PG 19. PR not available. JE E31, E51, F31. KW Hyperinflation. Monetary Reform. Announcement Effects.

AB The introduction of a new currency has often occurred as part of a program to fight hyperinflation. In this context, nonuniform conversion rates for different types of assets and liabilities have been used as a means of reducing an initial "excess" stock of liquidity. The paper examines the anticipatory dynamics associated with such reforms. The analysis suggests that monetary reforms of this type have a deflationary effect upon announcement as well as during the transition period. Under uncertainty about the reform date, the direction of the initial jump in prices upon announcement is a priori ambiguous. Upon implementation, a monetary reform leads to a downward jump in prices.

\section{Aghezzaf, El Houssaine}

PD August 1992. TI Optimizing Constrained Subtrees of Trees. AU Aghezzaf. El Houssaine; Magnanti, Thomas L.; Wolsey, Laurence A. AA Universite Catholique de Louvain. SR Universite Catholique de Louvain CORE Discussion Paper: 9250:; Universite Catholique de Louvain. Voie du Roman Pays, 34, B-1348 Louvain-la-Neuve, BELGIUM. PG 21. PR not available. JE C44. KW Graph Theory. Weight Functions.

AB Given a tree $G=(V E)$ and a weight function defined on subsets of its nodes, we consider two associated problems. The first, called the "rooted subtree problem", is to find a maximum weight subtree. with a specified root, from a given set of subtrees. The second problem, called "the subtree packing problem", is to find a maximum weight packing of node disjoint subtrees chosen from a given set of subtrees, where the value of each subtree may depend on its root. We show that the complexity status of both problems is related, and that the subtree packing problem is polynomial if and only if each rooted subtree problem is polynomial.

\section{Aghion, Philippe}

PD August 1992. TI The Economics of Banknuptcy Reform. AU Aghion, Philippe; Hart, Oliver; Moore, John. AA Aghion: European Bank for Reconstruction and Development and DELTA. Paris. Hart: Massachusetts Institute for Technology. Moore: London School of Economics. 
SR Centre for Economic Performance Discussion Paper: 93; The Centre for Economic Performance, The London School of Economics and Political Science, Houghton Street. London WC2A 2AE, ENGLAND. PG 33. PR no charge. JE G33. G34, G38, E50. KW Bankruptcy. Firm's Debt. Firm's Shares.

AB We propose a new bankruptcy procedure. Initially, a firm's debts are cancelled, and cash and non-cash bids are solicited for the "new" (all-equity) firm. Former claimants are given shares, or options to buy shares, in the new firm on the basis of absolute priority. Options are exercised once the bids are in. Finally, a shareholder vote is taken to select one of the bids. In essence. our procedure is a variant on the U.S. Chapter 7, in which non-cash bids are possible; this allows for reorganization. We believe our scheme is superior to Chapter 11 since it is simpler. quicker. market-based, avoids conflicts. and places appropriate discipline on management.

\section{Agliardi, E.}

PD June 1991. TI Competing Technologies and Lock-in by Random Events. AA University of Cambridge. SR University of Cambridge Economic Theory Discussion Paper: 160; Department of Applied Economics, University of Cambridge, Sidgwick Avenue, Cambridge CB3 9DE, UNITED KINGDOM. PG 14. PR $\$ 5.00$ (L2.50), checks payable to University of Cambridge. JE O33. D83. KW Learning. Technology Adoption. Increasing Returns.

AB In this paper we study the choice of competing technologies with increasing returns occasioned by learningby-doing and learning-by-using phenomena. We study under what circumstance one technology can achieve a monopoly and eventually take the whole market by formulating a firm's optimal decision problem, when both uncertainty and increasing returns to adoption are present. In contrast with Arthur (1989) we allow agents to learn: the formulation of the decision problem takes into account the revision of the probabilities on the future states of the adoption process. according to a version of the two-armed bandits problem.

PD October 1991. TI Learning-By-Doing and Implications on Market Structures. AA University of Cambridge. SR University of Cambridge Economic Theory Discussion Paper: 161; Department of Applied Economics, University of Cambridge, Sidgwick Avenue, Cambridge CB3 9DE, UNITED KINGDOM. PG 26. PR \$5.00 (L2.50), checks payable to University of Cambridge. JE. L10, D83. KW Market Performance. Concentration.

AB This implications of learning-by-doing on the structure, conduct and performance of an industry are analyzed. The circumstances under which exit and changes in the degree of concentration in an industry may arise are studied, in the presence of learning possibilities when firms are assumed to be non-identical. The findings can be interpreted from the perspective of an analysis of the evolution of such an industry.

PD October 1991. TI Technology Adoption and the Optimal Rate of Obsolescence. AA University of Cambridge. SR University of Cambridge Economic Theory Discussion Paper: 162; Department of Applied Economics, University of Cambridge, Sidgwick Avenue, Cambridge CB3 9DE, UNITED KNNGDOM. PG 15. PR \$5.00 (L2.50), checks payable to University of Cambridge. JE O33, O31. KW Innovation.

AB The decision to adopt new technologies is studied through a multistage model. It incorporates multiple sequential technological innovations and the possibility of implementing technologies that have already been discovered. It is shown how such a decision is affected by the relevant parameters, i.e. the cost of adoption, the probability of discovery, the discount factor. How the decision about adoption is affected by the presence of a rival is also studied.

PD February 1992. TI Self-Reinforcing Mechanisms and Market Information. AU Agliardi, E.; Bebbinton. M. S. AA University of Cambridge. SR University of Cambridge Economic Theory Discussion Paper: 168; Department of Applied Economics, University of Cambridge, Sidgwick Avenue, Cambridge CB3 9DE, UNITED KINGDOM. PG 13. PR \$5.00 (L2.50), checks payable to University of Cambridge. JE O33. D83. KW Network Externalities. Technology. Lock-in Effect.

AB We consider the possibility of switching between two technological standards when there are network externalities and imprecise market information. Multiple equilibria in terms of market shares can arise. The main result is that lock-in to one of multiple equilibria is not a permanent outcome when the source of the lock-in is network externalities. The market lingers at prevalence of one standard with intermittent transitions to prevalence of the other. In other words. lock-in is a temporary occurrence.

\section{Ahmed, Shaghil}

TI The Importance of the Tax System in Determining the Marginal Cost of Funds. AU Croushore. Dean; Ahmed, Shaghil.

\section{Alkan, A.}

PD June 1992. TI Monotonicity and the Fair Assignment Solution. AA Universite Catholique de Louvain and Bogazici University. SR Universite Catholique de Louvain CORE Discussion Paper: 9244; Universite Catholique de Louvain, Voie du Roman Pays, 34, B-1348 Louvain-la-Neuve, BELGIUM. PG 10. PR not available. JE D61, D63. KW Assignment Problem. Fairness.

AB Given any problem involving assignment of indivisible objects and a sum of money among individuals. there is a fair assignment (namely the minmax money assignment) which can be extended monotonically to a new fair assignment for any object added or person removed, and another (the maxmin value assignment) extendable similarly for any object removed or person added. This however is the extent of compatibility between fairness and monotonicity axioms in the assignment problem. No allocation other than the minmax money allocation is extendable. An analogue holds for the maxmin value allocation by example.

\section{Allen, Polly Reynolds}

PD April 1992. TI The Dynamics of the Fundamental Determinants of the Natural Real Exchange Rate. AU Allen. Polly Reynolds; Stein. Jerome L. AA Allen: University of Connecticut. Stein: Brown University. SR Brown University Department of Economics Working Paper: 92-6; Department of Economics, Brown University, Providence. Rhode Island 02912. PG 28. PR no charge. JE F30, F31, F32, F11. KW Real Exchange Rate. Capital Movements. Foreign Debt. Growth.

AB The natural real exchange rate is the rate that would be produced in a Neoclassical economy, where aggregate demand 
is equal to capacity output and there are no noisy short term speculative capital flows. There are long term capital flows generated by productivity and thrift. which we call the fundamentals. We develop a medium to long run model of the fundamental determinants of the natural real exchange rate in an economy which satisfies the stylized facts, and is amenable to empirical testing of the hypothesis that the exchange rates have been as stable as are justified by the fundamentals. We analyze the trajectories of the real exchange rate. the capital intensity and foreign debt intensity resulting from two fundamental disturbances: a change in social saving and a change in the productivity of capital.

\section{Almekinders, Geert J.}

PD December 1992. TI Daily Bundesbank and Federal Reserve Intervention and the Conditional Variance Tale in DM/\$-Returns. AU Almekinders, Geert J.; Eijffinger, Sylvester C. W. AA Eijffinger: Board of Governors of the Federal Reserve System. Almekinders: Tilburg University. The Netherlands. SR Board of Governors of the Federal Reserve System International Finance Discussion Paper: 438; Division of International Finance. Board of Governors of the Federal Reserve System, Washington, D.C. 20551. PG 17. PR no charge. JE F31, C22. KW Foreign Exchange. Exchange Rates.

AB This paper reports on the results of an empirical investigation into the objectives of daily foreign exchange market intervention by the Deutsche Bundesbank and the Federal Reserve System in the U.S. dollar-deutschmark market. Tobit analysis is implemented to estimate the intervention reaction functions consistently. It is found that an increase in the conditional variance in daily exchange rate returns derived from GARCH model estimated in the paper, led the Bundesbank and the Federal Reserve to increase the volume of intervention, both in case of dollar-sales and purchases on account of their leaning against the wind policy.

\section{Alter, George}

PD July 1992. TI The Savings of Ordinary Americans: The Philadelphia Saving Fund Society in the Mid-Nineteenth Century. AU Alter, George; Rotella, Elyce; Goldin, Claudia. AA Alter and Rotella: Indiana University. Goldin: Harvard University and National Bureau of Economic Research. SR National Bureau of Economic Research Working Paper: 4126: National Bureau of Economic Research. 1050 Massachusetts Avenue, Cambridge, MA 02138. PG 24. PR \$5.00. JE E21. KW Savings Behavior.

AB We explore the savings behavior and saving rates of ordinary Americans through their accounts at the Philadelphia Saving Fund Society, the oldest mutual savings bank in the United States founded in 1916 to encourage thrift among the working poor. Our sample continues the 2,734 accounts opened in 1850 . of which one-quarter were linked to the 1850 census manuscripts. Savings accounts were generally brief affairs; only 30 percent lasted more than 5 years but median balances mounted to about three-quarters of annual income in about three to four years. Deposits and withdrawals were infrequent. but substantial. Account holders did not generally use their accounts for the short-run fluctuations in income we suspect they experienced.

\section{Altman, Edward I.}

PD August 1991. TI Corporate Bond Rating Drift: An
Examination of Rating Agency Credit Quality Changes Over Time. AU Altman, Edward I.; Kao, Duen Li. AA Altman: General Motors Corporation. Kao: New York University. SR New York University Salomon Brothers Working Paper: S-91-40; Salomon Brothers Center for the Study of Financial Institutions, Graduate School of Business Administration. New York University, 90 Trinity Place, New York, NY 10006. PG not available. PR not available. JE G14. KW Bond Rating.

AB not available.

\section{Altonji, Joseph G.}

PD August 1992. TI The Effects of Labor Market Experience. Job Seniority, and Job Mobility on Wage Growth. AU Altonji, Joseph G.: Williams, Nicolas. AA Altonji: Northwestern University and National Bureau of Economic Research. Williams: University of Cincinnati. SR National Bureau of Economic Research Working Paper: 4133; National Bureau of Economic Research, 1050 Massachusetts Avenue, Cambridge. MA 02138. PG not available. PR $\$ 5.00$. JE J63, J64, J60. KW Tenure. Seniority. Layoffs. Quits. AB This paper studies the returns to seniority, the returns to experience. and the effects of seniority and experience at the time of a quit or layoff on changes in the job match specific component of wages. We show that these returns are not identified in widely used regression models that relate the wage changes of stayers, quits, and layoffs to tenure and experience. We deal with the identification of problems in two ways. First. we obtain theoretical bounds on key unidentified parameters using a simple model of wages and mobility. Second. we check the implications of assumptions about the linear tenure slope for the estimates of the returns to tenure, experience and the effect of tenure on job match gains.

PD August 1992. TI The Effects of High School Curriculum on Education and Labor Market Outcomes. AA Northwestern University and National Bureau of Economic Research. SR National Bureau of Economic Research Working Paper: 4142; National Bureau of Economic Research. 1050 Massachusetts Avenue. Cambridge, MA 02138. PG not available. PR \$5.00. JE I20, I21, J24, J31. KW Education. High School. Schooling.

AB There is much public discussion but almost no evidence on the effects of high school curriculum on postsecondary education and on success in the labor market. I use the large variation in curriculum across U.S. high schools to identify the effects on wages and educational attainment of specific courses of study. The main finding is that the return to additional courses in an academic subject is small. One cannot account for the value of a year of high school with estimates of the value of the courses taken by the typical student during the year.
Alvarez, $\mathbf{F}$.
TI Banking in Computable General Equilibrium Economies. AU Diaz-Gimenez, J.; Prescott. E.; Fitzgerald. T.; Alvarez, F.

\section{Amaya, Jorge}

PD August 1992. TI Numerical Experiments with the Symmetric Affine Scaling Algorithm on Degenerate Linear Programming Problems. AA Universite Catholique de Louvain. SR Universite Catholique de Louvain CORE Discussion Paper: 9241; Universite Catholique de Louvain. Voie du Roman Pays, 34, B-1348 Louvain-la-Neuve, BELGIUM. PG 17. PR not available. JE C61, C63. 
KW Linear Program.

AB In this paper we report numerical results on the symmetric affine scaling algorithm applied to degenerate linear programming problems. The performance is measured in terms of the number of iterations needed to reach a prefixed level of tolerance. We have found that the number of iterations increases with the number of primal variables and, for most problems, slightly decreases with the increases of degeneracy. Problems are randomly generated, with a prescribed degree of degeneracy.

\section{Amel, Dean F.}

PD September 1992. TI A Dynamic Model of Entry and Performance in the U.S. Banking Industry. AU Amel, Dean F.: Liang. J. Nellie. AA Board of Governors of the Federal Reserve System. SR Board of Governors of the Federal Reserve System Finance and Economics Discussion Series: 210; C/O Stephen A. Sharpe, Mail Stop 89. Federal Reserve Board. Washington, DC 20551. PG 20. PR no charge. JE G21, L11. KW Banks. Probit Estimation. Partial Adjustment Model.

AB A two equation model of entry and market performance is estimated utilizing data on new bank and branch entry into over 2.300 local banking markets over the period 1977-88. The entry equation measures the entry response of firms to market attributes that reflect the long-term attractiveness for entry and entry barriers. The discrete nature of entry is accounted for by using probit or ordered-probit estimation procedures. Market performance, measured by return on assets, is assumed to follow a partial adjustment model towards long-run equilibrium profits, and is affected directly by entry and indirectly by entry through market structure. Estimated coefficients suggest that a competitive process is at work in banking markets that limits the ability of "above-normal" profits to persist. Coefficients suggest that high profits attract new entrants, and that entry, in turn, directly reduces market profits, particularly in rural markets. A test of strong potential competition in urban markets cannot be rejected.

\section{An, Chong-Bum}

PD July 1992. TI The "Window Problem" In Studies of Children's Attainments: A Methodological Exploration. AU An. Chong-Bum; Haveman, Robert; Wolfe, Barbara. AA An: Daewoo Research Institute. Haveman: University of Wisconsin. Wolfe: University of Wisconsin and National Bureau of Economic Research. SR National Bureau of Economic Research Technical Paper: 125; National Bureau of Economic Research. 1050 Massachusetts Avenue, Cambridge MA 02138. PG not available. PR \$3.00. JE C40, C24, C23. C50. KW Truncated Information. Children's Attainment. Econometric Methodology.

AB Numerous studies of the determinants of children's attainments rely on observations of circumstances and events at age 14 as proxies for information over the entire childhood period. Using 21 years of panel data from the Michigan PSID on 825 children who were 14-16 years old in 1979. we evaluate the effects of using truncated or "window" (e.g., age 14) information in models of the determinants of attainments (e.g.. education, nonmarital fertility) of young adults. Correlations between truncated and full-childhood variables are presented. along with 5 tests of the reliability of estimates based on "window" measurements. The tests are designed to evaluate the differential effects of data accuracy, multiple occurrence of events, duration of circumstances, and the timing of events or circumstances during childhood between "window" and full childhood information. We conclude that most of the standard truncated variables serve as weak proxies for multi-year information in such models. and draw the implications of these findings for future data-collection and research.

\section{Anderlini, Luca}

PD November 1991. TI Cooperation and Effective Computability. AU Anderlini, Luca: Sabourian, Hamid. AA University of Cambridge. SR University of Cambridge Economic Theory Discussion Paper: 167: Department of Applied Economics. University of Cambridge. Sidgwick Avenue, Cambridge CB3 9DE, UNITED KINGDOM. PG 39. PR $\$ 5.00(\mathrm{~L} 2.50)$, checks payable to University of Cambridge. JE C71, C73. KW Common Interest Game. Game Theory.

AB A Common Interest game in which there exists a unique pair of pay-offs which strictly Pareto-dominates all other payoffs. We consider the undiscounted and (the limit of) discounted repeated games obtained by the infinite repetition of such a two-player stage game. We show that if supergame strategies are restricted to be computable within Church's thesis, the only pair of pay-offs which survives any computable tremble is the Pareto-efficient pair. The result is driven by the ability of the players to use the early stages of the game to communicate their intention to play cooperatively in the future.

\section{Anderson, Gary S.}

PD September 1992. TI Symbolic Algebra Programming for Analyzing the Long Run Dynamics of Economic Models. AA University of Maryland. SR University of Maryland Department of Economics Working Paper: 92-9; University of Maryland. Department of Economics. College Park, MD 20742. PG 25. PR no charge. JE C88. C63, C50. KW Nonlinear Equation Systems. Mathematical Software.

AB This paper shows how symbolic algebra programs can facilitate the analysis of the dynamics of these nonlinear equation systems. I have used the symbolic algebra capabilities of Mathematica to develop a collection of programs for analyzing the asymptotic behavior of economic models. These symbolic programming algorithms implement a set of algorithms originally designed for numerical processing. The paper shows how to use these tools to derive formulae for characterizing the long run dynamics of economic models.

\section{Anderson, Paul F.}

TI Determining The Order and Direction of Multiple Brand Extensions. AU Dawar, Niraj: Anderson, Paul F.

\section{Anderson, S. P.}

PD August 1992. TI Probabilistic Voting and Platform Selection in Multi-Party Elections. AU Anderson, S. P.; Kats, A.: Thisse, J. - F. AA Anderson: University of Virginia. Kats: Virginia Polytechnic Institute. Thisse: Universite Catholique de Louvain and Universite de Paris I - Sorbonne. SR Universite Catholique de Louvain CORE Discussion Paper: 9246; Universite Catholique de Louvain. Voie du Roman Pays, 34, B-1348 Louvain-la-Neuve, BELGIUM. PG 23. PR not available. JE D72. D81. KW Stochastic Voting. Political Parties.

AB The literature on stochastic voting to date has focused almost exclusively on models with only two candidates (or 
parties). This paper studies multiparty competition with stochastic voting. We look at two different models in which candidates aim to maximize their expected vote, as well as a model where the objective of candidates is rank minimization. The equilibria of these models are derived and characterized. We show that the properties of the equilibria are quite different from those derived in deterministic models. Furthermore. the analysis shows that deterministic voting models are not robust since the introduction of even a minute level of uncertainty leads to a drastic change in predictions. Consequently. we argue that the deterministic model provides a misleading benchmark. Stochastic models provide a much richer framework. and the nature of the uncertainty in voter choice is a key determinant of the qualitative properties of the equilibria.

\section{Andrade, Isabel}

PD September 1992. TI Is the UK Treasury Bill Rate a Good Proxy for Expected Inflation in the UK? AU Andrade, Isabel: Clare. Andrew. AA Andrade: University of Southampton and ISEG/Universidade Tecnica de Lisboa. Clare: University of Southampton. SR University of Southampton Discussion Paper in Economics and Econometrics: 9226; Department of Economics. University of Southampton, Southampton SO9 5NH, ENGLAND. PG 7. PR no charge. JE E31, E43. KW Fisher Effect.

AB The conjecture that short term interest rates reflect agent's changing perceptions of future inflation is known as the Fisher Effect. In this paper we test for both short and long-run Fisher Effects using UK data. Using both Kalman filtering techniques and the Johansen procedure for inference on cointegrated time series we find no evidence of short or longrun Fisher Effects in the UK. Since in testing for the relationship between equity returns and expected inflation many researchers use a short government bill rate as a proxy for expected inflation. the main implication of our findings is that it would be inappropriate to use such a proxy for expected inflation in the UK.

\section{Andrews, Donald W. K.}

PD August 1992. TI Approximately Median-Unbiased Estimation of Autoregressive Models with Applications to U.S. Macroeconomic and Financial Time Series. AU Andrews, Donald W. K.: Chen. Hong-Yuan. AA Yale University. SR Yale Cowles Foundation Discussion Paper: 1026; Yale University. Cowles Foundation. Box 2125, Yale Station, New Haven CT 06520. PG 31. PR no charge. JE C22, C32. KW Autoregressive Model. Macrooconomic Time Series. Unit Root.

AB This paper introduces approximately median-unbiased estimators for univariate $\operatorname{AR}(p)$ models with time trends. Confidence intervals also are considered. The methods are applied to the Nelson-Plosser macroeconomic data series. the extended Nelson-Plosser macroeconomic data series, and some annual stock dividend and price series. The results show that most of the series exhibit substantially greater persistence than least squares estimates and some Bayesian estimates suggest. For example, for the extended Nelson-Plosser data set. eight of the fourteen series are estimated to have a unit root, while six are estimated to be trend stationary. In contrast. the least squares estimates indicate trend stationarity for all of the series.

Andrikopoulos, Andreas A.

TI The Demand for Domestic and Imported Alcohol
Beverages in Ontario, Canada. AU Brox, James A.; Carvalho, Emanuel: Andrikopoulos, Andreas A.

PD July 1992. TI Cost Structure, Inter-Factor Substitution and Complementarity, and Efficiency in the Canadian Agricultural Sector. AU Andrikopoulos. Andreas A.: Brox. James A. AA Andrikopoulos: University of Waterloo. Brox: University of Waterloo and University of British Columbia. SR University of British Columbia Department of Economics Discussion Paper: 92-13; Department of Economics, University of British Columbia 997-1873 East Mall, Vancouver, B.C. Canada V6T 1 W5. PG not available. PR JE Q12. KW Agriculture. Cost Function. Efficiency.

AB The purpose of this paper is to investigate the coststructure. pairwise input relationships. and the technological aspects of the Canadian agricultural sector. The theoretical approach applied in this investigation is the CES-translog production technology in its generalized form. The theoretical model has been tested by using time series data (1947-1985) and four factors of production (i.e., land. capital. labor, and intermediate inputs). The method used to estimate the model is the full-information maximum likelihood technique.

\section{Anjaria, Shailendra J.}

PD August 1992. TI Working Paper Summaries. AA International Monetary Fund. SR International Monetary Fund Working Paper: 92/58; International Monetary Fund, Washington, DC 20431. PG 47. PR not available. JE A00. KW Abstracts. Paper Summaries.

AB This compilation of summaries of Working Papers released during January-June 1992 is being issued for the first time as a part of the Working Paper series. It is designed to provide the reader with an overview of the research work performed by the staff during the period. Future compilations of summaries will be issued at six-month intervals.

Antoniewicz, Rochelle L.

PD August 1992. TI A Causal Relationship Between Stock Returns and Volume. AA Board of Governors of the Federal Reserve System. SR Board of Governors of the Federal Reserve System Finance and Economics Discussion Series: 208; C/O Steven A. Sharpe. Mail Stop 89. Federal Reserve Board. Wash., DC 20551. PG 50. PR no charge. JE C14, C32, G13. KW Linear Causality. Nonparametric Specification Test. Vector Autoregression.

AB A causal relationship between daily trading volume and stock returns is explored for a broad cross-section of individual securities The main result shows volume leads returns by one day for roughly 44 percent of the securities. A bivariate VAR attempts to capture this joint behavior of volume and return. A nonparametric specification test indicates the model weakly underestimates the conditional mean return and more strongly underestimates the conditional variance. This implies a positive effect from abnormally high volume onto expected return remains unaccounted for in the VAR model.

\section{Arias, Maria Eugenia}

PD 1992. TI The Transfer of Organizational Management Techniques Across Borders: Combining Neo-Institutional and Comparative Perspectives. AU Arias, Maria Eugenia; Guillen, Mauro F. AA Arias: INSEAD. Guillen: Yale University. SR INSEAD Working Papers: 92/41/OB; INSEAD, Boulevard de Constance, Fontainebleau, 77305 
Cedex, FRANCE. PG 36. PR not available. JE L.20, L22, M10. KW Organizational Management. International Transfers. Organizational Behavior.

AB In this paper we propose combining elements from the neo-institutional school on organizations with elements drawn from the comparative world-systemic approach to macroscopic process of social change to study the transfer of organizational mangement techniques across national boundaries. We first show the limitations of previous research on international transfers. We then discuss the applicability of neo-institutional theory to the study of international transfers and suggest ways it can be modified to deal with cross-national flows. We conclude by putting forth a number of propositions to guide empirical work.

\section{Ashayeri, Jalal}

TI Strategic Marketing, Production, and Distribution Planning of an Integrated Manufacturing System. AU Van Wassenhove. Luk: Ashayeri, Jalal: Pourbabai, Behnam.

\section{Ashenfelter, Orley}

PD August 1992. TI Estimates of the Economic Return to Schooling from a New Sample of Twins. AU Ashenfelter. Orley: Krueger, Alan B. AA Princeton University and National Bureau of Economic Research. SR National Bureau of Economic Research Working Paper: 4143; National Bureau of Economic Research, 1050 Massachusetts Avenue, Cambridge. MA 02138. PG not available. PR \$5.00. JE I21, I20, J24, J31. KW Schooling. Returns to Schooling.

AB This paper uses a new survey to contrast the wages of genetically identical twins with different schooling levels. Multiple measurements of schooling levels were also collected to assess the effect of reporting error on the estimated economic returns to schooling The data indicate that omitted ability variables do not bias the estimated return to schooling upward. but that measurement error does bias it downward. Adjustment for measurement error indicates that an additional year of schooling increases wages by $16 \%$, a higher estimate of the economic returns to schooling than has been previously found.

\section{Aumann, Robert J.}

PD September 1992. TI Long-Term Competition- A Game Theoretic Analysis. AU Aumann, Robert J.: Shapley, Lloyd S. AA Aumann: Hebrew University of Jerusalem. Shapley: University of California, Los Angeles. SR University of California at Los Angeles Department of Economics Working Paper: 676; Department of Economics, University of California at Los Angeles, 2263 Bunche., Los Angeles. CA 90024. PG 17. PR \$2.50; checks payable to U.C. Regents. JE C72. KW Folk Theorem. Perfect Equilibrium. Repeated Games.

AB Quite a bit is known about Nash noncooperative equilibria in "continuingly competitive" situations, and we shall review some of this material here. It turns out that individual self-interest in such situations can in fact dictate a kind of cooperative behavior, in many cases, sustained by the fear of "punishment" by the other players for failing to "cooperate" with the general plan--this in spite of the fact that the player have no way of legally binding themselves to carry out such punishment. The ability of the noncooperative theory to describe such arrangements and to account for their stability in a "selfish" world is an encouraging point in its favor. The price that is paid, however, is the high degree of nonuniqueness in the Nash solutions. which removes from this theory most of its predictive power.

\section{Backus, D.}

PD November 1991. TI International Real Business Cycles. AU Backus. D.: Kehoe. P.: Kydland. F. AA Backus: New York University. Kehœe: University of Minnesota and Federal Reserve Bank of Minneapolis. Kydland: Carnegie-Mellon University. SR Federal Reserve Bank of Minneapolis Staff Report: 146; Research Department, Federal Reserve Bank of Minneapolis, 250 Marquette Ave. Minneapolis. MN 55401. PG 24. PR no charge. JE E32, F41. KW Trade Dynamics. Capital Mobility.

AB We ask whether a two-country real business cycle model can account simultaneously for domestic and international aspects of business cycles. With this question in mind. we document a number of discrepancies between theory and data. The most striking discrepancy concerns the correlations of consumption and output across countries. In the data, outputs are generally more highly correlated across countries than consumptions. In the model we see the opposite.

PD April 1992. TI International Evidence on the Historical Properties of Business Cycles. AU Backus, D.; Kehoe. P. AA Backus: New York University. Kehoe: Federal Reserve Bank of Minneapolis. SR Federal Reserve Bank of Minneapolis Staff Report: 145; Research Department. Federal Reserve Bank of Minneapolis, 250 Marquette Ave., Minneapolis. MN 55401. PG 25. PR no charge. JE E32, E31, 057, N10. KW Output Volatility. Prices.

AB We contrast properties of real quantities with those of price levels and stocks of money for ten countries over the last century. Although the magnitude of output fluctuations has varied across countries and periods, relations among real quantities have been remarkably uniform. Properties of price levels, however, exhibit striking differences between periods. Inflation rates are more persistent after World War II than before, and price level fluctuations are typically procyclical before World War II, countercyclical afterward. Fluctuations in money are less highly correlated with output in the postwar period. but are no more persistent than in earlier periods.

PD July 1992. TI In Search of Scale Effects in Trade and Growth. AU Backus, D.; Kehoe, P.; Kehoe, T. AA Backus: New York University. Kehoe, P. and T.: University of Minnesota and Federal Reserve Bank of Minneapolis. SR Federal Reserve Bank of Minneapolis Staff Report; 152; Research Department. Federal Reserve Bank of Minneapolis. 250 Marquette Ave., Minneapolis, MN 55401. PG 28. PR no charge. JE O41, F12. KW Increasing Returns. Human Capital.

AB We look for the scale effects predicted by some theories of trade and growth based on the dynamic returns to scale that arise from leaming by doing, investment in human capital, or development of new products. We find little empirical evidence of a relation between the growth rate of GDP per capita and the measures of scale implied by the theory. Restricting attention to the manufacturing sector, however, we find a significant relation between the growth rate of output per worker and the relevant scale variables. We also find that growth rates are significantly related to measures of intra-industry trade. 
Bagwell, Laurie Simon

PD September 1992. TI Conspicuous Consumption, Pure Profits and the Luxury Tax. AU Bagwell. Laurie Simon: Bernheim, B. Douglas. AA Bagwell: Northwestern University. Bernheim: Princeton University and National Bureau of Economic Research. SR National Bureau of Economic Research Working Paper: 4163: National Bureau of Economic Research, 1050 Massachusetts Avenue, Cambridge, MA 02138. PG 34. PR \$3.00. JE D11, H21, H23. KW Excise Tax. Utility Taxation.

AB We examine a model of conspicuous consumption and explore the nature of competition in markets for conspicuous goods. We assume that. in addition to intrinsic utility, individuals seek status, and that perceptions of wealth affect status. Under identifiable conditions, the model generates Veblen effects: utility is positively related to the price of the good consumed. Equilibria are then characterized by the existence of "budget" brands (which are sold at a price equal to marginal cost). as well as "luxury" brands (which are sold at a price above marginal cost, despite the fact that producers are perfectly competitive). Luxury brands are not intrinsically superior to budget brands but are purchased by consumers who seek to signal high levels of wealth. Within the context of this model, an appropriately designed luxury tax is a nondistortionary tax on pure profits.

\section{Banerji, Rukmini}

PD March 1992. TI Agricultural Conditions and Children's Work and Schooling in Rural India: A District Level Analysis. AA University of Chicago. SR Economics Research Center/NORC Discussion Paper: 92-4: Economics Research Center/NORC, 1155 E. 60th St. Eilis, Chicago, Illinois 60637. PG 50. PR \$2.00; send requests to Librarian. NORC. JE I20, O20. KW Education. Gender. Agriculture.

AB In the last several decades. India has witnessed major social and economic changes. Two important developments have been a rapid expansion of the education system and dramatic increases in overall agricultural production. Agricultural growth, however, has been uneven. Some parts of India have prospered as a result of the "green revolution" while other parts have remained backward. In education as well, while the increases in overall enrollments have been impressive various educational inequalities persist. This paper focuses on rural India, and uses district level data from 1971 to examine patterns of children's school attendance and participation in different work activities in the context of wide variations in production and stratification conditions in the agricultural sector, and in government expenditures on education across the country. The paper finds that rural children's participation in work and attendance in school varies considerably by gender.

\section{Barany, Imre}

PD November 1992. TI The Complex of Maximal Lattice Free Simplices. AU Barany. Imre; Howe, Roger; Scarf. Herbert E. AA Barany: Mathematical Institute, Budapest. Howe and Scarf: Yale University. SR Yale Cowles Foundation Discussion Paper: 1032; Yale University. Cowles Foundation, 30 Hillhouse Ave., Box 2125, Yale Station, New Haven CT 06520. PG 15. PR no charge. JE C61. KW Integer Programming.

AB The simplicial complex $K(A)$ is defined to be the collection of simplices, and their proper subsimplices. representing maximal lattice free bodies of the form $\{x$ : $A x$ is less than or equal to $b$ J, with $A$ a fixed $(n+1) \times n$ matrix. The topological space associated with $K(A)$ is shown to be homeomorphic to $n$-dimensional Euclidean space and the space obtained by identifying lattice translates of these simplices is homeomorphic to the n-torus.

\section{Barham, Vicky}

PD June 1992. TI Volunteer Work and Club Size: Nash Equilibrium and Optimality. AU Barham, Vicky; Boadway, Robin: Marchand, Maurice; Pestieau, Pierre. AA Barham and Marchand: Universite Catholique de Louvain. Boadway: Queen's University. Pestieau: Universite Catholique de Louvain and Universite de Liege. SR Universite Catholique de Louvain CORE Discussion Paper: 9240.: Universite Catholique de Louvain. Voie du Roman Pays, 34, B-1348 Louvain-la-Neuve, BELGIUM. PG 20. PR not available. JE C72, J22, J31, J32. KW Game Theory. Volunteer Labor Supply.

AB The non-cooperative provision of public goods is analyzed in the context of a two-stage game in which club size is determined endogenously. Equilibrium club size and voluntary labor supply are shown to be inefficient. The impact of optimally-chosen fiscal policies using simple instruments is studied. When agents do not derive nonpecuniary benefits from volunteer work, lump-sum grants can be used to implement the first-best equal treatment allocation but private provision is fully crowded out. Otherwise, it is found that simple fiscal instruments cannot implement the first-best equal-treatment allocation unless club size is directly regulated.

\section{Bauwens, L.}

PD August 1992. TI Approximate HPD Regions for Testing Residual Autocorrelation Using Augmented Regressions. AU Bauwens, L.; Rasquero, A. AA Bauwens: Universite Catholique de Louvain. Rasquero: GREQE. SR Universite Catholique de Louvain CORE Discussion Paper: 9238: Universite Catholique de Louvain. Voie du Roman Pays, 34, B-1348 Louvain-la-Neuve. BELGIUM. PG 16. PR not available. JE C11, C15, C22. KW Bayesian Analysis. Autoregressive Process.

AB We evaluate two tests of residual autocorrelation in the linear regression model in a Bayesian framework. Each test checks if an approximate highest posterior density region of the parameters of the autoregressive process of the error contains the null hypothesis. The approximation consists in computing the posterior density of the coefficients of the AR process using augmented regressions. The first test uses the initial regression augmented with its lagged Bayesian residuals and can be done with tables of the Fisher distribution. The second test augments the initial regression with lagged dependent and explanatory variables, and requires numerical integration. The tests are evaluated through a small Monte-Carlo experiment, which indicates that the first test (easier to compute) is more powerful than the second one.

\section{Bayet, A.}

PD September 1992. TI Relations Verticales, Integration et Barrieres a l'Entree. AU Bayet, A.; Rosenwald, F. AA Bayet: ENSAE. Rosenwald: INSEE. SR Unite de Recherche Document de Travail ENSAE/INSEE: 9217; INSEE, Unite de Recherche, 18 Bd. Adolphe Pinard, 75675 Paris cedex 14. FRANCE. PG 14. PR no charge. JE L22. 
KW Entry Barriers. Vertical Restraints. Entry Deterrence. AB The aim of this paper is to study the role of integration or of long-term contracts within vertical structures trying to protect themselves against the entry of potential competitors. The initial vertical structure is composed of a producer and a retailer; they are in different situations, for the producer is upstream and the retailer is in an intermediate position between downstream and upstream; this difference doesn't have any consequence as long a producer and retailer are in a position of monopoly but will lead to asymmetries when the initial structure faces potential entrants. The paper is written in French.

\section{Bean, Charles}

PD July 1992. TI Economic and Monetary Union in Europe. AA London School of Economics. SR Centre for Economic Performance Discussion Papers: 86; The Centre for Economic Performance. The London School of Economics and Political Science, Houghton Street, London WC2A 2EA, ENGLAND. PG 36. PR no charge. JE F33. E58, H77. KW European Monetary Union. Fiscal Federalism.

AB This paper assesses the costs and benefits of monetary union in Europe. It is argued that neither the costs nor the benefits are in principle likely to be as great as critics and proponents respectively have suggested. Fiscal issues are, it is argued. likely to be far more significant. Fiscal federalism is by no means a necessary corollary of monetary union and the "Maastricht rules" on public debt and deficits will place harmful constraints on national fiscal policies. Finally the Community's Structural Funds are unlikely to be the most efficient way of redistributing resources between member states.

\section{Beaulieu, J. Joseph}

TI Seasonal Unit Roots in Aggregate U.S. Data. AU Miron, Jeffrey A.; Beaulieu. J. Joseph.

\section{Bebbinton, M. S.}

TI Self-Reinforcing Mechanisms and Market Information. AU Agliardi, E.; Bebbinton, M. S.

\section{Beichman, Arnold}

PD October 1992. TI Can Our Civilization Survive? AA Stanford University. SR Stanford Hoover Institute International Studies Working Paper: I-92-12; The Hoover Institution, Stanford University, Stanford, CA 94305. PG 31. PR no charge. JE A13. KW Anti-Americanism. Western Civilization.

AB There is an ever-growing anti-Americanism among the influential Marxist intellectuals who teach or write in the social sciences. Even more alarming is that the focus of intellectual attack is not only the United States but Western civilization. In attacking Western Civilization, these intellectuals are renouncing its three fundamental concepts: 1 . The idea that there is such a thing as objective truth. 2 . That there is meaning to the Judeo-Christian tradition. 3. That there is meaning to traditional moral precepts and traditional moral laws.

\section{Benhabib, Jess}

PD November 1991. TI Indeterminacy and Increasing Returns. AU Benhabib, Jess; Farmer, Roger E. A. AA Benhabib: New York University. Farmer: University of California, Los Angeles. SR University of Cambridge
Economic Theory Discussion Paper: 165; Department of Applied Economics. University of Cambridge. Sidgwick Avenue, Cambridge CB3 9DE, UNITED KINGDOM. PG 21. PR \$5.00 (L2.50), checks payable to University of Cambridge. JE O41, E32, D62. D43. KW Growth Model. Externalities. Monopolistic Competition.

AB We investigate the properties of the one-sector growth model with increasing returns. Two possible organizational structures are provided, each of which is capable of reconciling the existence of increasing returns in the aggregate technology with competitive behavior by firms. The first of these involves input externalities and the second monopolistic competition. We show, for parametric values that are in close accord with recent literature in real business cycle theory, that the model displays in indeterminate steady state. We point out that one may exploit this indeterminacy to generate a model of business cycle fluctuations that is driven by the self-fulfilling beliefs of the agents in the model.

PD December 1991. TI The Aggregate Effects of Monetary Externalities. AU Benhabib, Jess; Farmer, Roger E. A. AA Benhabib: New York University. Farmer: University of California, Los Angeles. SR University of Cambridge Economic Theory Discussion Paper: 164; Department of Applied Economics, University of Cambridge. Sidgwick Avenue, Cambridge CB3 9DE. UNITED KINGDOM. PG 28. PR $\$ 5.00(\mathrm{~L} 2.50)$, checks payable to University of Cambridge. JE E42, D62, C51. KW Transaction Externality. Rational Expectations. Monetary Economy.

AB A theoretical model of the monetary economy is constructed in which money is used to facilitate exchange. Our model differs from existing approaches by allowing an important role for an externality in transacting. We calibrate the model and argue that the calibrated model has rational expectations equilibria in which beliefs may influence allocations independently of fundamentals. One of these equilibria provides a way of understanding the covariance of prices and money in small vector autoregressions.

PD September 1992. TI A Note on the Political Economy of Immigration. AA New York University. SR New York University Economic Research Reports: 92-42; New York University, Faculty of Arts and Science. Department of Economics, Washington Square. New York. N.Y. 10003. PG 13. PR no charge. JE D31, J11, F22, 015. KW Wealth Distribution.

AB We study how immigration policies that impose capital and skill requirements would be determined under majority voting when natives differ in their wealth and vote for policies that maximize their income. We also consider political outcomes when the economy grows, immigration is continuous and immigrants gradually acquire voting rights.

PD October 1992. TI The Role of Human Capital in Economic Development: Evidence from Aggregate CrossCountry and Regional U.S. Data. AU Benhabib, Jess; Spiegel. Mark M. AA New York University. SR New York University Economic Research Reports: 92-46; New York University, Faculty of Arts and Science, Department of Economics, Washington Square, New York, N.Y. 10003. PG 27. PR no charge. JE O41, 051, O57, 015. KW Growth. Capital Accumulation.

AB We use international cross-country and regional United States estimates of physical and human capital accumulation to run the growth accounting regressions implied by an aggregate 
production function based upon a Cobb-Douglas technology. Our results indicate that human capital either enters insignificantly in explaining per capita growth rates, or with the incorrect sign. We next entertain alternative roles for human capital in economic growth. We specify a growth model in which the Solow residual, or the growth rate of total factor productivity, depends on a nation's human capital stock. Tests of the specification implied by this model do indeed indicate a positive role for human capital. Finally, we find that a limited role in explaining growth exists for "ancillary variables." such as political instability and income distribution, once one has accounted for differences in rates of factor accumulation.

\section{Bennett, Adam}

PD August 1992. TI Interest Rate Policy in Central and Eastern Europe: The Influence of Monetary Overhangs and Weak Enterprise Discipline. AU Bennett. Adam; Schadler. Susan. AA International Monetary Fund. SR International Monetary Fund Working Paper: 92/68; International Monetary Fund, Washington. DC 20431. PG 19. PR not available. JE E52, E61, E65. KW Interest Rates. Macroeconomic Policy. Monetary Overhang.

AB Interest rate policy in the newly reforming Central and Eastern European countries has generally been geared toward establishing positive real interest rates and defending the exchange rate. The principal instrument for this task has been administrative increases in controlled interest rates. This paper examines the effect of these adjustment on inflation, the real interest rate, and the exchange rate. It points out the risk that when financial discipline over enterprises is weak raising nominal interest rates may do little more than raise credit growth, the rate of depreciation and ultimately inflation. Simulations attempt to shed light on the importance of these linkages.

\section{Berger, Allen N.}

PD October 1992. TI Bank Efficiency Derived from a Profit Function. AU Berger, Allen N.; Hancock, Diana; Humphrey, David B. AA Berger and Hancock: Board of Governors of the Federal Reserve System. Humphrey: Florida State University. SR Board of Governors of the Federal Reserve System Finance and Economics Discussion Series: 211: C/O Stephen A. Sharpe, Mail Stop 89, Federal Reserve Board, Washington, DC 20551. PG 41. PR no charge. JE G21, D21. KW Banking. Joint Production. Specialization.

AB Both input and output inefficiencies are derived from a profit function for U.S. banks. These inefficiencies are decomposed into allocative and technical components in a new way using shadow prices. About half of all potential variable profits are estimated to be lost to inefficiency. Most inefficiencies are from deficient output revenues, rather than excessive input costs. Larger banks are found to be more efficient than smaller banks, which may offset scale diseconomies found elsewhere. Tests of a new concept, "optimal scope economies." suggest that joint production is optimal for most banks, but that specialization is optimal for others.

\section{Berlin, Mitchell}

PD August 1992. TI Universal Banking: Should Banks Hold Equity in Borrowing Firms? AU Berlin, Mitchell; John. Kose; Saunders, Anthony. AA New York University.
SR New York University Salomon Brothers Working Paper: S-92-45; Salomon Brothers Center for the Study of Financial Institutions, Graduate School of Business Administration, New York University, 90 Trinity Place, New York, NY 10006. PG 21. PR not available. JE G21, G28, G11. KW Banking Regulation.

AB This paper develops a theoretical model of an informed universal bank that may hold both the equity and debt claims of commercial firms. The optimal debt-equity mix for an informed universal bank is structured to mitigate conflicts of interest between the firm and its fixed claimants, especially its uninformed non equity stakeholders. Specifically, we focus on the bank's role in mitigating two potential conflicts of interest: (i) the firm's incentive to seek unnecessary concessions from uninformed stakeholders, and (ii) the firm's incentive to shift risk to fixed claimants by choosing excessively risky investment projects. It is shown that an informed bank can convince uninformed nonequity stakeholders to make necessary concessions to a financially distressed firm by committing to a ceiling on its equity share when the firm is in distress.

\section{Bernheim, B. Douglas}

TI Conspicuous Consumption, Pure Profits and the Luxury Tax. AU Bagwell, Laurie Simon; Bernheim, B. Douglas.

\section{Berry, Steven T.}

PD August 1992. TI The Automobile Industry and the Mexico-U.S. Free Trade Agreement. AU Berry. Steven T:; Lopez-de Silanes, Florencio; Grilli, Vittorio. AA Berry: Yale University and National Bureau of Economic Research. Lopez-de-Silanes: Harvard University. Grilli: University of London, Centre for Economic Policy Research, and National Bureau of Economic Research. SR National Bureau of Economic Research Working Paper: 4152; National Bureau of Economic Research, 1050 Massachusetts Avenue, Cambridge, MA 02138. PG not available. PR \$5.00. JE L92, F13, F14, F17. KW Trade. Auto Industry. Mexico.

AB This paper considers the likely effect on the automobile industry of a free trade agreement between the U.S. and Mexico. As there are currently large restrictions on imports into Mexico, one important outcome of a free trade agreement would be the opening of the Mexican market to U.S. producers. The current state of the Mexican Auto industry is considered in great detail, suggesting that the Mexican industry will continue to prosper, increasing output but also relying heavily on production from U.S. owned plants and on inputs imported from the U.S. and Canada. However, much of the existing domestically oriented industry is likely to be replaced by other North American producers. Finally, an econometric demand analysis implies that economic growth together with declines in prices to world levels could rapidly expand the size of the Mexican auto market. The free trade agreement represents an opportunity for product diversification and rationalization in the auto industry.

\section{Bertaut, Carol}

PD June 1992. TI Precautionary Portfolio Behavior. AU Bertaut. Carol; Haliassos. Michael. AA University of Maryland. SR University of Maryland Department of Economics Working Paper: 92-8; University of Maryland. Department of Economics, College Park, MD 20742. PG 27. PR no charge. JE G11, E44. KW Consumption CAPM. 
Stockholding.

AB We compute optimal portfolios for a multi-period CCAPM with income and stockholding risk, and then confront results with data from the Survey of Consumer Finances. The main source of CCAPM puzzles is low-income households. Their average holdings of liquid riskless assets far exceed their stockholding; and costly borrowing coexists with low-rate liquid assets. Typical estimates of income risk lower demand for stocks relative to liquid assets, but appear insufficient to account for portfolio data. even when bad states involve very low incomes. The combination of income risk, risk aversion, and a wedge between borrowing and lending rates preclude stockholding at zero wealth, and bring stockholding at low net worth close to the data for young households. When the model accounts for stockholding, it usually underpredicts holdings of riskless assets. The neglected role of the latter in transactions may be contributing to this underprediction.

\section{Bertocchi, Graziella}

PD October 1992. TI Learning, Experimentation and Monetary Policy. AU Bertocchi, Graziella; Spagat, Michael. AA Brown University. SR Brown University Department of Economics Working Paper: 92-23; Department of Economics, Brown University, Providence, Rhode Island 02912. PG 15. PR no charge. JE D83, EO0, E52. KW Experimentation. Monetary Policy. Learning.

AB We present a model of monetary policy where the policymaker faces uncertainty about which he is learning in a Bayesian fashion. A fixed money supply rule is not optimal since the learning leads to adjustments in the monetary action. We present cases in which it is optimal to bear some cost in terms of current output performance in order to gain information that can be used in the formulation of future monetary policy: experimentation therefore pays. We also show that even passive learning without experimentation still leads to an activist monetary policy, i.e., one that is responsive to new information.

\section{Betancourt, Roger R.}

PD May 1992. TI An Analysis of the U.S. Distribution System. AA University of Maryland. SR University of Maryland Department of Economics Working Paper: 92-6; University of Maryland. Department of Economics, College Park, MD 20742. PG 61. PR no charge. JE L81. KW Distribution. Foreign Trade.

AB This study starts with a conceptual framework for the analysis of distribution systems and it proceeds by applying this framework to the U.S. distribution system. It considers the size. structure and operation of the U.S. system from this point of view, with special emphasis on what happened in the 1980's. It identifies several important factors in the functioning of the system and assesses their implications for the system's role in foreign trade.

PD September 1992. TI The Distribution Sector in a CPE: Cuba. AA University of Maryland. SR University of Maryland Department of Economics Working Paper: 92-10; University of Maryland, Department of Economics, College Park, MD 20742. PG 20. PR no charge. JE L81, P23. P27, 017. KW Central Planning. Rationing. Black Market. AB In this paper we present a conceptual framework for the analysis of the distribution sector and discuss the modifications necessary for its application to a centrally planned economy. The main characteristics of the distribution sector in Cuba during the 1980's are described using primarily the data available in the Statistical Yearbook. The evolution of this sector is analyzed in terms of the role played by the rationing system, alternative markets (both farmers markets and government run parallel markets) and illegal or informal sector activities. Several findings are striking: The deterioration in the level of economic activity in this sector since 1985, preceding the demise of other CPEs; the growth of economic activity in both alternative markets from 1982-1985; the importance of the food sector in Cuba's distribution system; and significant signs of a repressed demand for distribution services.

PD September 1992. TI An International Comparison of the Determinants of Retail Margins. AU Betancourt, Roger R.; Gautschi, David A. AA Betancourt: University of Maryland. Gautschi: University of Washington. SR University of Maryland Department of Economics Working Paper: 92-11; University of Maryland, Department of Economics, College Park, MD 20742. PG 22. PR no charge. JE L81, D21, D23. KW Distribution. CrossCountry Comparison.

AB In this paper we compare the results of applying a new economic framework for the analysis of retail margins to 1982 interindustry retail data for France. Germany, and the U.S. Use of the same theoretical framework and econometric methodology separately for each of the three bodies of data yields robust empirical regularities with respect to functional form and the role of distribution services in explaining retail margins. An interesting feature of these results is that they arise despite substantial differences in classification and in the retail environment of the three countries.

\section{Bhagwati, Jagdish}

PD November 1991. TI The Stolper-Samuelson Theorem: Then and Now. AA Columbia University. SR Columbia University Department of Economics Discussion Paper: 606; Department of Economics. Columbia University, New York, New York 10027. PG 6. PR \$5.00. JE F10, A11. KW Stolper-Samuelson Theorem. Tribute.

AB The celebration of the Stolper-Samuelson theorem is a splendid idea. The Stolper-Samuelson theorem has all the virtues of a major scientific construct in economics, It has the power of paradox: it demonstrated. contrary to earlier intuition that one could unambiguously infer changes in real wages. resulting from goods price changes, without having to discover who consumed what. Then again, by the critical test of marginal productivity, it has been a roaring success: it has produced an unceasing flood of research, as scores of us have follow where the masters led. Indeed, the Schumpeterian followers among us have wandered off in many directions. Following comparative advantage, mindful that familiarity breeds good science, and recognizing that others will describe the paths down which they went. I shall focus only on the three major ways in which I participated in the development of the Stolper-Samuelson analysis.

PD January 1992. TI U.S. Immigration Policy. AA Columbia University. SR Columbia University Department of Economics Discussion Paper: 605; Department of Economics, Columbia University, New York. New York 10027. PG 16. PR \$5.00. JE F22. F01. KW Immigration. Refugees.

AB Two different sets of emerging issues, one national and the other international are addressed in this paper: first. the 
growing shift in our legal immigration policy towards admitting skilled people; and second, the dramatic escalation in the world economy and policy of the flows of refugees and displaced persons, currently constituting a stock of 17 million by the UN High Commissioner of Refugees, and the likely prospect of substantial illegal flow from the developing to the developed countries due to demographic factors and the growing network of migration streams that provide the conduits facilitating the influx of illegal and legal migrants. In the former case, the United States policy needs to be extended in several directions. In the latter case, the United States needs to undertake dramatic new initiatives to fill the lacuna on migration questions in the array of international instructions created at Bretton Woods and subsequently in the postwar period.

PD April 1992. TI Regionalism and Multilateralism: An Overview. AA Columbia University. SR Columbia University Department of Economics Discussion Paper: 603; Department of Economics. Columbia University. New York. New York 10027. PG 39. PR \$5.00. JE F10, F13. KW International Trade. Trading Blocs.

AB Arguing that multilateralism among the trading nations is a shared objective of most economists, the paper differentiates between two main questions raised by regionalism today: 1) The Static Impact-Effect Question: Would preferential trading arrangements be trade-diverting or trade-creating; and what can we do to ensure that they are the latter? 2) The Dynamic-Time Path Question: Whether these arrangements are immediately trade-diverting or trade-creating, will they expand and will the process of such coagulation of subsets of "trading blocs" lead to eventual multilateral free trade among all, or will these arrangements lead to a fragmentation of the world trading system; and in turn how does this process compare with the multilateral process (such at the GATT) as a way of getting to multilateralism for all?.

PD April 1992. TI Fair Trade, Reciprocity and Harmonization: The New Challenge to the Theory and Policy of Free Trade. AA Columbia University. SR Columbia University Department of Economics Discussion Paper: 604; Department of Economics. Columbia University. New York. New York 10027. PG 47. PR \$5.00. JE F10, F12, F13. KW Free Trade. International Trade. Fair Trade.

AB A backward glance shows that earlier crises, some of equal and others of greater significance, have occurred in regard to the policy presumption in favor of free trade: all reflecting different blends of current economic circumstance and theoretical reflections. Moreover, and this is a theme that I develop principally in this paper, the true and greater crisis that we face in regard to the theory and policy of Free Trade today comes, not from the theoretical modelling of imperfect competition in product markets during the 1980 's, but from the growth of demands for "level playing fields". "harmonization", "fair trade" et. al.. all of which are variously undermining insidiously the legitimacy and feasibility of Free Trade since it is virtually impossible to harmonize everything so that playing fields are truly level in every way.

\section{Bils, Mark}

PD August 1992. TI Inter-Industry Mobility and the Cyclical Upgrading of Labor. AU Bils, Mark; McLaughlin. Kenneth J. AA Bils: University of Chicago and National Bureau of Economic Research. McLaughlin: University of Michigan and University of Rochester. SR National Bureau of Economic Research Working Paper: 4130; National Bureau of Economic Research, 1050 Massachusetts Avenue, Cambridge, MA 02138. PG not available. PR \$5.00. JE J60. J20, J62. KW Labor Market. Cyclical Fluctuations. Mobility.

AB We investigate whether a market-clearing model of the labor market is consistent with the cyclical upgrading of labor: workers tend to move to higher paying industries in expansions and to lower paying industries in contractions. By applying Roy's (1951) model of self-selection to industry fluctuations, we show that cyclical upgrading can be consistent with market clearing. Applying the model to inter-industry mobility patterns in panel data, we find data of substantial selection by comparative advantage. However, the panel data reveal a selection process that is consistent with cyclical upgrading. Thus the model does not simultaneously account for interindustry mobility in panel data and cyclical upgrading.

\section{Blau, Francine D.}

PD July 1992. TI Race and Gender Pay Differentials. AU Blau. Francine D.; Kahn, Lawrence M. AA Blau: University of Illinois and National Bureau of Economic Research. Kahn: University of Illinois. SR National Bureau of Economic Research Working Paper: 4120; National Bureau of Economic Research. 1050 Massachusetts Avenue. Cambridge, MA 02138. PG 32. PR \$5.00. JE J70, J15. J16. KW Pay Differentials. Wage Discrimination.

AB In this paper we review research findings from the 1980's and early 1990's on race and gender pay gaps. In addition. we present some evidence from the Current Population Surveys (1972, 1982 and 1989) regarding the impact of shifts in the industrial composition of employment and in interindustry wage differentials on these gaps. The gender gap in pay was stable in the 1970's but fell steadily in the 1980's; the opposite patterns were observed for black-white wage differentials - - a trend towards convergence in the 1970's and stability in the 1980 's. Understanding these new trends comprises the unifying theme of our review.

\section{Bloch, Francis}

PD March 1992. TI Sequential Formation of Coalitions with Fixed Payoff Division. AA Brown University. SR Brown University Department of Economics Working Paper: 92-5; Department of Economics, Brown University. Providence, Rhode Island 02912. PG 43. PR no charge. JE D71. KW Sequential Formation. Coalitions. Labor Supply.

AB This paper analyzes a sequential game of coalition formation when the division of the coalitional surplus is fixed and the payoffs are defined relative to the whole coalition structure. Gains from cooperation are represented by a valuation which maps coalition structures into payoff vectors. I show that any core stable coalition structure can be attained as a stationary perfect equilibrium of the game. If stationary perfect equilibria may fail to exist in general games. they always exist in symmetric games. Furthermore, stationary perfect equilibria of symmetric games generate a coalition structure which is generically unique up to a permutation of the players. The game is applied to the formation of associations of firms and of cartels in oligopolies.

\section{Blomberg, Stephen Brock}

PD October 1992. TI Growth, Political Instability, and 
the Defense Burden. AA Board of Governors of the Federal Reserve System. SR Board of Governors of the Federal Reserve System International Finance Discussion Paper: 436; Division of International Finance. Board of Governors of the Federal Reserve System, Washington, D.C. 20551. PG 31. PR no charge. JE H56, J24. KW Military Spending. Human Capital Formation.

AB This paper develops a model to examine the economic effects of political instability and military expenditure. In the model. "kleptocracies" use defense as "imperfect" insurance against the probability of being overthrown. Increasing defense has a secondary effect of augmenting the human capital stock (a spin-off effect). However, defense investment comes at the expense of consuming scarce resources (a crowding out effect). The paper's central contribution is to model each of these effects and their relationship to one another. The resulting theory predicts that the equilibrium is Pareto inefficient and that increased political instability and increased defense can inhibit economic growth. Empirically, increases in political instability are found to decrease growth while increases in defense are found to decrease political instability. The paper also finds that increases in defense have a direct negative effect on growth. although the relation is weak.

\section{Blomstrom, Magnus}

PD August 1992. TI Host Country Competition and Technology Transfer by Multinationals. AU Blomstrom. Magnus; Zejan, Mario; Kokko, Ari. AA Blomstrom:Stockholm School of Economics and National Bureau of Economic Research. Zejan and Kokko: Stockholm School of Economics. SR National Bureau of Economic Research Working Paper: 4131; National Bureau of Economic Research, 1050 Massachusetts Avenue, Cambridge, MA 02138. PG not available. PR \$5.00. JE F23, F13. O33. KW Multinational Firms. Technology Flow. Rivalry. AB This paper examines whether rivalry in host country markets may force multinational firms to increase the technology transfer to their foreign affiliates. Such technology flows should be interesting from the perspective of the host country and its firms, since they would increase the potential for "spillovers". Using detailed (unpublished) industry data from Mexican manufacturing industry we find that indicators for local competition are positively related to the technology imports of foreign owned affiliates. The effects appear to be strong in consumer goods industries, which suggest that foreign multinationals are especially sensitive to the local market environment when barriers to entry in the form of complex technology or high capital requirements are relatively low.

PD August 1992. TI What Explains Developing Country Growth? AU Blomstrom. Magnus; Zejan, Mario; Lipsey, Robert E. AA Zejan: Stockholm School of Economics. Blomstrom: Stockholm School of Economics and National Bureau of Economic Research. Lipsey: Queens College, City University of New York, and National Bureau of Economic Research. SR National Bureau of Economic Research Working Paper: 4132; National Bureau of Economic Research, 1050 Massachusetts Avenue, Cambridge, MA 02138. PG not available. PR \$5.00. JE O40, 047, O10. KW Income Growth. Investment. Development.

AB Among developing countries, there was no gross relationship between real income per capita in 1960 and subsequent growth in per capita income. However, once other significant influences, such as education, changes in labor force participation rates, inflows of foreign investment, price structures. and fixed investment ratios are taken into account, the lower the 1960 income level, the faster the income growth. This "conditional" convergence was particularly strong among the poorest half of the developing countries, contradicting the idea of a "convergence club" confined to relatively well-off countries. Inflows of direct investment were an important influence on growth rates for higher income developing countries, but not for lower income ones. For the latter group. secondary education, changes in labor force participation rates. and initial distance behind the United States were all major factors.

\section{Boadway, Robin}

TI Volunteer Work and Club Size: Nash Equilibrium and Optimality. AU Barham, Vicky; Boadway, Robin; Marchand, Maurice: Pestieau, Pierre.

\section{Boldrin, Michele}

PD June 1992. TI Acyclicity and Dynamic Stability: Generalizations and Applications. AU Boldrin. Michele; Montrucchio. Luigi. AA Boldrin: Northwestern University. Montrucchio: Universita di Torino. SR Northwestern University Center for Mathematical Studies in Economics and Management Science Discussion Paper: 980; J.L. Kellogg Graduate School of Management. Northwestern University, 2001 Sheridan Road, Evanston, II 60208. PG 21. PR per copy: $\$ 3.00$ U.S. and Canada. $\$ 5.00$ via international mail. Make check payable to Northwestern University. JE C60. C61. C62. KW Stability. Acyclicity. Programming Problems. AB We study the asymptotic stability of infinite horizon concave programming problems. Turnpike theorems for this class of models generally have to assume a low level of discounting. By generalizing our preceding work we provide a one-parameter family of verifiable conditions that guarantee convergence of the optimal paths to a stationary state. We call this property theta-acyclicity. In the one dimensional case we show that supermodularity implies our property but not vice versa. In the multidimensional case supermodularity has no relevant implications for the asymptotic behavior of optimal paths. We apply theta-acyclicity to a pair models which study firms' dynamic behavior as based on adjustment costs. The first is the familiar model of competitive equilibrium in an industry in the presence of adjustment costs. In the second case firms act strategically and we study the dynamic evolution implied by the closed-loop Nash equilibria. In both instances our criteria apply and allow us to obtain stability results that are much more general than those already existing in the literature.

\section{Bomfim, Antulio N.}

PD July 1992. TI Near Rationality and Strategic Complementarity in a Macroeconomic Model: Policy Effects. Persistence, and Multipliers AU Bomfim. Antulio N.: Diebold, Francis X. AA Bomfim: Board of Governors of the Federal Reserve System. Diebold: University of Pennsylvania. SR Board of Governors of the Federal Reserve System Finance and Economics Discussion Series: 205; C/O Steven A. Sharpe. Mail Stop 89. Federal Reserve Board, Wash., DC 20551. PG 27. PR no charge. JE E10, E52. KW Aggregate Dynamics. Heterogeneity. Expectations.

AB Motivated by recent developments in the imperfect competition and strategic complementarity literatures, we examine an intentionally simple and stylized aggregative 
economic model, when the assumptions of fully rational expectations and perfect competition are relaxed. We show that small deviations from rational expectations, taken alone, lead only to small deviations from classical policy-ineffectiveness. but that the situation can change dramatically when imperfect competition is introduced. The strategic complementarity associated with imperfect competition magnifies the effects of even small departures from rational expectations. producing equilibria with policy effectiveness, output persistence and multiplier effects.

\section{Bonanno, Giacomo}

PD September 1992. TI The Logical Representation of Extensive Games with Perfect Information. AA University of California, Davis. SR University of California at Davis Economics Department Working Paper: 408; Department of Economics, University of California at Davis, Davis, CA 95616. PG 11. PR $\$ 3.00$ U.S. and Canada. $\$ 4.00$ international. JE C72. KW Extensive Form Games. Propositional Calculus.

AB Given an extensive form with perfect information G. we associate with every arc an atomic sentence and with every decision node a set of well-formed formulas(wffs) of propositional calculus [the set of such wffs is denoted by Gamma(G). Using a semantics for propositional calculus that differs from the standard one based on truth tables, we show that the extensive form is a model for $\operatorname{Gamma}(G)$, that is, every wff in Gamma(G) is true for G. We also show that, within the standard semantics for propositional calculus, there is a oneto-one correspondence between the set of plays of $G$ and the set of valuations that satisfy all the wffs in Gamma(G).

PD September 1992. TI A Characterization of Sequential Equilibrium. AA University of California, Davis. SR University of California at Davis Economics Department Working Paper: 409: Department of Economics, University of California at Davis, Davis, CA 95616. PG 17. PR $\$ 3.00$ U.S. and Canada. $\$ 4.00$ international. JE C72. KW Subgame-Perfect Equilibrium. Sequential Equilibrium.

AB We define four properties of beliefs (Contraction Consistency. Tree Consistency. Individual Rationality and Choice Consistency) and show that these properties are implied by the notion of sequential equilibrium and are sufficient to yield subgame perfection and sequential rationality. In order to obtain consistency as defined by Kreps and Wilson one needs two further properties: Minimal Revision and Agreement. The six properties together provide a characterization of sequential equilibrium.

\section{Bonin, John P.}

PD September 1992. TI Incentives and Monitoring in Cooperatives Under Labor-Proportionate Sharing Schemes. AU Bonin. John P.: Putterman, Louis. AA Bonin: Wesleyan University. Putterman: Brown University. SR Brown University Department of Economics Working Paper: 92-16; Department of Economics. Brown University. Providence, Rhode Island 02912. PG 23. PR no charge. JE D23, D21, L21. KW Incentives. Monitoring. Cooperatives.

AB The purpose of the present paper is to extend existing models of PC (producers' cooperatives) internal incentives in which the payment system is assumed to be by share of the labor input, "needs", or a mix of the two, to the case in which measurement of labor input is imperfect and costly. We briefly recapitulate the standard PC internal incentive model, assuming no information problem. We consider the impact of imperfect measurement and monitoring on effort supply under two alternative models of monitoring technology. In the course of extending partial equilibrium results to a total equilibrium setting, we also show how recent work in oligopoly theory provides a solution to the stability problem not previously addressed in a satisfactory way for the whole class of cooperative models in which our analysis belongs. We also consider the cost of monitoring more explicitly, and analyzes the optimal choice of monitoring level given that this cost must be borne by PC members.

\section{Borenstein, Severin}

PD August 1992. TI Do Gasoline Prices Respond Asymmetrically to Crude Oil Price Changes? AU Borenstein, Severin; Cameron, A. Colin; Gilbert, Richard. AA Cameron: University of California. Davis. Gilbert: University of California, Berkeley. Borenstein: University of California. Davis and National Bureau of Economic Research. SR National Bureau of Economic Research Working Paper: 4138; National Bureau of Economic Research, 1050 Massachusetts Avenue, Cambridge, MA 02138. PG not available. PR \$5.00. JE L91, L92, L95. KW Gasoline Prices. Market Power.

AB Our empirical investigation confirms the common belief that retail gasoline prices react more quickly to increases in crude oil prices than to decreases. Nearly all of the response to a crude oil price increase shows up in the pump price within 4 weeks, while decreases are passed along gradually over 8 weeks. The asymmetry could indicate market power of some producers or distributors. or it could result from inventory adjustment costs. By analyzing price transmission at different points in the distribution chain we investigate these theories. We find that some asymmetry occurs at the level of the competitive spot market for gasoline, perhaps reflecting inventory costs. Wholesale gasoline prices, however, exhibit no asymmetry in responding to crude oil price changes, indicating that refiners who set wholesale prices are not the source of the asymmetry appears in the response of retail prices to wholesale price changes. We argue that this probably reflects short run market power among retail gasoline sellers.

Borensztein, E. R.

PD July 1992. TI The Output Decline in the Aftermath of Reform: The Cases of Bulgaria. Czechoslovakia, and Romania. AU Borensztein, E. R.; Demekas, D. G.; Ostry, J. D. AA International Monetary Fund. SR International Monetary Fund Working Paper: 92/59; International Monetary Fund, Washington, DC 20431. PG 39. PR not available. JE E20, D50, P50. KW Economic Reform. Output Decline.

AB This paper analyzes the declines in economic activity experienced by Bulgaria, the Czech and Slovak Federal Repubic (CSFR), and Romania in the period since the initiation of market-oriented reforms in these countries. The paper reviews developments in the three countries and empirically investigates two questions that are key to the interpretation of the output decline: First, to what extent does the output fall reflect "structural change" (or a reallocation of resources across sectors) rather than a conventional recession? Second, to what extent have demand-side or supply- side forces been dominant in generating the output decline? 
Boudoukh, Jacob

PD June 1992. TI Testing Inequality Restrictions Implied from Conditional Asset Pricing Models. AU Boudoukh, Jacob; Richardson, Matthew; Smith, Tom. AA Boudoukh: New York University. Richardson: University of Pennsylvania. Smith: Duke University. SR New York University Salomon Brothers Working Paper: S-92-42; Salomon Brothers Center for the Study of Financial Institutions, Graduate School of Business Administration. New York University, 90 Trinity Place. New York. NY 10006. PG 23. PR not available. JE G12, C52. KW CAPM. Asset Returns.

AB This paper develops tests of inequality restrictions implied from conditional asset pricing models. The methodology is easy to implement, requires little knowledge of the conditional distribution of asset returns, and is valid under fairly weak assumptions. As an application, we provide tests of several asset pricing models and document results which are in contrast to recent empirical work in these areas.

PD June 1992. TI The Equity Risk Premium and the Term Structure: Two Centuries of Evidence. AU Boudoukh, Jacob; Richardson, Matthew; Whitelaw, Robert F. AA Boudoukh and Whitelaw: New York University. Richardson: University of Pennsylvania. SR New York University Salomon Brothers Working Paper: S-92-43; Salomon Brothers Center for the Study of Financial Institutions. Graduate School of Business Administration. New York University, 90 Trinity Place, New York, NY 10006. PG 18. PR not available. JE E43. G12. KW Term Premium. Asset Pricing.

AB This paper investigates the relation between the risk premium and the term structure over the past two centuries. We find that the ex-ante risk premium is increasing in the spread between long and short bonds (although at a decreasing rate). Moreover, the ex-ante premium changes signs depending on whether the spread is positive or negative. We show that these empirical results are consistent with consumption based asset pricing models under reasonable parameterizations.

\section{Brams, Steven J.}

PD July 1992. TI Intransigence in Negotiations: The Dynamics of Disagreement. AU Brams, Steven J.; Doherty, Ann E. AA Brams: New York University. Doherty: Unknown. SR New York University Economic Research Reports: 92-30; New York University. Faculty of Arts and Science, Department of Economics, Washington Square, New York, N.Y. 10003. PG 31. PR no charge. JE C78, F42. KW Bargaining. Game Theory. Impasse.

AB Three-party negotiations are analyzed in which the players are able not only to rank alternatives but also have a preference for impasse. In a dynamic model, players progressively invoke fallback positions to try to prevent inferior outcomes from being implemented in a game of incomplete information. A player's intransigence, or unwillingness to retreat to fallback positions. generally works to its advantage. Greater size (or an enhanced ability to effect preferred outcomes) also helps, but intransigence is a potent force by itself. Recent world trade negotiations are analyzed as a game among the United States, the European Community, and Japan. The positions of these players on the critical issues in these negotiations-agricultural supports and market accessindicates why an agreement supported by all three players has been difficult to achieve. The game-theoretic analysis illuminates the rational basis of disagreement and why it develops in the manner it does.

PD July 1992. TI An Envy-Free Cake Division Algorithm. AU Brams, Steven J.; Taylor, Alan D. AA Brams: New York University. Taylor: Unknown. SR New York University Economic Research Reports: $92-$ 31; New York University, Faculty of Arts and Science, Department of Economics. Washington Square, New York, N.Y. 10003. PG 42. PR no charge. JE D63. KW Equity. Fair Division.

AB An algorithm is given that provides an envy-free division of a cake among $n$ people, each of whom may have a different way of measuring the value of fractional parts of the cake. Previous results were (1) non-constructive, (2) produced a division based on the weaker notion of fairness in which each person believed he or she received at least $1 / n$th of the cake. but not necessarily the largest piece. or (3) worked only for the case $\mathrm{n}=3$.

\section{Brennscheidt, Gunnar}

PD September 1992. TI Experiments on Predictions: Aggregate Behavior. AA University of Bonn. SR Universitat Bonn Sonderforschungsbereich 303 . Discussion Paper: B-221: Sonderforschungsbereich 303 an der Universitat Bonn, Adenauerallee 24-42, D-5300 Bonn 1, DEUTSCHLAND. PG 33. PR no charge. JE C91. D84. KW Rational Expectations. Rational Predictions.

AB This paper describes some experiments on the influence of exogenous variables on expectations. In all experiments. the time series to be predicted was generated by a linear econometric model involving two or three artificial exogenous variables. After a literature review in this chapter, Chapter 1 gives the theoretical background for rational expectations and least-squares learning in presence of exogenous variables. Chapter 2 describes the experimental design and explains the notation. Chapter 3 turns to the analysis of aggregate (average and median) predictions.

\section{Bresnahan, Timothy F.}

PD August 1992. TI General Purpose Technologies: "Engines of Growth?" AU Bresnahan. Timothy F.; Trajtenberg, Manuel. AA Bresnahan: Stanford University and National Bureau of Economic Research. Trajtenberg: TelAviv University and National Bureau of Economic Research. SR National Bureau of Economic Research Working Paper: 4148; National Bureau of Economic Research, 1050 Massachusetts Avenue, Cambridge, MA 02138. PG not available. PR \$5.00. JE O33, O47, 049. O14. KW Technical Progress. Economic Growth. Invention.

AB Whole eras of technical progress and economic growth appear to be driven by a few key technologies, which we call General Purpose Technologies (GPT's). GPT's are characterized by pervasiveness (they are used as inputs by many downstream sectors), inherent potential for technical improvements, and "innovational complementarities", meaning that the productivity of $R \& D$ in downstream sectors increases as a consequence of innovation in the GPT. Thus. as GPT's improve they spread throughout the economy, bringing about generalized productivity gains. Our analysis shows that the characteristics of GPT's imply a sort of increasing returns to scale phenomenon, and that this may have a large role to play in determining the rate of technical advance; on the other hand this phenomenon makes it difficult for decentralized economy to fully exploit the growth opportunities offered by evolving 
GPT's.

Broadie, Mark

TI Safety First Portfolio Choice. AU Goetzmann, William N.: Broadie, Mark.

\section{Brooks, Robert D.}

PD July 1992. TI The Form of Time Variation of Systematic Risk: Some Australian Evidence. AU Brooks, Robert D.: Faff, Robert W.: Lee, John H. H. AA Brooks and Lee: Royal Melboume Institute of Technology and Monash University. Faff. Monash University. SR Monash Department of Econometrics Research Working Paper: 8/92; Department of Econometrics. Monash University. Clayton. Victoria 3168, AUSTRALIA. PG 13. PR no charge. JE C32, C52. KW Varying Coefficient. Stochastic Parameter.

AB Many studies have investigated the issue of time stationarity of an asset's systematic risk. While there is considerable evidence to suggest that an asset's systematic risk is best described by some stochastic parameter model, little work has been conducted in determining the most appropriate stochastic parameter model. This paper addresses this issue. We extend the study conducted by Faff, Lee and Fry (1992) to investigate which varying coefficient model best describes the systematic risk of assets in the Australian equity market. for those assets for which a constant coefficient model is found to be inadequate. Our results suggest that generally in cases where a stochastic parameter is appropriate a Hildreth-Houck (1968) random coefficient model is the preferred model.

Brox, James A.

PD July 1992. TI Financial Capital and Productivity in Residential Construction. AA University of British Columbia and University of Waterloo. SR University of British Columbia Department of Economics Discussion Paper: 92-11; Department of Economics. University of British Columbia 997-1873 East Mall, Vancouver, B.C. Canada V6T 1W5. PG not available. PR JE R31. KW Housing. Productivity.

AB The purpose of this paper is to investigate the cost structure. pairwise input relationships. and the technological aspects of the Canadian residential construction sector. The theoretical approach applied in this investigation is the translog production technology in its generalized form. The theoretical model has been tested by using time-series data (1973-1987) for the provinces of Quebec. Ontario and British Columbia. Five factors of production (i.e., land, capital, labor, materials and financial capital) are considered. The method used to estimate the model is the full-information maximum likelihood tochnique. The estimation results and the implied elasticities confirm the inclusion of financing in the cost structure, reject the assumptions of homothetic and neutral technical change. but fail to reject the assumption of constant returns to scale.

PD July 1992. TI The Demand for Domestic and Imported Alcohol Beverages in Ontario. Canada. AU Brox, James A.: Carvalho, Emanuel: Andrikopoulos, Andreas A. AA Brox: University of Waterloo and University of British Columbia. Andrikopoulos and Carvalho: University of Waterloo. SR University of British Columbia Department of Economics Discussion Paper: 92-12; Department of Economics, University of British Columbia 997-1873 East Mall. Vancouver, B.C. Canada V6T IW5. PG not available.
PR JE D12. KW Alcohol. Dynamic Demand System. AB The purpose of this paper is to estimate simultaneously dynamic demand functions and, consequently, income and price elasticities for domestic and imported alcoholic beverages for the province of Ontario. The methodology used is the almost ideal demand system, originally developed by Deaton and Muellbauer (1980), augmented by Pollak's (1970) habit formation hypothesis. The empirical application uses time series (1958-1978) for imported and domestically produced spirits, wine, and beer. The findings provide strong support favoring the dynamic version of the almost ideal demand system over its static alternative. but little evidence of strong substitution between domestic and imported products.

TI Cost Structure, Inter-Factor Substitution and Complementarity, and Efficiency in the Canadian Agricultural Sector. AU Andrikopoulos, Andreas A.; Brox, James A.

\section{Buschena, David E.}

PD August 1992. TI Not Just Another Paper Showing Violations of the Expected Utility Model: The Effects of Alternative Similarity on Risky Choice. AU Buschena, David E.; Zilberman. David. AA University of California. Berkeley. SR University of California at Berkeley. Department of Agricultural and Resource Economics (CUDARE) Working Paper: 633; Department of Agricultural and Resource Economics, 313 Giannini Hall, UC Berkeley. Berkeley, CA 94720. PG 38. PR \$16.25. JE D50, D80. KW Expected Utility Model. Risk. Risky Choice.

AB This paper explores the dependence of choice on the relative differences in the characteristics of the risky alternatives. The empirical results of our analysis show: 1) there is a strong effect on the degree of violations of Expected Utility from differences between the question pairs, 2) that the Expected Utility model holds for a particular and significant class of alternatives dependent on these relative differences and 3) that the effects of the relative question differences result in a significant proportion of individuals having intransitive patterns of choice.

\section{Caballero, Ricardo J.}

PD September 1992. TI Uncertainty. Investment, and Industry Revolution. AU Caballero, Ricardo J.; Pindyck. Robert S. AA Massachusetts Institute of Technology and National Bureau of Economic Research. SR National Bureau of Economic Research Working Paper: 4160; National Bureau of Economic Research, 1050 Massachusetts Avenue, Cambridge, MA 02138. PG 19. PR \$3.00. JE D81, D92, E22. KW Aggregate Uncertainty. Entry.

AB We study the effects of aggregate and idiosyncratic uncertainty on the entry of firms, total investment, and prices in a competitive industry with irreversible investment. We first use standard dynamic programming methods to determine firms' entry decisions, and we describe the resulting industry equilibrium and its characteristics, emphasizing the effects of different sources of uncertainty. We then show how the conditional distribution of prices can be used as an alternative means of determining and understanding the behavior of firms and the resulting industry equilibrium. Finally, we use fourdigit U.S. manufacturing data to examine some implications of the model.

PD September 1992. TI Microeconomic Rigidities and Aggregate Price Dynamics. AU Caballero, Ricardo J.; Engel, 
Eduardo M. R. A. AA Caballero: Massachusetts Institute of Technology and National Bureau of Economic Research. Engel: Harvard University. SR National Bureau of Economic Research Working Paper: 4162; National Bureau of Economic Research, 1050 Massachusetts Avenue, Cambridge. MA 02138. PG 24. PR \$3.00. JE E31, D21. KW Inflation. Price Adjustment.

AB This paper is an attempt to enrich the characterization of the sluggish behavior of the aggregate price level. Our contribution to this vast literature is to explicitly consider microeconomic heterogeneity and its interaction with nonlinear microeconomic price adjustment policies. The model we propose outperforms the constant-probability-ofadjustment/partial- adjustment model in describing the path of postwar U.S. inflation. Using only aggregate data we infer that the probability that a firm adjusts its price depends on the sign and the magnitude of the deviation of the price from its target level. At the aggregate level we find that the aggregate price responds less to negative shocks than to positive shocks, that the size of this asymmetry increases with the size of the shock. and that the number of firms changing their prices - and therefore the flexibility of the price level to aggregate shocks varies endogenously over time in response to changes in economic conditions.

\section{Cadot, Olivier}

PD August 1992. TI R\&D: Who Does the R, who Does the D? AU Cadot. Olivier: Desruelle, Dominique. AA Cadot: INSEAD. Desruelle: Montreal University. SR INSEAD Working Papers: 92/45/EP; INSEAD. Boulevard de Constance, Fontainebleau. 77305 Cedex. FRANCE. PG 19. PR not available. JE O32. KW Research. Development.

AB The paper considers the relationship between country size and the relative importance of research vs. development activities. We first consider the allocation of scientists between research and development in a two-country, two-sector model where the research sector is characterized by a race. We show that an increase in country size in the sense of a proportional increase in the number of domestically available scientists and in the number of opportunities for development leads to a higher proportion of scientists being in the development sector. We also show that if the "final prizes" of a two-stage R\&D race are positively related to country size, the conditional probability of success in the development stage given success in the research stage is higher for a large country than for a small country.

\section{Cagan, Phillip}

PD February 1992. TI Does the Endogeneity of Money Disprove Monetary Effects on Activity: A Test of U.S. Data 1880-1929. AA Columbia University. SR Columbia University Department of Economics Working Paper: 592; Department of Economics. Columbia University, New York. NY 10027. PG 9. PR \$5.00; checks payable to U.C. Regents. JE E40, E32, E50. KW Money. Business Cycles. Comovements. Causality.

AB Some recent studies attribute the well-established comovements between money and business cycles solely to endogenous responses of money. This conflicts with the traditional view of a causal influence in both directions. Some statistical "causality tests" do find an exogenous monetary effect, but the effect appears quite small. A different kind of test is presented here for the 1880-1929 U.S. period, distinguishing the endogenous (inside) and exogenous (outside) components of money. Contrary to the view that only the endogenous component is related to GNP, both components are jointly and equally related, reflecting a combined effect on activity.

\section{Calvo, Guillermo A.}

PD August 1992. TI Capital Inflows and Real Exchange Rate Appreciation in Latin America: The Role of External Factors. AU Calvo, Guillermo A.; Leiderman, Leonardo; Reinhart, Carmen M. AA International Monetary Fund. SR International Monetary Fund Working Paper: 92/62 : International Monetary Fund. Washington. DC 20431. PG 38. PR not available. JE G10, G41. KW Capital Flows. International Interest Rates. Latin America.

AB The characteristics of recent capital inflows into Latin America are discussed. It is argued that these inflows are partly explained by conditions outside the region. like recession in the United States and lower international interest rates. This suggests the possibility that a reversal of those conditions may lead to a future capital outflow, increasing the macroeconomic vulnerability of Latin American economies. Policy options are argued to be limited.

PD August 1992. TI Output Collapse in Eastern Europe: The Role of Credit. AU Calvo, Guillermo A.; Coricelli, Fabrizio. AA Calvo: International Monetary Fund. Coricelli: The World Bank. SR International Monetary Fund Working Paper: 92/64; International Monetary Fund, Washington, DC 20431. PG 14. PR not available. JE P20. KW Bank Credit. Liquidity Crunch. Output Contraction. Credit Contraction.

AB Real bank credit in Eastern European countries after their recent stabilization programs is shown to have fallen sharply, except in the case of Hungary. The meaning of the fall is discussed under the present value and liquidity perspectives. Moreover, it shown that the hypothesis that output contraction may be partly due to credit contraction cannot be ruled out. The hypothesis is tested on a sample of 85 branches of industry in Poland. The rationale for expecting a connection between credit and output and policy options to attenuate the liquidity crunch in post- socialist economies is also subject to analysis.

\section{Cameron, A. Colin}

TI Do Gasoline Prices Respond Asymmetrically to Crude Oil Price Changes? AU Borenstein, Severin; Cameron, A. Colin; Gilbert. Richard.

\section{Canning, David}

PD April 1992. TI Learning Language Conventions in Common Interest Signaling Games. AA Columbia University. SR Columbia University Department of Economics Discussion Paper: 607; Deparment of Economics, Columbia University, New York, New York 10027. PG 26. PR \$5.00. JE D83, C72. KW Learning. Signaling Games.

AB I examine a model with imperfect information in which agents play a common interest signaling game and use the empirical frequencies of outcomes in the past to predict the information content of current signals. For messages which have not been used in the past I assume that the receiver uses a "default" action and the sender knows this action. This dynamic learning model has multiple steady states, corresponding to the pure strategy sequential equilibria of the one shot game, 
including equilibria in which the signal sent has no information content. However, once we add a small probability of a mistake in each signal and action the outcome converges with probability one. to a fully revealing signaling equilibrium.

PD May 1992. TI Learning the Subgame Perfect Equilibrium. AA Columbia University. SR Columbia University Department of Economics Discussion Paper: 608; Department of Econamics. Columbia University, New York, New York 10027. PG 10. PR \$5.00. JE C72. D83. KW Learning. Game Theory. Subgame Perfection.

AB Consider an extensive form game which is played repeatedly by agents who use empirical frequencies of past behavior to predict current actions (i.e., fictitious play). We restrict attention to generic games in which there are no ties in payoffs for choices at any node for any fixed pure strategy choices in the future. We assume the game is one of perfect. but incomplete. information; all information sets contain just one node but agents know only their own payoffs and not the payoffs of other players at the terminal nodes. Beliefs about behavior at nodes which have not been set in the past are given exogenously. In this framework we show that steady states of the learning process correspond to Nash equilibria of the game. In addition. for any initial exogenous beliefs we show that the system converges to a steady state in finite time.

\section{Caplin, Andrew}

PD 1992. TI Asymmetric Information, Adjustment Costs and Market Dynamics. AU Caplin. Andrew; Leahy, John. AA Caplin: Columbia University. Leahy: Harvard University. SR Columbia University Department of Economics Discussion Paper: 601: Department of Economics. Columbia University. New York, New York 10027. PG 21. PR \$5.00. JE D82, D92, D20. KW Individual Inertia. Adjustment Costs. Market Dynamics. Asymmetric Information.

AB In this paper we consider the interaction between two fundamental influences on market dynamics: the inertia that results when agents face fixed costs of adjusting their behavior and the potential for market data to transmit information between asymmetrically informed agents. The interaction we have in mind is the following. Agents facing non-convex adjustment costs respond to most shocks by accumulating "potential energy" rather than by altering their behavior. Only significant changes in circumstance yield opportunities profitable enough to offset the cost of adjustment. As a side effect, this inertial behavior sets up a barrier to the cost of adjustment. It becomes difficult to assess the information that other agents possess because they react the same way to so many different shocks. We explore this information-adjustment cost mechanism in the specific setting of a growing industry with fixed entry costs.

PD April 1992. TI Aggregation and Optimization with State-Dependent Pricing. AU Caplin, Andrew: Leahy, John. AA Caplin: Columbia University. Leahy: Harvard University. SR Columbia University Department of Economics Discussion Paper: 599; Department of Economics. Columbia University. New York, New York 10027. PG 22. PR \$5.00. JE E10. E11. KW Aggregation. StateDependent Pricing. Individual Inertia. Aggregate Dynamics. AB In this paper we take the first steps towards combining the literature on optimal state-dependent strategies with the literature on the aggregation of such rules. Studies of optimization have generally examined the individual's problem in isolation, taking the movements of aggregates as exogenous. Models of aggregation, on the other hand, have generally treated the policies of individual agents as data while studying the importance of such policies for aggregate fluctuations. What has been lost is the interplay between optimization and aggregation, the feedback between individual optimization and the behavior of the economy as a whole. We have developed a model in which it is possible to study optimal state-dependent pricing in combination with an endogenously derived stochastic path of the aggregate price level.

PD April 1992. TI Business as Usual. Market Crashes and Wisdom After the Fact. AU Caplin, Andrew; Leahy, John. AA Caplin: Columbia University. Leahy: Harvard University. SR Columbia University Department of Economics Discussion Paper: 602; Department of Economics, Columbia University, New York. New York 10027. PG 19. PR \$5.00. JE G10, D40. KW Market Collapse. Routine Behavior.

AB Routine behavior tends to trap information locally. This creates the possibility of large swings in the general mood of a market when routines are broken. We present a model that connects the potential for market collapse to the difficulties of leaming the opinions of others during periods when business is being conducted in a routine manner. The model is suggestive of difficulties that may occur in markets, such as the office and housing markets where investment is irreversible, it takes time to build, and demand is uncertain.

PD May 1992. TI Individual Inertia and Aggregate Dynamics. AA Columbia University. SR Columbia University Department of Economics Discussion Paper: 600; Department of Economics, Columbia University. New York, New York 10027. PG 25. PR \$5.00. JE E10. E11. KW Individual Inertia. Aggregate Dynamics.

AB Many economists believe that prices are sticky in the short-run, so that shocks to nominal variables have real effects on the economy. It is very difficult to provide microeconomic underpinnings for this view. Even if one believes that individual nominal prices are sticky it is not clear what implications this has for the dynamics of the aggregate price level. This article surveys the recent literature exploring the connections between the microeconomics and the macroeconomics of sticky prices. The aggregation literature has a broader objective than simply to increase our understanding of price dynamics. One of the main goals of macroeconomics in general is to explain how exogenous shocks influence such aggregates as the price level, the level of employment, capital investment, and expenditure on consumer durables. In each case, the underlying individual decisions involve elements of inertia. The broad objective of the aggregation literature is to increase our understanding of the linkages between individual inertia and aggregate dynamics.

\section{Carroll, Christopher D.}

PD May 1992. TI How Does Future Income Affect Current Consumption? AA Board of Governors of the Federal Reserve System. SR Board of Governors of the Federal Reserve System Economic Activity Section Working Paper: 126; Board of Governors of the Federal Reserve System Economic Activity Section. Stop \#80. Federal Reserve Board. Washington, D.C. 20551. PG 28. PR no charge. JE D12, D91, E21, E24. KW Life Cycle Model. Permanent 
Income Hypothesis. Precautionary Saving.

AB This paper tests one of the clearest implications of the simple Life Cycle model of consumption: that current consumption should depend on the expected level of lifetime income. Using two micro data sources, the paper constructs estimates of predictable life cycle changes in income for a panel of consumers and discovers that current consumption appears to be completely unrelated to such predictable changes in income. However, the degree of uncertainty in future income is found to have an important effect on current consumption: consumers with more uncertain income consume less. The results are supportive of a "buffer-stock" model of consumption like that of Carroll (1991) in which prudent consumers do not spend out of expected future income because that income is too uncertain.

\section{Carvalho, Emanuel}

TI The Demand for Domestic and Imported Alcohol Beverages in Ontario. Canada. AU Brox, James A.: Carvalho, Emanuel: Andrikopoulos, Andreas A.

\section{Casella, Alessandra}

PD May 1992. TI Public Goods in Trade: on the Formation of Markets and Political Jurisdictions. AU Casella, Alessandra: Feinstein, Jonathan S. AA Casella: University of California. Berkeley. Feinstein: Stanford University. SR Hoover Institute Working Papers in Economics: E-92-12; Domestic Studies Program Working Paper Series, Hoover Institution. Stanford University. Stanford. CA 94305. PG 47. PR not available. JE D71, D72, H41, F15. KW Clubs. Public Goods. Integration.

AB Current policy debates center on the relationship between economic and political integration. To address this problem, we construct a simple general equilibrium model where the return from private trade depends on a public good. Heterogeneous agents choose a political jurisdiction (a "club"), where the public good is voted upon. financed and supplied; and a market. where private exchanges are concluded. Preferences over the public good vary with individuals' position in the market. and as the region develops, the structure of economic transactions evolves, causing changes in political affiliation. We show that in general the political boundaries established by the clubs can be distinct from market borders. leading to international trade between members of different clubs. If trade across clubs entails transaction costs, economic integration leads initially to political unification. However, the unification is temporary: at still higher levels of development traders prefer the diversity offered by multiple clubs.

PD August 1992. TI Arbitration in International Trade. AA University of California, Berkeley. SR National Bureau of Economic Research Working Paper: 4136; National Bureau of Economic Research, 1050 Massachusetts Avenue, Cambridge, MA 02138. PG not available. PR \$5.00. JE F10, F13. KW International Contracts. International Arbitration. Trade.

AB The great majority of international contracts provides that any disputes which may arise will be decided by arbitration. Legal scholars argue that international arbitration is leading to the development of legal doctrine attuned to the needs of business and independent of national laws. This paper studies international arbitration as an example of the role of private trade in shaping international institutions. We review the provisions and the practice of international arbitration, and present a general equilibrium model of the relationship between the expansion of trade and the adoption of arbitration. The model focuses on the heterogeneity existing among economic agents in terms of their legal needs. It shows how arbitration alters the size and composition of markets, while at the same time responding to exogenous change in trade. Overall, the model does remarkably well in generating results commonly discussed in the legal literature.

\section{Cecchetti, Stephen G.}

PD July 1992. TI Testing Volatility Restrictions on Intertemporal Marginal Rates of Substitution Implied by Euler Equations and Asset Returns. AU Cecchetti. Stephen G.: Lam, Pok-sang; Mark, Nelson C. AA Cecchetti: Ohio State University and National Bureau of Economic Research. Lam and Mark: Ohio State University. SR National Bureau of Economic Research Technical Paper: 124; National Bureau of Economic Research, 1050 Massachusetts Avenue, Cambridge MA 02138. PG not available. PR \$3.00. JE G10.G12, C40. KW Asset Pricing. Volatility Bounds.

AB The Euler equations derived from a broad range of intertemporal asset pricing models, together with the first two unconditional moments of asset returns, imply a lower bound on the volatility of the intertemporal marginal rate of substitution. We develop and implement statistical series imply tests of these lower bound restrictions. We conclude that the availability of relatively short time series of consumption data undermines the ability of tests that use the restrictions implied by the volatility bound to discriminate among different utility functions.

\section{Chang, Roberto}

PD September 1992. TI Political Party Negotiations, Income Distribution and Endogenous Growth. AA New York University. SR New York University Economic Research Reports: 92-39; New York University, Faculty of Arts and Science, Department of Economics. Washington Square. New York, N.Y. 10003. PG 30. PR no charge. JE D72, D78, O12, E61, H23. KW Social Classes. Taxation.

AB This paper examines the determination of the rate of growth in an economy in which two political parties, each representing a different social class, negotiate the magnitude and allocation of taxes. Taxes may increase growth if they finance public services, but reduce growth when used to redistribute income between classes. The different social classes have different preferences about growth and redistribution. The resulting conflict is resolved through the tax negotiations between the political parties. I use the model to obtain empirical predictions and policy lessons about the relationship between economic growth and income inequality. In particular, the model implies that, although differences in growth rates across countries may be negatively related to income inequality, redistributing wealth does not enhance growth.

\section{Chemmanur, Thomas J.}

PD June 1992. TI Reputation, Renegotiation, and the Choice Between Bank Loans and Publicly Traded Debt. AU Chemmanur. Thomas J.; Fulghieri, Paolo. AA Columbia University. SR Columbia First Boston Series in Money, Economics and Finance Working Paper: FB92-24: Columbia University, Graduate School of Business, First Boston Series, New York, NY 10027. USA. PG 21. 
PR $\$ 5.00$ academics and non-profit institutions; $\$ 6.00$ corporations (add $\$ 1.00$ outside U.S., Canada and Puerto Rico). JE G32, G21, G33. KW Borrowing. Liquidation.

AB We develop a model of firms' choice between bank loans and publicly traded debt, taking into account the possibility of renegotiating the debt contract in the event of financial distress. We analyze a double-sided incentive problem between lenders and entrepreneurs. Entrepreneurs have private information about the chance of their firm being in financial distress. They raise capital to implement their projects either by borrowing from banks (multi-period players in the debt market) or by issuing publicly traded debt to ordinary investors (single-period players). If a firm is in financial distress, lenders undertake a costly evaluation of the firm. based on which they choose either to liquidate the firm or to allow it to continue under a renegotiation arrangement. We show that in the equilibrium of the above dynamic game, banks' desire to acquire a reputation for making the "right" renegotiation versus liquidation decision provides them with an endogenous incentive to devote a larger amount of resources to evaluating firms compared to that devoted by bondholders.

\section{Chen, Hong-Yuan}

TI Approximately Median-Unbiased Estimation of Autoregressive Models with Applications to U.S. Macroeconomic and Financial Time Series. AU Andrews. Donald W. K.; Chen. Hong-Yuan.

\section{Chichilnisky, Graciela}

PD March 1992. TI The Cone Condition. Properness, and Extremely Desirable Commodities. AA Columbia University. SR Columbia University Department of Economics Discussion Paper: 593; Department of Economics. Columbia University. New York, NY 10027. PG 7. PR \$5.00. JE D50, C70. KW Walrasian Equilibrium. Core Equivalence. Topological Vector Spaces.

AB This note links two conditions which have generated some interest in the literature and have an important role in proving the existence of an equilibrium, the second welfare theorem and the core equivalence theorem in infinite dimensional commodity spaces: These are the cone condition introduced in Chichilnisky and Kalman (1980), and the properness condition in Mas Colell (1986a), which were studied also in Yannelis and Zame (1986). Aliprantis, Brown and Burkinshaw (1987a), (1987b), and (1989). Aliprantis and Burkinshaw (1988), Mas-Colell (1986b). Chichilnisky and Heal (1984, 1992), and Rustichini and Yannelis (1991) among others. I establish that these two conditions are the same. Indeed, the cone condition coincides also with the assumption of an extremely desirable commodity used in Yannelis and Zame (1986) and Rustichini and Yannelis (1991).

\section{Choi, Jay Pil}

PD February 1992. TI Making Sense of Inefficient Intrafirm Transactions: A Signalling Approach. AA Columbia University. SR Columbia University Department of Economics Discussion Paper: 609; Department of Economics, Columbia University, New York, New York 10027. PG 11. PR \$5.00. JE D21, L22. KW Intermediate Goods. Intrafirm Transactions. Signalling. AB We provide a signalling model of inefficient intrafirm transactions. If an integrated firm still retains the option of buying intermediate goods in the open market, the decision to make or buy can be a signal about its production cost of the intermediate good. Particularly, the decision to supply internally can be a signal that its internal production cost is favorable compared to the market price. Consequently, a firm with a higher cost than the market price might have an incentive to mimic the firms with a lower cost; it forgoes the chance to buy from the market at a lower acquisition cost in order to induce output contraction by the rival firm in the final product market. This incentive for signalling will lead a firm which would otherwise buy from the market to supply internally, because of the strategic consequences in the downstream market.

PD February 1992. TI An Information Concealment Theory of Vertical Integration. AA Columbia University. SR Columbia University Department of Economics Discussion Paper: 610; Department of Economics. Columbia University, New York, New York 10027. PG 19. PR \$5.00. JE D21, L22. KW Vertical Integration. Information.

AB A model of vertical integration is proposed in which the motive for vertical integration lies in the concealment of information to other firms, rather than uncovering of a new information. Since a vertically integrated firm trades internally rather than making pubicly observable market transactions. vertical integration offers an opportunity for the integrated firm to turn previously observable market data into private information. It will be shown that when the acquisition cost of input is uncertain. the ex ante profit of a downstream firm will increase if the ex post realized value is profit information. thereby providing a theory of vertical integration based on strategic information concealment. Welfare implications of vertical integration are also considered. Finally, we demonstrate that the vertically integrated firm will adopt an inefficient sourcing rule when there are alternative, but inferior input suppliers.

\section{Christiano, Lawrence $\mathbf{J}$.}

PD August 1992. TI Liquidity Effects, Monetary Policy, and the Business Cycle. AU Christiano, Lawrence J.; Eichenbaum, Martin. AA Christiano: Federal Reserve Bank of Minneapolis. Eichenbaum: Northwestern University, National Bureau of Economic Research, and Federal Reserve Bank of Chicago. SR National Bureau of Economic Research Working Paper: 4129; National Bureau of Economic Research, 1050 Massachusetts Avenue, Cambridge, MA 02138. PG 34. PR \$5.00. JE E51. E58, E25. KW Money Supply Shocks. Wages.

AB This paper presents new empirical evidence to support the hypothesis that positive money supply shocks drive shortterm interest rates down. We then present a quantitative. general equilibrium model which is consistent with hypothesis. The two key features of our model are that the (i) money shocks have a heterogeneous impact on agents and (ii) ex post inflexibilities in production give rise to a very low short-run interest elasticity of money demand. Together, these imply that, in our model. a positive money supply shock generates a large drop in the interest rate comparable in magnitude to what we find in the data. In sharp contrast to sticky nominal wage models, our model implies that positive money supply shocks lead to increases in the real wage. We report evidence that this is consistent with the U.S. data. finally, we show that our model can rationalize a version of the Real Bills Doctrine in which the monetary authority accommodates technology shocks, thereby 
smoothing interest rates.

\section{Christopeit, Norbert}

PD November 1991. TI On the Existence of ArbitrageFree Measures in Contingent Claim Valuation. AU Christopeit. Norbert: Musiela, Marek. AA Christopeit: University of Bonn. Musiela: University of New South Wales. SR Universitat Bonn Sonderforschungsbereich 303Discussion Paper: B-206: Sonderforschungsbereich 303 an der Universitat Bonn Adenauerallee 24-42, D-5300 Bonn 1, GERMANY. PG 11. PR no charge. JE G10, G13. KW Financial Markets. Portfolio Strategies. Semimartingale Theory.

AB A problem of both practical and theoretical importance is to obtain a criterion of whether a given model for the price process allows for an equivalent martingale measure or not and to provide a method of constructing such a measure. These two questions are addressed in the present paper. The main result is a simple tests for existence of an equivalent martingale measure.

\section{Ciccone, Antonio}

PD June 1992. TI Start-up Costs and Pecuniary Externalities as Barriers in Economic Development. AU Ciccone. Antonio; Matsuyama, Kiminori. AA Ciccone: Stanford University. Matsuyama: Northwestern University. SR Hoover Institute Working Papers in Economics: E-92-14: Domestic Studies Program Working Paper Series, Hoover Institution. Stanford University, Stanford, CA 94305. PG 30. PR not available. JE L16, O11, O31. KW Dynamic Monopolistic Competition. Endogenous Growth. Roundabout Production.

AB One critical aspect of economic development is that productivity growth and a rising standard of living are realized through more roundabout methods of production and increasing specialization of intermediate inputs or producer services. We develop a dynamic general equilibrium model of monopolistic competition and show that an economy that inherits a small range of specialized intermediate inputs can be trapped into a lower stage of development. The limited availability of specialized inputs forces the final goods producers to use a labor intensive technology, which in turn implies a small inducement to introduce new intermediate products. The startup costs, which make the intermediate goods producers subject to dynamic increasing returns, and pecuniary externalities associated with the process of starting up new firms in the intermediate goods sector play essential roles in the model.

\section{Clare, Andrew}

PD 1992. TI An APT Approach to Modelling the Quality of Securities House' Capital. AA Southampton University. SR University of Southampton Discussion Paper in Economics and Econometrics: 9223; Department of Economics. University of Southampton, Southampton S09 5NH, ENGLAND. PG 15. PR no charge. JE G12, G18. G24, G28. KW Arbitrage Pricing Theory. Securities Firms.

AB In recent years regulators have focussed their attention on the activities of securities houses and investment firms with an eye towards ensuring financial market stability. Assessing the quality of securities house' capital is an important part of this monitoring process. Ideally as the riskiness of the securities house' balance sheet increased regulators would require them to hold more capital. The key question then for regulators is how they should proceed in obtaining accurate measures of the riskiness of the complex balance sheet of securities firms. In this paper a market measure of the probability of securities house failure [originally suggested by Miles and Hall (1988)] which incorporates the APT is proposed. The usefulness of the measure is tested by constructing synthetic house balance sheets. The measure is found to be generally sensitive to changes in the asset and liability quality of a securities house and also to the degree of leverage of the firm.

TI Is the UK Treasury Bill Rate a Good Proxy for Expected Inflation in the UK? AU Andrade, Isabel; Clare. Andrew.

\section{Clements, Benedict}

PD August 1992. TI Currency Substitution: The Recent Experience of Bolivia. AU Clements. Benedict: Schwartz. Gerd. AA International Monetary Fund. SR International Monetary Fund Working Paper: 92/65; International Monetary Fund. Washington, DC 20431. PG 14. PR not available. JE E40. E41. KW Currency Substitution. Exchange Rate Depreciation. Dollarization.

AB This paper analyzes the determinants of currency substitution in Bolivia in the period following the 1984-85 hyperinflation. We find that expected exchange rate depreciation and actual interest rate differentials between boliviano and dollar deposits in the Bolivian banking system are statistically significant determinants of the degree of currency substitution. However, the explanatory power of these variables is low compared to variables that measure the degree of inertia in the currency substitution process. Thus, further reductions in inflation or higher interest rates for boliviano bank deposits are likely to have but a small effect on dollarization.

\section{Coate, Steve}

TI Robin-Hooding Rents: Exploiting the Pecuniary Effects of In-Kind Programs. AU Zeckhauser, Richard; Coate. Steve; Johnson, Stephen.

\section{Cochrane, John H.}

PD March 1992. TI A Cross-Sectional Test of a Production-Based Asset Pricing Model. AA University of Chicago and National Bureau of Economic Research. SR National Bureau of Economic Research Working Paper: 4025; National Bureau of Economic Research. 1050 Massachusetts Avenue. Cambridge. MA 02138. PG 34. PR \$3.00. JE G12, C51, C52. KW Stock Returns. Factor Pricing.

AB This paper tests a factor pricing model for stock returns. The factors are returns on physical investment, inferred from investment data via a production function. The tests examine the model's ability to explain the variation in expected returns across assets and over time. The model is not rejected. It performs about as well as the CAPM and the Chen, Roll and Ross factor model, and it performs substantially better than a simple consumption-based model. In comparison tests. the investment return factors drive out all the other models. The paper also provides an easy technique for estimating and testing dynamic. conditional asset pricing models. All one has to do is include factors and returns scaled by instruments in an unconditional estimate. This procedure imposes none of the usual restrictions on conditional moments, and does not require prewhitened or orthogonalized factors. 
Cole, Nancy

PD September 1992. TI Employer-Provided Job Training: Who Really Pays? AA University of California, Los Angeles. SR University of California at Los Angeles Department of Economics Working Paper: 677s; Department of Economics, University of California at Los Angeles, 2263 Bunche., Los Angeles. CA 90024. PG 27. PR \$2.50; checks payable to U.C. Regents. JE J41. KW Job Training. Human Capital.

AB Employment investments in job training are risky since employees may leave their jobs. taking with them the employer's investment in human capital. Specific human capital theory predicts that firms and workers will form implicit bonding arrangements to protect investments in specific human capital. However, although several studies have documented the empirical significance of long-term tenure, it is difficult to distinguish between the various motives that might give rise to observed worker-firm attachments. In this paper I examine the relationships between bonding and employer investments in human capital. I find that firms that provide company training programs bond workers through wage premiums. In contrast. firms that provide general training-tuition aid or apprenticeship training- are likely to use pensions as a bonding device. These firms are more likely to provide noncontributory pensions than either firms with company training programs or firms with no training program.

\section{Cooper, Russell}

PD June 1992. TI Autos and the National Industrial Recovery Act: Evidence on Industry Complementarities. AU Cooper, Russell: Haltiwanger, John. AA Cooper: Boston University. Haltiwanger: University of Maryland. SR University of Maryland Department of Economics Working Paper: 92-7; University of Maryland. Department of Economics, College Park, MD 20742. PG 39. PR no charge. JE L62. L51, K23. KW Automobile Industry. Coordination Problem. Production Smoothing.

AB This paper investigates the motivations for, and implications of, the Automobile Industry code negotiated in 1933 and modified in 1935 under the National Industrial Recovery Act. The amended code contained a provision calling for automobile producers to alter the timing of new model introductions and the annual automobile show as a means of regularizing employment in the industry. We analyze two models of the annual automobile cycle to explain key features of the automobile industry during the 1920's and 1930's. In one model, the NIRA code simply codified a change in industry behavior that would bave taken place anyway due to a change in fundamentals in the economy during the early 1930's. The competing model introduces a coordination problem into the determination of the equilibrium timing of new model introductions. From the perspective of this model, the NIRA code succeeded in moving the industry from an equilibrium with relatively too little production smoothing to a more efficient equilibrium. Our analysis of this period provides evidence in favor of the second model.

\section{Coricelli, Fabrizio}

TI Output Collapse in Eastern Europe: The Role of Credit. AU Calvo, Guillermo A.; Coricelli, Fabrizio.

\section{Cornelli, Francesca}

PD October 1992. TI
Monopolistic Insurance Market with Adverse Selection. AU Comelli, Francesca; Yosha, Oved. AA Comelli: London School of Economics. Yosha: Brown University. SR Brown University Department of Economics Working Paper: 92-20; Department of Economics. Brown University. Providence. Rhode Island 02912. PG 17. PR no charge. JE D82, G22, G28, L51. KW Insurance. Adverse Selection. Regulation.

AB In a monopolistic insurance market with adverse selection low risk individuals obtain little or no coverage. We study the effectiveness of a particular form of government intervention in this market. namely the entry of a public insurance firm to the market. For all parameter configurations the resulting game has a unique equilibrium where the public firm breaks even on average, the monopolist makes strictly positive expected profits, high risk individuals remain fully covered at a strictly higher level of expected utility, and the coverage of low risk individual strictly increases with no loss in expected utility. Moreover. the gains in expected utility in certainty equivalence terms, more than offset the loss in expected profits to the monopolist, generating a Hicks-Kaldor welfare improvement.

\section{Cragg, John G.}

PD July 1992. TI Testing and Determining Arbitrage Pricing Structure from Regressions on Macro Variables. AU Cragg, John G.; Donald, Stephen G. AA Cragg: University of British Columbia. Donald: University of Florida. SR University of British Columbia Department of Economics Discussion Paper: 92-14; Department of Economics, University of British Columbia 997-1873 East Mall. Vancouver, B.C. Canada V6T 1W5. PG 37. PR JE G12, C30. KW Model Selection. Arbitrage Pricing Theory.

AB This paper suggests a different way of estimating and testing the APT based on using macro-type variables which are possibly subject to measurement error. The common-factor structure assumed by the model implies that the matrix of regression coefficients will be of the same rank as the number of independent latent factors and the APT hypothesis is that the rank of the matrix including also the estimates of the constant will be of the same rank. Procedures for estimating this rank and testing the APT restriction are suggested. These procedures turn out to be robust to a fairly wide variety of specifications of the nature of the disturbances in the company returns and allow for the APT valuation equation to have random coefficients over time. Modification resulting in a rather impractical procedure is required when the basic factor loadings are also random. The simpler procedures are applied to twenty years of monthly data with high success, though serious problems of wider implication, emerging from some forms of the model selection criteria used, do emerge.

\section{Crone, Theodore $\mathrm{M}$.}

PD September 1992. TI Vector-Autoregression Forecast Models for the Third District States. AU Crone, Theodore M.: Delaney, Sherry: Mills, Leonard O. AA Crone: Federal Reserve Bank of Philadelphia. Delaney: University of Virginia. Mills: Federal National Mortgage Association. SR Federal Reserve Bank of Philadelphia Research Working Paper: 92-19; Working Papers, Department of Research, Federal Reserve Bank of Philadelphia, 10 Independence Mall. Philadelphia. PA 19106. PG 12. PR no charge except overseas airmail. 
$\$ 2.00$; checks/money orders in U.S. funds payable to Federal Reserve Bank of Philadelphia. JE C32. KW State Economies. VAR Model.

AB Vector-autoregression (VAR) forecast models have been developed for many state economies. Much of this work has been done by economists within the Federal Reserve System. This paper extends that work by developing VAR forecast models in the Minnesota tradition for the three states in the Third Federal Reserve District -- Pennsylvania, New Jersey, and Delaware.

\section{Croushore, Dean}

PD August 1992. TI The Importance of the Tax System in Determining the Marginal Cost of Funds. AU Croushore, Dean: Ahmed. Shaghil. AA Croushore: Federal Reserve Bank of Philadelphia. Ahmed: Pennsylvania State University. SR Federal Reserve Bank of Philadelphia Research Working Paper: 92-15: Working Papers. Department of Research. Federal Reserve Bank of Philadelphia, 10 Independence Mall, Philadelphia, PA 19106. PG 11. PR no charge except overseas airmail. \$2.00: checks/money orders in U.S. funds payable to Federal Reserve Bank of Philadelphia. JE H21. KW Tax Schedule. Taxation.

AB This paper extends the literature on the marginal cost of public funds to incorporate the different ways in which the tax schedule can be altered. It derives analytical expressions for the marginal cost of funds for two cases: one in which the progressivity of the tax system is maintained, and another in which the tax schedule is shifted up proportionately. We calculate values of these marginal-cost-of-funds concepts for plausible ranges of key parameters, including a comparison of the results when nonlabor income is and is not taxed. The main result is that if the uncompensated labor-supply elasticity is zero, if only labor income is taxed, and if the tax schedule is shifted proportionately, then the marginal cost of funds (MCF) is exactly unity, regardless of the values of any other parameters of the model.

\section{Dalmazzo, Alberto}

PD January 1992. TI Outside Options in a Bargaining Model With Decay in the Size of the Cake. AA London School of Economics. SR London School of Economics Suntory-Toyota International Centre for Economics and Related Disciplines Working Paper: TE/92/239; London School of Economics Houghton Street, London WC2A 2AE, ENGLAND. PG 20. PR no charge. JE C78, J31. KW Bargaining. Outside Options.

AB The paper analyses a simple Rubinstein-type bargaining model in which there is no discounting and the cake decays over time at a positive rate. As a consequence, outside options enter players' unique Perfect Equilibrium payoffs. It is then shown that these payoffs, when the interval between two subsequent calls shrinks to zero, take the "split-the-difference" form. (These results generalize easily to the case of three-party bargaining). This can justify the common practice. in labor economics, of deriving wage-equation expressions from Nashmaximands in which the status-quo points are shifted to the outside option levels.

PD August 1992. TI Wage Negotiations and Capital Structure: A Strategic Bargaining Approach. AA London School of Economics and University of Siena. SR Centre for Economic Performance Discussion Paper: 91: The Centre for Economic Performance. The London School of Economics and
Political Science, Houghton Street. London WC2A 2AE, ENGLAND. PG 25. PR no charge. JE J31, G32, C70. KW Wage Bargaining. Debt. Capital Structure.

AB We analyze the relation between firms' debt and bargained wage level and its implications for the optimal choice of the capital structure. Similarly to Hart and Moore (1991), we place the analysis of the feasible debt contracts in a strategic bargaining setting. in which both the management and the workforce of the firm have human capital specificities in production. We obtain that debt repayments constrain wage levels, providing an advantage for debt financing. Moreover. either underinvestment can arise, due to wealth constraints, or, on the contrary, firms may borrow more than what is required by the production process.

\section{Davidson, James}

PD May 1992. TI An Ll-Convergence Theorem for Heterogeneous Mixingale Arrays with Trending Moments. AA London School of Economics. SR London School of Economics Suntory-Toyota International Centre for Economics and Related Disciplines Working Paper: EM/92/242; London School of Economics, Houghton Street, London WC2A 2AE, ENGLAND. PG 9. PR no charge. JE C19. KW Laws of Large Numbers. Mixingales. Nonstationarity: AB This paper gives a generalization of an L1-convergence theorem for dependent processes due to Andrews (1988). Among the cases covered by this result are weak laws of large numbers of random sequences $\{\mathrm{Xt}\}$ having moments tending to either infinity or zero as $t$ approaches infinity.

\section{Dawar, Niraj}

PD 1992. TI Determining The Order and Direction of Multiple Brand Extensions. AU Dawar, Niraj; Anderson, Paul F. AA Dawar: INSEAD. Anderson: Pennsylvania State University. SR INSEAD Working Papers: 92/36/MKT; INSEAD, INSEAD, Boulevard de Constance, Fontainebleau. 77305 Cedex, FRANCE. PG 27. PR not available. JE M30, M31. KW Brand Extensions. Marketing.

AB The process of managing a successful brand involves exercising the brand's equity to profitable ends. Brand extension provides a means of leveraging such equity. One means of arriving at distant brand extensions is through the introduction of intermediate brand extensions (Keller and Aaker 1992). Given a set of potential extensions, a brand manager may wish to determine the order in which to introduce these extensions. In addition, it may be necessary to take into account the direction in which these extensions will be undertaken. Two experiments provide evidence for the importance of considering order and direction of extension. Results show that undertaking extensions in a particular order can allow distant extensions to be as coherent and that following a consistent direction in extension allows for greater coherence and purchase likelihood for the target extension.

\section{de Bartolome, Charles A. M.}

PD July 1992. TI The Privatization of the New York City Subway. AU de Bartolome. Charles A. M.: Ramsey, James B. AA New York University. SR New York University Economic Research Reports: 92-32; New York University. Faculty of Arts and Science, Department of Economics, Washington Square, New York, N.Y. 10003. PG 26. PR no charge. JE L33, R42, L32, H54. KW Urban Transit. Private Ownership. 
AB The privatization of the New York City subway is proposed. Each line should be operated separately. The operator should pay a fixed price for the capital associated with the line and bid a profit share to be paid to the city. Statistics suggest the New York City subway is operated similarly to other subways and that similar benefits would be realized by the privatization of other subways. We provide an upper bound on the competitive fare which compares favorably with fares charged by buses and taxis.

De Toldi, $M$.

PD August 1992. TI On Seasonal Effects in Duration Models. AU De Toldi, M.; Gourieroux. C.: Monfort, A. AA Monfort: INSEE. Gourieroux: CEPREMAP. De Toldi: ENSAE. SR Unite de Recherche Document de Travail ENSAE/INSEE: 9216: INSEE. Unite de Recherche. $18 \mathrm{Bd}$. Adolphe Pinard. 75675 Paris cedex 14. FRANCE. PG 25. PR no charge. JE C41. KW Seasonality. Stock Sampling.

AB We introduce a seasonal duration model taking into account both entry and exit seasonal effects. Different estimation methods of this model are considered for the case of stock sampling. This methodology is applied to the study of prepayments of car credits and this allows to derive the probabilistic properties of the cash-flows.

\section{Deacon, Robert T.}

PD August 1992. TI The Structure of an Environmental Transaction: The Debt-for-Nature Swap. AU Deacon, Robert T.: Murphy, Paul. AA University of California, Santa Barbara. SR University of California at Santa Barbara Department of Economics Working Paper: 15-92: Working Papers Coordinator, Department of Economics, University of California. Santa Barbara. CA 93106. PG 45. PR no charge. JE Q23, K32, Q20. KW Transactions Costs. Environmental Law.

AB The record of recent activity in debt-for-nature swaps is studied. the practical significance of swaps completed to date is assessed, and prominent claims in the environmental literature on the rationale for using debt in these transactions are evaluated. The structure of debt-for-nature contracts completed to date is examined from the perspective that such contracts reflect the form and magnitude of transaction costs involved in exchanging environmental services. The contract structure that has emerged is found to be a product of several factors, including: relatively weak incentives to enforce existing legal claims to environmental resources in developing countries, high costs for delineating and observing environmental outcomes. and the fact that nominal ownership of these resources often rests with a national government.

\section{Deepak, Lal}

PD October 1992. TI In Praise of the Classics: The Relevance of Classical Political Economy for Development Policy and Research. AA University of California, Los Angeles and University College. London. SR University of California at Los Angeles Department of Economics Working Paper: 679; Department of Economics. University of California at Los Angeles, 2263 Bunche, Los Angeles, CA 90024. PG 22. PR \$2.50; checks payable to U.C. Regents. JE O20.021. KW Poverty. Equity. Growth.

AB This paper examines the relevance of the classical approach to the study of economic development in three areas: (a) the scope of the subject -- in particular the relevance of the "why" questions rather than the "how" questions which have been the major concern of theorizing on economic development; (b) the analytical framework for policy analysis, in which unlike the contemporary "public economics" school the polity is not subsumed into a committee of Platonic Guardians, and (c) an empirical research methodology which meets many of the epistemological objections against the currently fashionable positivist methodology based on Popperian falsificationism.

\section{Del Boca, Daniela}

PD September 1992. TI Expenditure Decisions of Divorced Mothers and Income Composition. AU Del Boca, Daniela: Flinn, Christopher. AA Del Boca: University of Turin. Flinn: New York University. SR New York University Economic Research Reports: 92-40; New York University. Faculty of Arts and Science. Department of Economics. Washington Square, New York, N.Y. 10003. PG 31. PR no charge. JE D12, J12, J13. KW Child Support. Consumption.

AB In this paper we analyze the relationship between the income sources of custodial divorced parents and their expenditure patterns. While recipients of child support transfers are not typically legally required to observe explicit expenditure guidelines, it is of interest to determine whether individuals receiving such transfers allocate their income differentially from those who do not. We use data from the Consumer Expenditure Survey to directly investigate the issue of whether or not divorced mothers receiving child support income spend larger amounts on "child goods" than those not receiving child support holding total household income constant. Our empirical results indicate that income composition does affect the expenditure patterns of divorced mothers and that consumption externalities exist even among divorced parents.

\section{Delaney, Sherry}

TI Vector-Autoregression Forecast Models for the Third District States. AU Crone. Theodore M.; Delaney. Sherry; Mills, Leonard $\mathrm{O}$.

\section{Demange, Gabrielle}

PD September 1992. TI Optimality of Incomplete Markets. AU Demange, Gabrielle; Laroque, Guy. AA Demange: DELTA. Laroque: INSEE. SR Unite de Recherche Document de Travail ENSAE/INSEE: 9218; INSEE, Unite de Recherche, 18 Bd. Adolphe Pinard, 75675 Paris cedex 14, FRANCE. PG 24. PR no charge. JE D52, D51. KW Financial Structure. Market Structure.

AB In a static exchange economy, where the traders' initial endowments are risky, the optimality of the financial structure is studied when markets are incomplete. Only financial structures with the same number of assets are compared. Two definitions of the efficiency of a market structure are introduced. First, a market structure is universally dominated if there is another market structure that yields a larger set of feasible utility levels, this for all economies. We provide a general characterization of the class of market structures that are not universally dominated. Second, a market structure is optimal when it yields an allocation of risks which cannot be Pareto-dominated through the implementation of any other market structures of prespecified rank. Finally, we study in 
detail the situation where the fundamental risks in the economy are Gaussian, restricting the attention to linear market structures.

Demekas, D. G.

TI The Output Decline in the Aftermath of Reform: The Cases of Bulgaria, Czechoslovakia, and Romania. AU Borensztein. E. R.; Demekas, D. G.; Ostry, J. D.

\section{Desai, Meghnad}

PD July 1992. TI Some Simple Dynamics of Transition: From Command to Market Economy. AU Desai. Meghnad; Estrin. Saul. AA Desai: London School of Economics. Estrin: London School of Economics and London Business School. SR Centre for Economic Performance Discussion Paper: 85: The Centre for Economic Performance. The London School of Economics and Political Science, Houghton Street. London WC2A 2AE, ENGLAND. PG 19. PR no charge. JE P00, P47, E61, E42, E30. KW Transition. East European Economies. Planned Economy.

AB The recent experience of Eastern European economiesHungary, Poland and Czechoslovakia-is analyzed in terms of two simple models, the first model characterizes the planned economy and derives an expression for the monetary overhang. The second model analyses the dynamics of transition in terms of an Aggregate Demand-Aggregate Supply model with price expectations. The simultaneous occurrence of inflation and output loss is derived. Extensions to cover a more complex scenario are discussed.

\section{Desruelle, Dominique}

TI R\&D: Who Does the $R$, who Does the D? AU Cadot, Olivier; Desruelle, Dominique.

\section{DeWitt, Diane E.}

PD March 1991. TI Who Bears the Burden of Energy Taxes? AU DeWitt, Diane E.; Dowlatabadi, Hadi; Kopp. Raymond J. AA DeWitt and Kopp: Resources for the Future. Dowlatabadi: Carnegie Mellon University. SR Resources for the Future Quality of the Environment Division Discussion Paper: QE91-12: Quality of the Environment Division. Resources for the Future, 1616 P Street, NW, Washington, D.C. 20036. PG 41. PR \$2.25 prepaid. U.S. funds. JE H23. Q48. KW Carbon Dioxide Emissions. Carbon Tax. Tax Burden.

AB For environmental reasons, taxes on energy products have developed a large following among Washington policymakers and politicians. Since it has been argued that energy taxes are good for the environment, foster conversation, reduce our dependency on foreign sources of supply, and are generally believed to be spread "thinly" over the tax paying public. one can expect political interest in such taxes to continue. The purpose of this study is to take a first look at the distributional consequences of various energy tax schemes, both those employed for fiscal reasons and those related to environmental policies. In particular, are these taxes in fact small and are they spread evenly over U.S. households? If the answer to this is yes, then desirability of carbon taxes may be reinforced. However, if these taxes are large and/or borne unevenly by households, then politicians and welfare economists will have much to discuss.

\section{Dhillon, Amrita}

PD March 1992. TI Perfect Correlated Equilibria. AU Dhillon, Amrita; Mertens, Jean-Francois. AA Universite Catholique de Louvain and S.U.N.Y. SR Universite Catholique de Louvain CORE Discussion Paper: 9239; Universite Catholique de Louvain. Voie du Roman Pays, 34, B-1348 Louvain-la-Neuve, BELGIUM. PG 17. PR not available. JE C71, D81. KW Game Theory. Revelation Principle. Uncertainty.

AB The (epsilon-) perfect correlated equilibria (P.C.E.) are those induced by a (epsilon-) perfect equilibrium of some correlation device. The "revelation principle" fails for this concept - the direct mechanism may not yield a perfect equilibrium. The approximately perfect correlated equilibria (A.P.C.E.) are the limits of epsilon-P.C.E., and we obtain a full characterization for them. Even the A.P.C.E. are "acceptable". We argue on an example that, among those. these are the P.C.E. which seem the "right" concept.

\section{Diamond, Larry J.}

PD October 1992. TI International and Domestic Factors in Africa's Trend Toward Democracy. AA Stanford University. SR Stanford Hoover Institute International Studies Working Paper: I-92-14; The Hoover Institution, Stanford University. Stanford. CA 94305. PG 30. PR no charge. JE H11, 055, D72. KW Political Reform. Democratization.

AB The pace and spread of political regime change in Africa since 1989 has been breathtaking. The program on African Governance at the Carter Center, which has been tracking democratic trends on the continent, estimates that more than half of all African states are now democratic or manifest moderate to strong commitments to democratic change. I will survey the principal causes - domestic and international - of the recent trend toward democracy in Africa. I will show that this trend is the result of a remarkably broad and deep conjuncture of factors both within individual African countries, across the continent, and throughout the world - particularly in the Western democratic donor countries and the former communist bloc. This historical conjuncture creates the most propitious opportunities for democratic development since formal independence in Africa. but it also presents formidable challenges.

\section{Diaz-Gimenez, J.}

PD January 1992. TI Liquidity Constraints in Economies with Aggregate Fluctuations: A Quantitative Exploration. AU Diaz-Gimenez, J.; Prescott, E. AA Diaz-Gimenez: Universidad Carlos III de Madrid. Prescott: Federal Reserve Bank of Minneapolis and University of Minnesota. SR Federal Reserve Bank of Minneapolis Staff Report: 149; Research Department, Federal Reserve Bank of Minneapolis. 250 Marquette Ave., Minneapolis, MN 55401. PG 17. PR no charge. JE D58, E42, E44, G21. KW Monetary Assets. Open Market Operations. General Equilibrium.

AB We extend and apply computable general equilibrium models to the study of economies where liquidity constrained agents hold liquid assets as a substitute for insurance against both idiosyncratic and aggregate uncertainty. By varying their holdings of these assets, agents buffer their streams of consumption against bad draws in their production opportunities. Our model economies include two types of nominally denominated government securities: one that bears 
no interest and determines the unit of account and another one that is issued in a large denomination and sells at a discount. We use this model to explore the effects on real economic activity of monetary policies implemented through open market operations.

PD March 1992. TI Banking in Computable General Equilibrium Economies. AU Diaz-Gimenez. J.; Prescott, E.; Fitzgerald, T.; Alvarez, F. AA Diaz-Gimenez: Carlos III University. Madrid. Spain. Prescott. Fitzgerald and Alvarez: Federal Reserve Bank of Minneapolis and University of Minnesota. SR Federal Reserve Bank of Minneapolis Staff Report: 153: Research Department. Federal Reserve Bank of Minneapolis, 250 Marquette Ave., Minneapolis, MN 55401. PG 25. PR no charge. JE D58, G21, E52. KW Banks. Monetary Policy.

AB In this paper we develop a computable general equilibrium economy that models the banking sector explicitly. Banks intermediate between households and between the household sector and the government sector. Households borrow from banks to finance their purchases of houses and they lend to banks to save for retirement. Banks pool households' savings and they purchase interest-bearing government debt and non-interest bearing reserves. We use this structure to answer two sets of questions: one normative in nature that evaluates the welfare costs of alternative monetary and tax policies, and one positive in nature that studies the real effects of following a procyclical interest-rate policy rule.

Diebold, Francis X.

TI Near Rationality and Strategic Complementarity in a Macroeconomic Model: Policy Effects. Persistence. and Multipliers AU Bomfim, Antulio N.; Diebold, Francis X.

Doherty, Ann E.

TI Intransigence in Negotiations: The Dynamics of Disagreement. AU Brams. Steven J.; Doherty, Ann E.

Donald, Stephen G.

TI Testing and Determining Arbitrage Pricing Structure from Regressions on Macro Variables. AU Cragg, John G.; Donald. Stephen G.

Donaldson, J.

PD September 1991. TI Anticipation and the Aggregation of Idiosyncratic Risks. AU Donaldson, J.; Dutta, Jayasri. AA Donaldson: Columbia University. Dutta: University of Cambridge. SR University of Cambridge Economic Theory Discussion Paper: 163: Department of Applied Economics. University of Cambridge. Sidgwick Avenue. Cambridge CB3 9DE, UNTTED KINGDOM. PG 45. PR \$5.00 (L2.50). checks payable to University of Cambridge. JE D82. E32. KW Business Cycles. Private Information. Aggregate Shock.

AB This paper examines the role of private information as a source of variation in aggregate productivity. An economy is considered where several firms face uncertainty in the form of productivity shocks. In the absence of private information. there are no aggregate effects from these idiosyncratic shocks: output is constant over time. If firms can anticipate their own future productivity, the optimal allocation displays aggregate randomness. Output, employment and investment vary cyclically. It is also shown that this model is observationally equivalent to one where all firms face the same aggregate shock.

\section{Dowlatabadi, Hadi}

PD October 1990. TI Electric Vehicles and the Environment: Consequences for Emissions and Air Quality in Los Angeles and U.S. Regions. AU Dowlatabadi, Hadi; Krupnick. Alan J.; Russell, Armistead. AA Dowlatabadi and Krupnick: Resources for the Future. Russell: Carnegie-Mellon University. SR Resources for the Future Quality of the Environment Division Discussion Paper: QE-91-01: Quality of the Environment Division, Resources for the Future, $1616 \mathrm{P}$ Street, NW. Washington. D.C. 20036. PG 138. PR \$2.25 prepaid. U.S. funds. JE Q25, L94. KW Electric Vehicles. Air Quality.

AB Introduction of electric vehicles (EV) into the vehicle mix of Los Angeles and other major cities would, in 2010. significantly reduce net emissions of the major mobile source pollutants (hydrocarbons. carbon monoxide, nitrogen oxides. and benzene). This is so, irrespective of how and where the electricity for charging the batteries is generated and even when advanced (low emissions and high efficiency) gasoline and methanol vehicles representing performance targets set by CARB for the year 2000 are being replaced by relatively low efficiency electric vehicles representing 1990 electric vehicle technologies. The emissions of carbon dioxide will be reduced also unless the electricity supplied to EVs is from coal-fired plants. Regional acid deposition could increase or decrease, depending on the emissions characteristics of the incremental power plant, but the effects would be small in either case.

PD October 1990. TI The Impact of Pricing Rules on Electric Utility Emissions. AU Dowlatabadi, Hadi: Hahn. Robert W. AA Dowlatabadi: Resources for the Future. Hahn: American Enterprise Institute. SR Resources for the Future Quality of the Environment Division Discussion Paper: QE9103; Quality of the Environment Division, Resources for the Future, 1616 P Street, NW, Washington, D.C. 20036. PG 22. PR \$2.25 prepaid, U.S. funds. JE L51, Q25. KW Electricity Generation. Pollution. Pricing.

AB This paper examines the environmental impact of different approaches to pricing electricity. There are two basic results that emerge from the analysis. First, pricing mechanisms that do not take environmental concerns into account cannot, in general, be expected to reduce pollution. Second, pricing decisions that do take account of environmental externalities can lead to unambiguous reductions in certain kinds of emissions, provided they are designed appropriately.

TI Who Bears the Burden of Energy Taxes? AU DeWitt, Diane E.; Dowlatabadi, Hadi; Kopp, Raymond J.

TI Implementing Environmental Costing in the Electric Utility Industry AU Palmer, Karen; Dowlatabadi, Hadi.

\section{Dubey, Pradeep}

PD October 1992. TI Is Gold an Efficient Store of Value? AU Dubey, Pradeep; Geanakoplos. John; Shubik, Martin. AA Dubey: SUNY. Geanakoplos and Shubik: Yale University. SR Yale Cowles Foundation Discussion Paper: 1031; Yale University, Cowles Foundation, 30 Hillhouse Ave., Box 2125. Yale Station. New Haven CT 06520. PG 19. PR no charge. JE E42, E51. KW Money. Currency. Tobacco.

AB Gold and tobacco have both been used as money. One 
difference between the two is that gold yields utility, on account of its beauty, without diminishing its quantity. Tobacco yields utility when it is consumed. If this were the only difference, which would be the better money?

\section{Duck, Nigel $\mathbf{W}$.}

PD September 1992. TI Evidence on Breaking Trend Functions from Nine Countries. AA University of Bristol. SR University of Bristol Economics Working Paper: 92/341: Department of Economics. University of Bristol, Alfred Marshall Bldg., 8 Woodland Road. Bristol BS8 ITN. ENGLAND. PG 9. PR No charge. JE E32, C22. KW Unit Roots. Trend Stationarity. Trend Breaks.

AB Procedures suggested by Perron $(1989,1990)$ are used to examine whether there is a unit root in real output for nine countries in the period 1870-1989. The broad finding is that while conventional Dickey-Fuller tests fail to reject a unit root for any country. once allowance is made for breaks in the slope and level of the trend function the unit root hypothesis can be rejected for most countries.

\section{Duclos, Jean-Yves}

PD April 1992. TI Progressivity, Redistribution and Equity, with Application to 1985 Britain. AA London School of Economics. SR London School of Economics SuntoryToyota International Centre for Economics and Related Disciplines Working Paper: WSP/69; London School of Economics, Houghton Street, London WC2A 2AE. ENGLAND. PG 57. PR no charge. JE D63. KW Income Redistribution. Equity.

AB This study displays a framework in which the progressivity, redistribution and equity of taxes and benefits can be systematically discussed. First, we present a computer model of the tax and benefit system in 1985 Britain, using a sample of 1985 Family Expenditure Survey income units. We discuss the characteristics of the system and we introduce indices of local progressivity, indicating in the process how the use of such indices can provide benchmarks to the impact of taxation and transfers on social welfare. We then proceed to discuss ways and means of portraying the global benefits, later deriving a general set of indices of vertical and horizontal equity that may reveal the desirability of various tax and benefit proposals. A persistent aim is that of identifying clearly the separate contribution of individual taxes and benefits to the global progressivity and equity of a complete tax and benefit system.

\section{Dutta, Jayasri}

TI Anticipation and the Aggregation of Idiosyncratic Risks. AU Donaldson, J.; Dutta, Jayasri.

PD March 1992. TI Efficiency Wages and Underemployment in the Long Run. AA University of Cambridge. SR Universite Catholique de Louvain CORE Discussion Paper: 9245: Universite Catholique de Louvain. Voie du Roman Pays. 34, B-1348 Louvain-la-Neuve, BELGIUM. PG 32. PR not available. JE E24, E22. J41. KW Capital Accumulation. Labor Productivity.

AB This paper considers the possibility of long run underemployment with capital accumulation. Wages affect labor productivity; possibly, but not necessarily, through worker's nutrition. Firms' set wages, and underemployment results, provided the aggregate capital stock is low. As capital accumulates, the economy achieves full employment. We consider the conditions on population growth, as well as industrial structure, which allow an economy to escape from persistent underemployment.

\section{Dutta, Soumitra}

PD 1992. TI Integrating Global Operations with Information Technology: Lessons from a Case Study. AU Dutta. Soumitra; Jelassi. Tawfik. AA INSEAD. SR INSEAD Working Papers: 92/48/TM: INSEAD. Boulevard de Constance, Fontainebleau, 77305 Cedex. FRANCE. PG 10. PR not available. JE O33, L65, F23. KW International Corporation. Technological Choice.

AB In the early 1980's. BP Chemicals faced challenges calling for some fundamental changes in its business strategy. The strong emphasis on production was giving way to a renewed search for new sources of competitive advantage such as enhanced customer service. In 1985, BP Chemicals embarked on an ambitious project to integrate all aspects of its international commercial activities. An information system, the Commercial System, was to form the core of this project and enable the organizational changes required for this integration. After overcoming the difficulties of implementing a large international information system. BP Chemicals is now facing the challenge of initiating major changes in its organizational structure and business processes. This paper describes the strategic planning and implementation of the Commencial System, and attempts to draw some lessons from the experience.

\section{Eden, Benjamin}

PD October 1992. TI Asymmetric Information and the Excess Volatility of Stock Prices. AU Eden. Benjamin; Jovanovic, Boyan. AA Eden: University of Iowa and Technion I Israel Institute of Technology. Jovanovic: New York University. SR New York University Economic Research Reports: 92-47; New York University. Faculty of Arts and Science. Department of Economics, Washington Square, New York. N.Y. 10003. PG 17. PR no charge. JE G12, D82. KW Public Information. Asset Pricing.

AB This paper argues that some of the volatility of stock prices in excess of fundamentals results from fluctuations in the amount of public information over time. The model assumes that dividends and consumption are constant in the aggregate but that there are good firms and bad firms whose identity may be unknown to the public, as in Akerlof's "lemons" problem. The paper then shows that the collective valuation of the constant dividend stream depends on the degree of informational asymmetry.

\section{Edlin, Aaron S.}

TI Discouraging Rivals: Managerial Rent Seeking and Economic Insufficiencies. AU Stiglitz, Joseph E.; Edlin. Aaron S.

\section{Eichenbaum, Martin}

TI Liquidity Effects, Monetary Policy, and the Business Cycle. AU Christiano, Lawrence J.; Eichenbaum, Martin.

\section{Eichengreen, Barry}

PD August 1992. TI Three Perspectives on the Bretton Woods System. AA University of California. Berkeley and National Bureau of Economic Research. SR National Bureau of Economic Research Working Paper: 4141; National 
Bureau of Economic Research, 1050 Massachusetts Avenue. Cambridge. MA 02138. PG not available. PR \$5.00. JE F33, F34. KW Monetary Systems. Bretton Woods. International Monetary Reform.

AB The twenty years that have passed since the collapse of the Bretton Woods-System provide sufficient distance to safely assess the operation of the post-World War II international monetary system. This paper considers the history and historiography of Bretton Woods from three perspectives. First. I ask how the questions posed today about the operation of Bretton Woods differ from those asked twenty years ago. Second. I explore how today's answers to familiar questions differ from the answers offered in the past. Third, I examine the implications of Bretton Woods experience for international monetary reform.

\section{Eijffinger, Sylvester C. W.}

TI Daily Bundesbank and Federal Reserve Intervention and the Conditional Variance Tale in DM/\$-Returns. AU Almekinders, Geert J.: Eijffinger, Sylvester C. W.

\section{El Hajj, Marina}

TI Managing Under Deadly Conditions. AU Kets De Vries, Manfred F. R.; El Hajj, Marina.

\section{Ellam, Michael}

PD December 1991. TI Quarterly National Income Accounts for Interwar Germany, 1925-1938. AU Ellam. Michael; Kitson, Michael; Solomou, S; Weale, $M$. AA Ellam: London School of Economics. Kitson, Solomou, and Weale: University of Cambridge. SR University of Cambridge Department of Applied Economics Working Paper: 9202: Department of Applied Economics. University of Cambridge, Sidgwick Avenue, Cambridge CB3 9DE, UNITED KNNGDOM. PG 11. PR $\$ 5.00(\mathrm{~L} 2.50)$, checks payable to University of Cambridge. JE C82, N14. KW Interpolation. Macroeconomic Data. World Depression. AB This paper applies interpolation and regression methods to derive German quarterly macroeconomic data from annual econometric relationships between national accounting aggregates and related indicator variables for which quarterly information is available. These data are then used to discuss the timing and causes of the German recovery from world depression in 1932.

\section{Elliot, Graham}

PD June 1992. TI Inference in Time Series Regression when the Order of Integration of a Regressor is Unknown. AU Elliot, Graham; Stock, James H. AA Elliot: Harvard University. Stock: Harvard University and National Bureau of Economic Research. SR National Bureau of Economic Research Technical Paper: 122; National Bureau of Economic Research, 1050 Massachusetts Avenue, Cambridge MA 02138. PG not available. PR \$3.00. JE C12, C22, C32, C40. KW Unit Roots. Pretests. Time Series Regressions.

AB It is well known that the distribution of statistics testing restrictions on the coefficients in time series regressions can depend on the order of integration is rarely known. This paper examines two conventional approaches to this problem, finds them unsatisfactory, and proposes a new procedure. The two conventional approaches - - simply to ignore unit root problems or to use unit root pretests to determine the critical values for second-stage inference - - both often induce substantial size distortions. In the proposed alternative procedure, the secondstage test is conditional on a first-stage "unit root" statistic developed in Stock (1992); the second-stage critical values vary continuously with the value of the first-stage statistic. The procedure is shown to have the correct size asymptotically and to have good local asymptotic power against Granger-causality alternatives.

\section{Engel, Eduardo M. R. A.}

TI Microeconomic Rigidities and Aggregate Price Dynamics. AU Caballero, Ricardo J.; Engel, Eduardo M. R. A.

\section{Estrin, Saul}

TI Some Simple Dynamics of Transition: From Command to Market Economy. AU Desai, Meghnad: Estrin, Saul.

PD July 1992. TI The Determinants of Investment in Employee Owned Firms: Evidence from France. AU Estrin. Saul; Jones, Derek C. AA Estrin: London School of Economics and London Business School. Jones: Hamilton College. SR Centre for Economic Performance Discussion Paper: 87 ; The Centre for Economic Performance. The London School of Economics and Political Science, Houghton Street. London WC2A 2AE, England. PG 17. PR no charge. JE E22, M21. KW France. Investment. Employee Profit Sharing.

AB In this paper we use a large panel data set to test competing hypotheses about investment in employee owned firms (EOF'S) especially the view that EOF's will invest less. Most of the variables stressed by labor-management theorists as inhibiting investment are found not to play any role in practice. but the volume of investment is found to be positively associated with the share of investment funded externally. This highlights the crucial role of external finance in supporting investment in EOF's.

PD July 1992. TI Firms in Transition: Modelling Enterprise Adjustment. AU Estrin, Saul: Hare, Paul G. AA Estrin: London Business School and London School of Economics. Hare: Heriot-Watt University and London School of Economics. SR Centre for Economic Performance Discussion Paper: 89: The Centre for Economic Performance, The London School of Economics and Political Science, Houghton Street, London WC2A 2AE, ENGLAND. PG 26. PR no charge. JE D21. KW Eastern Europe. Enterprise Behavior. Profits.

AB One of the key issues in the transition processes of Eastern Europe has to do with changes in enterprise behavior. Economic performance in the region will initially depend at least as much on how existing firms change as on the entry of new ones. This paper develops a framework for analyzing enterprise responses, identifying three phases. These are "pretransition" where firms have price and output targets and seek to minimize output subject to a profits constraint; "commercialization" in which prices are liberalized and budget constraints harder; and "privatization" in which firms behave like profit-maximizing firms in a market economy. The analysis derives distributions of outcomes for firms, depending on their efficiency level and their profit constraint. Some of the conclusions provide the basis for empirical testing using enterprise datasets. 
Evandrou, Maria

PD April 1992. TI The Distribution of Welfare Benefits in Kind. AU Evandrou. Maria; Falkingham, Jane; Hills, John; Le Grand, Julian. AA London School of Economics. SR London School of Economics Suntory-Toyota International Centre for Economics and Related Disciplines Working Paper:WSP/68; London School of Economics. Houghton Street, London WC2A 2AE, ENGLAND. PG 68. PR no charge. JE H51, H52, KW Government Spending. Health. Education. Housing.

AB This paper explores the value to households in different income and socio-economic groups of benefits from public spending on education, the National Health Service, and subsidies to local authority housing. Its results are drawn from secondary analysis of the 1987 General Household Survey. The paper compares these findings with those which the Central Statistical Office derives from the Family Expenditure Survey. The GHS provides detailed information on the use of health services and higher education, allowing. for instance, the allocation of higher education for students living away from home to their households of origin. The results confirm that the total of these benefits in kind is "pro poor," in the sense that households in lower income groups receive on average more in absolute terms than those at the top of the income distribution. However, the advantage we find for the lowest income groups is much less than that found by the CSO, and our total is greatest in the middle of the distribution.

\section{Evans, George W.}

PD January 1992. TI Local Convergence of Recursive Learning to Steady States and Cycles in Stochastic Nonlinear Models. AU Evans, George W.; Honkapohja, Seppo. AA Evans: London School of Economics. Honkapohja: Academy of Finland and University of Helsinki. SR London School of Economics Suntory-Toyota International Centre for Economics and Related Disciplines Discussion Paper: TE/92/236; London School of Economics. Houghton Street. London WC2A 2AE, ENGLAND. PG 29. PR no charge. JE E32, D83. KW Rational Expectations. Learning. Stability. Business Fluctuations.

AB This paper examines a method, or algorithm, by which agents in an economy may learn about steady states and cycles in stochastic nonlinear models. Conditions under which "learning" occurs are examined and this throws light on the conditions required by "rational expectations".

PD January 1992. TI Rationalizability, Strong Rationality and Expectational Stability. AU Evans, George W.: Guesnerie, Roger. AA Evans: London School of Economics. Guesnerie: EHESS, Paris. SR London School of Economics Suntory-Toyota International Centre for Economics and Related Disciplines Working Paper: TE/92/237: London School of Economics Houghton Street, London ENGLAND. PG 20. PR no charge. JE D83, C73, KW Rational Expectations. Rationalizability. Strong Rationality. Expectational Stability.

AB It is commonplace in economic models to assume rational expectations. This paper examines the stability of such expectations and looks at two different concepts of stabilityexpectations stability, based upon iterative convergence of expectations, and strong rationality, based upon rationalizable solutions to an associated game. It is shown that in an economy with homogeneous agents the concepts coincide.
Evans, Martin D. D.

PD August 1992. TI Do Expected Shifts in Inflation Policy Affect Real Rates? AU Evans, Martin D. D.: Lewis, Karen K. AA Evans: New York University. Lewis: University of Pennsylvania. SR National Bureau of Economic Research Working Paper: 4134; National Bureau of Economic Research, 1050 Massachusetts Avenue, Cambridge. MA 02138. PG not available. PR \$5.00. JE E31, E40, E64. KW Real Interest Rates. Inflation. Policy.

AB This paper presents a new explanation for the negative correlation between ex post real interest rates and inflation found in earlier empirical studies. We begin by showing that there is a strong negative correlation between the permanent movements in ex post real interest rates and inflation. We argue that such a correlation can arise when people incorporate anticipated shifts in inflation policy into their expectations. Using new time series techniques we are able to reject the hypothesis that nominal interest rates were unaffected by anticipated switches in inflation policy in the post-war era. To evaluate the impact of these switches, we then calculate the effects of inflationary expectations upon real rates using a Markov switching model of inflation. Inflation forecasts based upon a the estimates of this rational model behave similarly to inflation forecasts from the Livingston survey.

\section{Evstigneev, Igor}

PD July 1992. TI Markov Fields over Countable Partially Ordered Sets: Extrema and Splitting. AU Evstigneev, Igor; Greenwood, Priscilla Edson. AA Evstigneev: University of Moscow and University of Bonn. Greenwood: University of British Columbia. SR Universitat Bonn Sonderforschungsbereich 303- Discussion Paper: A-371; Sonderforschungsbereich 303 an der Universitat Bonn Adenauerallee 24-42. D-5300 Bonn 1. GERMANY. PG 93. PR no charge. JE C10. KW Partially Ordered Sets. Random Fields. Markov Processes.

AB In the present paper, we try to develop general technique for studying discrete Markov fields. In particular, we introduce and examine certain classes of "random time changes", random transformations of $\mathrm{T}$ where (T,S) is a partially ordered set. which preserve the Markov property and yield new, interesting classes of Markov fields.

\section{Faff, Robert W.}

TI The Form of Time Variation of Systematic Risk: Some Australian Evidence. AU Brooks, Robert D.; Faff, Robert W.; Lee, John H. H.

\section{Falkingham, Jane}

TI The Distribution of Welfare Benefits in Kind. AU Evandrou, Maria; Falkingham, Jane; Hills, John; Le Grand, Julian.

\section{Fan, Gang}

PD September 1992. TI Decentralized Socialism and Macroeconomic Stability: Lessons from China. AU Fan, Gang; Woo. Wing Thye. AA Fan: Chinese Academy of Social Sciences. Woo: University of California, Davis. SR University of California at Davis Economics Department Working Paper: 411; Department of Economics. University of California at Davis, Davis, CA 95616. PG 27. PR no charge. JE E30, E58, H32, P30. KW State Enterprise. Fiscal Imbalance. Inflation. 
AB Using a survey of 300 state-owned enterprises (SOE's), we argue that the acceleration of inflation in China after 1984 was caused by the decentralization reforms in the state sector. These reforms allowed the SOE's to realize their innate tendencies to over-consume and over-invest. The evidence suggests that the increasing government budget deficits were caused by an upward "wage drift": and that there has been a decline in production efficiency in the $1984-88$ period. The latter implies that the efficiency improvements in SOE's immediately after 1978 (found by earlier studies) was only a temporary phenomenon: and that the higher aggregate growth rate of $1984-88$ came from other sources.

Farmer, Roger E. A.

TI Indeterminacy and Increasing Returns. AU Benhabib. Jess: Farmer. Roger E. A.

TI The Aggregate Effects of Monetary Externalities. AU Benhabib. Jess; Farmer. Roger E. A.

Favero, Carlo A.

PD January 1992. TI Oil Investment in the North Sea. AU Favero, Carlo A.; Pesaran. M. Hashem. AA Favero: University of London. Pesaran: University of Cambridge. SR University of Cambridge Department of Applied Economics Working Paper: 9204; Department of Applied Economics, University of Cambridge. Sidgwick Avenue, Cambridge CB3 9DE, UNITED KINGDOM. PG 31. PR $\$ 5.00$ (L2.50). checks payable to University of Cambridge. JE L71, D92, D21. KW Intertemporal Choice. Exploration. Extraction.

AB Investment in oil production on the United Kingdom Continental Shelf (UKCS) involves three separate but highly interrelated activities: exploration, development and extraction. The exploration and extraction decisions have been analyzed recently by Pesaran (1990) and Favero (1992). The aim of this paper is to provide a model of the investment decision on the UKCS, where the development process is explicitly modeled within an intertemporal optimization framework. The model highlights the importance of the lengthy time lags that exist between price and tax changes and changes in oil supplies form UKCS. The empirical results demonstrate the importance of theoretical considerations in modeling the oil supply process and illustrate the pitfalls involved in relying on standard unrestricted distributed lags models in econometric analysis of oil investment.

PD February 1992. TI Uncertainty and Irreversible Investment: An Empirical Analysis of Development of Oilfields on the UKCS. AU Favero, Carlo A.; Pesaran, M. Hashem; Sharma. S. AA Favero: University of London. Pesaran: University of Cambridge and University of California, Los Angeles. Sharma: University of California, Los Angeles. SR University of Cambridge Department of Applied Economics Working Paper: 9210; Department of Applied Economics, University of Cambridge. Sidgwick Avenue, Cambridge CB3 9DE, UNITED KINGDOM. PG 13. PR $\$ 5.00$ (L2.50), checks payable to University of Cambridge. JE E22. L71, C53, C61. KW Optimal Stopping. Oil Exploration.

AB The aim of this paper is to analyze the implications of the theory of irreversible investment under uncertainty for investment in oilfields on the United Kingdom Continental Shelf (UKCS). We model the decision to proceed with the development investment as an optimal stopping problem and apply the established theory to derive the determinants of the optimal policy. Data on the length of the time period between discovery and development are available for individual oil fields on the UKCS. The theory is examined empirically by exploring the significance of the determinants of the optimal policy in explaining the variation in the development lag of individual oil fields. We find strong effect of expected price and associated price uncertainty on the length of the appraisal stage of the investment projects.

\section{Feenberg, Daniel}

PD August 1992. TI The Risk and Duration of Catastrophic Health Care. AU Feenberg. Daniel; Skinner, Jonathan. AA National Bureau of Economic Research. SR National Bureau of Economic Research Working Paper: 4147; National Bureau of Economic Research, 1050 Massachusetts Avenue, Cambridge, MA 02138. PG not available. PR \$5.00. JE I12, I18, I19, G22. KW Health Insurance. Medical Expenses.

AB Catastrophic medical expenses are an important economic risk facing the elderly. Little is known about the persistence of such out-of-pocket medical costs. We measure the time-series property of medical costs using information on medical deductions from a panel of tax returns. During the period of analysis, 1968-73, taxpayers could deduct medical expenses above 3 percent income. We correct for the resulting censoring bias using multivariate Tobit estimated with a variant of the smoothed simulated maximum likelihood (SSML) method. The data suggest that the burden of out-of-pocket medical expenses is substantially larger for lower income families. Furthermore, the estimated coefficients suggest substantial time-persistence in out-of-pocket medical care costs; a $\$ 1$ increase in out-of-pocket medical spending is predicted to increase future spending by an additional $\$ 2.80$. These results may shed light both on the social value of catastrophic health insurance as well on aggregate saving behavior.

\section{Feinman, Joshua N.}

PD September 1992. TI The Continuing Weakness in M2. AU Feinman, Joshua N.; Porter, Richard D. AA Board of Governors of the Federal Reserve System. SR Board of Governors of the Federal Reserve System Finance and Economics Discussion Series: 209; C/O Stephen A. Sharpe. Mail Stop 89, Federal Reserve Board. Washington, DC 20551. PG 38. PR no charge. JE EA1. KW Money Demand. Opportunity Costs.

AB In recent years, conventional money demand models have systematically overpredicted M2 growth, which has remained very sluggish relative to nominal income despite large declines in standard measures of opportunity costs. We develop an alternative money demand model in which the relevant opportunity cost measure is not chosen a priori. but rather is jointly estimated along with the other parameters of the model. Using this framework, we find that the opportunity cost measure that best fits the data over the entire sample period may actually have risen in recent years, despite the declines in short-term market interest rates, which would be consistent with the notion of a shrinking and less competitive depository sector. 
Feinstein, Jonathan S.

TI Public Goods in Trade: on the Formation of Markets and Political Jurisdictions. AU Casella. Alessandra; Feinstein, Jonathan S.

\section{Fernandez, Raquel}

PD September 1992. TI Income Distribution. Communities and the Quality of Public Education: A Policy Analysis. AU Fernandez, Raquel; Rogerson, Richard. AA Fernandez: Boston University and National Bureau of Economic Research. Rogerson: University of Minnesota. SR National Bureau of Economic Research Working Paper: 4158; National Bureau of Economic Research, 1050 Massachusetts Avenue. Cambridge, MA 02138. PG not available. PR \$3.00. JE I22, 128, H22. KW Taxation. Educational Finance.

AB This paper analyzes within the context of a multicommunity model the effects of several policies that affect the financing of public education. The key features of the model are: (i) individuals differ with respect to income. (ii) individuals choose in which community to reside, (iii) communities are characterized by a proportional tax on income and a quality of public education, and (iv) a community's tax rate is chosen by majority vote. We examine three types of policies: subsidies for residency of specific income groups in particular communities, ceilings or floors on community level educational spending, and income redistribution. In each case we examine the consequences of these policies for other welfare and the quality of education across communities. We identify several policies which make all individuals better off and increase the quality of education in all communities.

\section{Fishelson, Gideon}

PD August 1992. TI Backstop Technology for an Exhaustible Resource: A New Look at an Old Problem. AA Tel-Aviv University. SR Tel Aviv Sackler Institute of Economic Studies Working Paper: 8/92; Department of Economics. Tel Aviv University, Ramat Aviv 69978, Tel Aviv. ISRAEL. PG 19. PR no charge. JE I11, Q30. KW Backstop Technology. Exhaustible Resources. Perfectly Competitive Industry.

AB The 15 year old problem of the behavior of prices of an exhaustible resource when faced with a backstop technology is reworked for a more complete set of possible market outcomes. The market demand is assumed linear which further distinguishes between a competitive market and a monopoly. The analysis shades light from other angles on previous findings and brings up some fine points that were bypassed in previous research like the behavior when the cost of the backstop is below current price or even further lower, below the price at which the elasticity of demand is unity.

PD August 1992. TI Imperfect Competition in a Market of an Exhaustible Resource. AA Tel-Aviv University. SR Tel Aviv Sackler Institute of Economic Studies Working Paper: 9/92; Department of Economics, Tel Aviv University, Ramat Aviv 69978. Tel Aviv, ISRAEL. PG 15. PR no charge. JE Q30. KW Imperfect Competition. Exhaustible Resources. Stackelberg Cooperation.

AB In this paper we study the paths of market prices and the extracted quantities of an exhaustible resource when the market ownership of the mines is of imperfect competition. The major part of the study is devoted to the Cournot-Nash case, with minor extensions to a Stackelberg duopoly and a cooperation between the two firms. The unique characteristics of the study is of perfect common property of the resource and perfect substitution of the rate of extraction and cumulative extraction in the costs of mining of each of the firms. If corner solutions are not a priori encountered, then the typical static characteristics are maintained also in the dynamic case.

\section{Fitzgerald, T.}

TI Banking in Computable General Equilibrium Economies. AU Diaz-Gimenez, J.; Prescott, E.; Fitzgerald, T.; Alvarez, F.

\section{Fleurbaey, Marc}

PD May 1992. TI The Requisites of Equal Opportunity. AA INSEE. SR Unite de Recherche Document de Travail ENSAE/INSEE: 9213; INSEE. Unite de Recherche. 18 Bd. Adolphe Pinard, 75675 Paris cedex 14. FRANCE. PG 21. PR no charge. JE D63. KW Equity. Egalitarianism.

AB Equal opportunity is achieved when the outcome prospects of individuals are made identical through an adequate allocation of external resources, whatever the original handicaps of the individuals. This definition implies very stringent separability conditions on the outcome function, which may render equal opportunity merely empty in most usual circumstances. This paper studies these conditions, and examines the tradeoff between general existence and the set of desirable properties contained in the ideal of equal opportunity. A characterization of two dual solutions (Conditional Equality and Egalitarian-Equivalence) is provided.

PD June 1992. TI Reward Patterns of Fair Division. AA INSEE. SR Unite de Recherche Document de Travail ENSAE/INSEE: 9212; INSEE, Unite de Recherche, $18 \mathrm{Bd}$. Adolphe Pinard, 75675 Paris cedex 14, FRANCE. PG 36. PR no charge. JE D63, D51, D39. KW Justice. Monotonicity.

AB The fair solutions proposed in the literature of fair division are sensitive to the preference profiles of the agents. As a consequence, each of them displays a specific distribution pattern which may be interpreted as rewarding certain kinds of preferences at the expense of others. In the basic models with private goods and decreasing returns, the Equal Income Competitive Equilibrium tends to favor the eccentric preferences, whereas most egalitarian-equivalent solutions tend to reward the agents who like particular resources. The identification of the rewarding pattern of each mechanism sheds light on its ethical content, and may help select the adequate solution in concrete applications. In this analysis, a Preference Monotonicity property, comparable to the Population Monotonicity and Resource Monotonicity properties, turns out to be satisfied by many solutions.

\section{Flinn, Christopher}

TI Expenditure Decisions of Divorced Mothers and Income Composition. AU Del Boca, Daniela; Flinn. Christopher.

\section{French, Mark W.}

PD August 1992. TI Effects of Risk on the Demand for Oil Inventories. AA Board of Governors of the Federal Reserve System. SR Board of Governors of the Federal Reserve System Finance and Economics Discussion Series: 206; C/O Steven A. Sharpe, Mail Stop 89. Federal Reserve Board. Wash., DC 20551. PG 17. PR no charge. JE Q40. KW Oil Inventories. Risk. 
AB The Iraqi invasion of Kuwait soon led to a selloff of U.S. oil inventories, but the drop was relatively modest compared to the shift in spot-futures spreads. Verleger (1990) suggested that the change in this relationship was due to precautionary inventory hoarding, resulting from increased uncertainty or volatility of crude oil price and supply. This paper constructs a disaggregate monthly model of U.S. crude and gasoline inventories to test Verleger's assertion. Measures of risk are introduced to augment the usual transactions and speculative considerations. This model mimics well the inventory changes in late 1990, offering support for Verleger's assertion.

\section{Fudenberg, Drew}

PD June 1992. TI Learning Mixed Equilibria. AU Fudenberg. Drew; Kreps. David M. AA Fudenberg: Massachusetts Institute of Technology. Kreps: Stanford University. SR Massachusetts Institute of Technology Department of Economics Working Paper: 92-13; Department of Economics. Massachusetts Institute of Technology, Cambridge, MA 02139. PG 64. PR \$6.00 Domestic. $\$ 8.00$ Overseas. $\$ 3.00$ Student. JE C72, D83. KW Game Theory. Mixed Strategies. Learning.

AB This paper explores learning models in the spirit of the method of ictitious play. We extend the previous literature by generalizing the lasses of behavior rules, and by considering games with more than two layers. Most importantly, we reformulate the study of convergence to mixed trategy equilibrium, using Harsanyi's notion of perturbed games.

\section{Fujita, Masahisa}

PD August 1992. TI Technological Linkages and Efficient Location of Indivisible Activities: KoopmansBeckmann and Von Thunen Unified. AU Fujita, Masahisa; Thisse, J. - F. AA Fujita: University of Pennsylvania. Thisse: Universite of Catholique de Louvain and Universite de Paris I Sorbonne. SR Universite Catholique de Louvain CORE Discussion Paper: 9243: Universite Catholique de Louvain. Voie du Roman Pays, 34, B-1348 Louvain-la-Neuve, BELGIUM. PG 24. PR not available. JE C72, D21, D24. KW Land Capitalization. Game Theory.

AB Consider a model a la Koopmans-Beckmann involving two indivisible and interactive firms. as well as a continuum of workers. Firm 1 uses labor, while firm 2 uses labor and good 1 produced by firm 1: both goods 1 and 2 can be exported but good 1 cannot be imported. The land capitalization process, based on workers' competition on a perfectly competitive land market, is used to design a noncooperative game between firms 1 and 2. The equilibria of this game always exist and are socially optimal. Various extensions of the basic model are also discussed.

\section{Fulghieri, Paolo}

TI Reputation, Renegotiation, and the Choice Between Bank Loans and Publicly Traded Debt. AU Chemmanur. Thomas J.; Fulghieri, Paolo.

\section{Fullerton, Johanna}

PD September 1992. TI Management Consultancy: Dimensions of Client-Consultant Relationships. AU Fullerton, Johanna; West. Michael. AA Fullerton: University of Sheffield. West: University of Sheffield and London School of Economics. SR London School of Economics Centre for Economic Performance Discussion
Paper: 99; Centre for Economic Performance. London School of Economics. Houghton Street, London WC2A 2AE, ENGLAND. PG 19. PR no charge. JE L20. M11. M12. KW Repertory Grids. Contracts.

AB Although a great deal of management consultancy has been carried out in a wide variety of settings, very little research has been conducted examining underlying dimensions of the client-consultant relationship. The present study examines consultant and client perceptions of the consulting relationship. A procedure based on repertory grid technique was employed to elicit dimensions of client consultant relationships from 22 management consultants and 16 of their clients within a major UK company. Dimensions were found to fall within four broad categories: those relating to the client; those relating to the consultant: dimensions associated with contract details; and dimensions focused on relationship building. Consultants viewed dimensions relating to relationship building as most important, while clients placed greater emphasis on dimensions associated with contract details. Recommendations are made for monitoring and enhancing client-consultant relationships.

\section{Gabel, H. Landis}

PD June 1992. TI Trade Liberalization, Transportation, and the Environment. AU Gabel, H. Landis; Roller, LarsHendrik. AA INSEAD. SR INSEAD Working Papers: 92/37/EP; INSEAD. Boulevard de Constance, Fontainebleau. 77305 Cedex, FRANCE. PG 17. PR not available. JE F14, F15, R41, Q32. KW Transport Demand. European Trade Liberalization. Environmental Impact.

AB This paper is an empirical study of the consequences of European trade liberalization for international transport demand and its environmental impact. The European market is broken into nine trading blocks, and trade flow equations for 29 industries are estimated for the period 1975-1985. A simulation of the change in volumes of trade by industry and the distances traded goods must move generates an estimate of the increased transport demand in each industry. The study concludes that the greatest increases will be in the demand for international transportation by sea, but that in terms of land-based transportation, there will be a large relative shift from rail to road. This will have a major adverse environmental impact which is discussed in the paper.

PD June 1992. TI Corporate Responses to Environmental Concerns. AU Gabel, H. Landis; Sinclair-Desgagne, Bernard. AA INSE.AD. SR INSEAD Working Papers: 92/42/EP: INSEAD. Boulevard de Constance. Fontainebleau, 77305 Cedex, FRANCE. PG 24. PR not available. JE Q20, Q28, Q32, Q38, M11. KW Environmental Policy. Environmental Resources. Management.

AB This paper discusses several systems of incentives and control that firms may use in order to improve their management of environmental resources and to facilitate compliance with environmental regulation.

Gabszewicz, J. J.

PD April 1992. TI Oligopoly Equilibria in Exchange Economies. AU Gabszewicz, J. J.; Michel, P. AA Gabszewicz: Universite Catholique de Louvain. Michel: Universite de Paris I. SR Universite Catholique de Louvain CORE Discussion Paper: 9247; Universite Catholique de Louvain, Voie du Roman Pays, 34, B-1348 Louvain-la-Neuve, BELGIUM. PG 25. PR not available. JE D43, D51. 
KW Partial Equilibrium. Equilibrium Concept.

AB This paper extends the notion of Cournot-Walras equilibrium introduced by Codognato and Gabszewicz (1991) in a particular context (homogeneous oligopoly) to a general class of pure exchange economies. Some examples are considered. corresponding to oligopolistic structures analyzed in partial equilibrium. Finally, we discuss a possible extension of the concept to the case of a productive economy, and illustrate this discussion by means of an example embodying linear technologies.

\section{Gagnon, Joseph E.}

PD July 1992. TI Markup Adjustment and Exchange Rate Fluctuations: Evidence From Panel Data on Automobile Exports. AU Gagnon. Joseph E.: Knetter. Michael M AA Gagnon: Federal Reserve Board of Governors. Knetter: Dartmouth College and National Bureau of Economic Research. SR National Bureau of Economic Research Working Paper: 4123; National Bureau of Economic Research. 1050 Massachusetts Avenue, Cambridge, MA 02138. PG 22. PR \$5.00. JE F14, F40, F10. KW Markup Adjustment. Export Prices.

AB This paper uses bilateral automobile export unit values from the United States, Germany and Japan to measure the importance of markup adjustment that is associated with exchange rate changes across export destination markets. Japanese auto export prices exhibit a high degree of markup adjustment that has the effect of stabilizing prices in units of the buyer's currency. There is weak evidence of this behavior in German auto exports. Where it exists, markup adjustment is very persistent, not merely a short run phenomenon. The dynamic pattern of adjustment is consistent with invoicing in the exporter's currency, except for exports to the United States and Canada.

\section{Gali, Jordi}

PD June 1992. TI Keeping up with the Joneses: Consumption Externalities, Portfolio Choice, and Asset Prices. AA Columbia University. SR Columbia First Boston Series in Money, Economics and Finance Working Paper: FB92-22; Columbia University. Graduate School of Business. First Boston Series, New York, NY 10027. USA. PG 8. PR $\$ 5.00$ academics and non-profit institutions; $\$ 6.00$ corporations (add $\$ 1.00$ outside U.S., Canada and Puerto Rico). JE G11, G12, D62, D11. KW Optimal Portfolio. Asset Pricing.

AB We study the implications for optimal portfolio decisions and equilibrium asset prices of the hypothesis that agents care about other agents' consumption level (in addition to their own). That hypothesis is introduced in two settings: (i) a oneperiod CAPM model, and (ii) a multiperiod asset pricing model. The presence of externalities is shown to affect the optimal risky share, as well as the size of adjustments in the latter in response to exogenous changes in the risk-adjusted equity premium. In equilibrium, the equity premium is also affected by the sign and the intensity of the externalities.

PD July 1992. TI Long Run Effects of Business Cycles. AU Gali, Jordi: Hammour, Mohamad L. AA Columbia University. SR Columbia First Boston Series in Money. Economics and Finance Working Paper: FB-92-26; Columbia University, Graduate School of Business, First Boston Series. New York, NY 10027. USA. PG 23. PR \$5.00 academics and non-profit institutions; $\$ 6.00$ corporations (add $\$ 1.00$ outside U.S., Canada and Puerto Rico). JE E32, C32. KW Economic Fluctuations. Technology Shock. Demand Shock.

AB This paper investigates the interaction between economic fluctuations and productivity. A simple theoretical model and an associated empirical VAR model are developed, in which two types of shocks-"technology" and "demand" shocks-affect the dynamics of a measure of productivity and an index of the business cycle. Identification is achieved by assuming that demand shocks have no contemporaneous effect on productivity. Using U.S. data, we find that positive demand shocks have a negative long run impact on productivity. That result is robust to the measure of productivity and the cyclical indicator used. A number of interpretations are discussed and related to the existing literature.

\section{Galor, Oded}

PD September 1992. TI Family Size, Income Distribution and Economic Growth: Theory and Cross-Country Evidence. AU Galor, Oded; Zang. Hyoungsoo. AA Brown University. SR Brown University Department of Economics Working Paper: 92-19; Department of Economics. Brown University. Providence, Rhode Island 02912. PG 31. PR no charge. JE J10, O15, O40. KW Income Distribution. Growth. Fertility.

AB This paper analyzes theoretically and empirically the role of family size and income distribution in explaining disparities in per capita output and growth rates across countries. The analysis demonstrates that the combined effect of family size as well as income distribution has a larger predictive power than that of the separate effects in explaining per capita output and growth performance across countries. The theoretical analysis demonstrates that due to borrowing constraints countries with smaller average family size and with more equal distribution of income attain higher per capita output. The empirical analysis shows strong evidence in support of the empirical implications of the theoretical model. In particular, the effect of the population (or labor force) growth rate on economic growth, suggested by the neoclassical growth model, is shown to be insignificant. whereas that of the family size as suggested by the current paper is shown to be significant.

\section{Gann, L. H.}

PD May 1992. TI Reflections on the Japanese and German Empires of World War II. AA Stanford University. SR Stanford Hoover Institute International Studies Working Paper: I-92-7: The Hoover Institution. Stanford University, Stanford, CA 94305. PG 47. PR no charge. JE N44. N45, N14, N15. KW Germany. Japan. Political History.

AB Parallels between World War II Japan and Germany are examined.

\section{Garber, Alan M.}

PD September 1992. TI Economic Foundations of CostEffectiveness Analysis. AU Garber. Alan M.; Phelps. Charles E. AA National Bureau of Economic Research. SR National Bureau of Economic Research Working Paper: 4164; National Bureau of Economic Research, 1050 Massachusetts Avenue, Cambridge, MA 02138. PG 29. PR \$3.00. JE D61, Ill, D78. KW Resource Allocation. Medical Intervention. Aggregation.

AB In order to address several controversies in the application of cost-effectiveness analysis, we investigate the 
principles underlying the technique and discuss the implications for the evaluation of medical interventions. Using a standard von Neumann-Morgenstern utility framework, we show how a cost-effectiveness criterion can be derived to guide resource allocation decisions. We investigate its relation to age, gender. income level and risk aversion. Cost-effectiveness analysis can be a useful and powerful tool for resource allocation decisions, but in the presence of heterogeneous preferences and personal characteristics, a cost-effectiveness criterion that is applied at the population level is unlikely to yield Pareto-optimal resource allocations.

\section{Garber, Peter M.}

PD July 1992. TI The Dissolution of the AustroHungarian Empire: Lessons for Currency Reforms. AU Garber, Peter M.; Spencer, Michael G. AA International Monetary Fund. SR International Monetary Fund Working Paper: 92/66; International Monetary Fund. Washington, DC 20431. PG 34. PR not available. JE E50, F30, N20. KW Currency Reforms. Monetary Policy Coordination.

AB This paper investigates the currency reforms undertaken subsequent to the dissolution of the Austro-Hungarian Empire in 1918. The reforms were motivated by the lack of coordination of monetary policy and the absence of a rule for sharing seigniorage. Because the Successor States' reforms were not carried out simultaneously, individuals could choose where to convert their crowns based on where their real value was greatest. The cross-border flows of notes was substantial, to the detriment of Hungary which was last to reform. The Austrian and Hungarian currencies were stabilized only with the help of League of Nations financial programs.

\section{Garratt, Rod}

PD July 1992. TI Concavifiability and the Marginal Rate of Substitution. AU Garratt. Rod: Qin, Cheng-Zhong. AA University of California. Santa Barbara. SR University of California at Santa Barbara Department of Economics Working Paper: 14-92; Working Papers Coordinator, Department of Economics, University of California. Santa Barbara. CA 93106. PG 10. PR no charge. JE C69. KW Convex Preferences. Homothetic Preference.

AB We provide conditions related to the concavifiability of convex preference relations that are testable and that use familiar terms. These results are derived from Kannai's Proposition 2.1 (ii) (J. of Math. Econ. 4 (1977) pp. 4-5). We prove that, under an additional mild assumption, any homothetic preference relation is concavifiable.

\section{Gautschi, David A.}

TI An International Comparison of the Determinants of Retail Margins. AU Betancourt, Roger R.; Gautschi. David A.

\section{Gazeley, Ian}

PD July 1992. TI Output and Employment During the Interwar Period: The Case of the Ship-Building Industry. AU Gazeley, Ian; Rice. Patricia. AA Gazeley: University of Sussex. Rice: University of Southampton. SR University of Southampton Discussion Paper in Economics and Econometrics: 9224; Department of Economics. University of Southampton, Southampton SO9 5NH, ENGLAND. PG 32.
PR no charge. JE N64, N14. KW Great Depression. Supply Shock.

AB Recently, the traditional view that the Great Depression arose from a collapse in aggregate demand has been challenged by economists who claim the fundamental problems lay on the supply-side of the market. This paper examines these issues in the context of the shipbuilding industry. A model of the determination of price, output and employment within shipbuilding is developed and estimated. The results support the view that the collapse of output and employment between 1930 and 1932 arose from a negative demand shock in the form of a sharp fall in the volume of world trade. However, in the case of shipbuilding, the impact on employment was exacerbated by nominal wage developments.

\section{Geanakoplos, John}

TI Is Gold an Efficient Store of Value? AU Dubey, Pradeep; Geanakoplos, John; Shubik, Martin.

\section{Geweke, J.}

PD December 1991. TI Evaluating the Accuracy of Sampling-Based Approaches to the Calculation of Posterior Moments. AA Federal Reserve Bank of Minneapolis and University of Minnesota. SR Federal Reserve Bank of Minneapolis Staff Report: 148; Research Department. Federal Reserve Bank of Minneapolis. 250 Marquette Ave., Minneapolis, MN 55401. PG 21. PR no charge. JE C11. KW Bayesian Inference. Data Augmentation. Gibbs Sampling.

AB Data augmentation and Gibbs sampling are two closely related. sampling-based approaches to the calculation of posterior moments. The fact that each produces a sample whose constituents are neither independent nor identically distributed complicates the assessment of convergence and numerical accuracy of the approximations to the expected value of functions of interest under the posterior. In this paper methods for spectral analysis are used to evaluate numerical accuracy formally and construct diagnostics for convergence. These methods are iliustrated in the normal linear model with informative priors, and in the Tobit-censored regression model.

\section{Ghysels, Eric}

PD May 1992. TI Christmas, Spring and the Dawning of Economic Recovery. AA University of Montreal. SR Yale Cowles Foundation Discussion Paper: 1027; Yale University, Cowles Foundation, Box 2125. Yale Station, New Haven CT 06520. PG 24. PR no charge. JE C22. C32, E32. KW Tuming Points. Periodicity. Business Cycles. Seasonality.

AB Six months of the year, which for convenience we call the spring and Christmas seasons, have a statistically significant higher number of troughs than the other six months of the year. In contrast, peaks do not exhibit any clustering. These results are drawn from the NBER chronology as well as alternative chronologies. As peaks are evenly distributed and troughs are not, it also appears that contraction lengths following peaks in the off-season are longer which is also an indication of the uneven propensity to switch regime throughout the year. This paper deliberately takes a "model-free" and "distribution free" approach to test and document these phenomena.

PD July 1992. TI On the Periodic Structure of the Business Cycle. AA Yale University. SR Yale Cowles Foundation Discussion Paper: 1028; Yale University, Cowles 
Foundation, Box 2125, Yale Station. New Haven CT 06520. PG 24. PR no charge. JE C22, C32, E32. KW Seasonality. Business Cycles. Markov Switching Regime.

AB In this paper, we test whether a regime shift from expansion to recession and vice versa is. ceteris paribus, equally likely throughout the year. If not, then it may, for instance, be less likely to get out of a recession in the middle of the winter than it is, say, in the spring or summer. We make use of Markov switching regime models to test the hypothesis of interest. The evidence is based on the conventional NBER business cycle chronology as well as alternatives to it. We find that recessions exhibit a periodic pattern in their switching regime transition probability structure. It is particularly the months associated with Christmas and Spring that appear to have higher switching probabilities from recession to expansion. Our results also imply that a recession and an expansion are. on average. longer or shorter depending on what time of the year they start. Such results suggest the presence of seasonal patterns in business cycle durations. Our paper investigates issues which go beyond linear dependence between seasonality and business cycles.

\section{Gianessi, Leonard P.}

PD July 1991. TI Reducing Pesticide Use with No Loss in Yields? A Critique of a Recent Cornell Report. AA Resources for the Future. SR Resources for the Future Quality of the Environment Division Discussion Paper: QE9116: Quality of the Environment Division. Resources for the Future, 1616 P Street. NW. Washington. D.C. 20036. PG 30. PR \$2.25 prepaid, U.S. funds. JE Q16, Q18, Q28. KW Pesticide Use. Alternative Agriculture. Integrated Pest Management. Water Quality.

AB Based on a literature review, researchers at Cornell University recently concluded that it might be possible to reduce pesticide use on 40 crops with no decline in crop yields, substantial environmental benefits, and only a slight rise in food prices. A critical evaluation of the Cornell Study reveals it to be seriously flawed. The Cornell Study relies on information that is seriously out of date. In some instances, the Cornell Study uses in a misleading way the findings of the studies that are cited to support its claims. If the techniques recommended in the study were adopted as alternatives to pesticides, the consequences might be the opposite of those claimed by the Cornell Study. In certain cases pesticide use would rise. environmental quality would deteriorate, and crop yields would decline significantly. Lack of information is the primary factor that limits public policy research in simulating the adoption of alternative practices.

\section{Gibbons, Robert}

PD August 1992. TI Does Executive Compensation Affect Investment? AU Gibbons, Robert; Murphy, Kevin J. AA Gibbons: Cornell University and National Bureau of Economic Research. Murphy: Harvard University. SR National Bureau of Economic Research Working Paper: 4135: National Bureau of Economic Research. 1050 Massachusetts Avenue. Cambridge. MA 02138. PG not available. PR \$5.00. JE J33, J44, L10. KW Investment. Compensation. Perquisites.

AB Investment decisions require trading of current expenditures against future revenues. If revenues extend far enough into the future, the executives responsible for designing long-run investment policy may no longer be in office by the time all the revenues are realized. We present evidence that: (1) on average, executives are close to leaving office (relative to the payout period of many investments); (2) bonuses based on accounting earnings constitute an important part of compensation for the typical executive; and (3) executives respond in predictable ways to compensation plans based on accounting measures of earnings. Based on these facts, we hypothesize that existing compensation policy induces executives to reduce investments during their last years in office. In our empirical work, however, we find that investment expenditures on research and development and on advertising tend to be largest in the final years of a CEO's time in office. We offer several possible explanations for this surprising finding.

\section{Gilbert, Richard}

TI Do Gasoline Prices Respond Asymmetrically to Crude Oil Price Changes? AU Borenstein, Severin; Cameron, A. Colin: Gilbert, Richard.

\section{Gilboa, Itzhak}

PD August 1992. TI Case-Based Decision Theory. AU Gilboa, Itzhak; Schmeidler, David. AA Gilboa: Northwestern University. Schmeidler: Ohio State Univerity and Tel Aviv University. SR Northwestern University Center for Mathematical Studies in Economics and Management Science Discussion Paper: 994: J.L. Kellogg Graduate School of Management, Northwestern University, 2001 Sheridan Road, 3-014 Leverone Hall. Evanston. IL 60208. PG not available. PR per copy: $\$ 3.00$ in the U.S.A. or Canada: $\$ 5.00$ via international mail. Make check payable to Northwestern University. JE C70, D10, D11, D21, D40. KW Decision Theory. Expected Utility. Bounded Rationality. Learning.

AB This paper suggests the view that decision-making under uncertainty is, at least partly, case-based. We propose a model in which cases are assumed as primitives. and provide a simple axiomatization of a decision rule which chooses a "best" act based on its past performance in "similar" cases. Each act is evaluated by the sum-over cases in which it was chosen-of the product of the similarity of the past case to the problem at hand and the utility level that resulted from this act in the past. The paper also discusses various aspects. variations and applications of the basic model.

\section{Glick, Reuven}

PD August 1992. TI Global versus Country-Specific Productivity Shocks and the Current Account. AU Glick, Reuven; Rogoff, Kenneth. AA Glick: Federal Reserve Bank of San Francisco. Rogoff. Princeton University and National Bureau of Economic Research. SR National Bureau of Economic Research Working Paper: 4140, National Bureau of Economic Research, 1050 Massachusetts Avenue, Cambridge, MA 02138. PG not available. PR \$5.00. JE F30, F32. O47. KW Investment. Current Account. Productivity Shocks. AB The intertemporal approsch to the current account is often regarded as theoretically elegant but of limited empirical significance. This paper derives highly tractable current account and investment specifications that we estimate without resorting to calibration or simulation methods. In time-series data for eight industrialized countries, we find that countryspecific productivity shocks tend to worsen the current account, whereas global shocks have little effect. Both types of shock 
raise investment. It is a puzzle, however, for the intertemporal model that long-lasting local productivity shocks have a larger impact effect on investment than on current account.

\section{Glomm, Gerhard}

PD September 1992. TI Inequality and Social Stability of Economies with Collective Property Rights. AU Glomm. Gerhard; Lagunoff. Roger D. AA Glomm: University of Virginia. Lagunoff. University of Pennsylvania. SR University of Pennsylvania Center for Analytic Research in Economics and Social Science (CARESS) Working Paper: 92-26; University of Pennsylvania. Center for Analytic Research in Economics and the Social Sciences. McNeil Building. 3718 Locust Walk. Philadelphia. PA 19104-6297. PG 19. PR no charge. JE D31, D51. KW Income Inequality. Core Specialization.

AB In this paper, a model of an economy with collective property rights defined over some commodities is considered. We investigate what role. if any. income inequality plays in providing social stability in the sense that the economy exhibits a nonempty core. It is shown through a series of examples that reductions of income inequality can play a crucial role in providing social stability to the extent that these reduction increase "specialization" in the economy. We give a general result to this effect. It is also shown that our notion of specialization is not limited to the privatized sector of the economy. Even in economies in which there is no privately held property, sufficient specialization guarantees that the economy is socially stable.

\section{Goetzmann, William N.}

PD March 1992. TI Market Response to Mutual Fund Performance. AU Goetzmann, William N.: Greenwald, Bruce; Huberman. Gur. AA Columbia University. SR Columbia First Boston Series in Money, Economics and Finance Working Paper: FB-92-25: Columbia University, Graduate School of Business, First Boston Series, New York, NY 10027. USA. PG 14. PR $\$ 5.00$ academics and nonprofit institutions: $\$ 6.00$ corporations (add $\$ 1.00$ outside U.S.. Canada and Puerto Rico). JE G11. KW Mutual Funds.

AB A simple decision model for mutual fund investors may be constructed that relies upon past returns as well as other measures. Because no-arbitrage arguments do not apply to open-end mutual funds, investors rightfully anticipate differences in past and future risk-adjusted performance. Cross-sectional regressions of net inflows to funds demonstrate that investors base their choice of managers upon preceding year returns. This response factor differs from year to year, depending upon the total wealth available to invest in the mutual fund industry. Our use of seasoned funds, and our choice of a dollar measure of investor response minimizes but does not eliminate the bias caused by censorship of data. The attrition of mutual funds with negative growth implies that the response cannot be correctly measured. Previous researchers, have interpreted asymmetries in response as evidence suggestive of investor irrationality. We conjecture that this may be induced at least partly by survivorship.

PD June 1992. TI Non-Temporal Components of Residential Real Estate Appreciation. AU Goetzmann. William N.: Spiegel. Matthew. AA Columbia University. SR Columbia First Boston Series in Money, Economics and Finance Working Paper: FB-92-20; Columbia University. Graduate School of Business. First Boston Series, New York.
NY 10027. USA. PG 19. PR $\$ 5.00$ academics and nonprofit institutions; $\$ 6.00$ corporations (add $\$ 1.00$ outside U.S., Canada and Puerto Rico). JE E22, R31. KW Repeat Sales. Home Improvement. Price Risk.

AB This paper proposes a control for the problem of fixed components in the capital appreciation return used in the repeat sales regression. We find a consistent bias in the index resulting from the repeat sales regression which may be eliminated through simple methods. The sign and magnitude of the bias, as well as its systematic variation across properties, suggest that it is caused by incremental home improvements, as well as by price risk. We propose a maximum likelihood method for estimating the first and second moments of the fixed and temporal components of real estate returns that relies upon relatively small samples. In samples of 100 and 250 repeatsales observations, it provides reliable estimates of the nontemporal and temporal return components, the variance of these components, and of the average correlation across individual properties in the market.

PD June 1992. TI Safety First Portfolio Choice. AU Goetzmann. William N.: Broadie, Mark. AA Columbia University. SR Columbia First Boston Series in Money, Economics and Finance Working Paper: FB-92-23; Columbia University. Graduate School of Business. First Boston Series. New York, NY 10027. USA. PG 8. PR \$5.00 academics and non-profit institutions; $\$ 6.00$ corporations (add $\$ 1.00$ outside U.S.. Canada and Puerto Rico). JE G11, G22. KW Insurance. Stock Market Simulation.

AB In this study, we show how a dynamic insurance program can be implemented within a mean-variance framework. The approach combines elements of the single period safety first idea suggested by Telser and developed by Leibowitz with multiperiod insurance strategies like CPPI and TIPP. The insurance program allows the user to set a probability of hitting specified floor or target and also allows for changing risk attitudes through time. When the insurance strategy is tested on historical data, the insured portfolio achieves high long term returns while mostly avoiding long bear markets. In order to understand how the insurance strategy might perform in the future, we simulate returns of the stock market and compare the insurance strategy to buy and hold strategies. An additional benefit of the safety first approach is that it specifies a strategy for underfunded portfolios as well as overfunded portfolios.

\section{Goldberg, Linda S.}

PD August 1992. TI Black-Market For Currency, Hoarding Activity and Policy Reform. AU Goldberg, Linda S.: Karimov, I'dar. AA Goldberg: New York University and National Bureau of Economic Research. Karimov: IIASA, Austria and CEMI. Moscow. SR National Bureau of Economic Research Working Paper: 4153; National Bureau of Economic Research, 1050 Massachusetts Avenue, Cambridge. MA 02138. PG not available. PR \$5.00. JE O17, P00, P29. KW Economic Reform. Transition to Market Economy. Black Market.

AB In the former Soviet Union and throughout Eastern Europe. black-market exchange rates and second-economy prices often are interpreted by policy-makers as indicative of post-reform levels. However, these exchange rates and prices can provide highly-biased signals for policy setting. These biases are especially important when exchange rates fixed on the basis of these signals are expected to play a nominal anchor role during stabilizations. This paper traces the paths and biases 
in black-market exchange rates, second-economy prices, hoarding stocks, and privately-held dollars balance after policy-initiatives or other changes in the economic environment are implemented. The stimuli studied are official exchange-rate adjustments. price reforms, foreign-aid packages, altered risks of monetary confiscation or currency reforms, and goods-supply related initiatives. We provide the conditions under which announcements of reform lead shortrun prices or exchange rates to overshoot or to undershoot their long-run equilibrium levels.

PD August 1992. TI Black Markets for Currency, Hoarding Activity and Policy Reforms. AU Goldberg, Linda S.; Karimov, Il'dar. AA Goldberg: New York University and National Bureau of Economic Research. Karimov: IISA. Austria and CEMI. Moscow. SR New York University Economic Research Reports: 92-38; New York University, Faculty of Arts and Science, Department of Economics, Washington Square. New York, N.Y. 10003. PG 31. PR no charge. JE O17, F36, F31, P52. KW Exchange Rates. Eastern Europe. Reform.

AB See other entry.

\section{Goldin, Claudia}

TI The Savings of Ordinary Americans: The Philadelphia Saving Fund Society in the Mid-Nineteenth Century. AU Alter, George; Rotella. Elyce; Goldin. Claudia.

\section{Goldman, Fred}

TI Determinants of Interest Rates on Tax-Exempt Hospital Bonds. AU Grossman, Michael; Goldman, Fred; Mobilia, Pamela; Nesbitt, Susan W.

Golob, John E.

PD October 1992. TI Allais Theory Suggests a Solution and an Explanation for the Equity Premium Puzzle. AA Federal Reserve Bank of Kansas City. SR Federal Reserve Bank of Kansas City Research Working Paper: 92-04; Research Division, Federal Reserve Bank of Kansas City, 925 Grand Ave.. Kansas City, MO 64198. PG 34. PR no charge. JE D58, G12, D81. KW Risk Premia. Allais Paradox.

AB When general equilibrium models are used to simulate asset prices and returns they typically predict risk premia for risky assets that are much lower than those measured in actual equity markets, and this result is referred to as the "equity premium puzzle." This paper suggests that the Allais paradox. which Allais developed as evidence against expected utility and in support of his own theory of behavior under uncertainty, can be interpreted in a way that is similar to the equity premium puzzle. Motivated by this similarity, asset prices and returns are simulated using a class of preferences that are based on Allais' theory. With parameter values that have been independently estimated, this model yields risky and risk-free asset returns that are compatible with historical data. To provide intuition for this result. the equity premium puzzle is explained from the perspective of Allais' critique of expected utility.

\section{Gomme, Paul}

PD August 1992. TI On the Cyclical Allocation of Risk. AU Gomme, Paul: Greenwood, Jeremy. AA Gomme: Institute for Empirical Macroeconomics and Simon Fraser
University. Greenwood: University of Western Ontario and University of Rochester. SR University of Western Ontario Department of Economics Research Report: 9205; Department of Economics. Social Sciences Center, University of Western Ontario, London, Ontario, CANADA N6A 5C2. PG 21. PR \$5.00 Canada. \$7.00 elsewhere. JE E30, E32, E25. KW Real Business Cycles. Business Cycles. Income Distribution. Risk.

AB A real business cycle model with heterogeneous agents is parameterized, calibrated, and simulated to see if it can account for some stylized facts characterizing postwar U.S. business cycle fluctuations, such as the countercyclical movement of labor's share of income, and the acyclical behavior of real wages. There are two types of agents in the model, workers and entrepreneurs, who participate on an economy-wide market for contingent claims. On this market workers purchase insurance from entrepreneurs, through optimal labor contracts, against losses in income due to business cycle fluctuations. The model is used to study the allocation of risk and the distribution of income over the business cycle.

\section{Gordon, Roger H.}

PD September 1992. TI Taxes and the Form of Ownership of Foreign Corporate Equity. AU Gordon, Roger H.: Jun, Joosung. AA Gordon: University of Michigan. Jun: Yale University. SR National Bureau of Economic Research Working Paper: 4159; National Bureau of Economic Research, 1050 Massachusetts Avenue, Cambridge. MA 02138. PG 27. PR \$3.00. JE G11, H24, F21. KW Taxation. Porfolio Choice. International Diversification.

AB Investors can achieve international diversification in their portolios not only through purchasing foreign equity directly but also through investing in domestic firms which then invest abroad. Yet these alternative approaches are taxed very differently. A number of countries have also imposed various forms of capital controls restricting direct purchases of foreign equity. This paper estimates the degree to which these tax and nontax factors have affected the relative use of these two alternative methods of international diversification. using data on investment in the U.S. by investors from each of ten other countries during the period 1980-1989. While the composition of equity flows differs dramatically across countries, taxes do not appear to play an important role in the data in explaining this variation.

\section{Gourieroux, C.}

PD November 1991. TI Testing Non Nested Hypotheses. AU Gourieroux, C.: Monfort, A. AA Gourieroux: CREST-CEPREMAP. Monfort: INSEE. SR Unite de Recherche Document de Travail ENSAE/INSEE: 9207; INSEE. Unite de Recherche, 18 Bd. Adolphe Pinard, 75675 Paris cedex 14, FRANCE. PG 57. PR no charge. JE C12. KW Hypothesis Testing. Generalized Wald Test. Encompassing.

AB We carefully define the notions of non-nested hypotheses, especially we distinguish partially and globally non nested hypotheses. For this purpose it is necessary to introduce a suitable metric measuring the closeness of the hypotheses: this leads to two concepts of pseudo-true value. We describe the extension of the usual testing procedures; Wald. score. likelihood ratio tests. We obtain different forms of the test statistics depending on the kind of pseudo-true value which is used. The artificial nesting models are presented first for some 
specific problems in which the nesting models may have interesting interpretations, then in the general case.

PD June 1992. TI Testing Encompassing and Simulating Dynamic Econometric Models. AU Gourieroux, C.; Monfort, A. AA Monfort: INSEE. Gourieroux: CREST-CEPREMAP. SR Unite de Recherche Document de Travail ENSAE/INSEE: 9214: INSEE, Unite de Recherche, $18 \mathrm{Bd}$. Adolphe Pinard. 75675 Paris cedex 14, FRANCE. PG 31. PR no charge. JE C12. KW Indirect Information. Hypothesis Tests. Non-Nested Hypotheses.

AB We define, in a dynamic framework, the notions of binding functions, images, reflecting sets, indirect identification, indirect information and encompassing. We study the properties of the notion of encompassing when the true distribution does not necessarily belong to one of the two models of interest. In this context we propose various test procedures of the hypothesis of encompassing. Some of these procedures are based on simulations and some of them are linked with the notion of indirect estimation (in particular the GET and Simulated GET procedures). As a by-product, we get an asymptotic theory of the tests of non-nested hypotheses in the dynamic case.

PD July 1992. TI Indirect Inference. AU Gourieroux, C.: Monfort, A.; Renault, E. AA Gourieroux: CEPREMAP. Monfort: INSEE. Renault: GREMAQ. SR Unite de Recherche Document de Travail ENSAE/INSEE: 9215; INSEE, Unite de Recherche, 18 Bd. Adolphe Pinard, 75675 Paris cedex 14. FRANCE. PG 31. PR no charge. JE C15, C12. KW Simulation Methods. Specification Tests.

AB In this paper we present inference methods which are based on an "incorrect" criterion. in the sense that the optimization of this criterion does not directly provide a consistent estimator of the parameter of interest; moreover the argument of the criterion, called the auxiliary parameter, may have a larger dimension than that of the parameter of interest. A second step, based on simulations, provides a consistent and asymptotically normal estimator of the parameter of interest. Various testing procedures are also proposed. The methods described in this paper only requires that the model can be simulated. Therefore they should be useful for models whose complexity rules out a direct approach. Various fields of applications are suggested (microeconometrics, finance, macroeconometrics...).

TI On Seasonal Effects in Duration Models. AU De Toldi, M.; Gourieroux, C.; Monfort, A.

Gozalo, Pedro L.

PD July 1992. TI A Consistent Model Specification Test for Nonparametric Estimation of Regression Function Models. AA Brown University. SR Brown University Department of Economics Working Paper: 92-14; Department of Economics. Brown University, Providence. Rhode Island 02912. PG 24. PR no charge. JE C12, C14, C52. KW Asymptotic Normality. Consistent Misspecification Test. Nonparametric Regression.

AB This paper proposes a general framework for specification testing of the regression function in a nonparametric smoothing estimation context. The same analysis can be applied to cases as varied as testing for omission of variables, testing certain nonlinear restrictions in the regressors and, testing the correct specification of some parametric or semiparametric model of interest. e.g.. to test a certain type of nonlinearity of the regression function. Furthermore, the test can be applied to iid and time series data. and some or all of the regressors are allowed to be discrete. A Monte Carlo simulation is used to assess the performance of the test in small and medium size samples.

PD August 1992. TI Nonparametric Analysis of Engel Curves: Estimation and Testing of Demographic Effects. AA Brown University. SR Brown University Department of Economics Working Paper: 92-15: Department of Economics, Brown University, Providence, Rhode Island 02912. PG 25. PR no charge. JE D12, C14, C52. KW Demographic Effects. Nonparametric Regression. Engel Curves.

AB Nonparametric kernel regression estimation techniques are applied to two issues of empirical demand analysis: the effects of household demographic variables on demand analysis, and testing of some of the specifications used to incorporate demographic effects into demand systems. The results are based on the 1985 Consumer Expenditure Survey for the U.S. Nonparametric methods prove to be an excellent medium for the analysis of demographic effects using expenditure data. In particular, we show that the additive separability of the age of the reference person, assumed by most parametric models, is not supported by the data. We also show that the coefficients of Equivalence Scales depend not only on household composition, but also on the level of income and the age of the reference person. questioning the additive separability assumptions used to construct most Equivalence Scales.

\section{Grandmont, Jean-Michel}

PD June 1992. TI Expectations Driven Nonlinear Business Cycles. AA CNRS/CEPREMAP and Yale University. SR Yale Cowles Foundation Discussion Paper: 1022: Yale University. Cowles Foundation, Box 2125, Yale Station, New Haven CT 06520. PG 33. PR no charge. JE E32. KW Business Cycles. Nonlinear Dynamics. Sunspot Equilibria. Bifurcations.

AB The first part of the paper is a brief introduction to the concepts and methods used in recent endogenous business cycles models. It is argued that endogenous business cycles models have become more and more credible alternatives to describe observed fluctuations in our economies. The second part of the paper reviews recent studies suggesting that selffulfilling expectations are often dynamically unstable when learning is taken into account. It is suggested that on account of the important nonlinearities involved in learning, actual learning dynamics may generate highly complex, even chaotic, trajectories.

\section{Green, David A.}

PD July 1992. TI The Economic Effects of Unemployment Insurance in Canada: An Empirical Analysis of UI Disentitlement. AU Green, David A.; Riddell, W. Craig. AA University of British Columbia. SR University of British Columbia Department of Economics Discussion Paper: 92-15; Department of Economics. University of British Columbia 997-1873 East Mall, Vancouver, B.C. Canada V6T 1W5. PG 81. PR JE J26, J65. I38. KW Unemployment Insurance. Adverse Selection. Retirement Decision.

AB This paper provides an overview of the Canadian Unemployment Insurance (UI) program, including its 
evolution. salient features, relative size, and knowledge about its labor market impacts. Understanding of these impacts is limited, and we conclude that an "event study" approach is a promising way to further this knowledge. We examine the effects of the 1976 UI disentitlement of the elderly on their labor force behavior and find evidence of significant adverse selection effects. Interactions with the public pension system suggest that poverty among the elderly could be best addressed through changes in programs other than UI.

\section{Green, Francis}

PD June 1992. TI The Employer Size-Wage Effect: Is Monopsony the Explanation? AU Green. Francis: Machin. Stephen; Manning. Alan. AA Green: Leicester University. Machin: University College, London and London School of Economics. Manning: London School of Economics. SR Centre for Economic Performance Discussion Paper: 79; The Centre for Economic Performance. The London School of Economics and Political Science, Houghton Street, London WC2A 2AE. ENGLAND. PG 18. PR no charge. JE J30, J42, J51. KW Wages. Employer Size. Monopsony. AB This paper looks at evidence on the employer size-wage effect for the U.K. using data from the General Household Survey. British Social Attitudes Survey and the Workplace Industrial Relations Survey. We find much larger effects in the non-union sector and for women. We consider various theoretical explanations for the size-wage effect and conclude that our findings are most consistent with a dynamic monopsony model.

\section{Greenwald, Bruce}

TI Market Response to Mutual Fund Performance. AU Goetzmann, William N.; Greenwald, Bruce; Huberman, Gur.

\section{Greenwood, Jeremy}

PD January 1992. TI On the Existence and Uniqueness of Nonoptimal Equilibria in Dynamic Stochastic Economies. AU Greenwood. Jeremy; Huffman, G. AA Greenwood: Federal Reserve Bank of Minneapolis and University of Western Ontario. Huffman: University of California, Riverside and University of Western Ontario. SR Federal Reserve Bank of Minneapolis Staff Report; 151; Research Department. Federal Reserve Bank of Minneapolis, 250 Marquette Ave., Minneapolis, MN 55401. PG 14. PR no charge. JE O41. E13, C62. KW Growth Models. Stationary Equilibria.

AB The question of the existence and uniqueness of a stationary equilibrium for distorted versions of the standard neoclassical growth model is addressed in this paper. The conditions presented guaranteeing the existence and uniqueness of nontrivial equilibrium for the class of economies under study are simple and intuitively appealing, while the existence and uniqueness proof developed is elementary. Example are presented illustrating that economies with distortional taxation. endogenous growth with externalities, and monopolistic competition can all fit into the framework developed.

TI On the Cyclical Allocation of Risk. AU Gomme, Paul; Greenwood. Jeremy.

\section{Greenwood, Priscilla Edson}

TI Markov Fields over Countable Partially Ordered Sets:
Extrema and Splitting. AU Evstigneev, Igor; Greenwood, Priscilla Edson.

\section{Gregory, Allan W.}

PD November 1992. TI Residual-Based Tests for Cointegration in Models with Regime Shift. AU Gregory, Allan W.; Hansen. Bruce E. AA Gregory: Queen's University. Hansen: University of Rochester. SR University of Rochester Center for Economic Research Working Paper: 335: Department of Economics. University of Rochester, Rochester, NY 14627. PG 18. PR no charge. JE C12, C15, C22, C52. KW Level Shift. Regime Shift. Cointegration. Brownian Motion.

AB In this paper we examine tests for cointegration which allow for the possibility of regime shifts. We propose ADFZalpha- and $\mathrm{Zt}$-type tests designed to test the null of no cointegration against the alternative of cointegration in the presence of a possible regime shift. In particular we consider cases where the intercept and/or slope coefficients have a single break of unknown timing. A formal proof is provided for the limiting distributions of the various tests for the regime shift model. Critical values are calculated for the tests by simulation methods and a simple Monte Carlo experiment is conducted to evaluate finite sample performance. In the limited set of experiments, we find that the tests can detect cointegrating relations when there is a break in the intercept and/or slope coefficient. For these same experiments. the power of the conventional ADF and /or slope coefficient. For these same experiments. the power of the conventional ADF test with no allowance for regime shifts falls sharply.

\section{Grilli, Vittorio}

TI The Automobile Industry and the Mexico-U.S. Free Trade Agreement. AU Berry, Steven T.: Lopez-de Silanes, Florencio; Grilli, Vittorio.

\section{Grossman, Gene $M$.}

PD August 1992. TI Protection For Sale. AU Grossman, Gene M.: Helpman, Elhanan. AA Grossman: Princeton University. Helpman: Tel Aviv University. SR National Bureau of Economic Research Working Paper: 4149; National Bureau of Economic Research, 1050 Massachusetts Avenue. Cambridge. MA 02138. PG not available. PR \$5.00. JE A12, D72. KW Political Contribution. Lobby Groups. Political Influence.

AB We develop a model in which special interest groups make political contributions in order to influence an incumbent government's choice of trade policy. In the political equilibrium the interest groups bid for protection, and each group's offer is optimal given the offers of the others. The politicians maximize their own welfare, which depends on the total amount of contributions collected and on the aggregate welfare of voters. We study the structure of protection that emerges in political equilibrium and the equilibrium contributions that are made by the different industry lobby groups. and show why these groups may in some cases prefer to have the government use trade policy to transfer income rather than more efficient means.

\section{Grossman, Herschel I.}

PD July 1992. TI Production. Appropriation, and Land Reform. AA Brown University. SR Brown University Department of Economics Working Paper: 92-4; Department of 
Economics, Brown University. Providence, Rhode Island 02912. PG 14. PR no charge. JE D74. Q15. KW Resource Allocation. Production. Appropriation. Property Rights.

AB This paper develops a theory of the endogenous determination of the equilibrium distribution of property. It also adds to the growing literature on general equilibrium models of the allocation of resources between productive and appropriative activities. More specifically, this paper formalizes the idea that land reform can be an optimal response of a landowning class to the threat of extralegal appropriation of land rents. The analysis shows that, depending on the technology of production and the technology of appropriation. equilibria with and without land reform and with and without resources allocated to appropriative activities are possible. A central result is that, if the technology of extralegal appropriation is good both absolutely and relative to the competitive wage share of output on the landlords' land, then it is the landlords' interest to distribute to the peasant families sufficient land to induce them not to engage in appropriative activities.

\section{Grossman, Michael}

PD August 1992. TI Determinants of Interest Rates on Tax-Exempt Hospital Bonds. AU Grossman. Michael; Goldman. Fred: Mobilia, Pamela; Nesbitt, Susan W. AA Grossman: City University of New York and National Bureau of Economic Research. Goldman and Nesbitt: New School for Social Research and National Bureau of Economic Research. Mobilia: Brooklyn College and National Bureau of Economic Research. SR National Bureau of Economic Research Working Paper: 4139; National Bureau of Economic Research, 1050 Massachusetts Avenue, Cambridge, MA 02138. PG not available. PR $\$ 5.00$. JE I11, I18, 119 . KW Hospital Finance. Bonds. Health Care.

AB The aim of this paper is to examine the determinants of interest rates on tax-exempt hospital bonds. The results highlight the potential and actual roles of Federal and state policy in the determination of these rates. The shift to a Prospective Payment System under Medicare has subsidized the borrowing costs of some hospitals at the expense of others The selection of underwriters by negotiation rather than by competitive bidding results in higher interest rates. It is cheaper for hospitals in states with relatively high income tax rates to issue debt. The Federal tax act of 1986 raised the costs of hospital debt by encouraging bond issues to contain call features. Are the interest rate effects associated with these policies desirable or undesirable? This question can not be answered in the absence of estimates of the optimal subsidy that an average hospital should receive via its participation in tax-exempt markets, how this subsidy should vary among hospitals with different characteristics, and how the welfare costs associated with this subsidy can be minimized.

\section{Gruber, Jonathan}

PD September 1992. TI The Efficiency of a GroupSpecific Mandated Benefit: Evidence from Health Insurance Benefits for Maternity. AA Massachusetts Institute of Technology. SR National Bureau of Economic Research Working Paper: 4157: National Bureau of Economic Research. 1050 Massachusetts Avenue, Cambridge, MA 02138. PG 39. PR \$3.00. JE J13, J32, J38, G22, J31. KW Childbirth. Wage Determination.
AB I consider the effects of "group-specific mandated benefits", such as mandated maternity leave, which raise the costs of employing a demographically identifiable group. The efficiency of these policies, relative to more broad-based financing of benefits expansions, will largely be a function of the valuation of the mandated benefit by the targeted group. Such valuation should be reflected in substantial shifting of the cost of the mandate to group-specific wages; however, there may be barriers to the adjustment of relative wages which impede such shifting. I study several 1976 state mandates which stipulated that childbirth be covered comprehensively in health insurance plans, increasing the cost of insuring women of child-bearing age by as much as $5 \%$ of their wages. I find substantial shifting of the costs of these mandates to the wages of the targeted group.

\section{Guesnerie, Roger}

TI Rationalizability. Strong Rationality and Expectational Stability. AU Evans, George W.; Guesnerie, Roger.

PD February 1992. TI An Exploration of the Eductive Justifications of the Rational Expectations Hypothesis. AA EHESS, Paris. SR London School of Economics Suntory-Toyota International Centre for Economics and Related Disciplines Working Paper: TE/92/238; London School of Economics, Houghton Street, London WC2A 2AE, ENGLAND. PG 56. PR no charge. JE D83. KW Rational Expectations. Learning. Eductive Justification. AB Rational expectations can be justified by an appeal to an argument based upon agents determining expectations which are, in some sense. "reasonable" to hold. This paper takes the latter approach and looks at an eductive justification of the rational expectations hypothesis. Conditions under which such a justification is possible are examined.

\section{Guidotti, Pablo E.}

PD August 1992. TI Wage and Public Debt Indexation. AA International Monetary Fund. SR International Monetary Fund Working Paper: 92/67; International Monetary Fund. Washington, DC 20431. PG 24. PR not available. JE E60, F41. KW Wage Indexation. Debt Indexation. Precommitment.

AB This paper examines the relationship between the degree of wage indexation chosen by private agents and the degree of indexation of the public debt. It is shown that the government is likely to respond to an increase in the degree of wage indexation by increasing the portion of the public debt indexation on the degree of wage indexation is ambiguous. In equilibrium, depending on the sources of shocks to the economy, the degree of wage indexation may be positively or negatively related to that of debt indexation. This relationship is analyzed both in situations where the policymakers are able to precommit policies and in those where precommitment is not possible.

\section{Guillen, Mauro F.}

TI The Transfer of Organizational Management Techniques Across Borders: Combining Neo-Institutional and Comparative Perspectives. AU Arias. Maria Eugenia: Guillen, Mauro F.

\section{Ha, Jiming}

PD September 1992. TI Strategic Capital Taxation in 
Large, Open Economies with Mobile Capital. AU Ha, Jiming: Sibert. Anne. AA Ha: University of Kansas. Sibert: Federal Reserve Bank of Kansas City and University of Kansas. SR Federal Reserve Bank of Kansas City Research Working Paper: 92-01; Research Division. Federal Reserve Bank of Kansas City, 925 Grand Ave., Kansas City, MO 64198. PG 20. PR no charge. JE H25. F41. KW Corporate Tax.

AB This paper finds the path of Nash equilibrium taxes on investment. savings and labor in a dynamic, optimizing. equilibrium model of a large, open economy. The central result is that in the long run, the sign of the optimal home corporate $\operatorname{tax}$ is a function of the rate at which the home country discounts the future, relative to the rest of the world. If home and foreign consumers have identical preferences, then the Nash home corporate tax is zero. If home consumers are relatively impatient, then the Nash home corporate tax is strictly positive. If they are patient. the tax is strictly negative.

\section{Hahn, Frank}

PD February 1992. TI Incomplete Market Economies. AA University of Cambridge. SR University of Cambridge Economic Theory Discussion Paper: 166; Department of Applied Economics, University of Cambridge, Sidgwick Avenue, Cambridge CB3 9DE, UNTTED KINGDOM. PG 29. PR $\$ 5.00(\mathrm{~L} 2.50)$, checks payable to University of Cambridge. JE D52, D58. B41. KW Theory of Markets. Sunspot Theory.

AB This lecture to the British Academy deals with (a) economies in which there are too few securities to span the set of states of the world, (b) the problem of multiple second period spot equilibria and (c) how one might proceed to an endogenous theory of markets. A theorem is proved which relates multiple second period spot prices to Sunspot theory. Some remarks on the difficulties caused by imperfect competition and on the relevance of what has been discussed to Keynesian theory conclude the paper.

\section{Hahn, Robert W.}

TI The Impact of Pricing Rules on Electric Utility Emissions. AU Dowlatabadi. Hadi: Hahn. Robert W.

\section{Hajivassiliou, Vassilis A.}

PD July 1992, TI Simulation of Multivariate Normal Orthant Probabilities: Theoretical Computational Results. AU Hajivassiliou, Vassilis A.; McFadden, Daniel L.; Ruud, Paul A. AA Hajivassiliou: Yale University. McFadden and Ruud: University of California, Berkeley. SR Yale Cowles Foundation Discussion Paper: 1021; Cowles Foundation for Research in Economics, 30 Hillhouse Ave., Box 2125 Yale Station, New Haven, CT 06520. PG 49. PR no charge. JE C25. C35. KW Multinomial Probit Model. Acceptance. Rejection. Sequential Sampling.

AB An extensive literature in econometrics and in numerical analysis has considered the problem of evaluating the multiple integral $P(B ; m u$, Sigma). The problem is computationally difficult except in very special cases. The multinomial probit (MNP) model used in econometrics and biometrics has cell probabilities that are negative orthant probabilities with mu and Sigma depending on unknown parameters (and, in general, on covariates). Estimation of this model requires, for each trial parameter vector and each observation in a sample, evaluation of $\mathrm{P}(\mathrm{mu} ; \mathrm{B})$ and of its derivatives with respect to $\mathrm{mu}$ and Sigma.
This paper surveys Monte-Carlo tochniques that have been developed for approximations of $\mathrm{P}(\mathrm{mu} ; \mathrm{B})$ and its linear and logarithmic derivatives that limit computation while possessing properties that facilitate their use in iterative calculations for statistical inference. We find that the Geweke-HajivassiliouKeane Simulator is overall the most reliable method.

\section{Hakkio, Craig S.}

PD December 1991. TI The International Role of the Dollar. AA Federal Reserve Bank of Kansas City. SR Federal Reserve Bank of Kansas City Research Working Paper: 91-08: Research Division. Federal Reserve Bank of Kansas City, 925 Grand Ave., Kansas City. MO 64198. PG 23. PR no charge. JE F31, F33, F41. KW International Currency. World Financial Market.

AB The dollar was the dominant international currency following World War II. However, as the international economy has changed in dramatic ways, the international role of the dollar has also changed. Although the dollar's role has declined, it remains an important international currency. Furthermore, the world does not appear to be moving toward a tripolar monetary system. The dollar and the Deutschmark, not the yen, are the most important international currencies. The reasons for the decline in the dollar's role is due to the collapse of the Bretton Woods system in 1973, the decline in the relative importance of the United States, and deregulation of the world financial market.

\section{Haldrup, Niels}

PD September 1992. TI Heteroscedasticity in NonStationary Time Series, Some Monte Carlo Evidence. AA University of Aarhus. SR Aarhus Institute of Economics Memo: 1992-8; Institute of Economics, University of Aarhus. Building 350. Universitetsparken. DK-8000 Aarhus C, DENMARK. PG 17. PR no charge. JE C12. C15, C22. KW Heteroskedasticity. Dickey-Fuller Test.

AB In this paper we report a Monte Carlo study analyzing the implications of various types of heteroskedasticity on three types of unit root tests: The usual Dickey-Fuller test, Phillips' (1987) semi-parametric test and finally a Dickey-Fuller type test using White's (1980) heteroskedasticity consistent standard errors. The sorts of heteroskedasticity we examine are the GARCH model of Bollerslev (1986) and the Exponential ARCH model of Nelson (1991). In particular, we call attention to situations where the conditional variances exhibit a high degree of persistence as is frequently observed for returns of financial time series.

\section{Haliassos, Michael}

TI Precautionary Portfolio Behavior. AU Bertaut, Carol: Haliassos, Michael.

\section{Haltiwanger, John}

TI Autos and the National Industrial Recovery Act: Evidence on Industry Complementarities. AU Cooper. Russell: Haltiwanger, John.

\section{Hammour, Mohamad L.}

TI Long Run Effects of Business Cycles. AU Gali, Jordi; Hammour, Mohamad L.

\section{Hancock, Diana}

TI Bank Efficiency Derived from a Profit Function. 
AU Berger, Allen N.; Hancock, Diana; Humphrey, David B.

\section{Hansen, Bruce E.}

PD September 1992. TI Regression with Non-Stationary Variances. AA University of Rochester. SR University of Rochester Center for Economic Research Working Paper: 331; Department of Economics. University of Rochester, Rochester, NY 14627. PG 29. PR not available. JE C10, C22. C32. KW Asymptotic Theory. Nonstationary Time Series. AB A completely new asymptotic theory of regression is introduced for possibly non-stationary time series. The variables are assumed to be generated by a vector linear process with martingale difference innovations. The conditional variances of these martingale differences are allowed to be non-stationary processes. The primary requirement imposed on these processes is that they converge weakly in the Skorohod metric to cadlag stochastic processes. The types of nonstationary variances thereby permitted include deterministic variances, multiple structural breaks with random shift points, and positive functions of integrated or near-integrated processes.

TI Residual-Based Tests for Cointegration in Models with Regime Shift. AU Gregory. Allan W.: Hansen. Bruce E.

\section{Harding, Ann}

PD May 1992. TI Income Distribution and Redistribution across the Lifecycle: Evidence from Australia. AA Centre of Social and Economic Modelling. Canberra. SR London School of Economics Suntory-Toyota International Centre for Economics and Related Disciplines Working Paper: WSP 70 ; London School of Economics, Houghton Street. London WC2A 2AE. ENGLAND. PG 50. PR no charge. JE I38, H55. KW Lifecycle. Income. Tax-Transfer Policy. Redistribution. AB Studies which examine the impact of government taxes and expenditures at a single point in time usually conclude that such activities redistribute income from the rich to the poor. However, because there are such strong lifecycle influences on income, there have always been doubts about the extent to which cash transfers and taxes simply redistribute income across the lifecycle of individuals, rather than redistributing from those with low lifetime incomes. A new analysis of the impact of taxes and transfers over the entire lifetime in Australia suggest that, when cash transfers are compared with the amount of income taxes required to finance them, on average about 45 percent of taxes paid by males are returned to them as cash transfers during another point in their lifecycle. In contrast, for women. on average all income taxes levied are repaid to them as cash transfers at some other period in their lifecycle.

\section{Hardle, Wolfgang $\mathrm{K}$.}

PD July 1992. TI Nonparametric Approaches to Generalized Linear Models. AU Hardle. Wolfgang $\mathrm{K}$ : Turlach. Berwin A. AA Universite Catholique de Louvain. SR Universite Catholique de Louvain CORE Discussion Paper: 9237; Universite Catholique de Louvain. Voie du Roman Pays, 34, B-1348 Louvain-la-Neuve, BELGIUM. PG 14. PR not available. JE C14, C87, C51. KW Semiparametric Estimation. Nonparametric Estimation. Discrete Choice.

AB In this paper we investigate the gains of using nonparametric estimation methods in a family of models related to Generalized Linear Models. We focus especially on discrete choice models. We give an overview on different nonparametric and semiparametric approaches in this setting. In particular we discuss estimation methods such as average derivative estimation (ADE), semiparametric weighted least squares (Single Index Models, SIM), Projection Pursuit Regression (PPR) and Generalized Additive Models (GAM). Their performance in practice and theory is compared.

\section{Hare, Paul G.}

TI Firms in Transition: Modelling Enterprise Adjustment. AU Estrin, Saul; Hare, Paul G.

\section{Hart, Oliver}

TI The Economics of Banknuptcy Reform. AU Aghion, Philippe: Hart. Oliver; Moore. John.

\section{Hartwick, John M.}

PD July 1992. TI The Tragedy of the Commons Revisited. AA Queen's University. SR Queen's Institute for Economic Research Discussion Paper: 856; Department of Economics, Queen's University, Kingston, Ontario, CANADA K7L 3N6. PG 14. PR \$3.00 Canada: \$3.50 U.S. and elsewhere. JE C73, J11, 013. KW Common Property. Differential Game.

AB We formulate the Malthus-Hardin tragedy of the commons as a special case of dynamic game between "tribes". At each date a member of a tribe desires more newborns of her/his type and more current consumption, harvested from the commons. Equilibrium in the dynamic game yields steady state level of per capita consumption for each person and a steady population level for each tribe (births equal deaths). We obtain four outcomes, depending on our assumptions about the discount rates of members of a tribe and about the mode of competition for "large populations" for each tribe. We compare Nash open loop and Nash feedback solutions with a quadratic current utility function and observe a larger population under the feedback solution. The classic tragedy of the commons solution obtains as a special case of the open loop solution, one with an infinite rate of discount for players.

PD July 1992. TI A Differential R \& D Duopoly Game. AA Queen's University. SR Queen's Institute for Economic Research Discussion Paper: 857: Department of Economics, Queen's University. Kingston, Ontario, CANADA K7L 3N6. PG 10. PR \$3.00 Canada; \$3.50 U.S. and elsewhere. JE C73. O31, L13. KW Cournot Game. Research and Development.

AB At each date, the two players play an $R$ \& $D$ investment game "followed" by a Cournot quantity setting game. Each player's R \& D investment augments the common stock of technical knowledge and lowers goods production costs for each player. Profits gross of R \& D investment expenditures are quadratic in state (knowledge here) for each player. $R$ \& $D$ investment costs are assumed quadratic in each player's investment. The Nash feedback and Nash open-loop solutions differ in general with the feedback solutions being "more competitive", i.e., yielding lower production costs in the steady state.

\section{Haveman, Robert}

TI The "Window Problem" In Studies of Children's Attainments: A Methodological Exploration. AU An, Chong-Bum; Haveman. Robert: Wolfe, Barbara. 
Helpman, Elhanan

TI Protection For Sale. AU Grossman, Gene M.; Helpman, Elhanan.

\section{Helwege, Jean}

PD August 1992. TI Determinants of Savings and Loan Failure Rates: Estimates of a Time-Varying Proportional Hazand Function. AA Board of Governors of the Federal Reserve System. SR Board of Governors of the Federal Reserve System Finance and Fconomics Discussion Series: 207; C/O Steven A. Sharpe, Mail Stop 89, Federal Reserve Board. Wash., DC 20551. PG 31. PR no charge. JE G21. KW Savings and Loan Failure. Proportional Hazard.

AB A time-varying proportional hazard function of savings and loan failures is estimated using time-series cross-section data on thrifts from 1979 to 1990 . The methodology is unique in that the estimates of the conditional probability of failure take into account all of the uncensored information on thrift industry investment strategies over the decade. The results of the estimation indicate that holdings of residential mortgages, particularly adjustable rate mortgages, led to lower failure rates while commercial real estate investments increased the probability of failure among federally insured thrifts.

\section{Hendershott, Patric $\mathrm{H}$.}

PD July 1992. TI Office Market Values During the Past Decade: How Distorted Have Appraisals Been? AU Hendershott, Patric H.: Kane. Edward J. AA Hendershott: Ohio State University and National Bureau of Economic Research. Kane: Boston College and National Bureau of Economic Research. SR National Bureau of Economic Research Working Paper: 4128; National Bureau of Economic Research, 1050 Massachusetts Avenue. Cambridge. MA 02138. PG not available. PR \$5.00. JE L85, M20. G30. KW Real Estate. Office Market, Appraisers.

AB This paper develops evidence that, in a declining market, appraisal values may lag notably behind analytical measures of the discounted present value of commercial property cash flows. For the period 1982-92, alternative measures of the economic value of constant-quality office buildings are constructed using two benchmark projections designed to bracket expected future vacancy rates and real rents. Until 1992, the time path for both benchmark series lie consistently below that developed from the appraisal-based Russell/NCREIF office market index. This divergence implies that the rate of price appreciation reported by the Russell/NCREIF index is distorted: being slow to register price declines when markets first weaken and then having to overstate the rate of decline once the market begins to bottom out. The distortion may reflect incentives for investment managers and appraisers to smooth potentially temporary price volatility, as well as systematic differences in the character and condition of the properties that tend to trade at different stages of the real estate cycle.

\section{Henderson, Rebecca}

TI Ivory Tower versus Corporate Lab: An Empirical Study of Basic Research and Appropriability. AU Trajtenberg. Manuel; Henderson, Rebecca; Jaffe, Adam B.

\section{Henderson, Vernon}

PD May 1992. TI Industrial Development in Cities.
AU Henderson, Vernon; Kuncoro, Ari; Turner, Matt. AA Brown University. SR Brown University Department of Economics Working Paper: 92-9; Department of Economics. Brown University, Providence, Rhode Island 02912. PG 31. PR no charge. JE F00, O30, R30, L60. KW Industy Location. Growth. Urban Development.

AB Using extensive data on 1970 and 1987 urban characteristics. the paper analyzes changes in employment in specific manufacturing industries in cities between 1970 and 1987. Two sets of questions are the focus. First. what present or past characteristics of a city's economic environment are critical in determining current employment levels in different industries? How much persistence in employment patterns is there over time and what is the source of that persistence? The estimations which examine this first set of questions also give a framework to predict the impact of shocks to the economy on where industries locate (e.g., the impact of a Mexico-USA free trade agreement). The second set of questions explores what inferences can be made from the data and results concerning the nature of externalities in urban markets.

\section{Hendricks, Ken}

PD June 1992. TI The Economics of Hubs: The Case of Monopoly. AU Hendricks. Ken; Piccione. Michele; Tan. Guofu. AA University of British Columbia. SR University of British Columbia Department of Economics Discussion Paper: 92-09; Deparment of Economics, University of British Columbia 997-1873 East Mall, Vancouver, B.C. Canada V6T 1W5. PG 50. PR JE L00,L10. KW Airlines. Hubs. Networks.

AB In this paper, we study the optimization problem of an unregulated air carrier which is given the exclusive right to satisfy demand for air travel between any pair of $\mathbf{n}$ cities. It chooses a network of connections and a set of prices to maximize profits. Thus, both network design and prices are endogenous. We characterize the solution to this optimization problem for different cost structures. Our main result is that, if there are economies of density in the number of individuals traveling between two directly connected cities, the optimal network is often either a hub of size n-l or one in which every pair of cities is connected directly.

\section{Hildenbrand, Kurt}

PD February 1992. TI Computersimulierte Gleichgewichtsanalyse. AA University of Bonn. SR Universitat Bonn Sonderforschungsbereich 303Discussion Paper: A-363; Sonderforschungsbereich 303 an der Universitat Bonn Adenquerallee 24-42, D-5300 Bonn 1 , GERMANY. PG 87. PR no charge. JE C60. KW Equilibrium Theory. Allocation. Computer Simulation.

AB No abstract available. This paper is written in German.

\section{Hills, John}

TI The Distribution of Welfare Benefits in Kind. AU Evandrou, Maria: Falkingham, Jane; Hills, John; Le Grand, Julian.

\section{Hinojosa-Ojeda, Raul}

PD July 1992. TI Labor Issues in a North American Free Trade Area. AU Hinojosa-Ojeda, Raul; Robinson, Sherman. AA Hinojosa: University of California, Los Angeles. Robinson: University of California, Berkeley. SR University of California at Berkeley, Department of Agricultural and 
Resource Economics (CUDARE) Working Paper: 632; Department of Agricultural and Resource Economics, 313 Giannini Hall, UC Berkeley, Berkeley. CA 94720. PG 20. PR \$8.50. JE F13, F14, J21. KW Labor Market. Labor Migration. Unskilled Labor. NAFTA.

AB This paper surveys work analyzing the employment and wage implications of the formation of a North American Free Trade Area (NAFTA). Three types of models have been used: (1) partial equilibrium models based on historical extrapolation or regression analysis. (2) single-country computable general equilibrium (CGE) models, and (3) multi-country CGE models. Trade theory predicts that, even without international factor mobility, there should be movement toward wage convergence after the creation of NAFTA with Mexican unskilled wages rising and U.S. unskilled wages falling. . Model results indicate that, on the U.S. side, this result is not empirically robust. The effects of NAFTA on the U.S. side are small, and existing distortions create a second-best environment in which the theoretical predictions become ambiguous. All the CGE models generated plausible scenarios in which wages rise significantly in both the U.S. and Mexico.

\section{Hirshleifer, Jack}

PD September 1992. TI Anarchy and Its Breakdown. AA University of California, Los Angeles. SR University of California at Los Angeles Department of Economics Working Paper: 674; Department of Economics, University of California at Los Angeles, 2263 Bunche.. Los Angeles, CA 90024. PG 24. PR \$2.50; checks payable to U.C. Regents. JE POO. KW Anarchy. Conflict.

AB Anarchy is not mere chaos. and can constitute a stable system. However, not all environments can sustain an anarchic order. Each contestant in the model here balances optimally between producing out of current resources versus fighting to seize or defend a resource base. Anarchy is viable only when there are strongly diminishing returns to fighting effort (the 'decisiveness parameter ' $m$ ' must be sufficiently low), else any contender with an initial advantage would always gain total control. Under Cournot conditions, assuming viability, as $\mathbf{m}$ rises fighting levels increase and achieved incomes decrease. Under Stackelberg conditions all sides benefit from reduced levels of fighting. but followers do better than the leader--a consideration that tends to stabilize anarchy by reducing the motivation to seek leadership.

\section{Ho, Mun S.}

PD May 1992. TI Multivariate Tests of a Continuous Time Equilibrium Arbitrage Pricing Theory with Conditional Heteroscedasticity and Jumps. AU Ho, Mun S.; Perraudin. W. R. M.: Sorensen, Bent E. AA Ho: SUNY at Buffalo. Perraudin: University of Cambridge. Sorensen: Brown University. SR University of Cambridge Department of Applied Economics Working Paper: 9211; Department of Applied Economics. University of Cambridge. Sidgwick Avenue, Cambridge CB3 9DE, UNITED KINGDOM. PG 24. PR $\$ 5.00$ (L2.50), checks payable to University of Cambridge. JE G12. C32. KW Stock Returns. Stochastic Volatility. ARCH.

AB This paper uses ML and GMM techniques to estimate systems of stochastic differential equations that describe the behavior of stock returns. We test restrictions implied by a continuous time asset pricing model that builds on the work of Chamberlain (1988). The stochastic differential equations we estimate allow for mean-reverting stochastic volatility and for jumps of random size, and are therefore consistent with the observation that stock returns exhibit conditional heteroskedasticity and high unconditional kurtosis. We are able to distinguish whether excess kurtosis in returns simply reflects stochastic volatility or whether a satisfactory model requires in addition the inclusion of jump components. We examine whether the joint distribution of stock prices has changed between the two periods 1984-86 and 1987-89. and find that while the persistence in variance seemed to become somewhat less important, jumps in stock prices become more important.

PD May 1992. TI Multivariate Tests of a Continuous Time Equilibrium Arbitrage Pricing Theory With Conditional Heteroskedasticity and Jumps. AU Ho, Mun S.; Perraudin, W. R. M.; Sorensen. Bent E. AA Ho: State University of New York. Buffalo. Perraudin: University of Cambridge. Sorenson: Brown University. SR Brown University Department of Economics Working Paper: 92-7; Department of Economics, Brown University, Providence, Rhode Island 02912. PG 23. PR no charge. JE G12, C32. KW ARCH. Arbitrage Pricing. Factor Model. Maximum Likelihood.

AB See other entry.

Ho, Wai-Ming

PD April 1992. TI Liquidity. Exchange Rates, and Business Cycles. AA University of Western Ontario. SR University of Western Ontario Department of Economics Research Report: 9204; Department of Economics, Social Sciences Center, University of Western Ontario, London, Ontario, CANADA N6A 5C2. PG 34. PR \$5.00 Canada. $\$ 7.00$ elsewhere. JE E52, F31, F40, F41. KW Liquidity Effects. Exchange Rates. International Transmission Mechanism.

AB This paper presents a two-country, two-good, twocurrency model to study the role of liquidity effects in exchange rate determination and the international transmission of economic fluctuations. The model provides an exchange rate equation which is different from the simple purchasing power-parity law of exchange rate determination. Both monetary injections and real disturbances can lead to exchange rate fluctuations and comovements of interest rates. prices and output of the two economies. Whether the covariances of variables in the two countries are positive, negative, or zero depends critically upon the substitutability of the two consumption goods in consumers' preferences.

\section{Hofmann, Norbert}

PD February 1992. TI Option Pricing under Incompleteness and Stochastic Volatility. AU Hofmann, Norbert: Platen. Eckhard: Schweizer, Martin. AA Hofmann: University of Berlin. Platen: Australian National University and University of Berlin. Schweizer: University of Gottingen. SR Universitat Bonn Sonderforschungsbereich 303Discussion Paper: B-209; Sonderforschungsbereich 303 an der Universitat Bonn Adenauerallee 24-42, D-5300 Bonn 1 , GERMANY. PG 30. PR no charge. JE G10, G13. KW Option Pricing. Stochastic Volatility. Incomplete Markets.

AB We consider a very general diffusion model for asset prices which allows the description of stochastic and pastdependent volatilities. Since this model typically yields an incomplete market, we show that for the purpose of pricing 
options, a small investor should use the minimal equivalent martingale measure associated to the underlying stock price process. Then we present stochastic numerical methods permitting the explicit computation of option prices and hedging strategies, and we illustrate our approach by specific examples.

\section{Holmes, Thomas J.}

PD September 1992. TI Managerial Tenure, Business Age and Small Business Dynamics. AU Holmes, Thomas J.; Schmitz, James A., Jr. AA Holmes: University of Wisconsin. Schmitz: Federal Reserve Bank of Minneapolis. SR Bureau of the Census Center for Economic Studies Discussion Paper: 92-11: Center for Economic Studies, Bureau of the Census, Washington, DC 20233. PG 28. PR no charge. JE M10. L11. KW Managerial Quality.

AB This paper studies a Census Bureau survey of the small business sector that contains information on business age, business size and other proxies for business quality, information typically available on business data sets, as well as proxies for the quality of the manager of each business. information that is not common to such data sets. One of the key proxies for managerial quality is the length of time the manager has been running the business, that is, managerial tenure. With proxies for both the underlying quality of each business and for the quality of the manager running the business, we are able to begin separating the influences of the manager from that of the underlying business on such factors as business discontinuance and business transfer.

\section{Holtz-Eakin, Douglas}

PD July 1992. TI The Carnegie Conjecture: Some Empirical Evidence. AU Holtz-Eakin. Douglas; Joulfaian, David: Rosen, Harvey S. AA Holtz-Eakin: Syracuse University and National Bureau of Economic Research. Joulfaian: U.S. Department of the Treasury. Rosen: Princeton University and National Bureau of Economic Research. SR National Bureau of Economic Research Working Paper: 4118; National Bureau of Economic Research. 1050 Massachusetts Avenue, Cambridge, MA 02138. PG 19. PR \$5.00. JE J20, J62. KW Inheritance. Labor Supply. AB This paper examines tax return-generated data on the labor force behavior of people before and after they receive inheritances. The results are consistent with Andrew Carnegie's century-old assertion that large inheritances decrease a person's labor force participation. For example, a single person who receives an inheritance of over $\$ 150,000$ is roughly four times more likely to leave the labor force than a person with an inheritance below $\$ 25,000$. Additional, albeit weaker, evidence suggests that large inheritances depress labor supply, even when participation is unaltered.

PD July 1992. TI Public-Sector Capital and the Productivity Puzzle. AA Syracuse University and National Bureau of Economic Research. SR National Bureau of Economic Research Working Paper: 4122; National Bureau of Economic Research, 1050 Massachusetts Avenue. Cambridge. MA 02138. PG 15. PR \$5.00. JE D24, E22, E23. KW Capital Accumulation. Productivity, Production Functions.

AB A number of studies have suggested a quantitatively important relationship between public-sector capital accumulation and private sector productivity, with the most compelling evidence derived from analyses of state-level data.
Estimates herein of production functions that use standard techniques to control for unobserved. state-specific characteristics, however, reveal essentially no role for publicsector capital in affecting private sector productivity. Only estimates of state production functions that do not include such controls find substantial productivity impacts. This result reconciles existing econometric estimates with the findings of Hulten and Schwab based on growth accounting techniques, as such techniques effectively control for state-specific effects.

PD August 1992. TI Solow and the States: Capital Accumulation. Productivity and Economic Growth. AA Syracuse University and National Bureau of Economic Research. SR National Bureau of Economic Research Working Paper: 4144; National Bureau of Economic Research, 1050 Massachusetts Avenue, Cambridge, MA 02138. PG not available. PR \$5.00. JE E61, O40, O49. O15, J24. KW Growth. Capital Accumulation. Investment. Human Capital.

AB National, state, and local policy makers have increasingly focused their attention on policies toward economic growth, especially effort to raise the rate of investment. Recent studies of economic growth have raised a debate over the role played by the investment rate in the longrun performance of the economy. Evidence from the states suggests that the effects of capital accumulation are consistent with the predictions of the neoclassical focus on physical capital investment.

\section{Honkapohja, Seppo}

TI Local Convergence of Recursive Learning to Steady States and Cycles in Stochastic Nonlinear Models. AU Evans, George W.; Honkapohja, Seppo.

\section{Howe, Roger}

TI The Complex of Maximal Lattice Free Simplices. AU Barany. Imre; Howe, Roger; Scarf. Herbert E.

\section{Huberman, Gur}

PD March 1992.. TI Returns Volatilities Drop Following Large Dividend Payments. AU Huberman. Gur: Peles, Nadav. AA Columbia University. SR Columbia First Boston Series in Money. Economics and Finance Working Paper: FB-92-17; Columbia University, Graduate School of Business, First Boston Series, New York, NY 10027. USA. PG 18. PR \$5.00 academics and non-profit institutions: $\$ 6.00$ corporations (add $\$ 1.00$ outside U.S., Canada and Puerto Rico). JE G12, G35. KW Stock Returns. Returns Volatility.

AB Theoretically, cash distributions should be accompanied by increases in stock returns volatilities. We document the opposite effect for fourteen out of sixteen firms that paid large special dividends. These drops in volatility following the ex dividend day seem unrelated to the intensity of arrival of news stories about the firms.

TI Market Response to Mutual Fund Performance. AU Goetzmann, William N.; Greenwald, Bruce; Huberman, Gur.

PD September 1992. TI On the Incentives for Money Managers: A Signalling Approach. AU Huberman, Gur; Kandel, Shmuel. AA Huberman: Columbia University. Kandel: Tel-Aviv University. SR Columbia First Boston Series in Money, Economics and Finance Working Paper: FB- 
92-16: Columbia University. Graduate School of Business, First Boston Series, New York. NY 10027. USA. PG 21. PR $\$ 5.00$ academics and non-profit institutions; $\$ 6.00$ corporations (add \$1.00 outside U.S., Canada and Puerto Rico). JE G11. D83. KW Portfolio Choice. Screening Equilibrium.

AB Money managers select weights of managed portfolios to enhance their reputation in the spot market for their services. inevitably using their actions to signal their quality. We develop a two-asset signaling model of money managers. A unique screening equilibrium and (under certain parameter configurations) a host of pooling equilibria survive the ChoKreps Intuitive Criterion. In all the equilibria managers behave more aggressively than they would in the absence of the signaling motive, exaggerating their position in the risky asset.

Huffman, G.

TI On the Existence and Uniqueness of Nonoptimal Equilibria in Dynamic Stochastic Economies. AU Greenwood. Jeremy; Huffman, G.

\section{Hughes, Alan}

PD October 1991. TI Mergers and Economic Performance in the UK: A Survey of the Empirical Evidence 1950-1990. AA University of Cambridge. SR University of Cambridge Department of Applied Economics Working Paper: 9118: Department of Applied Economics. University of Cambridge. Sidgwick Avenue, Cambridge CB3 9DE, UNITED KINGDOM. PG 48. PR $\$ 5.00$ (L2.50), checks payable to University of Cambridge. JE G34. L11. KW Concentration. Industrial Structure. Investment.

AB This paper surveys the empirical evidence on the extent of merger activity and its impact upon industrial structure and corporate performance in the UK in the years 1950-90. An introductory section sets out alternative conceptual frameworks for the analysis of merger effects and is followed by a discussion of the internationalization of merger activity; the link between mergers and changes in conceintration and diversification; share price and accounting profit impacts; the links between merger and $R \& D$, investment and patterns of regional development; and the market for corporate control.

\section{Humphrey, David B.}

TI Bank Efficiency Derived from a Profit Function. AU Berger, Allen N.; Hancock, Diana; Humphrey, David B.

\section{Ingram, Peter}

TI Do Strikes Pay? AU Metcalf, David: Wadsworth, Jonathan; Ingram, Peter.

\section{Jaffe, Adam B.}

PD March 1991. TI Evaluating the Relative Effectiveness of Economic Incentives and Direct Regulation for Environmental Protection: Impacts on the Diffusion of Technology. AU Jaffe, Adam B.; Stavins, Robert N. AA Jaffe: Harvard University and Council of Economic Advisors. Stavins: Harvard University and Resources for the Future. SR Resources for the Future Quality of the Environment Division Discussion Paper: QE91-11; Quality of the Environment Division. Resources for the Future, $1616 \mathrm{P}$ Street, NW. Washington, D.C. 20036. PG 34. PR \$2.25 prepaid, U.S. funds. JE Q28. KW Energy-Saving Technology. Technology Diffusion.
AB The effect of public policies on technological change may, in the long run. be among the most important determinants of success in environmental protection. In this paper, we develop a new framework for analyzing the diffusion of environmentally desirable technology. This framework can be used to compare quantitatively the effectiveness of direct regulation and economic-incentive approaches to environmental protection in fostering adoption of energyconserving technologies, a particularly important issue in the context of greenhouse-gas emissions and the threat of global climate change. We develop a dynamic model of the adoption decision faced by an individual who must determine whether and at what time to invest in an existing energy-saving tochnology. First-order, necessary conditions emerge which are aggregated into a model which can be econometrically estimated with aggregate data, by taking account of unobserved heterogeneity among households.

TI Ivory Tower versus Corporate Lab: An Empirical Study of Basic Research and Appropriability. AU Trajtenberg. Manuel; Henderson, Rebecca; Jaffe, Adam B.

\section{Jefferson, Philip N.}

PD March 1992. TI Credit Rationing, Involuntary Unemployment. and Financial Collapse in General Equilibrium. AA Columbia University. SR Columbia University Department of Economics Discussion Paper: 594; Department of Economics. Columbia University. New York. New York 10027. PG 15. PR \$5.00. JE E51. J22, J64. KW Credit Rationing. Excess Supply. Involuntary Unemployment.

AB If credit rationing can exist in generai equilibrium, then some other market must experience "equilibrium" excess supply. This observation raises the question, "What other market exhibits this unique feature?". A model is presented where the other market is the labor market. The equilibrium excess supply in this context is involuntary unemployment. The model establishes an intimate link between credit market equilibria and the level and composition of unemployment. The arguments that establish constrained equilibria do not rely on efficiency wages, union, or other labor market sources of wage and price stickiness. Applications and implications of the model indicate the potential fruits of studying labor and credit markets jointly.

\section{Jelassi, Tawfik}

TI Integrating Global Operations with Information Technology: Lessons from a Case Study. AU Dutta, Soumitra; Jelassi, Tawfik.

\section{Jepsen, Gunner Thorlund}

PD August 1992. TI Measuring the Tax Evaders' Aversion Against Evading: An Introduction to an Empirical Research. AA University of Aarhus. SR Aarhus Institute of Economics Memo: 1992-7; Institute of Economics, University of Aarhus. Building 350. Universitetsparken. DK8000 Aarhus C, DENMARK. PG 14. PR no charge. JE H26, D81. KW Tax Evasion. Risk Aversion.

AB Tax evasion is widespread and commonly accepted even if it is officially considered a crime. This paper indicates in a simple model with wage contracting in the shadow economy where the traditional notions of the market are ill-defined. It should be possible to measure the incentive not to evade caused by a combination of risk aversion, moral attitudes and aversion 
against working too much overtime. This can be done by comparing the size of the enforcement instruments in the form of control and sanctions with wages paid in the grey market in relation to wages in the official market. It is discussed whether and how statistical material on work subsidized by the Danish government in the sector for maintenance and repair of houses and apartments can be used.

\section{Johansen, Soren}

PD August 1991. TI An I(2) Cointegration Analysis of the Purchasing Power Parity Between Australia and the United States. AA University of Copenhagen. SR Australian National University Working Paper in Economics and Econometrics: 231; Department of Economics, Australian National University, G.P.O. Box 4. Canberra 2601. AUSTRALIA. PG 23. PR no charge. JE C22, C32, C13. KW Autoregressive Models. Cointegration. Nonstationarity.

AB Cointegration analysis of autoregressive models allowing for $I(1)$ and $I(2)$ variables is briefly reviewed and the methods are illustrated by an analysis of the purchasing power parity between Australia and the United States.

\section{John, Kose}

TI Universal Banking: Should Banks Hold Equity in Borrowing Firms? AU Berlin, Mitchell; John, Kose; Saunders. Anthony.

\section{Johnson, Stephen}

TI Robin-Hooding Rents: Exploiting the Pecuniary Effects of In-Kind Programs. AU Zeckhauser, Richard: Coate. Steve; Johnson, Stephen.

\section{Jones, Chris M.}

PD 1991. TI The Dividend Puzzle and Tax. AU Jones, Chris M.: Molne, Frank. AA The Australian National University. SR Australian National University Working Paper in Economics and Econometrics: 225; Department of Economics, Australian National University, G.P.O. Box 4, Canberra 2601. AUSTRALIA. PG 30. PR no charge. JE G35. KW Dividends. Tax.

AB In this paper we use a two period GE model of the market for corporate shares to provide a simple geometric framework for analyzing the role of taxes and share purchases restrictions on firm dividend policy. Drawing on Miller (1988) and Masulis and Trueman (1988) we provide an explanation for the payment of dividends to fully taxable consumers. Firms use intercorporate equity to pay tax preferred capital gains to consumers when there are share repurchase restrictions. However, in the U.S. there is double corporate tax on inter-corporate equity which makes the payment of dividends attractive to high tax consumers. Under this explanation firms are are prepared to pay dividends and make new share issues simultaneously, a practice not explained by previous tax-based explanations. Our analysis also provides a natural role for financial intermediaries by explicitly allowing for inter-corporate equity.

\section{Jones, David S.}

PD June 1992. TI An Analysis of the Implementation of Prompt Corrective Action. AU Jones. David S.: King. Kathleen Kuester. AA Board of Governors of the Federal Reserve System. SR Board of Governors of the Federal Reserve System Finance and Economics Discussion Series:
204: Steven A. Sharpe, Mail Stop 89. Federal Reserve Board, Wash., DC 20551. PG not available. PR no charge. JE G28. KW Prompt Corrective Action. Bank Insolvency. Bank Failure.

AB Among the major provisions of the Federal Deposit Insurance Corporation Improvement Act of 1991 (FDICIA) is the requirement that the federal banking agencies implement. by year-end 1992, a capital-based policy of prompt corrective action (PCA). Under this framework each depository institution (DI) must be placed in one of five regulatory zones based on its capital position:(1) well capitalized, (2) adequately capitalized. (3) undercapitalized, (4) significantly undercapitalized, or (5) critically undercapitalized. For each of the three categories of undercapitalized DIs, FDICIA specifies corrective actions that must be undertaken and a menu of discretionary actions. This paper evaluates alternative capital-driven assignment rules based on their ability to target for corrective actions commercial banks that we have identified as exhibiting a high risk of becoming insolvent between January 1984 and June 1989.

Jones, Derek C.

TI The Determinants of Investment in Employee Owned Firms: Evidence from France. AU Estrin. Saul: Jones. Derek C.

Joulfaian, David

TI The Carnegie Conjecture: Some Empirical Evidence.

AU Hoitz-Eakin, Douglas; Joulfaian, David: Rosen, Harvey S.

\section{Jovanovic, Boyan}

TI Asymmetric Information and the Excess Volatility of Stock Prices. AU Eden, Benjamin; Jovanovic, Boyan.

\section{Jun, Joosung}

TI Taxes and the Form of Ownership of Foreign Corporate Equity. AU Gordon, Roger H.; Jun, Joosung.

\section{Kahn, Lawrence $M$.}

TI Race and Gender Pay Differentials. AU Blau. Francine D.: Kahn, Lawrence $M$.

Kaitala, V.

PD August 1992. TI The Acid Rain Game as a Resource Allocation Process with an Application to the Cooperation Among Finland, Russia, and Estonia. AU Kaitala. V.: Maler. K.- G.; Tulkens. H. AA Kaitala: The BEIJER International Institute of Ecological Economics and Helsinki University of Technology. Maler: The BEIER International Institute of Ecological Economics. Tulkens: Universite Catholique de Louvain. SR Universite Catholique de Louvain CORE Discussion Paper: 9242; Universite Catholique de Louvain. Voie du Roman Pays. 34, B-1348 Louvain-la-Neuve, BELGIUM. PG 14. PR not available. JE Q25, Q28, F42. KW Pollution. Incomplete Information.

AB We consider optimal cooperation in transboundary air pollution abatement among several countries under incomplete information. The countries negotiate on establishing a gradual cooperative emission reduction program to reduce the damages caused by sulphur depositions. A particular difficulty arising here is how the partners can guarantee that the costs and benefits from cooperation will be shared in such a way that 
none of them will be tempted to breach the agreement. To overcome this problem. use is made here of a cost sharing scheme that guarantees that individual costs of all parties are nonincreasing along the cooperative solution, and that no party or group of parties has an interest in proposing another abatement policy. This paper demonstrates the applicability and ease of computation of the method in a three-country acid rain negotiation problem among Finland. Russia, and Estonia.

\section{Kalai, Ehud}

PD September 1992. TI Bayesian Forecasting. AU Kalai. Ehud; Lehrer, Ehud. AA Northwestern University. SR Northwestern University Center for Mathematical Studies in Economics and Management Science Discussion Paper: 998; J.L. Kellogg Graduate School of Management, Northwestern University, 2001 Sheridan Road, 3-014 Leverone Hall Evanston, Il 60208. PG 13. PR per copy: $\$ 3.00$ in the U.S.A. or Canada. $\$ 5.00$ via international mail. Make check payable to Northwestern University. JE C11, C13, C70. KW Bayesian Forecasting.

$A B$ Let $\mathrm{X}=(\mathrm{X} 1, \mathrm{X} 2 \ldots)$ be a sequence of random variables distributed according to an unknown distribution. The paper provides a condition under which a conditional hypothetical distribution approaches the real one and thus making the Bayesian forecasting asymptotically accurate.

\section{Kandel, Shmuel}

TI On the Incentives for Money Managers: A Signalling Approach. AU Huberman, Gur; Kandel, Shmuel.

\section{Kandori, Michihiro}

PD July 1992. TI Evolution of Equilibria in the Long Run: A General Theory and Applications. AU Kandori, Michihiro: Rob. Rafael. AA Kandori: Princeton University. Rob: University of Pennsylvania. SR University of Pennsylvania Center for Analytic Research in Economics and Social Science (CARESS) Working Paper: 92-06R; University of Pennsylvania. Center for Analytic Research in Economics and the Social Sciences. McNeil Building, 3718 Locust Walk, Philadelphia, PA 19104-6297. PG 36. PR no charge. JE D83. C71. KW Learning. Experimentation. Coordination Games.

AB We study an adaptive process of leaming in the context of societal games played by randomly matched players. Our construction extends the analysis of Kandori, Mailath and Rob (1991) to general nxn games. The basic assumptions we employ are: (1) Players adjust their behavior from time to time, picking a best-response against the present strategy configuration played by others. (2) Players mutate or experiment with strategies which need not be best-responses. Experimentation also occurs from time to time, but much less frequently than the best-response adjustment. In this situation, we show that a unique behavior pattern emerges in the long run, even when the underlying game possesses multiple Nash equilibria. In general. the stable pattern, or the long run equilibrium, may or may not correspond to a Nashequilibrium. We first provide a general algorithm to determine the long run equilibrium, and then we apply to algorithm to pure coordination games and to games with strategic complementarities.

\section{Kane, Edward J.}

TI Office Market Values During the Past Decade: How Distorted Have Appraisals Been? AU Hendershott, Patric H.;
Kane. Edward J.

\section{Kao, Duen Li}

TI Corporate Bond Rating Drift: An Examination of Rating Agency Credit Quality Changes Over Time. AU Alman, Edward I.; Kao, Duen Li.

\section{Kaoru, Yoshiaki}

PD October 1990. TI "Black Mayonnaise" and Marine Recreation: Methodological Issues in Valuing A Cleanup. AU Kaoru, Yoshiaki; Smith, V. Kerry. AA Kaoru: Woods Hole Oceanographic Institution. Smith: North Carolina State University and Resources for the Future. SR Resources for the Future Quality of the Environment Division Discussion Paper: QE91-02: Quality of the Environment Division, Resources for the Future, 1616 P Street. NW. Washington, D.C. 20036. PG 46. PR \$2.25 prepaid, U.S. funds. JE Q25. KW Random Utility Model. Marine Recreation. Pollution Control.

AB There has been substantial increase in the use of random utility models (RUM) to estimate the values people would place on reducing marine pollution. This paper identifies and evaluates the importance of four methodological issues that arise in using the RUM framework for estimating the effects of estuarine quality on the choice of recreation sites and the benefits from reducing pollution. The issues include: (a) specifying the the set of alternatives to be indicated in the choice set; (b) evaluating how the definition of what constitutes an elemental alternative affects the plausibility of the independence of irrelevant alternatives: (c) examining the effects of the definition of alternatives for benefit measures: and (d) evaluating the implications of multiple pollutants for describing the factors influencing people's recreation site choices.

\section{Karimov, I''dar}

TI Black-Market For Currency, Hoarding Activity and Policy Reform. AU Goldberg, Linda S.; Karimov, Il'dar.

TI Black Markets for Currency, Hoarding Activity and Policy Reforms. AU Goldberg. Linda S.; Karimov, Il'dar.

Kats, A.

TI Probabilistic Voting and Platform Selection in MultiParty Elections. AU Anderson. S. P.: Kats, A.: Thisse. J. - F.

\section{Kehoe, $\mathbf{P}$.}

TI International Real Business Cycles. AU Backus, D.; Kehoe, P.; Kydland, F.

TI International Evidence on the Historical Properties of Business Cycles. AU Backus, D.; Kehoe, P.

TI In Search of Scale Effects in Trade and Growth. AU Backus, D.; Kehoe, P.; Kehoe, T.

\section{Kehoe, T.}

TI In Search of Scale Effects in Trade and Growth. AU Backus, D.; Kehoe, P.; Kehoe, T.

\section{Kende, Michael}

PD October 1991. TI Strategic Standardization in Trade with Network Externalities. AA INSEAD. SR INSEAD Working Papers: 92/50/EP; INSEAD, Boulevard de Constance. 
Fontainebleau, 77305 Cedex, FRANCE. PG 32. PR not available. JE O32, L21. KW Licensing. Compatible Goods.

AB This paper shows the effects on profits and consumer surplus of standardizing a good from which consumers derive greater utility the more consumers there are of a compatible good. The model is of a two-period. two-country world in which there is at most one firm developing the good in each country. In this framework one of the firms licensing its technology to other firms in the same country is a credible commitment to increase the output and thus the network of the licensed good. If the network externalities are large enough, licensing can increase the profit of the licensor even if there is no foreign competitor producing a similar good. If there is a foreign competitor, licensing increases profits of the licensor at the expense of the rival firm regardless of the level of network externalities. Licensing in this framework is a strategic trade policy. In all cases licensing. by increasing the size of the network of compatible goods, increases both domestic and foreign consumer surplus.

PD July 1992. TI Profitability Under an Open Versus a Closed System. AA INSEAD. SR INSEAD Working Papers: 92/49/EP; INSEAD, Boulevard de Constance, Fontainebleau, 77305 Cedex, FRANCE. PG 28. PR not available. JE L63, L23, L11. KW Computer System. Peripherals.

AB This paper explores the conditions under which the profits of a system developer are greater or less under a closed system versus an open system. In this context a closed system is defined to be one in which a system manufacturer produces and sells both the main component and peripherals, and an open system is one in which the system manufacturer sells only the main component and allows free competition in the production of peripherals. A closed system allows the producer to price discriminate by using the peripherals as a tied good. A manufacturer who opens its system loses profits on the peripherals, but is compensated by increased profits on sales of the main component due to the greater competition in peripherals. The results show that an open system is likely to be more profitable: the more elastic demand is for the system; the more differentiated are the peripherals; and the greater is the share of the main component in the total system budget of the consumer. The results are illustrated using examples of different IBM computer systems.

\section{Keser, Claudia}

PD 1991. TI International Duopoly Experiments and Simulations. AA University of Bonn. SR Universitat Bonn Sonderforschungsbereich 303- Discussion Paper: B197; Sonderforschungsbereich 303 an der Universitat Bonn Adenauerallee 24-42, D-5300 Bonn 1, GERMANY. PG 87. PR no charge. JE D43. C70. D23. KW Game Theory. Duopoly Game. Theory of Behavior. Experimental Research.

AB This paper presents the results of International Duopoly Experiments and Simulations (IDEAS), an experimental research project. These experiments study a duopoly game with demand inertia. The game is one of a multistage duopoly where the decision variables are prices in each period. Sales depend on current prices and also on past sales (demand inertia). Participants in these experiments, academic economists. developed a strategy for both a low cost and a high cost situation of the game. In a computer simulation, each participant's strategies interacted with all other participants' strategies for the respective opposite cost situation. The participants had been informed that the criterion for ranking performance of strategies was profit on average over all plays and that the rankings would be published.

PD 1992. TI Learning to Cooperate in Experiments on Multistage Price-Setting Duopolies with Symmetric Costs. AA University of Bonn. SR Universitat Bonn Sonderforschungsbereich 303 - Discussion Paper: B-220; Sonderforschungsbereich 303 an der Universitat Bonn. Adenauerallee 24-42, D-5300 Bonn 1, DEUTSCHLAND. PG 21. PR no charge. JE C92, C71. KW Dynamic Duopoly Game. Cooperation.

AB This article reports the results of experiments where subjects played twice a symmetric dynamic duopoly game. In this game two firms, facing the same unit cost of production. offer a homogeneous product during twenty-five periods. Prices in each period are the only decision variables. The dynamic relationship arises because sales depend not only on current prices but also on past sales. According to game-theory, this multiperiod duopoly game has a unique subgame perfect equilibrium solution. However, we shall see that actual individual price-setting behavior of subjects in the multiperiod duopoly situation is different from what is prescribed by the subgame perfect equilibrium solution. We find that in each period the average prices over all markets are above the subgame perfect equilibrium prices. Nevertheless, the average realized long-run profit is not significantly different from the profit which would be gained in the subgame perfect equilibrium solution.

\section{Kets De Vries, Manfred F. R.}

PD 1992. TI Managing Under Deadly Conditions. AU Kets De Vries, Manfred F. R.; El Hajj. Marina. AA INSEAD. SR INSEAD Working Papers: 92/43/OB; INSEAD, Boulevard de Constance, Fontainebleau. 77305 Cedex, FRANCE. PG 21. PR not available. JE M10, I19. KW Health. Managers. Psychiatry.

AB This exploratory study looks at the behavior of a number of CEOs (mostly owner-managers) who kept their companies running during a situation of great stress. Interviews were conducted with thirteen Lebanese CEOs in order to investigate what kind of impact the Lebanese war had on their behavior and emotional well-being. At the time of the interview, major PTSD symptoms were lacking and the subjects had no other noticeable psychiatric illnesses. Postulations are made about a number of personal and social factors that could explain such an outcome.

\section{King, Kathleen Kuester}

TI An Analysis of the Implementation of Prompt Corrective Action. AU Jones, David S.; King, Kathleen Kuester.

\section{King, Robert}

PD September 1992. TI Testing Long Run Neutrality. AU King, Robert: Watson, Mark W. AA King: University of Rochester and National Bureau of Economic Research. Watson: Northwestern University. Chicago Federal Reserve Bank, and National Bureau of Economic Research. SR National Bureau of Economic Research Working Paper: 4156; National Bureau of Economic Research. 1050 Massachusetts Avenue, Cambridge, MA 02138. PG 19. PR \$3.00. JE E10, C32. KW Lucas Critique. VAR Model. 
AB Propositions about long run neutrality are at the heart of most macroeconomic models. Yet. since the 1970's when Lucas and Sargent presented powerful critiques of traditional neutrality tests, empirical researchers have made little progress on testing these propositions. In this paper we show that, in spite of the Lucas-Sargent critique. long run neutrality can be lested without specifying a complete model of economic activity. This is possible when the variables are integrated. In this case. permanent shifts in the historical data can be uncovered using VAR methods, and neutrality can be tested when there is a priori knowledge of one of the structural impact multipliers or one of the structural long run multipliers. We use this framework to test four long run neutrality propositions: (i) the neutrality of money, (ii) the superneutrality of money. (iii) a vertical long run Phillips curve, and (iv) the Fisher effect.

\section{Kitson, Michael}

TI Quarterly National Income Accounts for Interwar Germany. 1925-1938. AU Ellam. Michael; Kitson. Michael: Solomou, S; Weale, $M$.

PD January 1992. TI The Move to Autarky: The Political Economy of Nazi Trade Policy. AA University of Cambridge. SR University of Cambridge Department of Applied'Economics Working Paper: 9201; Department of Applied Economics. University of Cambridge, Sidgwick Avenue, Cambridge CB3 9DE, UNITED KINGDOM. PG 15. PR $\$ 5.00$ (L2.50), checks payable to University of Cambridge. JE F13. N14, N44. KW Interwar Germany. Isolationism.

AB This paper evaluates the strategic objectives of Nazi trade policy. The finding show that during the 1930's Germany was able to isolate itself from the world economy, reduce its dependence on imported goods and reorientate the remainder of its trade towards weaker adjacent countries. The successful move to autarky helped Germany's preparation for war and subsequent military expansionism.

\section{Knetter, Michael M.}

TI Markup Adjustment and Exchange Rate Fluctuations: Evidence From Panel Data on Automobile Exports. AU Gagnon. Joseph E.; Knetter, Michael M.

PD August 1992. Tl Exchange Rates and Corporate Pricing Strategies. AA Dartmouth College and National Bureau of Economic Research. SR National Bureau of Economic Research Working Paper: 4151; National Bureau of Economic Research, 1050 Massachusetts Avenue. Cambridge, MA 02138. PG not available. PR \$5.00. JE L11, L21, F13. KW Pricing. Exporting.

AB This paper reviews the recent literature on pass-through and pricing-to-market. Pricing-to-market behavior is estimated for a new, larger data set with 60 German and 20 U.S. 7-digit industries. The results conform closely to what has been found elsewhere in smaller detailed data sets and at higher levels of aggregation. German exporters show more tendency to price-to market than U.S. exporters for the sample of industries studied, but there is much variation across the industries. Surprisingly. pricing-to-market is more pronounced in German exports of steel and chemicals than in consumer goods.

\section{Koehler, Anne}

PD July 1992. TI Rationalization of Exponential Smoothing in Terms of a Statistical Framework with
Multiplicative Disturbances. AU Koehler, Anne; Ord, Keith: Snyder, Ralph D. AA Koehler: Miami University. Ord: Penn State University. Snyder: Monash University. SR Monash Department of Econometrics Research Working Paper: 7/92; Department of Econometrics. Monash University. Clayton. Victoria 3168, AUSTRALIA. PG 8. PR no charge. JE C52, C32. KW Time Series Analysis. Forecasting.

AB It is established in this paper that exponential smoothing. in its most general linear form. is an optimal method of forecasting in large samples for time series with an irregular component, the size of which depends on a local mean. As such it is demonstrated that exponential smoothing has a statistical basis that extends beyond the framework of Box and Jenkins.

Kokko, Ari

TI Host Country Competition and Technology Transfer by Multinationals. AU Blomstrom, Magnus; Zejan, Mario; Kokko, Ari.

\section{Kollman, Ken}

TI Political Parties and Electoral Landscapes. AU Page. Scott E.; Kollman, Ken; Miller, John H.

\section{Koopman, Siem Jan}

PD May 1992. TI Exact Score for Time Series Models in State Space Form. AU Koopman. Siem Jan: Shephard, Neil. AA Koopman: Nuffield College. Shephard: London School of Economics. SR London School of Economics SuntoryToyota International Centre for Economics and Related Disciplines Working Paper: EM/92/241; London School of Economics, Houghton Street, London WC2A 2AE, ENGLAND. PG 20. PR no charge. JE C32. KW Smoothing. Kalman Filter. Unobserved Components Model.

AB The score vector for a time series model which fits into the Gaussian state space form can be approximated by numerically differentiating the log-likelihood. If the parameter vector is of length $p$. this involves the running of p+1 Kalman filters. This paper shows the score vector can be computed in a single pass of the Kalman filter and a smoother. For many classes of models this dramatically increases the speed and reliability of algorithms for the numerical maximization of likelihood.

\section{Kopp, Raymond J.}

TI Who Bears the Burden of Energy Taxes? AU DeWitt. Diane E; Dowlatabadi, Hadi; Kopp, Raymond J.

PD August 1991. TI The Proper Role of Existence Value in Public Decision Making. AA Resources for the Future. SR Resources for the Future Quality of the Environment Division Discussion Paper: QE91-17; Quality of the Environment, 1616 P Street, NW, Washington, D.C. 20036. U.S.A. PG 17. PR \$2.25 prepaid, U.S. funds. JE D62, A13, H43. KW Existence Value. Natural Resource Damage. Contingent Valuation.

AB Rosenthal and Nelson (1991) argue that existence value (nonuse value) has little or no role in public decision making. In particular, they argue that economists should not include existence value in benefit-cost analyses or natural resource damage awards because these values are ill-defined and difficult to measure. They suggest that if existence values are included in these public decisions. "The subjective element in economics 
will become much greater and the power of economic analysis to discriminate between more and less efficient states of the world will be eroded." The purpose of this note is to argue the opposite. Existence value is a well-defined economic concept and nothing more complicated than the value one places on a particularly pure public good. Moreover, this note argues that it is the failure to include existence value in public decision making that reduces our ability as economists to discriminate between more and less efficient states of the world.

\section{Kornhauser, Lewis A.}

PD July 1992. TI Multi-Defendant Settlements: The Impact of Joint and Several Liability. AU Kornhauser, Lewis A.; Revesz, Richard L. AA New York University. SR New York University Economic Research Reports: $92-$ 37: New York University. Faculty of Arts and Science, Department of Economics, Washington Square. New York. N.Y. 10003. PG 57. PR no charge. JE K41, C78, K32. KW Bargaining. Hazardous Waste.

AB This article offers a simple model of settlement between a single plaintiff and multiple defendants. In the model, a plaintiff makes take-it-or-leave-it offers to two defendants. Each defendant then decides independently whether to accept the offer or to litigate. These two defendants face a rule of joint and several liability with contribution (proportional to their size). In the event one defendant settles, the non-settling defendant loses its right to contribution, but its liability is set off by the amount of the settlement. The paper analyzes the settlement game involving the defendants as well as the plaintiff's optimal strategy for the full range of transaction costs and of correlation of the plaintiffs probability of success against the defendants. It shows that, for broad sets of circumstances, joint and several liability discourages settlements.

Korostelev, A. P.

PD not available. TI Minimax Linewise Algorithm for Image Reconstruction. AU Korostelev, A. P.; Tsybakov, A. B. AA Universite Catholique de Louvain. SR Universite Catholique de Louvain CORE Discussion Paper: 9249; Universite Catholique de Louvain, Voie du Roman Pays, 34 , B-1348 Louvain-la-Neuve, BELGIUM. PG 18. PR not available. JE C13. KW Image Analysis.

AB We study the problem of estimating the edges in noisy images by linewise procedures. We show that the straightforward estimation method (naive linewise procedure) does not attain the asymptotically minimax rate of accuracy as the number of observations tends to infinity. We propose the modified linewise procedure which has the asymptotically minimax rate.

\section{Kramarz, Francis}

T1 A Test of Negotiation and Incentive Compensation Models Using Longitudinal French Enterprise Data AU Abowd, John M.; Kramarz, Francis.

\section{Krelle, Wilhelm}

PD September 1992. TI A Problem of the Transition from a Planned to a Market Economy: Should Firms be Subsidized in Order to Avoid their Bankruptcy? AA University of Bonn. SR Universitat Bonn Sonderforschungsbereich 303 . Discussion Paper: B-222; Sonderforschungsbereich 303 an der Universitat Bonn, Adenauerallee 24-42, D-5300 Bonn 1. DEUTSCHLAND. PG 18. PR no charge. JE P26,
P16, H21. KW Subsidies. Transition Economies.

AB It will be shown that in the process of transition from a planned to a market economy subsidies for firms which otherwise would go bankrupt may be socially optimal if they remain below a certain level.

\section{Kreps, David M.}

TI Learning Mixed Equilibria. AU Fudenberg. Drew; Kreps, David M.

\section{Kretzmer, Peter E.}

PD September 1992. TI How Important are Monetary and Fiscal Policy in Explaining Postwar Aggregate U.S. Data? A Vector Autoregressive Approach. AA Federal Reserve Bank of Kansas City. SR Federal Reserve Bank of Kansas City Research Working Paper: 92-03: Research Division. Federal Reserve Bank of Kansas City, 925 Grand Ave., Kansas City, MO 64198. PG 21. PR no charge. JE C32, E63. H30. KW Data Filtering. Vector Autoregression.

AB This paper reexamines the role of monetary and fiscal policy in explaining postwar U.S. output. A vector autoregression approach is utilized. I conclude that at least twenty percent of output variability is attributable to monetary and fiscal policy. The monetary contribution is substantially larger than that estimated by some previous researchers. In reaching different conclusions than previous authors, the role that prefiltering of the data can play in statistical inference is highlighted. I argue that the obvious nonstationarity of base velocity over the sample period must be considered when making the filtering decision for money, output, interest rates and prices.

\section{Krishnan, Jayanthi}

TI Wealth Mobility in America: A View from the National Longitudinal Survey. AU Steckel, Richard H.; Krishnan, Jayanthi.

\section{Krishnan, Murugappa}

TI Preemptive Investment with Resalable Capacity. AU Roller, Lars-Hendrik; Krishnan. Murugappa.

\section{Krueger, Alan B.}

TI Estimates of the Economic Return to Schooling from a New Sample of Twins. AU Ashenfelter, Orley; Krueger, Alan B.

PD August 1992. TI A Comparative Analysis of East and West German Labor Markets Before and After Unification. AU Krueger, Alan B.; Pischke, Jorn-Steffen. AA Krueger: Princeton University. Pischke: ZEW. Germany. SR National Bureau of Economic Research Working Paper: 4154; National Bureau of Economic Research, 1050 Massachusetts Avenue, Cambridge, MA 02138. PG not available. PR \$5.00. JE J31. J24, N30. KW German Unification. Wage Structure. Labor Markets.

AB In 1988, the wage distribution in East Germany was much more compressed than in West Germany or the U.S. Since the collapse of Communism and unification with West Germany, however, the wage structure in eastern Germany has changed considerably. In particular, wage variation has increased, the payoff to education has decreased somewhat, industry differentials have expanded, and the white collar premium has increased. Although average wage growth has 
been remarkably high in eastern Germany, individual variation in wage growth is similar to typical western levels. The wage structure of former East Germans who work in western Germany resembles the wage structure of native West Germans in some respects, but their experience-earnings profile is flat.

Krupnick, Alan J.

PD September 1990. TI The Cost-Effectiveness and Energy Security Benefits of Methanol Vehicles. AU Krupnick. Alan J.; Walls, Margaret A.; Toman, Michael A. AA Resources for the Future. SR Resources for the Future Quality of the Environment Division Discussion Paper: QE90-25; Quality of the Environment Division, Resources for the Future, 1616 P Street. NW, Washington, D.C. 20036. PG 250. PR $\$ 2.25$ prepaid, U.S. funds. JE Q28, Q42. KW Methanol. Cost-Effectiveness. Energy Security. Emissions.

AB This study involves assessing the likely emissions from methanol vehicles in the years 2000 and 2010 and comparing them with expected emissions from gasoline vehicles in the same years. Impacts on ambient ozone levels in some U.S. cities are also examined. In addition, the study projects the cost of methanol in 2000 and 2010 and compares them to gasoline price forecasts. The emissions and ozone results are then combined with the cost information to assess the costeffectiveness of methanol for reducing VOC's and urban ozone in 2000 and 2010.

TI Electric Vehicles and the Environment: Consequences for Emissions and Air Quality in Los Angeles and U.S. Regions. AU Dowlatabadi, Hadi; Krupnick, Alan J.; Russell. Armistead.

PD January 1991. TI Transportation and Air Pollution in Urban Areas of Developed and Developing Countries. AA Resources for the Future. SR Resources for the Future Quality of the Environment Division Discussion Paper: QE9108; Quality of the Environment Division. Resources for the Future. 1616 P Street. NW. Washington. D.C. 20036. PG 41. PR \$2.25 prepaid, U.S. funds. JE O18, Q25. KW Urban Air Pollution. Transportation. Development.

AB Focusing only on the urban air quality issues in developed and developing countries, this paper examines the role now played by vehicles in urban quality.-their share of various types of emissions and the benefits (in physical and dollar terms) of emissions control--to help identify the most important pollutants and vehicle types to regulate. Then, from an efficiency perspective, a variety of policies are addressed that span the strategies for controlling vehicle emissions: alternate fuels and vehicles, targeting high polluting vehicles. transportation controls, and broader economic incentives, such as emissions fees. The paper recommends against tightening vehicle emissions standards in developed countries, a costly and. to judge by the continuing problems with carbon monoxide and ambient ozone, ineffective policy. Rather. efforts to target high emitting vehicles and to impose fees on fuels, vehicles, or emissions may prove more cost effective. For developing countries, the removal of lead from motor fuels and imposition of economic incentive approaches to transportation controls are identified as potentially costeffective strategies.

PD July 1991. TI Vehicle Emissions, Urban Air Quality, and Clean Air Policy. AA Resources for the Future. SR Resources for the Future Quality of the Environment
Division Discussion Paper: QE91-15; Quality of the Environment Division. Resources for the Future, 1616 P Street. NW. Washington, D.C. 20036. PG 43. PR \$2.25 prepaid. U.S. funds. JE Q25, R48. KW Vehicle Emissions. CostEffectiveness. Clean Air Act.

AB If U.S. cities are to meet National Ambient Air Quality Standards, major reductions in vehicular emissions will be necessary. This paper considers the contribution of vehicular emissions to total emissions and then offers a variety of hypotheses for why the impressive reductions in emissions have not resulted in attainment of ozone standards. Based on this discussion, alternative policies for reducing emissions and meeting ozone standards are considered, paying particular attention to their cost-effectiveness. Reformulated gasoline, targeting high emitters, and policies utilizing high-tech monitoring of vehicle emissions and the location and timing of driving (such as congestion tolls) appear most promising. Initiatives in the Clean Air Act Amendments to further tighten auto emissions standards and to promote alternate fueled vehicles are of questionable cost-effectiveness.

\section{Kuehlwein, Michael}

PD April 1992. TI Planned and Unplanned Transfers Among the Elderly. AA Pomona College. SR Hoover Institute Working Papers in Economics: E-92-8: Domestic Studies Program Working Paper Series, Hoover Institution. Stanford University, Stanford, CA 94305. PG 43. PR not available. JE E21. KW Gifts. Bequests. Transfer Taxes. Life Cycle. Theory of Saving.

AB Before 1976. gift taxes were much lower than estate taxes. Despite that, the affluent transferred most of their wealth to their heirs through bequests not gifts. I model the giftbequest choice for altruistic affluent individuals and find that all planned transfers occur as early as gifts. Planned bequests are zero and bequests occur only because wealthy individuals die early, before they are able to exhaust their wealth. Data from the Longitudinal Retirement History Survey indicate the wealthy do significantly dissave late in life. Analysis of the current, post-1976, transfer tax system suggest most affluent elderly transfers remain unplanned.

PD June 1992. TI Disaggregate Evidence on the Substitutability Between Public and Private Spending. AA Pomona College. SR Hoover Institute Working Papers in Economics: E92-16; Domestic Studies Program Working Paper Series, Hoover Institution, Stanford University, Stanford, CA 94305. PG 31. PR not available. JE E21. KW Consumption. Permanent Income Hypothesis. Substitutability. Fiscal Policy.

AB Several recent studies have suggested that government spending belongs in consumer's utility functions and that increases in such spending can significantly reduce private consumption expenditures. Virtually all such studies have relied on aggregate data. This paper attempts to shed light on the issue by examining aggregate spending data broken down into different functional categories (e.g. health care). The premise is that if public spending substitutes for private spending at the aggregate level, this should be most apparent among similar components of public and private spending. Employing a variety of specifications and datasets, I find no evidence of what is known as ex-ante crowding out. Predictable changes in government spending do not seem to elicit significant and offsetting changes in consumer spending, even among those components most likely to as substitutes. In fact. 
the estimated direction of these effects is consistently counter to that suggested by theory, indicating the possibility of some complementarity between public and private expenditures. Furthermore. I show that this failure to detect significant substitutability at the disaggregate level is consistent with results obtained with aggregate data.

\section{Kumar, Dharma}

PD May 1992. TI The Chinese and Indian Economies from ca 1914-1949. AA London School of Economics. SR London School of Economics Suntory-Toyota International Centre for Economics and Related Disciplines Working Paper: CP22; London School of Economics, Houghton Street, London WC2A 2AE, ENGLAND. PG 34. PR no charge. JE O47. O57. P24. KW China. India. National Income. Economic History.

AB This paper compares overall and sectoral trends in national income in India and China ca 1914 to 1949. Thomas Rawski has recently published a reworking of estimates for China, arguing that the older estimates by Yeh and Pakims underestimated the growth of income, and in particular agricultural output, due to the beneficial effects of market expansion. The data for India, which is much richer, shows a rate of growth of per capita income similar to the earlier estimates for China, and casts doubt on Rawski's arguments. But even the similarity is striking since China suffered far more political and physical calamities in this period than India. Finally, problems relating to agricultural yields, and handlooms are raised.

\section{Kuncoro, Ari}

TI Industrial Development in Cities. AU Henderson, Vernon; Kuncoro, Ari; Turner, Matt.

\section{Kuon, Bettina}

TI Demand Commitment Bargaining in Three-Person Quota Game Experiments. AU Selten, Reinhard; Kuon, Bettina.

\section{Kupiec, Paul}

PD October 1992. TI On the Ramifications of a Securities Transaction Tax for the Function and Efficiency of Capital Markets. AA Board of Governors of the Federal Reserve System. SR Board of Governors of the Federal Reserve System Finance and Economics Discussion Series: 212: C/O Stephen A. Sharpe. Mail Stop 89. Federal Reserve Board, Washington, DC 20551. PG 25. PR no charge. JE H24,G19. KW Financial Markets. Taxation.

AB This paper attempts to provide a more complete view of the potential effects of the adoption of a securities transactions tax on equity and equity derivative instruments. It adopts Tobin's (1984) taxonomy of financial market efficiency and considers the transactions tax's effects on information efficiency, fundamental valuation efficiency, insurance efficiency, and functional efficiency. Viewed from these perspectives, it concludes that it is unlikely that a securities transactions tax would enhance the efficiencies of the various functions of financial markets.

Kydland, F.

TI International Real Business Cycles. AU Backus, D.; Kehoe, P.; Kydland, F.

\section{Lagunoff, Roger D.}

PD September 1992. TI Sufficiently Specialized Economies Have Nonempty Cores. AA University of Pennsylvania. SR University of Pennsylvania Center for Analytic Research in Economics and Social Science (CARESS) Working Paper: 92-25; University of Pennsylvania, Center for Analytic Research in Economics and the Social Sciences. McNeil Building. 3718 Locust Walk, Philadelphia, PA 191046297. PG 19. PR no charge. JE D51. KW Specialization. Curvature Condition.

AB An economy with a nonempty core may plausibly be regarded as socially stable since there exists allocations against which no group in the economy wishes to "recontract out". Aside from classical economies, it is not generally known what are the primitives of an economy that give rise to a nonempty core. This paper provides two conditions of interest which are defined directly on the economic primitives. Together, they imply the existence of a nonempty core. The first is a notion of specialization - individuals hold goods and essential inputs to productive processes that are not readily available elsewhere in the economy. The second is a curvature condition. Each agent's preferences must display sufficient curvature so that another person's specialized holdings are valued by that agent. It is shown that for any economy of a general class if the economy is sufficiently specialized, and the curvature condition is satisfied, then the corresponding NTU game is balanced. Hence, the economy has a nonempty core.

TI Inequality and Social Stability of Economies with Collective Property Rights. AU Glomm, Gerhard; Lagunoff, Roger D.

\section{Lam, Pok-sang}

TI Testing Volatility Restrictions on Intertemporal Marginal Rates of Substitution Implied by Euler Equations and Asset Returns. AU Cecchetti, Stephen G.; Lam, Pok-sang; Mark, Nelson C.

\section{Lambelet, Jean-Christian}

PD March 1991. TI Business vs. Government or Why the Poor Sometimes Gang up on the Rich and Sometimes Don't. AA Universite de Lausanne and Graduate Institute. Geneva. SR Universite de Lausanne, Cahiers de Recherches economiques: 9104; Departement d'econometrie et d'economie politique. Universite de Lausanne. BFSH - Dorigny, CH-1015 Lausanne, SWTTZERLAND. PG 12. PR no charge. JE L11. L51, L70, L85, K11. D31. KW Income Distribution. Rental Market. Real Estate.

AB A lot of work has been done about the intersection of economics and politics, and I would be quite unable to add anything of interest to the general and profound analyses of such eminent minds as, for example, James Buchanan or Robert Nozick. So, rather than summarizing or parroting their work or that of others, consider a narrower. more specific and more practical issue, namely the relationship between housing and all that goes with it, on the economic side; and the entire legal and administrative apparatus which, on the political side, makes it its business to supervise, influence and shape the housing market. Swiss illustrations and examples are used.

PD April 1991. TI Pourquoi le Marche de L'Immobilier est-il Pareillement Politise? AA Universite de Lausanne and Graduate Institute, Geneva. SR Universite de Lausanne, Cahiers de Recherches economiques: 9105 : Departement 
d'econometrie et d'economie politique, Universite de Lausanne. BFSH - Dorigny, CH-1015 Lausanne. SWITZERLAND. PG 15. PR no charge. JE L11.L51, L70, L85, K11, D31. KW

AB No abstract available. This paper is written in French.

PD July 1991. TI Do Arms Races Lead to Peace? AA Universite de Lausanne and Graduate Institute. Geneva. SR Universite de Lausanne. Cahiers de Recherches economiques: 9108; Departement d'econometrie et d'economie politique. Universite de Lausanne, BFSH - Dorigny, CH-1015 Lausanne. SWTTZERLAND. PG 12. PR no charge. JE D74, H56, F01. KW Arms Races. Security. War and Peace.

AB From the standpoint of arms race analysis the end of the cold war would appear to be readily explainable in terms of the extended Richardsonian model which dominates the field. This paper offers counterarguments to this explanation of an end to the cold war which emphasizes economic factors.

PD October 1991. TI La Politique Monetaire Suisee en Perspective. AA Universite de Lausanne and Graduate Institute, Geneva. SR Universite de Lausanne, Cahiers de Recherches economiques: 9111: Departement d'econometrie et d'oconomie politique. Universite de Lausanne. BFSH Dorigny, CH-1015 Lausanne, SWITZERLAND. PG 15. PR no charge. JE E50, E58, E52, N20, N14. KW Monetary Policy. Monetarism.

AB No abstract available. This paper is written in French.

\section{Landesmann, Michael A.}

PD May 1992. TI Industrial Restructuring in Eastern Europe and East-West Trade Integration. AA University of Cambridge. SR University of Cambridge Department of Applied Economics Working Paper: 9213; Department of Applied Economics, University of Cambridge, Sidgwick Avenue, Cambridge CB3 9DE, UNITED KINGDOM. PG 29. PR $\$ 5.00$ (L2.50), checks payable to University of Cambridge. JE F15, F17, P33. P52. KW Export Growth. Specialization.

AB This paper first compares industrial structures and past experiences of structural change across East (EE) and West European (WE) economies. These show considerable diversity between EE economies in the degree to which their composition of industry differs from that of WE economies and in the way they experienced structural change in the past. The second part of the paper maps out a scenario of East-West European trade integration, assuming that export performances (and hence market shares) of EE economies converge to those of other WE economies; however, current "quality gaps" and inherited patterns of industrial production still leave a mark. The analysis shows that short-run export growth patterns may deviate significantly from longer-term specialization.

\section{Lang, Gunther}

PD December 1991. TI Fair Intergenerational Redistribution Policy. AA University of Bonn. SR Universitat Bonn Sonderforschungsbereich 303Discussion Paper: A-360; Sonderforschungsbereich 303 an der Universitat Bonn Adenauerallee 24-42, D-5300 Bonn 1. GERMANY. PG 12. PR no charge. JE D63, D51. KW Overlapping Generations Model. Fair Allocation. Optimal Economic Growth.

AB This paper introduces the concept of fairness to the framework of the standard overlapping-generations model. It is demonstrated that a unique fair allocation always exists, no matter whether the laissez-faire economy displays over-or underaccumulation of capital. Furthermore, fair allocations are compared with those resulting from utilitarian welfare maximization. It turns out that, for a given welfare function, a utilitarian planner realizes a fair allocation only by chance, depending on the real rate of interest.

\section{Laroque, Guy}

TI Optimality of Incomplete Markets. AU Demange, Gabrielle; Laroque, Guy.

\section{Layard, Richard}

PD June 1992. TI Unemployment in the OECD Countries. AU Layard, Richard; Nickell, Stephen J. AA Layard: London School of Economics. Nickel: Oxford University. SR Centre for Economic Performance Discussion Paper: 81: The Centre for Economic Performance. The London School of Economics and Political Science, Houghton Street, London WC2A 2AE, ENGLAND. PG 38. PR no charge. JE E31, J31, J23. KW Unemployment. Wages. Inflation. Corporate Performance.

AB This paper presents a theoretical framework followed by an empirical analysis of unemployment patterns in the OECD countries in post-war period. Our broad conclusions indicate. first. that both levels of unemployment and the size of the unemployment response to shocks depend on the structure of the unemployment benefit system and the mechanism of wage determination. Second, the persistence of unemployment depends again on the benefit and wage determination systems. and also on the degree of employment flexibility. Third. the impact of nominal shocks is negatively influenced by the degree of nominal flexibility in wage bargaining and the average variance of nominal shocks over the sample period.

\section{Lazear, Edward P.}

PD April 1992. TI Compensation, Productivity and the New Economics of Personnel. AA University of Chicago and Hoover Institution. Stanford University. SR Hoover Institute Working Papers in Economics: E-92-9; Domestic Studies Program Working Paper Series, Hoover Institution. Stanford University, Stanford. CA 94305. PG 60. PR not available. JE J30. KW Compensation. Incentives. Productivity. Personnel.

AB Economics has become increasingly important in understanding personnel issues. While economic analysis is somewhat rougher as a descriptive tool than industrial psychology, it is better as a rigorous conceptual framework on which prediction and normative prescription can be based. This essay discusses the ways by which economic analysis has enriched the understanding of personnel practices. It focuses in large part on compensation methods but looks also at some interesting labor market phenomena-for example, up or out promotion rules; tenure; job definitions; and separation behavior.

PD June 1992. TI Some Thoughts on Savings. AA University of Chicago and Stanford University. SR Hoover Institute Working Papers in Economics: E-92-17; Domestic Studies Program Working Paper Series, Hoover Institution, Stanford University. Stanford, CA 94305. PG 48. PR not available. JE D91. KW Savings. United States. Japan. 
AB The difference between American and Japanese saving rates has been noted often. Further, the recent decline in U.S. saving rates during the ' 80 's has worried many. Neither demographics nor economic variables are able to explain these differences. There are a number of reasons why the U.S. may suffer from undersaving. They all depend on the failure to internalize some form of externality. While these stories may imply undersaving, they do not receive support from nor reconcile the international or time series data on saving rates. U.S. saving rates may be too low, but neither the fact that they are below the Japanese rates nor the fact that they have fallen over time speaks to the issue.

\section{Le Grand, Julian}

TI The Distribution of Welfare Benefits in Kind. AU Evandrou, Maria: Falkingham. Jane: Hills. John: Le Grand, Julian.

\section{Leahy, John}

TI Asymmetric Information. Adjustment Costs and Market Dynamics. AU Caplin, Andrew; Leahy, John.

TI Aggregation and Optimization with State-Dependent Pricing. AU Caplin. Andrew: Leahy, John.

TI Business as Usual, Market Crashes and Wisdom After the Fact. AU Caplin, Andrew; Leahy, John.

Lee, Danny C.

PD September 1990. TI The Use of Production Indices in Planning and Evaluation Fisheries Management Programs. AA Resources for the Future. SR Resources for the Future Quality of the Environment Division Discussion Paper: QE-23; Quality of the Environment Division, Resources for the Future, 1616 P Street, NW, Washington, D.C. 20036. PG 34. PR \$2.25 prepaid. U.S. funds. JE Q22. KW Fisheries Management. Stock-Recruitment Models. Production Indices.

AB Production indices that estimate past or future levels of fish production can provide a common metric for comparing alternative management strategies. The types of indices best suited for use in program planning may be inappropriate for program evaluation. Program planning requires indices that best characterize the estimated production potential of future populations. In contrast, program evaluation involves empirical measurement of changes in realized production relative to prior production levels of management objectives. A simple model of the stock-recruitment relationship provides a basis for defining seven different indices that could be used in program planning. Differences among these indices and their potential use in the Columbia River Basin are discussed.

PD December 1990. TI Improving System Planning in the Columbia River Basin: Scope. Information Needs, and Methods of Analysis. AU Lee, Danny C.: Paulsen, Charles M. AA Resources for the Future. SR Resources for the Future Quality of the Environment Division Discussion Paper: QE91-07; Quality of the Environment Division. Resources for the Future, 1616 P Street. NW. Washington, D.C. 20036. PG 23. PR $\$ 2.25$ prepaid, U.S. funds. JE Q22, Q28. KW Columbia River. Fisheries Enhancement. Adaptive Management.

AB This report outlines a process for improving the information available to planners who are seeking to remediate environmental damages caused by hydroelectric development within the Columbia River Basin. Past deficiencies in system planning--inadequate system perspective, lack of economic analysis, and indifference to uncertainty--are short-term and longer-term improvements. We focus on the use of improved analytical methods to estimate the biological effects and economic costs of proposed measures, the use of costeffectiveness analyses as a means for comparing alternative management strategies, and the use of decision theory and adaptive management to address the uncertainty that is inherent in planning.

\section{Lee, Hau L.}

TI Economic Models For Vendor Evaluation with Quality Cost Analysis. AU Tagaras, George; Lee, Hau L.

\section{Lee, John H. H.}

TI The Form of Time Variation of Systematic Risk: Some Australian Evidence. AU Brooks, Robert D.; Faff, Robert W.; Lee, John H. H.

\section{Lee, Kevin C.}

PD July 1992. TI The Role of Sectoral Interactions in Wage Determination in the UK Economy. AU Lee, Kevin C.: Pesaran. M. Hashem. AA Lee: University of Cambridge. Pesaran: University of Cambridge and University of California. Los Angeles. SR University of Cambridge Department of Applied Economics Working Paper: 9214; Department of Applied Economics, University of Cambridge, Sidgwick Avenue. Cambridge CB3 9DE. UNITED KINGDOM. PG 32. PR $\$ 5.00(\mathrm{~L} 2.50)$, checks payable to University of Cambridge. JE J53, J31, J41. KW Unions.

AB A multisectoral union-firm model of wage-setting is developed to analyze sectoral interactions operating through expectations of wage opportunities in the economy as a whole. Using data for sixteen industrial sectors of the UK economy, it is shown that (i) expected outside wages exert an important influence on real wages in all sectors; (ii) pressure on wages internal to the sector are found primarily outside the "serviceproducing" sectors: (iii) unemployment rates and benefits show significantly only in a few sectors; (iv) complicated dynamic adjustments influence sectoral wage formation; (v) aggregate wage equations considered in the paper are subject to serious aggregation problems.

\section{Legros, Patrick}

PD July 1992. TI Efficient and Nearly Efficient Partnerships. AU Legros, Patrick; Matthews, Steven A. AA Legros: Comell University. Matthews: Northwestern University. SR Northwestern University Center for Mathematical Studies in Economics and Management Science Discussion Paper: 991; J.L. Kellogg Graduate School of Management, Northwestern University, 2001 Sheridan Road, 3-014 Leverone Hall. Evanston. IL 60208. PG 19. PR per copy $\$ 3.00$ in the U.S.A. or Canada; $\$ 5.00$ via international mail. Make check payable to Northwestern University. JE D21, D23, L22. KW Principal-Agent. Partnership. Moral Hazard. Approximate Efficiency.

AB This paper shows in two ways that the degree to which free-riding diminishes the performance of deterministic partnerships may be less than has been generally thought. First. a necessary and sufficient condition is provided for a partnership to sustain full efficiency. It implies that many nontrivial partnerships sustain efficiency, such as generic ones with finite action spaces, and neoclassical ones with Leontief 
tochnologies. Second. approximate efficiency is shown to be achievable in a large class of partnerships. including ones with smooth and monotonic production and disutility functions Approximate efficiency is achieved by mixed strategy equilibria: one partner takes. with small probability, an efficient action. The degree to which efficiency is approximated is restricted only by the amount of liability the partners can bear. Nonetheless, their equilibrium payments are not arbitrarily large.

\section{Lehrer, Ehud}

TI Bayesian Forecasting. AU Kalai. Ehud; Lehrer, Ehud.

\section{Leiderman, Leonardo}

TI Capital Inflows and Real Exchange Rate Appreciation in Latin America: The Role of External Factors. AU Calvo, Guillermo A.: Leiderman, Leonardo; Reinhart, Carmen M.

\section{Lennblad, Anna}

TI Inflation and Monetary Reform. AU Agenor, PierreRichard; Lennblad, Anna.

\section{Lewbel, A.}

PD April 1992. TI Mutual Fund Separation with General Preferences. AU Lewbel. A.; Perraudin. W. R. M. AA Lewbel: Brandeis University. Perraudin: University of Cambridge. SR University of Cambridge Department of Applied Economics Working Paper: 9212: Department of Applied Economics. University of Cambridge. Sidgwick Avenue, Cambridge CB3 9DE. UNITED KINGDOM. PG 15. PR $\$ 5.00$ (L2.50). checks payable to University of Cambridge. JE G11, D52, G12. KW Portfolio Choice. Incomplete Markets. Non-Expected Utility.

AB Necessary and sufficient restrictions on arbitrary (e.g. non-expected) utility functions for ordinary or monetary portfolio separation of any degree are derived for both complete and incomplete markets, generalizing the von Neumann-Morgenstern utility theorems of Cass and Stiglitz (1970). In complete markets, portfolio separation is shown to be nearly synonymous with Lewbel's (1991) definition of demand rank. Virtual price arguments are used to extend the results to incomplete markets. Asset pricing restrictions implied by utility-based mutual fund separation under incomplete markets are derived. In particular, a version of the CAPM is shown to hold for arbitrary preferences satisfying two fund monetary separation without the requirements of representative agent aggregation.

\section{Lewis, Karen K.}

TI Do Expected Shifts in Inflation Policy Affect Real Rates? AU Evans, Martin D. D.; Lewis, Karen K.

\section{Lian, Brad}

TI Presidents. The Use of Military Force, and Public Opinion. AU Oneal, John R.; Lian. Brad.

\section{Liang, J. Nellie}

TI A Dynamic Model of Entry and Performance in the U.S. Banking Industry. AU Amel. Dean F.: Liang. J. Nellie.

\section{Lichtenberg, Frank R.}

PD September 1992. TI R\&D Investment and
International Productivity Differences. AA Columbia Business School and National Bureau of Economic Research. SR National Bureau of Economic Research Working Paper: 4161; National Bureau of Economic Research, 1050 Massachusetts Avenue, Cambridge, MA 02138. PG 27. PR \$3.00. JE O32, F43, J24. KW Labor Productivity. Research and Development.

AB This paper extends previous research on the effect of investment on labor productivity at the country level by accounting for investment in R\&D. as well as for investment in fixed and human capital. Privately-funded R\&D investment is found to have a significant positive effect on productivity. Moreover, this effect appears to be quite large. The estimated social (national) rate of return to private $R \& D$ investment is about seven times as large as the return to investment in equipment and structures. The elasticity of GNP with respect to the privately-funded research capital stock is about $7 \%$. These findings do not support the hypothesis that there are complete. or at least instantaneous, international $R \& D$ spillovers. The social marginal product of government-funded research capital appears to be much lower than that of private research capital.

\section{Lieberman, Offer}

PD July 1992. TI Saddle Point Approximation for the Distribution of a Ratio of Quadratic Forms in Normal Variables. AA Monash University. SR Monash Department of Econometrics Research Working Paper: 9/92; Department of Econometrics, Monash University. Clayton, Victoria 3168. AUSTRALIA. PG 12. PR no charge. JE C10, C12. KW Density Function. Density Approximation. Fourier Transform.

AB In the present paper, the saddle point approximations to the density and tail probability of a ratio of quadratic forms in normal variables are derived. A numerical exposition via the Durbin-Watson test statistic reveals several desirable features. Beyond their accuracy and robustness to extreme scenarios, the approximations, which only involve a limited number of computable functions. provide the practitioner with an accessible and a very powerful tool.

\section{Lin, Shoukang}

PD August 1992. TI A Simple Monetary Model of a Shortage Economy. AA International Monetary Fund. SR International Monetary Fund Working Paper: 92/69; International Monetary Fund. Washington, DC 20431. PG 21. PR not available. JE D59, P22. P23. KW Economic Transition. Centrally Planned Economy. Monetary Overhang.

AB During the transition from a centrally planned economy to a market economy, many countries seem to have experienced some degree of macroeconomic instability. This paper attempts to provide a theoretical explanation of this phenomenon. The paper develops a simple monetary model and shows how macroeconomic stability can be achieved in a rigid centrally planned economy, despite the inherent structural imbalances and irrational price system. On the other hand, the study shows that without hardening enterprise budget constraints, wage and price decontrol tends to destabilize the economy and may lead to persistent budget deficits and inflation. The demand in a shortage economy, and clarifies the somewhat confusing concept of "monetary overhang" in the literature. 
Lindbeck, Assar

PD 1992. TI Patterns of Unemployment: An InsiderOutsider Analysis. AU Lindbeck, Assar: Snower, Dennis J. AA Lindbeck: University of Stockholm. Snower: University of London. SR Columbia University Department of Economics Discussion Paper: 598; Department of Economics. Columbia University, New York, New York 10027. PG 26 PR \$5.00. JE J60. J63, J64. J40. KW Unemployment. Labor Turnover. Labor Markets.

AB The aim of this paper is to provide a simple insideroutsider model that can account simultaneously for all of the stylized facts hypotheses concerning the determinants and evolution of unemployment. The model rests on two general observations: (i) Labor markets are characterized by significant labor turnover so that the gross flows of workers into and out of firms often far exceed the net changes in employment at these firms. and (ii) labor turnover costs play an important role in firm's employment decisions and in enabling insiders to gain market power in the wage setting process. Our analysis shows that if wage setters have imperfect information about productivity, significant labor turnover costs may not prevent large numbers of workers from moving into and out of jobs, but these costs can have an important influence on firms' hiring and retention rates thereby affecting both the level and persistence of unemployment.

PD February 1992. TI Price Inertia and Production Lags. AU Lindbeck, Assar; Snower, Dennis J. AA Lindbeck: University of Stockholm. Snower: University of London. SR Columbia University Department of Economics Discussion Paper: 597; Department of Economics. Columbia University, New York, New York 10027. PG 23. PR \$5.00. JE D10, D43, D57, E12, E31. KW Price Rigidities. Price Intertia New Keynesian Economics.

AB The paper shows how prolonged price inertia can arise in a macroeconomic system in which there are temporary price rigidities as well as production lags in the use of intermediate goods. In this context. changes in product demand-generated, say, by changes in the money supply -have long-lasting price and quantity effects. Specifically, a temporary demand shift generates "persistence" in price-quantity decisions, in the sense that the price-quantity effects of this shift persist for long after the shift has disappeared. A permanent demand shift generates "sluggishness" in price quantity decisions, in the sense that the full price effects of the shift take a long time to appear and that meanwhile quantity effects are present.

\section{Ling, Ts'ai}

PD May 1992. TI On the Road to Political Reform: Electing the Second National Assembly for Constitutional Reform in the Republic of China. December 21. 1991. AU Ling. Ts'ai; Myers, Ramon H. AA Stanford University. SR Stanford Hoover Institute International Studies Working Paper: I-92-6; The Hoover Institution, Stanford University, Stanford, CA 94305. PG 42. PR no charge. JE O53. D72, H11. KW Taiwan. Elections. Political Parties.

AB This paper traces the history of political reform in the ROC. Beginning in 1986 when the Kuomintang party first permitted opposition political parties, these reforms led to the December 1991 election of the Second National Assembly.

\section{Lipman, Barton}

$\begin{array}{llll}\text { PD October 1992. TI Limited Rationality and } \\ \text { Endogenously } & \text { Incomplete Contracts. AA Queen's }\end{array}$

University. SR Queen's Institute for Economic Research Discussion Paper: 858; Department of Economics, Queen's University, Kingston, Ontario, CANADA K7L 3N6. PG 28. PR \$3.00 Canada: \$3.50 U.S. and elsewhere. JE C78, D81. KW Bounded Rationality. Bargaining.

AB The purpose of this paper is to provide a simple model in which limited rationality endogenously generates incomplete contracts. I model limited rationality as in Lipman [1991. 1992]. focusing on the idea that boundedly rational agents do not necessarily know every implication of their knowledge, but may, at a cost. compute these implications. This assumption implies the existence of subjective uncertainty in addition to the objective uncertainty the agents are contracting over. The presence of noncontractable subjective uncertainty can lead to contracts which are incomplete with respect to the contractable objective uncertainty. The most surprising result is that strategic bargaining over contracts can lead to incomplete contracts even with infinitesimal computation costs.

\section{Lipsey, Robert E.}

PD July 1992. TI Foreign Direct Investment in the U.S.: Changes Over Three Decades. AA National Bureau of Economic Research and City University of New York. SR National Bureau of Economic Research Working Paper: 4124; National Bureau of Economic Research, 1050 Massachusetts Avenue, Cambridge, MA 02138. PG 61. PR \$5.00. JE F10, F32, F41. KW Investment. Trade Balances.

AB U.S. direct investment inflows in the 1980's were almost half the world's total. Even this large inflow leaves foreign firms employing less than 5 percent of the U.S. labor force. but twice that share in manufacturing. That increase is related to the internationalization of production by foreign firms more than to competitive weakness of U.S. firms. Foreign affiliates import more relative to their exports that U.S. firms but are moving closer to the behavior of U.S. firms. The trade balances of both are sensitive to exchange rates. The financing of foreign investment from retained earnings dropped almost to zero in the 1980 's. One reason is the rapid growth of this investment and another is its low profitability.

TI What Explains Developing Country Growth? AU Blomstrom, Magnus; Zejan, Mario; Lipsey, Robert E.

\section{Liu, Liang-Yn}

PD September, 1992. TI Saving Behavior Under Imperfect Financial Markets and the Current Account Consequences. AU Liu, Liang-Yn; Woo, Wing Thye. AA University of California, at Davis. SR University of California at Davis Economics Department Working Paper: 413: Department of Economics. University of California at Davis, Davis, CA 95616. PG 31. PR \$3.00 U.S. and Canada. \$4.00 international. JE D91. D92, E21, F32, F43. KW Financial Intermediation. Savings Behavior. Current Account Balance.

AB We seek to establish the general empirical importance of investment-motivated saving. Our hypothesis is that inadequate financial intermediation will induce agents to save more in order to undertake lumpy physical investment in the future. The result is a negative relationship between the degree of capital market imperfection and the size of the private sector component of the current account. A simulation exercise calibrated on Taiwan (and done without any reiterative searches) found a close match between the simulated and actual 
data. The high negative significance of the financial sophistication variable found in pooled regressions was robust to different specifications and sub-samples.

\section{Locatelli, Veronica}

PD September 1992. TI On Elephants and Blind Researchers: Methods for Accessing Culture in Organizations AU Locatelli, Veronica; West, Michael. AA Locatelli: University of Sheffield. West: University of Sheffield and London School of Economics. SR London School of Economics Centre for Economic Performance Discussion Paper: 95; Centre for Economic Performance, London School of Economics, Houghton Street, London WC2A 2AE, ENGLAND. PG 12. PR no charge. JE L20, C81. KW Twenty Statements Test. Organizational Culture.

AB This research compares two pre-existing methodologies for accessing culture, repertory grids and focused group discussions, with a modified version of the Twenty Statements Test (Kuhn and McPartland, 1954), a method originally developed to measure self concept. The comparison is made on the basis of three criteria: the levels and elements of culture accessed by the different methods; the amount and usefulness of the information gathered: and finally. the ease of use of the methods. The comparisons of the methods is based on information gathered from 158 participants in a major UK company and the results clearly suggest that the modified Twenty Statements Test has most potential as a method for accessing culture in organization.

\section{Lopez-de Silanes, Florencio}

TI The Automobile Industry and the Mexico-U.S. Free Trade Agreement. AU Berry, Steven T.; Lopez-de Silanes, Florencio; Grilli, Vittorio.

\section{Lu, Maozu}

PD June 1992. TI The Encompassing Principle and Specification Tests. AU Lu, Maozu: Mizon. Grayham E. AA Lu: Southampton University. Mizon: Southampton University and European University Institute, Italy. SR University of Southampton Discussion Paper in Economics and Econometrics: 9214; Department of Economics, University of Southampton. Southampton $\mathrm{S} 095 \mathrm{NH}$, ENGLAND. PG 15. PR no charge. JE C10, C12, C52. KW Encompassing. M-Tests. Conditional Moment Testing. AB The encompassing principle, as a generator of test statistics, is compared to the M-test or conditional moment testing principle. It is shown that the two principles are capable of generating the same test statistics, and in this sense equivalent. However, there are differences in motivation and emphasis underlying the principles which are important in econometric modelling. The equivalence between encompassing and parsimonious encompassing for nonlinear models is also established for a class of completing models.

\section{Ludema, Rodney D.}

PD January 1992. TI Cross-Border Externalities and Trade Liberalization: The Strategic Control of Pollution. AU Ludema. Rodney D.; Wooton, Ian. AA University of Western Ontario. SR University of Western Ontario Department of Economics Reseanch Report: 9202; Department of Economics. Social Sciences Center, University of Western Ontario, London, Ontario, CANADA N6A 5C2. PG 19. PR \$5.00 Canada. \$7.00 elsewhere. JE Q20, Q28, F10.
F12, L41. KW Public Finance. International Trade Environmental Policy.

AB We show that, in a non-cooperative setting, international trade restrictions may be used as instruments of environmental policy and also that the reverse is true, that pollution taxes and emission controls will be used in order to exploit monopoly power in trade. Thus, the formation of a free-trade area may not bring about the efficiency gains of unrestricted trade that would arise in the absence of the externality.

\section{Machin, Stephen}

TI The Employer Size-Wage Effect: Is Monopsony the Explanation? AU Green. Francis: Machin, Stephen; Manning, Alan.

PD June 1992. TI Minimum Wages, Wage Dispersion and Employment: Evidence from the U.K. Wages Council. AU Machin, Stephen; Manning, Alan. AA Machin: University College, London and London School of Economics. Manning: London School of Economics. SR The Centre for Economic Performance Discussion Paper: 80; The Centre for Economic Performance. The London School of Economics and Political Science, Houghton Street. London WC2A 2AE, ENGLAND. PG 15. PR no charge. JE J40, J30, J31, J38. KW Wages Councils. Minimum Wages. Employment. AB Debate about the effect of minimum wages on employment in the United Kingdom has not paid much attention to the impact of the existing system of minimum wages, the Wages Councils. In this paper, we look at the consequences of the declining importance of the Wages Councils in the 1980's for wage inequality and employment in the covered industries. We find that there has been a significant increase in wage inequality as a result of the failure to raise minimum wages in line with earnings, but there is no evidence that the declining minimum produced any beneficial employment effects. If anything, there seems to be a positive correlation between minimum wages and employment, an effect that seems particularly strong in the catering sector.

\section{Machina, Mark J.}

PD July 1991. TI A More Robust Definition of Subjective Probability. AU Machina. Mark I.: Schmeidler, David. AA Machina: University of California, San Diego. Schmeidler: Ohio State University and Tel-Aviv University. SR Universitat Bonn Sonderforschungsbereich 303Discussion Paper: A-365: Sonderforschungsbereich 303 an der Universitat Bonn Adenauerallee 24-42. D-5300 Bonn 1 . GERMANY. PG 51. PR no charge. JE D80, D81. KW Subjective Probability. Uncertainty. Subjective Uncertainty.

AB The goal of choice-theoretic derivations of subjective probability is to separate a decision maker's underlying beliefs (subjective probabilities of events) from their preferences (attitudes toward risk). Classical derivations have all relied upon some form of the Marschak-Samuelson "Independence Axiom" or the Savage "Sure-Thing Principle," which imply that preferences over lotteries conform to the expected utility hypothesis. This paper presents a choice-theoretic derivation of subjective probability, in a Savage-type setting of purely subjective uncertainty, which neither assumes nor implies that the decision maker's preferences over lotteries necessarily conform to the expected utility hypothesis. 
Magill, Michael J. P.

PD September 1992. TI Infinite Horizon Incomplete Markets. AU Magill, Michael J. P.; Quinzii, Martine. AA Magill: University of Southern California. Quinzii: University of California, Davis. SR University of California at Davis Economics Department Working Paper: 414; Department of Economics. University of California at Davis. Davis, CA 95616. PG 39. PR \$3.00 U.S. and Canada. $\$ 4.00$ international. JE D52, G11, G12. KW Infinite Horizon Model. Incomplete Markets.

AB The general equilibrium model with incomplete markets is extended to the case of an open-ended future. Such a model provides a natural setting for analyzing many problems of macroeconomics. The paper provides an initial step for such an analysis by establishing conditions under which an equilibrium exists. With short-lived numeraire assets an equilibrium always exists with long-lived assets an equilibrium exists for a dense set of payoff structures. The prices of infinite-lived securities in zero net supply are shown to permit speculative bubbles which affect (do not affect) the equilibrium allocation if markets are incomplete (complete). The prices of securities in positive net supply do not have bubbles.

Magnanti, Thomas L.

TI Optimizing Constrained Subtrees of Trees. AU Aghezzaf, El Houssaine; Magnanti, Thomas L.; Wolsey. Laurence A.

Malcomson, James $\mathbf{M}$.

PD September 1992. TI Contract Inefficiency, Wages and Employment: An Assessment. AA University of Southampton. SR University of Southampton Discussion Paper in Economics and Econometrics: 9225: Department of Economics, University of Southampton, Southampton SO9 5NH, ENGLAND. PG 27. PR no charge. JE J41. KW Bargaining. Turnover Costs. Efficiency Wages.

AB The literature on inefficiency in contracts governing wages and employment is assessed. Two main reasons for contract inefficiency are discussed: (1) Employees' bargaining power enables them to capture some of the rent from employment. Turnover cost, insider-outsider and trade union models analyze this. (2) Asymmetric and nonverifiable information results in employers making higher profits by paying "efficiency" wages above the market clearing level. The paper assesses (a) the implications of these for the characteristics of labor markets, (b) whether these characteristics are associated with inefficient employment levels, and (c), if so, whether there are policies that would reduce that inefficiency.

Maler, K.- G.

TI The Acid Rain Game as a Resource Allocation Process with an Application to the Cooperation Among Finland, Russia. and Estonia. AU Kaitala, V.: Maler, K.- G.; Tulkens, H.

Manelli, Alejandro $M$.

PD September 1992. TI Optimal Procurement Mechanisms. AU Manelli, Alejandro M.; Vincent, Daniel R. AA Northwestern University. SR Northwestern University Center for Mathematical Studies in Economics and Management Science Discussion Paper: 999; J.L. Kellogg Graduate School of Management, Northwestern University. 2001 Sheridan Road, 3-014 Leverone Hall Evanston. IL 60208.
PG not available. PR per copy: $\$ 3.00$ in the U.S.A. or Canada; $\$ 5.00$ via international mail. Make check payable to Northwestern University. JE D40. KW Procurement. Optimal Mechanisms.

AB The procurement of supplies is often conducted through the buyer analogue of an auction. Sealed bids are submitted and the contract is awarded to the lowest bidder. Although this method may be an optimal way of selling an object. an additional complication arises in the case of purchasing a good. When sellers are privately informed about the quality of the good to be sold, these mechanisms typically result in the provision of the lowest quality object. This paper characterizes optimal mechanisms in environments where sellers are privately informed about quality. It shows that the commonly used auction mechanisms is privately or socially optimal in only a small class of environments. In another plausible set of environments is the optimal mechanism is simply to order potential suppliers and to tender take-it-or leave it offers to each sequentially. We use the duality theorem of linear programming to provide a methodology by which necessary and sufficient conditions can be derived to determine when any incentive compatible trading environment maximizes social or private surplus.

\section{Manning, Alan}

TI The Employer Size-Wage Effect: Is Monopsany the Explanation? AU Green. Francis; Machin. Stephen; Manning, Alan.

TI Minimum Wages, Wage Dispersion and Employment: Evidence from the U.K. Wages Council. AU Machin, Stephen; Manning, Alan.

\section{Marchand, Maurice}

TI Volunteer Work and Club Size: Nash Equilibrium and Optimality. AU Barham. Vicky; Boadway. Robin; Marchand, Maurice; Pestieau, Pierre.

Mark, Nelson C.

TI Testing Volatility Restrictions on Intertemporal Marginal Rates of Substitution Implied by Euler Equations and Asset Returns. AU Cecchetti. Stephen G.; Lam. Pok-sang: Mark. Nelson C.

\section{Matsuyama, Kiminori}

PD May 1992. TI Custom Versus Fashion: PathDependence and Limit Cycles in a Random Matching Game. AA Northwestern University. SR Hoover Institute Working Papers in Economics: E-92-11: Domestic Studies Program Working Paper Series, Hoover Institution, Stanford University, Stanford, CA 94305. PG 45. PR not available. JE C73. KW Best Response Dynamics. Bifurcation. Equilibrium Refinement.

AB A pairwise random matching game is considered to identify the social environments that give rise to the social custom and fashion cycles. The game. played by Conformists and Nonconformists, can generate a variety of socially stable behavior patterns. In the path-dependence case. Conformists set the social custom and Nonconformists revolt against it; what action becomes the custom is determined by "history." In the limit cycle case. Nonconformists become fashion leaders and switch their actions periodically, while Conformists follow with delay. The outcome depends on the relative share on 
Conformists to Nonconformists as well as their matching patterns.

PD June 1992. TI The Market Size, Entrepreneurship, and the Big Push. AA Northwestern University. SR Hoover Institute Working Papers in Economics: E-92-13; Domestic Studies Program Working Paper Series, Hoover Institution. Stanford University. Stanford. CA 94305. PG 23. PR not available. JE O11, O14. KW Balanced Growth Doctrine. Complementarities. Industrialization.

AB The logic of "balanced growth" doctrine or "big push" hypothesis does not provide the rationale for the comprehensive central planning. unless coordinated expansion across different industries are difficult to achieve through spontaneous responses by creative entrepreneurs. To make this point I model the difficulty of coordination, by adding some inertia in the entrepreneurial decision processes in the Murphy-Schleifer-Vishny model of big push and analyze the transition explicitly. The level of "critical minimum effort," below which growth would not occur and above which it could. is derived as a function of the degree of inertia and the market size. This helps to distinguish the case in which the economy is caught in the poverty trap from the case in which the economy can escape and achieve a successful take-off. The model is also used to examine the effects of population growth. agricultural productivity, and fiscal policies in industrialization.

TI Start-up Costs and Pecuniary Externalities as Barriers in Economic Development. AU Ciccone, Antonio; Matsuyama, Kiminori.

\section{Matthews, Steven A.}

TI Efficient and Nearly Efficient Partnerships. AU Legros. Patrick; Matthews, Steven A.

PD August 1992. TI On Modeling Cheap Talk in Bayesian Games. AU Matthews, Steven A.; Postlewaite, Andrew. AA Matthews: Northwestern University. Postlewaite: University of Pennsylvania. SR Northwestern University Center for Mathematical Studies in Economics and Management Science Discussion Paper: 992; J.L. Kellogg Graduate School of Management, Northwestern University. 2001 Sheridan Road, Evanston, Il 60208. PG 21. PR per copy: $\$ 3.00$ U.S. and Canada. $\$ 5.00$ via international mail. Make check payable to Northwestern University. JE C70, C78. KW Private Information. Cheap Talk Games.

AB The "cheap talk games" studied in this chapter are games in which players with private information exchange payoffimelevant messages. Crawford and Sobel (1982) and Green and Stokey (1980) introduced the simplest cheap talk games, those in which a "sender" with private information sends a message to a "receiver" who then takes an action. We examine issues that arise in the modeling of face-to-face conversation among multiple informed parties. The modeling approach we follow represents a conversation as a finite, or even infinite, sequence of rounds of public message exchange that occurs before some underlying game is played. This is a straightforward extension of the predominant approach taken in the literature cited above. However, difficulties arise when this approach is extended to settings with multiple communication rounds and multiple informed parties. Using two examples, we show that the number of communication rounds can interact consequentially and arguably artificially with the number of informed players.

\section{Mayer, Thomas}

PD September 1992. TI What Economists Think of Their Econometrics. AA University of California, Davis. SR University of California at Davis Economics Department Working Paper: 406; Department of Economics, University of California at Davis. Davis. CA 95616. PG 4. PR \$3.00 U.S. and Canada. $\$ 4.00$ international. JE C10. KW Data Mining. Econometric Testing.

AB A survey of academic economists shows that many are concerned that data mining reduces the credibility of reported results. However, the survey does not support the view. expressed by Leamer and Cooley and LeRoy, that data mining makes most economists reject econometric results.

PD September 1992. TI Monetarism and Its Rhetoric. AA University of California, Davis. SR University of California at Davis Economics Department Working Paper: 415; Department of Economics. University of California at Davis, Davis, CA 95616. PG 31. PR \$3.00 U.S. and Canada. $\$ 4.00$ international. JE E10. E50. KW Monetarism. Friedman. Brunner. Meltzer.

AB Monetarism is much more than a doctrine that "only money matters." It more subtle and nuanced. Its rhetoric is inbetween the older Keynesian rhetoric and the more formalistic rhetoric that is currently popular. Much of what monetarists have taught has been absorbed in standard macro theory. There are important distinctions between Friedman's version and the Brunner-Meltzer version. Much of the monetarist case against discretionary monetary policy is based on the hypothesis that the central bank does not operate efficiently.

McFadden, Daniel L.

TI Simulation of Multivariate Normal Orthant Probabilities: Theoretical Computational Results. AU Hajivassiliou, Vassilis A.; McFadden, Daniel L.; Ruud, Paul A.

\section{McGuckin, Robert H.}

PD August 1992. TI Analytic Use of Economic Microdata: A Model for Researcher Access with Confidentiality Protection. AA Bureau of the Census. SR Bureau of the Census Center for Economic Studies Discussion Paper: 92-8; Center for Economic Studies, Bureau of the Census, Washington, DC 20233. PG 21. PR no charge. JE C81. KW Analytic Research. Data Access. Census Data.

AB A primary responsibility of the Center for Economic Studies (CES) of the U.S. Bureau of the Census is to facilitate researcher access to confidential economic microdata files. There is substantial recent literature arguing for the proposition that the largest single improvement that the U.S. statistical system could make is to improve its analytic capabilities. In this paper I briefly discuss these benefits to greater access for analytical work and ways to achieve them. Due to the nature of business data, public use databases and masking technologies are not available as vehicles for releasing useful microdata files. I conclude that a combination of outside and inside research programs, carefully coordinated and integrated is the best model for ensuring that statistical agencies reap the gains from analytic data users. Two options are considered: 1) Establish Census Bureau facilities in various universities or similar nonprofit research facilities and 2) Develop CES regional operations in existing Census Bureau regional offices. 
McLaughlin, Kenneth J.

TI Inter-Industry Mobility and the Cyclical Upgrading of Labor. AU Bils. Mark; McLaughlin. Kenneth J.

\section{Mei, Jianping}

PD July 1992. TI Excessive Gambling with Unfavorable Odds: Financial Institutions' Real Estate Investments. AU Mei, Jianping; Saunders, Anthony. AA New York University. SR New York University Salomon Brothers Working Paper: S-92-44: Salomon Brothers Center for the Study of Financial Institutions, Graduate School of Business Administration. New York University, 90 Trinity Place, New York, NY 10006. PG 22. PR not available. JE G21. G22, G12. KW Banks. Investment Strategy.

AB In this paper, we use real estate investment data for major groups of financial insitutions---commercial banks, thrifts and life insurance companies to evaluate their investment timing performance over the $1970-1989$ period. The recent poor performance of these financial institutions has been attributed (in part) to their expanded real estate investment powers. Our major finding is that real estate investments by U.S. financial institutions have largely been driven by ex post or past real estate returns rather than future expected returns. We show that such a strategy may be distinctly sub-optimal since there is a class of asset pricing models, which imply that high unexpected returns in the past imply low expected returns in the future. As a result, this apparent "counter-contrarian" real estate investment strategy---of buying high and selling low---offers a convincing explanation for the poor performance of U.S. financial institutions' in the real estate investment area.

\section{Melick, William R.}

PD October 1992. TI War and Peace: Recovering the Market's Probability Distribution of Crude Oil Futures Prices During the Persian Gulf Crisis. AU Melick. William R.: Thomas. Charles P. AA Board of Governors of the Federal Reserve System. SR Board of Governors of the Federal Reserve System International Finance Discussion Paper: 437: Division of International Finance, Board of Governors of the Federal Reserve System. Washington. D.C. 20551. PG 29. PR no charge. JE G13. KW Options Market. Price Expectations. Crude Oil.

AB This paper investigates the market's expectations for oil prices during the Persian Gulf crisis. To do so a general method for using options markets to recover the implied distribution for futures prices is developed. The method applies to a wide class of distributions. In particular, it is not limited to those distributions arising from diffusion or jump-diffusion processes.

\section{Meredith, Guy}

PD August 1992. TI Discretionary Monetary Policy Versus Rules: The Japanese Experience During 1986-91. AA International Monetary Fund. SR International Monetary Fund Working Paper: 92/63; International Monetary Fund, Washington, DC 20431. PG 14. PR not available. JE E52, E65, E47. KW Monetary Policy. Discretion. Japan. Stabilization.

AB This paper compares the hypothetical performance of various monetary policy rules with that of the discretionary policies actually pursued in Japan over the 1986-91 period. The results suggest that simple rules based on targeting growth in either the money supply, nominal income, or prices would have failed to stabilize economic variables more successfully than discretionary policies. At the same time. it appears that an indicator of monetary conditions incorporating movements in the real exchange rate and the real interest rate would have been useful in assessing the effect of current policies in future activity.

\section{Mertens, Jean-Francois}

TI Perfect Correlated Equilibria. AU Dhillon, Amrita; Mertens, Jean-Francois.

\section{Mester, Loretta J.}

PD July 1992. TI Efficiency in the Savings and Loan Industry. AA Federal Reserve Bank of Philadelphia and University of Pennsylvania. SR Federal Reserve Bank of Philadelphia Research Working Paper: 92-14; Working Papers. Department of Research. Federal Reserve Bank of Philadelphia, 10 Independence Mall, Philadelphia, PA 19106. PG 28. PR no charge except overseas airmail. \$2.00; checks/money orders in U.S. funds payable to Federal Reserve Bank of Philadelphia. JE G21, C21. KW S\&Ls. Ownership.

AB I use the stochastic econometric cost frontier approach to investigate efficiency in mutual and stock S\&Ls using 1991 data on U.S. S\&Ls. The standard frontier model is expanded to permit both the cost frontier and error structures to differ between S\&Ls of these two ownership forms. A likelihood ratio test indicates that the data support this unrestricted model, which implies efficient mutual and stock S\&Ls use different production technologies. Various measures of inefficiency show that on average stock S\&Ls are less efficient than mutual S\&Ls. The results suggest deregulation of interest rates and increased competition have had the predicted effect of curtailing agency problems in mutual S\&Ls, and might partially explain the large number of conversions of S\&Ls from mutual to stock ownership. The second part of the paper relates the inefficiency measures to several correlates. I find that higher capital-asset ratios are correlated with greater efficiency in both mutual and stock S\&Ls.

\section{Metcalf, David}

PD August 1992. TI Do Strikes Pay? AU Metcalf, David; Wadsworth, Jonathan; Ingram, Peter. AA Metcalf and Wadsworth: London School of Economics. Ingram: University of Surrey. SR Centre for Economic Performance Discussion Paper: 92; The Centre for Economic Performance. The London School of Economics and Political Science, Houghton Street, London WC2A 2AE, ENGLAND. PG 13. PR no charge. JE J50, J51, J52. KW Strikes. Wages.

AB One-in-forty manufacturing pay settlements involved a strike during the 1980's. Strike days lost were equivalent to half a day a year for each worker in manufacturing. On average, for the decade as a whole, real pay increases where there was a strike were 0.7 per cent a year higher than settlements without a strike. Larger bargaining groups were more likely to achieve above average pay increases from strike action than were bargaining groups with fewer employees. After controlling for other influences on settlements a strike is found to boost the annual real pay rise by 0.3 percent, equivalent to 45 pounds a year in 1991. The "average" strike in this sample lasts 11 days. Such a strike requires the wage gain to last for 30 years (with a discount rate of .06 or less) for the benefit to at least equal the cost. This hints that the average strike may not be a good investment for the union. But shorter strikes are more likely to 
be worthwhile.

Metcalf, Gilbert E.

PD June 1992. TI Specification Testing in Panel Data with Instrumental Variables. AA Princeton University and National Bureau of Economic Research. SR National Bureau of Economic Research Technical Paper: 123; National Bureau of Economic Research. 1050 Massachusetts Avenue, Cambridge MA 02138. PG not available. PR \$3.00. JE C10. C23. C33. C40. KW Panel Data. Instrumental Variables. Fixed Effects.

AB This paper shows a convenient way to test whether instrumental variables are correlated with individual effects in a panel data set. It shows the correlated fixed effects specification tests developed by Hausman and Taylor (1981) extend in an analogous way to panel data sets with endogenous right hand side variables. In the panel data context. different sets of instrumental variables can be used to construct the test. Asymptotically, I show that the test in many cases is more efficient if an incomplete set of instruments is used. However, in small samples one is likely to do better using the complete set of instruments. Monte Carlo results demonstrate the likely gains for different assumptions about the degree of variance in the data across observations relative to variation across time.

Michel, P.

TI Oligopoly Equilibria in Exchange Economies.

AU Gabszewicz, J. J.; Michel, P.

\section{Mikkelsen, Hans Ole}

PD June 1992. TI A Note on the Superiority of Variance Ratio Tests for Random Walks Against Long Memory Alternatives. AA University of Aarhus. SR Aarhus Institute of Economics Memo: 1992-6; Institute of Economics, University of Aarhus. Building 350. Universitetsparken. DK8000 Aarhus C, DENMARK. PG 7. PR no charge. JE C12, C15, C22. KW Dickey-Fuller Test. Monte Carlo Simulation.

AB It is well known that Dickey-Fuller and variance-ratio tests yield different conclusions concerning the null hypothesis of unit roots in several empirical applications. The conclusion then depends upon their relative power against relevant alternative hypotheses. This note presents Monte Carlo evidence that variance-ratio tests have much higher power than Dickey-Fuller tests against fractional alternatives. Also the power of variance-ratio tests increases much quicker with the sample size.

\section{Miller, John $\mathbf{H}$.}

TI Political Parties and Electoral Landscapes. AU Page, Scott E.; Kollman, Ken; Miller. John H.

Miller, $\mathbf{P}$.

PD April 1992. TI Real Effects of Monetary Policy in a World Economy. AU Miller. P.: Todd, R. AA Federal Reserve Bank of Minneapolis. SR Federal Reserve Bank of Minneapolis Staff Report: 154: Research Department, Federal Reserve Bank of Minneapolis, 250 Marquette Ave., Minneapolis, MN 55401. PG 42. PR no charge. JE F41, E52, E63. KW Trade. Relative Prices. Exchange Rates.

AB We present a 2-country model with heterogeneous agents in which changes in a country's monetary policy affect real interest rates, relative prices of traded and nontraded goods and real exchange rates. Nontransitory real effects of monetary policy stem solely from a friction (country-specific reserve requirements) that generates separate demands for a country's money and bonds. Without violating the classical assumptions of individual rationality and flexible prices, the model's implication seem qualitatively in accord with the U.S. experience of the 1980's: a monetary policy tightening leading to a rise in the real interest rate and to an initial rise in the real value of the dollar which is subsequently reversed. In the model a monetary policy change leads to different welfare effects for agents born at different times. living in different countries, or participating on different sides of a market. The welfare of some agents can be affected more by relative price changes than by real interest rate changes.

\section{Mills, Leonard 0.}

TI Vector-Autoregression Forecast Models for the Third District States. AU Crone. Theodore M.; Delaney, Sherry; Mills, Leonard O.

\section{Miron, Jeffrey A.}

PD August 1992. TI Seasonal Unit Roots in Aggregate U.S. Data. AU Miron, Jeffrey A.; Beaulieu, J. Joseph. AA Miron: Boston University. Beaulieu: Board of Governors of the Federal Reserve System. SR National Bureau of Economic Technical Paper: 126; National Bureau of Economic Research, 1050 Massachusetts Avenue, Cambridge, MA 02138. PG not available. PR \$3.00. JE C15, C10, C22, C32. KW Unit Roots. Seasonality.

AB In this paper we provide evidence on the presence of seasonal unit roots in aggregate U.S. data. The analysis is conducted using the approach developed by Hylleberg. Engle, Granger and Yoo (1990). We first derive the mechanics and asymptotics of the HEGY procedure for monthly data and use Monte Carlo methods to compute the finite sample critical values of the associated test statistics. We then apply quarterly and monthly HEGY procedures to aggregate U.S. data. The data reject the presence of unit roots at most seasonal frequencies in a large fraction of the series considered.

\section{Mizon, Grayham E.}

TI The Encompassing Principle and Specification Tests. AU Lu, Maozu; Mizon, Grayham E.

\section{Mobilia, Pamela}

TI Determinants of Interest Rates on Tax-Exempt Hospital Bonds. AU Grossman. Michael; Goldman. Fred: Mobilia, Pamela; Nesbitt, Susan W.

\section{Mohtadi, Hamid}

PD July 1992. TI Endogenous Growth, Health and the Environment. AU Mohtadi. Hamid: Roe. Terry. AA Mohtadi: University of Wisconsin-Milwaukee. Roe: University of Minnesota. SR University of Minnesota Economic Development Center Bulletin: 92-4; Department of Agricultural and Applied Economics, 232 Classroom Office Building, University of Minnesota, St. Paul, MN 55108. PG 27. PR no charge. JE O40, Q20. KW Endogenous Growth. Environment.

AB This paper studies the trade-offs between economic growth and environmental degradation. using an endogenous growth framework. The paper emphasizes the divergence 
between the equilibrium and the efficient path of growth when adverse environmental externalities are present. The paper also focuses on the linkage. in the producer choice set for factors of production. between "embodied effects" internal to consumers and the "disembodied effects" that are external, and acts through environmental degradation.

\section{Molne, Frank}

TI The Dividend Puzzle and Tax. AU Jones, Chris M.: Molne, Frank.

\section{Mondino, Guillermo}

PD October 1992. TI Recurrent High Inflation and Stabilization. A Dynamic Game. AU Mondino. Guillermo: Sturzenegger, Federico; Tommasi, Mariano. AA Mondino: University of Chicago. Sturzenegger: University of California, Los Angeles and National Bureau of Economic Research. Tommasi: University of California. Los Angeles. SR University of California at Los Angeles Department of Economics Working Paper: 678; Department of Economics, University of California at Los Angeles. 2263 Bunch.. Los Angeles. CA 90024. PG 35. PR \$2.50; checks payable to U.C. Regents. JE C73, D74. E31. KW Stabilization. Financial Adaptation. Markov Perfect Equilibrium.

AB We present a game theoretic model in which fluctuations between low and high inflation are endogenously generated as the outcome of an income distribution struggle. We use the model to interpret two facts that are salient in high inflation Latin America. First, inflation is perceived as the costly outcome of the mechanics of the politico-economic system. Second, governments repeatedly engage in transitory stabilization programs that are accepted by society. The game has features of conflict over relative income and features of coordination over inflation.

Monfort, A.

TI Testing Non Nested Hypotheses. AU Gourieroux, C.: Monfort, A.

TI Testing Encompassing and Simulating Dynamic Econometric Models. AU Gourieroux, C.; Monfort, A.

TI Indirect Inference. AU Gourieroux, C.; Monfort, A.; Renault. E.

TI On Seasonal Effects in Duration Models. AU De Toldi, M.; Gourieroux, C.; Monfort, A.

\section{Mongin, Philippe}

PD August 1992. TI Some Connections Between Epistemic Logic and the Theory of Nonadditive Probability. AA Universite Catholique de Louvain. SR Universite Catholique de Louvain CORE Discussion Paper: 9248; Universite Catholique de Louvain, Voie du Roman Pays, 34. B-1348 Louvain-la-Neuve, BELGIUM. PG 29. PR not available. JE C11. KW Bayesian Analysis. Belief Functions.

AB This paper is concerned with representations of belief by means of nonadditive probabilities of the Dempster-Shafer (D.S.) type. After surveying some foundational issues and results in the D.S. theory, including Suppes's related contributions, the paper proceeds to analyze the connection of the D.S. theory with some of the work currently pursued in epistemic logic. A preliminary investigation of the modal logic of belief functions a la Shafer is made. Then it is shown that the Alchourron-Gardenfors-Makinson (A.G.M.) logic of belief change is closely related to the D.S. theory. The final section compares the critique of Bayesianism which underlies the present paper with some important objections raised by Suppes against this doctrine.

\section{Montrucchio, Luigi}

TI Acyclicity and Dynamic Stability: Generalizations and Applications. AU Boldrin, Michele; Montrucchio, Luigi.

Moore, John

TI The Economics of Banknuptcy Reform. AU Aghion. Philippe: Hart. Oliver; Moore. John.

\section{Morris, Stephen}

PD September 1992. TI Acceptance Games and Protocols. AA University of Pennsylvania. SR University of Pennsylvania Center for Analytic Research in Economics and Social Science (CARESS) Working Paper: 92-22: University of Pennsylvania, Center for Analytic Research in Economics and the Social Sciences, McNeil Building. 3718 Locust Walk. Philadelphia, PA 19104-6297. PG 22. PR no charge. JE D82, C71. KW Private Information. Signals.

AB A group of agents with private information must decide whether to stay with the status quo or move to some alternative. We consider the incomplete information acceptance game. where each agent must accept or reject, depending on the signal he has observed, and unanimous acceptance is required to implement change. Agents have conflicting ordinal interpretation of signals if, whenever a signal represents good news about the alternative for the agent who observes it, it is bad news for all other agents. This occurs in a two agent trading problem with affiliated values. Under this assumption, there is a Pareto-dominant pure strategy Nash equilibrium of the acceptance game where each agent's strategy is to accept or reject depending on the signal he has observed. This equilibrium coincides with the set of signals where agents accept under a public acceptance protocol when agents publicly discuss their willingness to accept the trade, and converge to common knowledge of acceptance.

PD September 1992. TI The Re-sale Premium for Assets in General Equilibrium. AA University of Pennsylvania. SR University of Pennsylvania Center for Analytic Research in Economics and Social Science (CARESS) Working Paper: 92-23; University of Pennsylvania, Center for Analytic Research in Economics and the Social Sciences, McNeil Building. 3718 Locust Walk, Philadelphia, PA 19104-6297. PG 13. PR no charge. JE G12, D52. KW Incomplete Asset Markets. Re-Trading.

AB In general equilibrium with incomplete asset markets, many (but finite) time periods, re-trading of assets at each date and state of the world, and short sales constraints on asset holdings, the price of each asset is always at least as great as each agent's "fundamental" valuation - his marginal valuation of the future stream of payoffs from that asset. The price of asset $j$ in state $s$ is strictly greater than agent h's fundamental valuation if and only if the short sales constraint for asset $j$ binds in state $s$, or any state following $s$. The result generalizes to any constraint on asset holdings (possibly depending on prices and endowments) which has the property that agents can always hold more of any asset. 
PD September 1992. TI Revising Beliefs and Knowledge: A Generalization of Blackwell's Theorem. AA University of Pennsylvania. SR University of Pennsylvania Center for Analytic Research in Economics and Social Science (CARESS) Working Paper: 92-24; University of Pennsylvania. Center for Analytic Research in Economics and the Social Sciences, McNeil Building. 3718 Locust Walk, Philadelphia, PA 19104-6297. PG 33. PR no charge. JE D83. KW Information. Experiments.

AB If agents misinterpret information, an "experiment" must be characterized by both a true distribution of signals. and agents' (possibly incorrect) beliefs conditional on observing those signals. I show that an experiment is more valuable than another if and only if the former is sufficient in differences for the latter - the difference between the two true distributions of signals could have been derived from the difference between two other experiments where beliefs about one experiment are correct and sufficient for the other. This result specializes to Blackwell's (1951) theorem in the case where information is interpreted correctly. The result is used to generalize results in Geanakoplos (1989) about the value of information generated by possibility correspondences.

\section{Mullahy, John}

PD November 1990. TI Health Capital, Risk Aversion, and the Variance of Income: Assessing Some Welfare Costs of Alcoholism and Poor Health. AU Mullahy. John: Sindelar. Jody L. AA Mullahy: Trinity College and Resources for the Future. Sindelar: Yale University. SR Resources for the Future Quality of the Environment Division Discussion Paper: QE91-05; Quality of the Environment Division, Resources for the Future, 1616 P Street, NW, Washington. D.C. 20036. PG 35. PR $\$ 2.25$ prepaid, U.S. funds. JE I12. KW Health Capital. Risk Preferences. Alcoholism.

AB The economic costs of adverse health outcomes have typically been evaluated in a context of risk neutrality. an approach that ignores the potential welfare importance of individual's risk preferences. This paper presents a framework that unifies the research in health capital and earnings with that on risk preferences in the presence of stochastic outcomes. The framework is implemented to obtain estimates of the economic damages due to both general health problems as well as to one specific health problem that is of considerable interest from society's perspective: alcoholism.

PD December 1990. TI Detecting Heterogeneity and Overdispersion in Poisson Regression Models via Goodnessof-Fit. AA Trinity College and Resources for the Future. SR Resources for the Future Quality of the Environment Division Discussion Paper: QE91-06; Quality of the Environment. Resources for the Future, $1616 \mathrm{P}$ Street, NW, Washington, D.C. 20036. PG 28. PR \$2.25 prepaid. U.S. funds. JE C12. KW Poisson Distribution. Heterogeneity. Overdispersion.

AB This paper suggests an alternative to traditional tests for parameter heterogeneity and overdispersion in Poisson models. Specifically, a goodness-of-fit approach to detecting and testing for heterogeneity is developed and shown to have an interesting distribution-free character with respect to the heterogeneity distribution. An asymptotic goodness-of-fit test is suggested and applied in two examples. and a small sampling experiment is conducted to assess some size and power properties of the test in moderate-sized samples.
Murphy, Kevin J.

TI Does Executive Compensation Affect Investment? AU Gibbons, Robert; Murphy, Kevin J.

\section{Murphy, Paul}

TI The Structure of an Environmental Transaction: The Debt-for-Nature Swap. AU Deacon, Robert T.; Murphy, Paul.

\section{Musiela, Marek}

TI On the Existence of Arbitrage-Free Measures in Contingent Claim Valuation. AU Christopeit. Norbert: Musiela. Marek.

\section{Myers, Ramon H.}

TI On the Road to Political Reform: Electing the Second National Assembly for Constitutional Reform in the Republic of China, December 21, 1991. AU Ling, Ts'ai; Myers, Ramon $\mathrm{H}$.

\section{Myerson, Roger B.}

PD September 1992. TI Incentives to Cultivate Special Interest Groups under Alternative Electoral Systems. AA Northwestern University. SR Northwestern University Center for Mathematical Studies in Economics and Management Science Discussion Paper:1000 : J.L. Kellogg Graduate School of Management, Northwestern University. 2001 Sheridan Road, 3-014 Leverone Hall, Evanston, IL 60208. PG 48. PR per copy: $\$ 3.00$ in the U.S.A. or Canada; $\$ 5.00$ via international mail. Make checks payable to Northwestern University. JE D72. KW Voting. Elections. Candidates. Special Interest Groups.

AB A simple model is used to compare, under different electoral systems, the incentives for candidates to create inequalities among otherwise homogeneous voters, by making campaign promises that favor small groups, rather than appealing equally to all voters. In this game model, each candidate generates offers for voters independently out of a distribution that is chosen by the candidate, subject only to the constraints that offers must be nonnegative and have mean 1 . Symmetric equilibria with sincere voting are analyzed for twocandidate elections, and for multicandidate elections under rank-scoring rules, approval voting, and single transferable vote. Voting rules that can guarantee representation for minorities in multiseat election generate, in this model, the most severely unequal campaign promises.

\section{Nabeya, Seiji}

PD October 1992. TI Asymptotic Distributions of the Least Squares Estimators and Test Statistics in the Near Unit Root Model with Non-Zero Initial Value and Local Drift and Trend. AU Nabeya. Seiji; Sorensen. Bent E. AA Nabeya: Tokyo International University. Sorensen: Brown University. SR Brown University Department of Economics Working Paper: 92-18; Department of Economics. Brown University. Providence, Rhode Island 02912. PG 20. PR no charge. JE C22, C12. KW Asymptotic Distribution. Autoregressive Model. Characteristic Function. Unit Roots. AB This paper considers the distribution of the Dickey-Fuller test in a model with non-zero initial value and drift and trend. We show how stochastic integral representations for the limiting distribution can be derived from either the local to unity approach with local drift and trend or from the continuous 
record asymptotic results of Sorensen (1992). We also show how the stochastic integral representations can be utilized as the basis for finding the corresponding characteristic functions via the Fredholm approach of Nabeya and Tanaka (1988. 1990a). This "link" between those two approaches may be of general interest. We further tabulate the asymptotic distribution for the Schmidt-Phillips (1989) unit roots test. Our results show very clearly the dependence of the various tests on the initial value of the time series.

\section{Nakamura, Leonard I.}

PD August 1992. TI Bank Branching. AU Nakamura, Leonard I.; Parigi. Bruno M. AA Nakamura: Federal Reserve Bank of Philadelphia. Parigi: Virginia Polytechnic Institute and State University. SR Federal Reserve Bank of Philadelphia Research Working Paper: 92-18; Working Papers, Department of Research. Federal Reserve Bank of Philadelphia, 10 Independence Mall, Philadelphia, PA 19106. PG 26. PR no charge except overseas airmail, \$2.00; checks/money orders in U.S. funds payable to Federal Reserve Bank of Philadelphia. JE G21. KW Network Externalities. Banking.

AB In a model with heterogeneous depositors, we demonstrate an equilibrium in which branch banks and unit banks coexist. Branch banks have the advantage of a network externality: depositors who travel can access their deposits from multiple locations. However, branch banks have a cost disadvantage, in that linking branches is costly. Rooted in fundamentals and therefore suitable for both hypothesis testing and for welfare analysis, this model is helpful in understanding the social costs of restrictions on bank branching and for measuring the efficiency of banks with branches, analyzing the competitive structure and appropriate scale of banking markets. and explaining interest rate differentials across banks and regions.

\section{Ncube, Mthuli}

PD August 1991. TI The Black and Scholes Option Price as a Random Variable. AU Ncube, Mthuli; Satchell, Stephen. AA Mthuli: London School of Economics. Satchell: University of Cambridge and University of London. SR University of Cambridge Department of Applied Economics Working Paper: 9205: Department of Applied Economics, University of Cambridge, Sidgwick Avenue, Cambridge CB3 9DE. UNITED KNNGDOM. PG 22. PR \$5.00 (L2.50), checks payable to University of Cambridge. JE G12, G13, C10. KW Distribution Function. Volatility.

AB In this paper, the authors consider the properties of the Black and Scholes option price, considered as a random variable. The option is conditioned on the current price and/or the estimated volatility. In either case, exact results for the distribution function of the true option and the predicted option are derived. Extensions to puts and American contracts are considered and the bias of the predicted price is examined and a bias-adjusted Black and Scholes price is suggested. Some calculations from simulation that resemble UK data on the FTSE 100 Index European options are presented.

\section{Neeman, Zvika}

PD September 1992. TI On Determining the Importance of Attributes With a Stopping Problem. AA Northwestern University. SR Northwestern University Center for
Mathematical Studies in Economics and Management Science Discussion Paper: 1002; J.L. Kellogg Graduate School of Management, Northwestern University, 2001 Sheridan Road, Evanston, IL 60208. PG 26. PR per copy: \$3.00 U.S. and Canada. $\$ 5.00$ via international mail. Make check payable to Northwestern University. JE D00. D10, D80. D83. KW Consumer Preferences. Seanch. Product Attributes. Learning.

AB One of the approaches in consumer theory considers each product as a collection of attributes. Consequently, consumer preferences are defined over attributes. As opposed to the traditional approach, according to which consumer preferences for products are the underlying feature of economic modeling. they are now derived from the composition and strength of products' attributes. In this paper I try to answer the question of how one can determine the relative importance of the different attributes of a product. In order to answer this question a stopping problem model is constructed. An agent faces a sequence of i.i.d. multi-dimensional products of which he can observe only one attribute. At each stage the agent has to decide whether he wants to stop, taking the best product so far, or whether he prefers to continue by observing a specific attribute of the next product. The model is solved for an optimal observing policy.

\section{Nelson, Richard R.}

PD June 1992. TI Factors Behind Cross-Industry Differences in Technical Progress. AU Nelson, Richard R.; Wolff, Edward N. AA Nelson: Columbia University. Wolff. New York University. SR New York University Economic Research Reports: 92-27: New York University. Faculty of Arts and Science. Department of Economics. Washington Square, New York. N.Y. 10003. PG 24. PR no charge. JE O31, O32, O33. KW Technological Change. Research and Development.

AB Three findings of particular interest emerge from our study. First, as shown in previous work, both appropriability and opportunity make a positive contribution to $R$ and $D$ intensity. In our analysis, links with science and the contributions of university research are the key variables behind opportunity. Second, the contributions of upstream materials and equipment supplies appear to be substitutes for internal $\mathrm{R}$ and $\mathrm{D}$. In contrast, the contribution of research equipment suppliers seems to spur internal $R$ and D. Our third and most striking result is that, while both appropriability and opportunity affect $R$ and $D$ intensity. opportunity alone is related to the pace of technical advance in an industry.

\section{Nesbitt, Susan W.}

TI Determinants of Interest Rates on Tax-Exempt Hospital Bonds. AU Grossman, Michael; Goldman, Fred; Mobilia, Pamela; Nesbitt, Susan W.

\section{Nett, Lorenz}

PD December 1991. TI Mixed Oligopoly-A Survey. AA University of Bonn. SR Universitat Bonn Sonderforschungsbereich 303- Discussion Paper: A-358; Sonderforschungsbereich 303 an der Universitat Bonn Adenauerallee 24-42. D-5300 Bonn 1, GERMANY. PG 23. PR no charge. JE C70, D43. KW Public Firms. Mixed Oligopoly. Price Policy. Cournot-Paradox.

AB In this paper we present the main results of the literature on mixed oligopoly where all firms supply a homogeneous 
product. This kind of literature has also some importance for reconsidering oligopolistic markets where big share-holding companies operate. The structure of the paper is as follows: after presenting the basic framework. we demonstrate that in the mixed oligopoly market we have a "Cournot-Paradox" quite similar to the well-known Bertrand-Paradox. Having this in mind we present the literature ordered with respect to its main topics: optimal pricing policies, comparison of the allocations to the same situation where both firms are private. internal production costs. market entry and the role of strategic precommitment. Finally we give a conclusion, reveal several possible ways for future research and the difficulties which will arise in further theorizing on the subject.

PD August 1992. TI Negative Effects of Competition in a Medical-Service Market. AA University of Bonn. SR Universitat Bonn Sonderforschungsbereich 303 Discussion Paper: A-375; Sonderforschungsbereich 303 an der Universitat Bonn, Adenauerallee 24-42, D-5300 Bonn 1, DEUTSCHLAND. PG 6. PR no charge. JE Ill, I18. D61. KW Licensing. Health Care. Social Welfare.

AB A market for medical care is characterized by uncertain but inelastic demand and a "soft budget constraint". We assume that in such a market. government decides on giving licenses to different private institutions to provide medical service. In this paper we present an argument as to why competition has a negative effect on social welfare and therefore government should only provide one license. We also explain why in such a market the profit-maximizing institutions install too high a capacity in comparison to a social optimum.

\section{Newbery, David $M$.}

PD January 1992. TI The Role of Public Enterprise in the National Economy. AA University of Cambridge. SR University of Cambridge Department of Applied Economics Working Paper: 9209; Department of Applied Economics, University of Cambridge. Sidgwick Avenue. Cambridge CB3 9DE, UNIIED KNGDOM. PG 28. PR $\$ 5.00$ (L2.50), checks payable to University of Cambridge. JE L33, O12, P51. KW Privatization. Development. Market Failure.

AB Public sector enterprises (PSEs) continue to play an important role in many developing economies. though they are frequently poorly managed and contribute to fiscal deficits. The debate about privatization typically compares the efficiency of PSEs with comparable private firms, but the more interesting question is why in some countries both public and private firms are efficient, while in others both are inefficient. The paper argues that the key to successful development is the creation of future-oriented institutions to compensate for the critical missing market for future output, and this in turn requires the state to commit itself to ensuring secure title to future returns. If the private sector lacks confidence in its title the state may need to finance investment while establishing its reputation. The paper examines the evidence from Korea, India and Eastern Europe, discusses the appropriate boundaries of the state, and the management of PSEs.

PD September 1991 and April 1992. TI (1)CapacityConstrained Supply Function Equilibria: Competition and Entry in the Electricity Spot Market and (2)Competition and Regulation in the English Electricity Industry. AA University of Cambridge. SR University of Cambridge Department of Applied Economics Working Paper:
9208: Department of Applied Economics. University of Cambridge. Sidgwick Avenue, Cambridge CB3 9DE, UNITED KINGDOM. PG 27. PR $\$ 5.00(\mathrm{~L} 2.50)$, checks payable to University of Cambridge. JE Q41, L94. KW Electric Utilities. Generation. Deregulation.

AB (1)The British spot electricity market is best modeled as an equilibrium in supply functions. With constant and equal marginal costs, and linear demand, the Nash equilibrium in supply functions with capacity constraints can be derived analytically for a variety of market configurations. The paper examines the effect on industry equilibrium of asymmetry, the number of suppliers, and the threat of entry. Dividing the industry capacity among more suppliers may increase total industry profits, reduce consumer welfare, but increase social welfare. (2)While economists in other countries were arguing the theoretical case for deregulating generation, the UK Government privatized and vertically dismembered the electricity supply industry. leaving the fossil-fuel stations in two unequal-sized unregulated generators. The paper examines the extent to which unregulated competition in generation has worked, the problems of coordinating generation investment with grid investment, and of possibly excess entry exacerbated by conflicts of interest of the distributors who hold equity in new generators.

Nicholas, $\mathbf{S}$.

PD August 1992. TI Tall but Poor: Nutrition, Health, and Living Standards in Pre-Famine Ireland. AU Nicholas. S.; Steckel, Richard H. AA Nicholas: Australian National University and University of New South Wales. Steckel: Ohio State University and National Bureau of Economic Research. SR National Bureau of Historical Paper: 39; National Bureau of Economic Research, 1050 Massachusetts Avenue, Cambridge, MA 02138. PG not available. PR \$5.00. JE N33, N31. I30, I10. KW Living Standards. Height. AB This paper uses height data recorded on Convict Indents to study temporal patterns and regional differences in living standards in pre-famine Ireland. The approach is explicitly comparative and makes use of information from America and other parts of Europe. The Irish attained roughly the 16th centile of modern height standards and, though smaller than contemporary North Americans, were among the tallest in Europe, including the wealthier English. We suggest that a nutritious diet and epidemiological isolation were important factors in the high nutritional living standards of the Irish.

\section{Nickell, Stephen J.}

TI Unemployment in the OECD Countries. AU Layard. Richard: Nickell, Stephen J.

\section{Niou, Emerson M. S.}

PD June 1992. TI An Analysis of Dr. Sun Yat-Sen's Self-Assessment Scheme for Land Taxation. AU Niou, Emerson M. S.; Tan, Guofu. AA Niou: Duke University. Tan: University of British Columbia. SR University of British Columbia Department of Economics Discussion Paper: 92-10; Department of Economics, University of British Columbia 997-1873 East Mall. Vancouver, B.C. Canada V6T 1 Y2. PG 17. PR JE H20. KW Taxation. Self-Assessment Scbeme.

AB Dr. Sun Yat-sen proposed a method of self-assessment of land value in 1905 . Under his scheme, each owner submits his own valuation but the state reserves the right to purchase the 
land at the self-assessed value. Sun claimed that his land policy would deter landowners from under-assessing their property, and the annual tax would discourage them from over-valuation. An interesting aspect of his scheme is that it depends on the voluntary actions and truthful reports of the property owners. This paper analyzes the properties of this type of truthrevelation mechanism. In this paper, first, we show that Sun's scheme does not induce true reporting of land value. Second. we modify Sun's scheme by imposing an additional kind of cost on the landowners in the calculation of their expected profits. Under the modified scheme. government not only purchases the land at the underreported value, but also collects taxes based on the true land value.

\section{Noldeke, Georg}

PD February 1992. TI Unverifiable Information. Incomplete Contracts, and Renegotiation. AU Noldeke. Georg: Schmidt, Klaus M. AA Noldeke: University of Bonn. Schmidt: Massachusetts Institute of echnology. SR Universitat Bonn Sonderforschungsbereich 303Discussion Paper: B-211: Sonderforschungsbereich 303 an der Universitat Bonn Adenauerallee 24-42, D-5300 Bonn 1, GERMANY. PG 16. PR no charge. JE G13, L14. KW Incomplete Contracts. Renegotiation. Verifiability.

AB Hart and Moore (1988) argued that non-verifiability is a major cause for contract incompleteness and leads in general to underinvestment if the parties can not commit not to renegotiate their initial contract. We show that this result relies on the assumption that the courts cannot distinguish which party refused to trade. If this assumption is relaxed the first best can be achieved by giving control to one party which can decide unilaterally whether or not to enforce trade. Our result suggests that if relationship specific investments are nonverifiable, then vertical integration may perform better than separate ownership.

PD June 1992. TI The Evolutionary Foundations of Backward and Forward Induction. AU Noldeke, Georg; Samuelson. Larry. AA Noldeke: University of Bonn. Samuelson: University of Wisconsin. SR Universitat Bonn Sonderforschungsbereich 303- Discussion Paper:B-216; Sonderforschungsbereich 303 an der Universitat Bonn Adenauerallee 24-42, D-5300 Bonn 1, GERMANY. PG 35. PR no charge. JE C70, C73. KW Extensive Form Games. Perfect Information. Subgame Perfection. Equilibrium Refinements.

AB We examine the evolutionary foundations of common equilibrium refinement ideas for extensive form games, such as backward and forward induction. by examining the limiting outcome of an evolutionary process driven by stochastic learning and (rare) mutations. We show that the limiting outcome in a class of extensive form games with perfect information always includes the subgame perfect equilibrium outcome, but also contains other outcomes if the subgame perfect outcome fails a (strong) local stability property. The evolutionary system imposes a forward induction requirement that strengthens van Damme's; it selects announcement proof equilibria in a class of cheap talk games; and it yields results that would often be interpreted as satisfying forward induction, but does not always impose sufficient discipline on actions and conjectures at unreached subgames to yield results consistent with backward induction.

\section{Nucci, Alfred}

PD August 1992. TI The Characteristics of Business Owners Database. AA Bureau of the Census. SR Bureau of the Census Center for Economic Studies Discussion Paper: 92-7: Center for Economic Studies, Bureau of the Census, Washington, DC 20233. PG 89. PR no charge. JE C81. KW Microdata. Small Business.

AB The Bureau of the Census conducted the Characteristics of Business Owners (CBO) survey for the Small Business Administration and the Minority Business Development Agency in 1986 and 1991. The CBO collected information from national samples of 126,000 business owners, surveying the demographic and economic characteristics of owners and the economic performance of their firms. A major feature of the $\mathrm{CBO}$ is the large numbers of Hispanic. Asian. Other. Black, and Women businesses in addition to non-minority, male-owned businesses. The CBO data series also serves the broader purpose of providing data on characteristics of owners and firms in the small business population. The paper compares the content, survey procedures, and survey response of the 1982 and 1987 CBO surveys.

\section{O'Rourke, Kevin}

PD May 1992. TI Property Transactions in Ireland. 1708-1988: An Introduction. AU O'Rourke, Kevin: Polak. Ben. AA O'Rourke: Columbia University. Polak: Harvard University. SR Columbia First Boston Series in Money. Economics and Finance Working Paper: FB-92-18; Columbia University, Graduate School of Business, First Boston Series, New York, NY 10027. USA. PG 12. PR \$5.00 academics and non-profit institutions: $\$ 6.00$ corporations (add $\$ 1.00$ outside U.S., Canada and Puerto Rico). JE N53, N54, C81. KW Land Sales. Mortgages.

AB This note reports on a unique time series stretching from 1708 until 1988. which was obtained from the archives of the Registry of Deeds in Dublin. Since 1708, every sale of land has been recorded in the Registry, so that potential purchasers of land can satisfy themselves that the land really belongs to the sellers. Wills, mortgages and long term leases of land have also been registered in the Registry. The series may provide some indication of how economic activity in Ireland fluctuated over time.

PD May 1992. TI Were Heckscher and Ohlin Right? Putting History Back into the Factor-Price-Equalization Theorem. AU O'Rourke, Kevin; Williamson, Jeffrey G. AA O'Rourke: Columbia University. Williamson: Harvard University. SR Columbia First Boston Series in Money, Economics and Finance Working Paper: FB-92-19; Columbia University. Graduate School of Business. First Boston Series, New York, NY 10027. USA. PG 20. PR \$5.00 academics and non-profit institutions; $\$ 6.00$ corporations (add $\$ 1.00$ outside U.S., Canada and Puerto Rico). JE N71, N73, E31, F14. KW Commodity Prices. Wage Convergence.

AB Due primarily to transport improvements, commodity prices in Britain and America tended to equalize 1870-1913. This commodity price equalization was not simply manifested by the great New World grain invasion of Europe. Rather, it can be documented for intermediate primary products and manufactures as well. Heckscher and Ohlin, writing in 1919 and 1924. thought that these events should have contributed to factor price equalization. Based on Williamson's research reported elsewhere, Anglo-American real wages did converge over this period. and it was part of a general convergence 
between the Old and New World. This paper applies the venerable Heckscher-Ohline trade model to the late 19th century Anglo-American experience and finds that they were right: at least half of the real wage convergence observed can be assigned to commodity price equalization.

\section{Obstfeld, Maurice}

PD June 1992. TI Evaluating Risky Consumption Paths: The Role of Intertemporal Substitutability. AA University of California, Berkeley and National Bureau of Economic Research. SR National Bureau of Economic Research Technical Paper: 120; National Bureau of Economic Research, 1050 Massachusetts Avenue, Cambridge MA 02138. PG not available. PR \$3.00. JE D11, D91, D60, D81. KW Risk Aversion. Intertemporal Substitutability. Stochastic Consumption.

AB In dynamic stochastic welfare comparisons, a failure to clearly distinguish between risk aversion and intertemporal substitutability can result in misleading assessments of the impact of risk aversion on the welfare costs of consumptionrisk changes. The problem arises in any setting in which uncertainty is propagated over time, notably, but not exclusively, in economies with stochastic consumption trends. Regardless of the preference setup adopted, an increase in risk aversion amplifies the per-period costs of risks. The weights consumers use to cumulate the per-period costs or risk with persistent effects should. however. depend on intertemporal substitutability as well as on risk aversion. Under timeseparable expected utility preferences, an increase in the period utility function's curvature therefore alters the welfare effect of risk for reasons that in part are unrelated to risk aversion.

\section{Oneal, John R.}

PD July 1992. TI Presidents, The Use of Military Force, and Public Opinion. AU Oneal, John R.; Lian, Brad. AA University of Alabama. SR Stanford Hoover Institute International Studies Working Paper: I-92-8; International Studies Working Paper Series, Hoover Institution, Stanford University, Stanford. CA 94305. PG 25. PR not available. JE A12,D72. KW Presidency. Military Force. Popularity. AB It has been widely accepted among political scientists and in the media that the public rallies 'round the president when military force is used abroad. Indeed, this conventional wisdom has encouraged the view that presidents are apt to engage in saber rattling to divert attention away from domestic problems. We assess the rally effect by measuring the change in the president's popularity following all major uses of force by the United States from 1950 through 1984. A favorable response by the general public to the use of force is more likely when the United States is involved in a severe crisis, the president's actions are prominently reported, the country is not at war or fatigued by war, his initial popularity is low, and there is bipartisan support for his actions.

\section{Ord, Keith}

TI Rationalization of Exponential Smoothing in Terms of a Statistical Framework with Multiplicative Disturbances. AU Koebler. Anne; Ord. Keith; Snyder, Ralph D.

\section{Ostry, J. D.}

TI The Output Decline in the Aftermath of Reform: The Cases of Bulgaria, Czechoslovakia, and Romania. AU Borensztein. E. R.: Demekas, D. G.: Ostry, J. D.
Oz, Shy

PD August 1992. TI A Welfare Evaluation of Comparison Advertising. AA Tel-Aviv University. SR Tel Aviv Foerder Institute for Economic Research Working Paper: 10/92; Department of Economics, Tel Aviv University, Ramat Aviv 69978, Tel Aviv, ISRAEL. PG 18. PR no charge. JE M37. KW Advertising. Comparison Advertising.

AB This paper analyzes the welfare consequences of allowing comparison advertising. The analysis concentrates on the matching of heterogeneous consumers with differentiated brands aspect of advertising. The major findings are: (1) Comparison advertising is likely to be used when the consumer population is shrinking. and is not used when the market is expanding. (2) When the consumer population is moderately increasing or moderately decreasing, it is optimal for the FTC to encourage comparison advertising by small market share firms. (3) When the consumer population is declining, a market failure may occur when the high market share firm utilizes comparison advertising while social optimum implies that the low market share firm would use comparison advertising.

\section{Page, Scott E.}

PD August 1992. TI Political Parties and Electoral Landscapes. AU Page, Scott E.; Kollman, Ken; Miller. John H. AA Page and Kollman: Northwestern University. Miller: Carnegie Mellon University. SR Northwestern University Center for Mathematical Studies in Economics and Management Science Discussion Paper: 997; J.L. Kellogg Graduate School of Management. Northwestern University. 2001 Sheridan Road, Evanston, Il 60208. PG 18. PR per copy: $\$ 3.00$ U.S. and Canada. $\$ 5.00$ via international mail. Make check payable to Northwestern University. JE D70. D72. KW Voter Preferences. Party Platforms. Elections.

AB This paper studies the relationship between voters' preferences and the composition of party platforms in two-party democratic elections with adaptive parties. In the model. preferences determine an electoral landscape on which parties lœally adapt plafforms. Varying the distribution distribution of voters' preferences alters the landscapes' ruggedness and may effect parties' responsiveness. We find that in two-party democratic elections, adaptive parties generally locate in regions of high social utility but cannot always find winning platforms. We also show that parties' ability to locate winning platforms as well as the rate of convergence of party platforms depends upon the electoral landscape's ruggedness.

\section{Palmer, Karen}

PD September 1990. TI A Test for Cross-Subsidies in Local Telephone Rates: Do Business Customers Subsidize Residential Customers? AA Resources for the Future. SR Resources for the Future Quality of the Environment Division Discussion Paper: QE90-24; Quality of the Environment Division, Resources for the Future, 1616 P Street. NW, Washington, D.C. 20036. PG 46. PR \$2.25 prepaid. U.S. funds. JE LA1. L51, L96. KW Cross-Subsidization, Telecommunications. Regulation.

AB Recent regulatory and technological changes in telecommunications suggest that the local telecommunications market soon may present opportunities for profitable entry. Bypass activity by businesses combined with the generally higher business rates suggest that business service revenues may be subsidizing residential access to the local network. Prior to allowing wide-scale entry into local 
telecommunications, regulators need to know if local phone service rates exhibit cross-subsidies. Using data supplied by New England Telephone, this paper tests a new set of sufficient conditions for cross-subsidization that do not require observations on stand-alone cost. The results indicate that business service revenues subsidize residential service provision at nearly 65 percent of the suburban central offices. The sufficient conditions for a residential-to business crosssubsidy fail for all central offices in the sample.

PD November 1990. TI Diversification by Regulated Monopolies and Incentives for Cost-Reducing R\&D. AA Resources for the Future. SR Resources for the Future Quality of the Environment Division Discussion Paper: QE9104: Quality of the Environment Division. Resources for the Future, 1616 P Street, NW, Washington, D.C. 20036. PG 33. PR \$2.25 prepaid, U.S. funds. JE L43, L51. KW Diversification. Research and Development. Regulation.

AB Diversification of a regulated firm can result in dynamic efficiency gains as the firm faces new profit-maximizing opportunities. This paper presents a model in which the regulator induces the diversified firm to invest in $R \& D$ by making a reduction in the portion of fixed costs included in the regulated revenue requirement a precondition for allowing the firm to diversify. Under this rule, the diversified firm will pick a higher level of $R \& D$ investment that the undiversified firm and consumers of the regulated producer will benefit from the resulting lower prices.

PD November 1991. TI Implementing Environmental Costing in the Electric Utility Industry AU Palmer, Karen: Dowlatabadi. Hadi. AA Palmer: Resources for the Future. Dowlatabadi: Carnegie Mellon University. SR Resources for the Future Quality of the Environment Division Discussion Paper: QE91-13-REV; Quality of the Environment Division. Resources for the Future, 1616 P Street, NW, Washington, D.C. 20036. PG 57. PR \$2.25 prepaid. U.S. funds. JE Q28. L94. KW Electric Utility. Environmental Costing. Environmental Resolution.

AB Environmental costing refers to the regulatory practice of requiring electric utilities to incorporate environmental damage costs into electric utility planning and operations management. This practice is being adopted by a growing number of state public utility commissions. The effectiveness of environmental costing in achieving the optimal level of electricity production and pollution emissions will depend on how environmental costing is implemented. We develop a mixed integer programming-based utility planning model for a hypothetical mid-Atlantic utility and employ this model together with illustrative estimates of emissions damage costs to analyze the implications of different environmental costing regimes for generation technology choice, social and private costs of electricity production and electricity price. We find that for low-level investment decisions, patterns of generation or output price. We also find that applying environmental costing exclusively to new generating units fails to reduce the social costs of generating electricity.

Parigi, Bruno M.

TI Bank Branching. AU Nakamura, Leonard I.; Parigi, Bruno M.

Parish, William L.

PD September 1992. TI Daughters, Education, and
Family Budgets: Taiwan Experiences. AU Parish. William L.; Willis, Robert J. AA University of Chicago and NORC. SR Economics Research Center/NORC Discussion Paper: 92-8; Economics Research Center/NORC, 6030 S. Ellis, Chicago, Illinois 60637. PG 20. PR \$2.00; send requests to Librarian, NORC. JE J24, 120, J16, I22. KW Education. Human Capital Investment. Family.

AB Growth in the education of the labor force is commonly identified as one of the most important determinants of economic growth, and the distribution of education by sex is frequently argued to be a key determinant of gender inequality. In this paper, we examine how parents choose to invest in their children's education and. in particular. how they choose to invest in sons' versus daughters' education and the consequences of these choices for women's life chances. We explore this issue with retrospective data on the life cycle and family behavior of Taiwanese individuals who came of age from the 1940's onward. Broadly, our findings tend to be inconsistent with crude forms of East Asian models of patriarchal families and more consistent with economics models of the family in which attempts by altruistic parents to finance optimal investments in their children's buman capital may be frustrated by credit constraints.

\section{Park, Young S.}

PD May 1992. TI Non-Price Competition Among Japanese Brokerage Companies: A Game Theoretic Approach to Explain Loss Compensation. AA International University of Japan. SR New York University Salomon Brothers Working Paper: S-92-40; Salomon Brothers Center for the Study of Financial Institutions, Graduate School of Business Administration, New York University, 90 Trinity Place, New York, NY 10006. PG 21. PR not available. JE C71. KW Fund Managers. Japan.

AB This paper presents a game theoretical analysis which shows that providing loss compensation to fund managers of industrial corporations was the dominant strategy for the Japanese brokerage companies under non-price competition to capture market shares. Without the "Chinese Wall" between brokerage and underwriting activities, brokerage companies made frantic efforts to maintain strategic business with industrial corporations. Loss compensation was created under this context. As a conclusion, we argue that Japanese corporations should provide their fund managers with incentives to set goals at higher return with higher risk and these incentives should be accompanied by the liberalization of brokerage commissions to prevent loss compensation.

\section{Passmore, Wayne}

PD October 1992. TI The Influence of Risk-Adjusted Capital Regulations on Asset Allocation by Savings and Loans. AA Board of Governors of the Federal Reserve System. SR Board of Governors of the Federal Reserve System Finance and Economics Discussion Series: 213: C/O Stephen A. Sharpe. Mail Stop 89. Federal Reserve Board, Washington, DC 20551. PG 18. PR no charge. JE G21. G11. G28. KW S\&Ls. Mortgages.

AB Risk-adjusted capital regulations treat the risk of mortgages as greater than the risk of mortgage-backed securities, and the risk of mortgaged-backed securities as greater than that of Treasury securities, regardless of the income generated by these assets. The paper begins by examining the risks associated with mortgage lending and then 
attempts to measure the income that flows to savings and loans when they undertake these risks. Building on these income estimates. I rank the returns to equity of mortgage investments implied by the risk-adjusted capital standards. Presumably. institutions that are constrained by risk-adjusted capital standards will seek the highest returns to equity based on these rankings.

\section{Patterson, Malcolm}

PD September 1992. TI Collective Climates: A Test of Their Socio-Psychological Significance. AU Patterson, Malcolm; West, Michael; Payne, Roy, AA Patterson: University of Sheffield. West: University of Sheffield and London School of Economics. Payne: University of Manchester. SR Centre for Economic Performance Discussion Paper: 94; The Centre for Economic Performance, The London School of Economics and Political Science, Houghton Street, London WC2A 2AE, ENGLAND. PG 22. PR no charge. JE L20, L21. L22. KW Organizational Climate. Work Group Interaction.

AB This paper contributes to the debate in the literature on organizational climate concerning the conceptual and empirical meaning of aggregations of the perceptions of individuals. Use of the mean has been criticized because it cloaks the wide variations in perceptions that surround it. A recent move to demonstrate the existence of groups of people who do see climate in a similar way has used clustering techniques to identify such "collectives". Payne (1990) questioned the validity of this approach on the grounds that such collectives may not represent meaningful socio-psychological groups. The present paper is based on the view that meaningful collectives are most likely to emerge when people work together on common tasks and in relatively confined physical spaces. Despite finding an organization where such conditions exist the clustering technique largely fails to identify meaningful social collectives. The implications of these findings are discussed.

\section{Paulsen, Charles M.}

TI Improving System Planning in the Columbia River Basin: Scope. Information Needs, and Methods of Analysis. AU Lee. Danny C.; Paulsen. Charles M.

\section{Payne, Roy}

TI Collective Climates: A Test of Their Socio-Psychological Significance. AU Patterson, Malcolm; West, Michael; Payne, Roy.

\section{Peles, Nadav}

TI Returns Volatilities Drop Following Large Dividend Payments. AU Huberman, Gur; Peles, Nadav.

\section{Peracchi, Franco}

PD July 1992. TI Labor Force Transitions of Older Workers. AU Peracchi, Franco; Welch, Finis. AA Peracchi: New York University. Welch: Texas A\&M University and Unicon Research Corp. SR New York University Economic Research Reports: 92-36; New York University. Faculty of Arts and Science, Department of Economics, Washington Square, New York, N.Y. 10003. PG 22. PR no charge. JE J22, J23, J14. KW Aging. Labor Force Participation.

AB We use the Current Population Survey (CPS) to describe what we believe are the most salient features regarding the labor force behavior of men and women aged 49 and over during the last two decades. Our data, from the adjacent year matched CPS files, begins in 1968 when male participation rates appear to be at a post-World War II high. Since then. male participation (defined as weeks employed/52) has fallen at all ages, but most abruptly for men aged 62-65. In 1968 , participation was 91.5 percent at age 50 , it was 83.8 percent at age 60 , at 65 it was 58.4 percent, and it was 28.5 percent at age 69. During the next 20 years, the participation rate fell by about 4-5 percentage points for men aged 50. and the drop was progressively larger for older men up through age 64. For men aged 60, the 1968-89 drop in participation is 15.8 percentage points, it is 30.5 percentage points (to a level of 36.6 percent) for men 64 years old. For men aged 67-69, participation rates by the end of our data are roughly 12 percentage points lower than at the beginning.

\section{Perotti, Roberto}

PD March 1992. TI Political Equilibrium. Income Distribution, and Growth. AA Columbia University. SR Columbia University Department of Economics Discussion Paper: 595; Department of Economics, Columbia University, New York, New York 10027. PG 21. PR \$5.00. JE O40.D30.D31. KW Income Distribution. Growth.

AB In the voluminous literature on income distribution and growth. two basic frameworks can be identified. A tradition going back at least to Kaldor (1956) emphasizes the causal effect of income distribution on capital accumulation and therefore on growth. The development economic literature that flourished in the ' 60 's and '70's following the seminal work of Kuznets (1955) concentrated mainly on the opposite causal link, from growth to income distribution. Both mechanisms are at work in the model of this paper. However, the focus here is not on capital accumulation, but on the effects of redistribution on investment in buman capital. Specifically, this paper starts from the observation that income distribution is not a given, but it can be modified to some extent in an economy where the tax system redistributes income.

PD March 1992. TI Increasing Returns to Scale, Politics, and the Timing of Stabilization. AA Columbia University. SR Columbia University Department of Economics Discussion Paper: 596; Department of Economics, Columbia University, New York, New York 10027. PG 25. PR \$5.00. JE D30, D72, O40. KW Income Distribution. Economic Policy. Political Process.

AB In the last two decades the economic policy of several developing countries has been repeatedly characterized by perverse cycles of "unsustainable policies" and attempts at stabilization. Delays in stabilization are not necessarily inconsistent with rationality, provided one is willing to drop the representative agent assumption. Once the existence of different groups is recognized, a delay in stabilizing the economy can be optimal for some if by doing so they can impose a higher share of the burden of adjustment on others. A recent model by Alesina-Drazen(1991) develops this idea in game theoretic terms. This paper is based on a different approach. one that emphasizes the political process that may lead to the adoption of unsustainable policies. In particular, the main object of the model developed in this paper is to determine which groups are more likely to support such policies and under what conditions. 
Perraudin, W. R. M.

TI Mutual Fund Separation with General Preferences. AU Lewbel, A.: Perraudin, W. R. M.

TI Multivariate Tests of a Continuous Time Equilibrium Arbitrage Pricing Theory with Conditional Heteroscedasticity and Jumps. AU Ho. Mun S.; Perraudin, W. R. M.; Sorensen, Bent E.

TI Multivariate Tests of a Continuous Time Equilibrium Arbitrage Pricing Theory With Conditional Heteroskedasticity and Jumps. AU Ho, Mun S.; Perraudin, W. R. M.; Sorensen. Bent E.

\section{Perry, Motty}

PD February 1992. TI A Non-Cooperative View of Coalition Formation and the Core. AU Perry, Motty; Reny, Philip. AA University of Western Ontario. SR University of Western Ontario Department of Economics Research Report: 9203: Department of Economics, Social Sciences Center. University of Western Ontario, London, Ontario, CANADA N6A 5C2. PG 24. PR $\$ 5.00$ Canada. $\$ 7.00$ elsewhere. JE D50, D51, C72. KW Core. Coalitions.

AB In this work we provide a non-cooperative implementation of the core. However, we do not merely implement the core. The nature of the game form employed is designed to reflect the motivating story as accurately as possible. The present results thus provide formal content of the usual intuitive justification for the core. In our view, the core would lose much of its appeal were it not possible to provide such a non-cooperative foundation.

\section{Pesaran, M. Hashem}

PD September 1991. TI Equilibrium Asset Pricing Models and Predictability of Excess Returns: Theory and Evidence. AU Pesaran, M. Hashem; Potter, Simon M. AA Pesaran: University of Cambridge and University of California, Los Angeles. Potter: University of California, Los Angeles. SR University of Cambridge Department of Applied Economics Working Paper: 9120; Department of Applied Economics, University of Cambridge, Sidgwick Avenue, Cambridge CB3 9DE, UNITED KINGDOM. PG 22. PR $\$ 5.00(\mathrm{~L} 2.50)$, checks payable to University of Cambridge. JE G12, G14, C22. KW Discount Factors. Volatility. Stock Prices.

AB There is now a wide body of empirical evidence suggesting that excess returns are predictable and stock prices are excessively volatile. Such evidence can always be interpreted as due to variations in unobservable discount factors in general equilibrium. We characterize the types of unobservable discount factors and economic structures that are incompatible with a prediction of negative excess returns by a simple sufficient condition: good times for the economy are good times for the stock market. Using previously estimated empirical models, evidence is presented of statistically significant negative predictions of excess returns on the Standard and Poor 500 and the value weighted CRSP stock indices, especially in 1987.

TI Oil Investment in the North Sea. AU Favero, Carlo A.; Pesaran. M. Hashem.

TI Uncertainty and Irreversible Investment: An Empirical Analysis of Development of Oilfields on the UKCS. AU Favero, Carlo A.; Pesaran, M. Hashem; Sharma, S.
PD June 1992. TI Estimating Long-Run Relationships from Dynamic Heterogeneous Panels. AU Pesaran, M. Hashem; Smith, Ron. AA Pesaran: University of Cambridge and University of California, Los Angeles. Smith: University of London. SR University of Cambridge Department of Applied Economics Working Paper: 9215; Department of Applied Economics, University of Cambridge, Sidgwick Avenue, Cambridge CB3 9DE, UNITED KINGDOM. PG 34. PR \$5.00 (L2.50), checks payable to University of Cambridge. JE C23, C13, C21, C22. KW Dynamic Model. Panel Data. Labor Demand.

AB It is now quite common to have panels in which both the number of groups and number of time periods are quite large. Four procedures tend to be used with such data: they are averaged over groups and aggregate time-series estimated; they are averaged over time and cross-sections estimated on group means; they are pooled, assuming the slope coefficients are the same and the pooled regression estimated; or separate regressions are estimated for each group and the coefficients averaged over group. It often seems to be assumed that all four procedures produce unbiased estimates of the mean of the coefficients for dynamic models with lagged dependent variables. We show that this is not the case. In particular, aggregating and pooling can produce highly misleading results, while cross-section regressions are only appropriate under very specific conditions. The heterogeneous panel estimator when both $\mathrm{T}$ and $\mathrm{N}$ are large seems to be the most appropriate of all the four procedures.

TI The Role of Sectoral Interactions in Wage Determination in the UK Economy. AU Lee, Kevin C.; Pesaran. M. Hashem.

PD August 1992. TI Forecasting Stock Returns. AU Pesaran, M. Hashem; Timmermann, A. AA Pesaran: University of Cambridge and University of California, Los Angeles. Timmermann: University of London. SR University of Cambridge Department of Applied Economics Working Paper: 9216; Department of Applied Economics. University of Cambridge, Sidgwick Avenue, Cambridge CB3 9DE. UNITED KINGDOM. PG 27. PR $\$ 5.00$ (L2.50), checks payable to University of Cambridge. JE G11, G14, G12. KW Transactions Costs. Excess Returns. Market Efficiency.

AB The paper presents new evidence on the predictability of excess returns on common stocks for the Standard and Poor's 500 and the Dow Jones Industrial portfolios at the monthly, quarterly and annual frequencies. It shows that recursive predictions obtained on the basis of the excess returns regressions are capable of correctly predicting a statistically significant proportion of the signs of the actual returns. The paper also shows that switching portfolios constructed on the basis of the signs of the recursive predictions mean-variance dominate the respective market portfolios when trading takes place on a quarterly or annual basis. This result holds even under a high transaction cost scenario. However, due to the larger number of transactions at the monthly frequency the monthly switching portfolios only mean-variance dominate the respective market portfolios when transaction costs are zero or low.

\section{Pestieau, Pierre}

TI Volunteer Work and Club Size: Nash Equilibrium and Optimality. AU Barham, Vicky; Boadway, Robin; 
Marchand, Maurice; Pestieau, Pierre.

\section{Pezzey, John}

PD July 1992. TI Some Interactions between Environmental Policy and Public Finance. AA University of Bristol. SR University of Bristol Working Paper: 92/340; Department of Economics. University of Bristol, 8 Woodlands Road, BRISTOL, BS8 1TN, IRELAND. PG 48. PR no charge. JE D45, H23, Q28. KW Pollution Taxes. Tax Revenues. Pollution Standards.

AB A decomposition by Ulph of the overall welfare benefit of using pollution taxes to correct externalities and reduce existing taxes is discussed, and an alternative definition suggested which is perhaps more relevant to policymakers. Many revenue-neutral control policies. including optimal and arbitrary tax-subsidies, and optimally and arbitrarily taxes standards, are categorized. A simple model of optimal commodity taxation with a consumption externality is used to compare the different policies. Many results depend on the relative sizes of the government's revenue requirement and the externality damage. For a realistic revenue requirement, an important result is that welfare rises, for both arbitrary and optimal pollution targets, as we move from a pollution standard plus uniform increases in taxes, to a conventionally calculated "revenue-ignoring" policy, to a constrained pollution taxsubsidy, and then to a pure pollution tax. This strengthens the theoretical case for using taxes rather than standards.

Phelps, Charles E.

TI Economic Foundations of Cost-Effectiveness Analysis. AU Garber, Alan M.; Phelps. Charles E.

Phillips, Peter C. B.

PD July 1992. TI Bayesian Model Selection and Prediction with Empirical Applications. AA Yale University and University of Auckland. SR Yale Cowles Foundation Discussion Paper: 1023; Yale University, Cowles Foundation, Box 2125. Yale Station. New Haven CT 06520. PG 15. PR no charge. JE C11, C50, C51, C52. KW Bayes Model. Bayesian Measure. Model Selection. Forecast.

AB This paper builds on some recent work by the author and Werner Ploberger $(1991,1992)$ on the development of "Bayes models" for time series and on the the authors' new model selection criterion "PIC". The PIC criterion is used in this paper to determine both the lag order and the trend degree in an autoregression with deterministic trend. A new forecast encompassing test for "Bayes models" is developed which allows one Bayes model to be compared with another on the basis of their respective forecasting performance. The paper reports an extended empirical application of the new methodology to the Nelson-Plosser (1982)/Schotman-Van Dijk (1991) data. It is shown that simple, parsimonious "Bayes models" forecast-encompass fixed "Bayes models" of the "AR(3) + linear trend" variety for most of these series. In some case, the forecast performance of the parsimonious "Bayes models" is substantially superior. The results cast doubt on the value of working with fixed format time series models in empirical research and demonstrate the practical advantages of evolving format "Bayes models". The paper makes a new suggestion for modelling interest rates in terms of reciprocals of levels rather than levels (which display more volatility) and shows that the best data-determined model for this transformed series is martingale.
PD August 1992. TI Bayes Models and Forecasts of Australian Macroeconomic Time Series. AA Yale University and University of Auckland. SR Yale Cowles Foundation Discussion Paper: 1024; Yale University, Cowles Foundation, Box 2125. Yale Station, New Haven CT 06520. PG 16. PR no charge. JE C11, C50, C51, C52. KW Bayes Model. Bayes Measure. Model Selection.

AB This paper provides an empirical implementation of some recent work by the author and Werner Ploberger on the development of "Bayes models" for time series. The methods offer a new data-based approach to model selection. to hypothesis testing and to forecast evaluation in the analysis of time series. A particular advantage of the approach is that modeling issues in such as lag order, parameter constancy, and the presence of deterministic and stochastic trends all come within the compass of the same statistical methodology, as do the evaluation of forecasts from competing models. The paper shows how to build parsimonious empirical "Bayes models" using the new approach and applies the methodology to some Australian macroeconomic data. "Bayes models" are constructed for 13 quarterly macroeconomic time series over the period 1959(3)-1987(4). These models are compared with certain fixed format models (like an $\mathrm{AR}(4)+$ linear trend) in terms of their forecasting performance over the period 1988(1)-1991(4).

PD August 1992. TI Bayes Method for Trending Multiple Time Series with an Empirical Application to the U.S. Economy. AA Yale University and University of Auckland. SR Yale Cowles Foundation Discussion Paper: 1025; Yale University, Cowles Foundation. Box 2125, Yale Station, New Haven CT 06520. PG 50. PR no charge. JE C11. C32. C51. KW Bayes Model. Bayes Measure. Causality. Cointegration.

AB Multiple time series models with stochastic regressors are considered and primary attention is given to vector autoregressions (VAR's) with trending mechanisms that may be stochastic, deterministic or both. In a Bayesian framework the data density in such a system implies the existence of a time series "Bayes model" and "Bayes measure" of the data. These are predictive models and measures for the next period observation given the historical trajectory to the present. Issues of model selection, hypothesis testing and forecast evaluation are all studied within the context of these models and the measures are used to develop selection criteria, test statistics and encompassing tests within the compass of the same statistical methodology. Of particular interest in applications are lag order and trend degree, causal effects, the presence and number of unit roots in the system, and for integrated series the presence of cointegration and the rank of the cointegration space, which can be interpreted as an order selection problem. The paper develops a statistical framework for addressing these features of multiple time series and reports an extended empirical application of the methodology to a model of the U.S. economy that sets out to explain the behavior of and to forecast interest rates, unemployment, money stock, prices and income.

\section{Piccione, Michele}

PD May 1992. TI Finite Automata Play a Repeated Extensive Game. AU Piccione, Michele; Rubinstein, Ariel. AA Piccione: University of British Columbia. Rubinstein: Tel Aviv University. SR University of British Columbia Department of Economics Discussion Paper: : Department of Economics, University of British Columbia 997-1873 East 
Mall. Vancouver, B.C. Canada V6T 1W5. PG 18. PR JE C70. KW Game Theory. Bounded Rationality. AB The paper analyses a two-player game in which each player has to choose an automaton (machine) which plays an infinitely repeated extensive game. We assume that the preferences of the players depend both on repeated game payoffs and the number of states of their machine. In contrast to repeated normal form games. it is shown that if the stage-game is an extensive game with perfect information, any Nash equilibrium of the machine game will induce a path consisting of a constant play of a Nash equilibrium of the stage-game.

TI The Economics of Hubs: The Case of Monopoly. AU Hendricks, Ken; Piccione, Michele; Tan, Guofu.

Pindyck, Robert S.

TI Uncertainty. Investment, and Industry Revolution. AU Caballero, Ricardo J.; Pindyck, Robert S.

\section{Pischke, Jorn-Steffen}

TI A Comparative Analysis of East and West German Labor Markets Before and After Unification. AU Krueger, Alan B.; Pischke, Jorn-Steffen.

\section{Pissarides, Christopher A.}

PD August 1992. TI Search Theory at Twenty-One. AA London School of Economics. SR Centre for Economic Performance Discussion Paper: 90; The Centre for Economic Performance. The London School of Economics and Political Science. Houghton Street, London WC2A 2AE, ENGLAND. PG 25. PR no charge. JE J64. KW Unemployment. Vacancies. Matching Search Function.

AB This paper reviews recent work in search theory, twentyone years after the publication of the influential Phelps volume. It concentrates on work that builds on the concept of the matching function. It reviews the empirical foundations of the matching function, its implications for labor market equilibrium. in particular wage formation and employment dynamics, and suggests directions for future work.

\section{Platen, Eckhard}

TI Option Pricing under Incompleteness and Stochastic Volatility. AU Hofmann. Norbert; Platen, Eckhard; Schweizer, Martin.

\section{Polak, Ben}

Tl Property Transactions in Ireland, 1708-1988: An Introduction. AU O'Rourke, Kevin; Polak, Ben.

\section{Porter, Richard D.}

TI The Continuing Weakness in M2. AU Feinman, Joshua N.; Porter, Richard D.

\section{Postlewaite, Andrew}

TI On Modeling Cheap Talk in Bayesian Games. AU Matthews, Steven A.; Postlewaite, Andrew.

Potter, Simon M.

TI Equilibrium Asset Pricing Models and Predictability of Excess Returns: Theory and Evidence. AU Pesaran, M. Hashem; Potter, Simon M.

\section{Pourbabai, Behnam}

TI Strategic Marketing, Production, and Distribution Planning of an Integrated Manufacturing System. AU Van Wassenhove, Luk; Ashayeri, Jalal; Pourbabai, Behnam.

\section{Poyago-Theotoky, Joanna}

PD October 1992. TI Optimum versus Equilibrium R\&D Cooperation in Oligopoly. AA University of Bristol. SR University of Bristol Economics Working Paper: 92/342; Department of Economics, University of Bristol, Alfred Marshall Bldg., 8 Woodland Road, Bristol BS8 1TN, ENGLAND. PG 38. PR No charge. JE O31, L13, L15. KW Joint Venture. Information Spillover.

AB This paper analyzes a simple oligopoly model with information spillovers where firms spend on R\&D that will affect their costs of production. It is shown that when a Research Joint Venture (RJV) is formed among a subset of the firms comprising the industry there is always an improvement over the non-cooperative case; that is, firms in a RJV are able to produce more R\&D output (cost reduction) by spending relatively less in comparison to the non-cooperating firms. However, the main finding of the present paper is that, depending on the magnitude of the information spillover, the market may not provide enough incentives for the optimum degree of cooperation to take place. It is shown that the equilibrium size of a RJV is usually less than the optimum size. where the optimum requires all firms to participate in a cooperative agreement. The policy implications of the above result are that, in certain circumstances, there should be clear encouragement for firms competing in high-technology industries to form industry wide cooperative agreements.

\section{Prescott, E.}

TI Liquidity Constraints in Economies with Aggregate Fluctuations: A Quantitative Exploration. AU DiazGimenez, J.: Prescott. E.

TI Banking in Computable General Equilibrium Economies. AU Diaz-Gimenez, J.; Prescott. E.; Fitzgerald, T.; Alvarez, F.

Price, Lydia J.

PD May 1992. TI Recursive Least-Squares Approach to Data Transferability: Exposition and Numerical Results. AU Price. Lydia J.: Vanhonacker, Wilfried R. AA INSEAD. SR INSEAD Working Papers: 92/38/MKT: INSEAD, Boulevard de Constance, Fontainebleau, 77305 Cedex. FRANCE. PG 20. PR not available. JE C10, C52, M31. KW Transferability. Random Coefficient Regression. Recursive Least Squares.

AB Data transferability refers to the transfer of information from a set of independently estimable models to a new but structurally equivalent model for which data on some predictors are missing. Using a random-coefficient regression framework this paper discusses a recursive least-squares approach to execute the transfer and estimate all parameters of the new model. Numerical results document the method's sensitivity to practically relevant dimensions and, as such. establish its general applicability.

\section{Purvis, Douglas D.}

PD September 1992. TI Economic Integration, Currency Areas. and Macroeconomic Policy. AA Queen's University. SR Queen's Institute for Economic Research Discussion 
Paper: 859: Department of Economics, Queen's University, Kingston, Ontario. CANADA K7L 3N6. PG 38. PR \$3.00 Canada: \$3.50 U.S. and elsewhere. JE F36. F31, F33, F13. KW Free Trade Agreement. Exchange Rates.

AB In this essay I review some of the issues pertaining to the performance of flexible exchange rates. but the primary focus of the essay is on the exchange rate implications of economic integration. Of particular interest is the Canada-US Free Trade Agreement and which now appears likely to evolve into a broader North American Free Trade Agreement, or NAFTA, incorporating Mexico. While the FTA to date has not given rise to any strong constituency for a North American monetary union, the increased international integration that the FTA and NAFTA represent has led to renewed interest in the debate over whether Canada's national interests might be better served with a fixed exchange rate vis a vis the U.S. dollar. I reject the case for a fixed Canada-U.S. exchange rate, and argue that the current Bank of Canada regime--a flexible exchange rate with a medium-term inflation target--is not only appropriate but the only one supported by available evidence and theory about how the economy functions.

\section{Putterman, Louis}

TI Incentives and Monitoring in Cooperatives Under Labor-Proportionate Sharing Schemes. AU Bonin, John P.; Putterman, Louis.

\section{Qin, Cheng-Zhong}

TI Concavifiability and the Marginal Rate of Substitution. AU Garratt, Rod; Qin, Cheng-Zhong.

\section{Quinzii, Martine}

TI Infinite Horizon Incomplete Markets. AU Magill, Michael J. P.: Quinzii, Martine.

\section{Ramaswamy, Ramana}

PD January 1992. TI Growth and Structural Change in the Swedish Model. AU Ramaswamy, Ramana; You. Jong-il. AA University of Cambridge. SR University of Cambridge Department of Applied Economics Working Paper: 9203: Department of Applied Economics. University of Cambridge. Sidgwick Avenue, Cambridge CB3 9DE. UNITED KINGDOM. PG 23. PR $\$ 5.00$ (L2.50), checks payable to University of Cambridge. JE J51. O41. O52. KW Collective Bargaining. Endogenous Growth. Efficiency Wages.

AB The relationship between wage bargaining institutions and labor market performance constituted an important agenda for research in labor economics in the 1980's. The focus of the paper is, however, on the relationship between wage bargaining institutions and growth. The Swedish experience with solidaristic bargaining - i.e. a combination of centralized bargaining and wage equalization - is used as a case study for analyzing this relationship. Wage bargaining institutions and growth are linked in this paper by structural change. We provide a two-sectoral "endogenous growth" model with efficiency wage properties for explaining both the successes and failures of the Swedish model.

\section{Ramsey, James B.}

PD June 1992. TI A Reassessment of Dimension Calculation Using Some Monetary Data. AU Ramsey, James B.; Rothman, Phillip. AA Ramsey: New York University.
Rothman: East Carolina University. SR New York University Economic Research Reports: 92-28; New York University, Faculty of Arts and Science, Department of Economics, Washington Square. New York, N.Y. 10003. PG 13. PR no charge. JE C22, E40. KW Chaos. Nonlinearity. Small Sample Bias.

AB In a previous article Ramsey and Rothman wamed against incautious use of the Grassberger-Procaccia procedure to estimate correlation dimension with relatively small data sets and recommended an improved procedure. In this paper we apply those techniques to a series used by DeCoster and Mitchell who claimed that their dimension calculations produced evidence of chaos. We show that even with the enhanced procedures of Ramsey and Yuan, there is no evidence for a simple attractor in these data. However, dimension calculations do not provide evidence either for or against the presence of nonlinear dynamical processes that are not restricted to attracting sets.

TI The Privatization of the New York City Subway. AU de Bartolome, Charles A. M.; Ramsey, James B.

Rao, Vijayendra

PD July 1992. TI Does "Prestige" Matter? Compensating Differentials for Social Mobility in the Indian Caste System. AA NORC and University of Chicago. SR Economics Research Center/NORC Population Research Center Discussion Paper: 92-6; Librarian. Economics Research Center/NORC, 1155 E. 60th St.. Chicago, II 60637. PG 16. PR \$2.00. JE J24, A13. O53. KW India. Occupational Choice.

AB A fair amount of theoretical work has attempted to incorporate social factors into formal economic models, but few economists have attempted to test whether such "social consumption" matters. In this paper, I test if there are compensating differentials associated with the prestige of an occupation in the context of the Indian caste system. The caste system divides a community into hierarchical strata. All individuals are born into a particular caste which is associated with a traditional occupation. If individuals gain utility from being in the more prestigious traditional occupation of a higher-ranked caste, theory predicts that some individuals, when choosing an occupation, will tradeoff the income generated by the occupation for its prestige value. The theory is tested with panel data on rural households spread over ten villages in India. Strong compensating differentials for prestige mobility are found, indicating that individuals value the social prestige inherent within an occupation.

\section{Rappoport, Peter}

PD June 1992. TI Matemal Age as an Indication for Amniocentesis: An Evaluation of the "35-Plus" Rule. AU Rappoport, Peter; Sicherman, Nachum. AA Rappoport: Rutgers University. Sicherman: Columbia University. SR Columbia First Boston Series in Money, Economics and Finance Working Paper: FB-92-21: Columbia University, Graduate School of Business, First Boston Series, New York, NY 10027. USA. PG 18. PR \$5.00 academics and non-profit institutions; $\$ 6.00$ corporations (add $\$ 1.00$ outside U.S., Canada and Puerto Rico). JE I12, J13, D61. KW Health Care. Pregnancy. Cost-Benefit Analysis.

AB Amniocentesis is recommended to expectant mothers 35 or older, but not to younger women who have no other indications for potential abnormality, unless they specifically 
request it. We show that the "35-plus" rule ignores patients" attitudes toward the possible adverse outcomes: an abortion induced by the procedure, and the birth of a chromosomally abnormal child. Instead of balancing expected costs and benefits, the 35-plus rule balances only the probabilities of the two adverse outcomes, and is correct only if the patient regards each as equally bad. We also examine the probabilities associated with different outcomes based on recent literature.

Rasquero, A.

TI Approximate HPD Regions for Testing Residual Autocorrelation Using Augmented Regressions. AU Bauwens, L.; Rasquero, A.

\section{Ratliff, William E.}

PD October 1992. TI The Same Monkey in Managua. AA Stanford University. SR Stanford Hoover Institute International Studies Working Paper: I-92-11: The Hoover Institution. Stanford University, Stanford, CA 94305. PG 15. PR no charge. JE H11. KW Nicaragua. Sandinistas. Dictatorship.

AB During the 1970's Nicaragua rose up against Anastasio Somoza, in the end under the primary leadership of the Sandinista National Liberation Front (FSLN). In the 1980's violent and non-violent opposition to the FSLN's National Directorate drove the most unlikely of parties into the same political bed, those ranging from the conservative right to the Marxist-Leninist left. In each decade, the majority of Nicaraguans simply wanted to get repressive monkeys off their backs. I will begin by focusing on the three fundamental components of Directorate thought which, when pursued as government policy, dragged Nicaragua into both its second civil war in as many decades and certain conflict with the United States. I will then turn to the interrelated common repressive features of Somocismo and Sandinismo and focus on the political and military violence of the Sandinista revolution which precipitated the "counterrevolution.".

Rausser, Gordon C.

TI Intraorganizational Influence Relations and the Optimality of Collective Action. AU Zusman, Pinhas; Rausser, Gordon C.

\section{Ray, Debraj}

PD May 1992. TI Equilibrium Binding Agreements. AU Ray, Debraj; Vohra, Rajiv. AA Ray: Boston University and Indian Statistical Institute. Vohra: Brown University. SR Brown University Department of Economics Working Paper: 92-8: Department of Economics. Brown University, Providence, Rhode Island 02912. PG 34. PR no charge. JE C71, C78. D43. KW Cournot Oligopoly. Binding Agreements. Coalition Structure.

AB This paper studies binding agreements, and the coalition structures that form under such agreements. We start with a game in strategic form, and assume that is possible to write such agreements. Our task is to characterize, in a consistent way, what coalitions can credibly achieve once they object to a particular proposal. This leads to our solution concept, which is then used to analyze the class of symmetric TU games. In particular. we study the Cournot oligopoly and show that despite the intrinsic advantages to merging, the grand coalition will not form, in general, under a binding agreement.

\section{Razin, Assaf}

PD September 1992. TI International Migration and International Trade. AU Razin, Assaf; Sadka, Efraim. AA Tel-Aviv University. SR Tel-Aviv Sackler Institute for Economic Research Working Paper: 11/92; Department of Economics, Tel-Aviv University, Ramat Aviv 69978, Tel-Aviv. ISRAEL. PG 42. PR no charge. JE F10, F20. KW Migration. Trade. Factor Mobility.

AB The study of international trade and international migration occupies a relatively small part of standard economic analysis. Conventionally, international trade theory tends to ignore international migration, which essentially changes the distribution of national communities. Similarly, the literature on international migration typically abstracts from the effects of labor migration on international flows of goods, services and capital. This chapter, which combines elements from these seemingly disjoint parts of the literature and presents them in a consistent analytical framework, lays the ground for the integration of the two disciplines into a unified treatment.

\section{Reed, Randal}

PD August 1992. TI An Analysis of Post-Product Development Market Research. AA Northwestern University. SR Northwestern University Center for Mathematical Studies in Economics and Management Science Discussion Paper: 996; J.L. Kellogg Graduate School of Management, Northwestern University, 2001 Sheridan Road, Evanston, IL 60208. PG 19. PR per copy: $\$ 3.00$ U.S. and Canada. $\$ 5.00$ via international mail. Make check payable to Northwestern University. JE D43, L13, L15, D50. KW Market Research. Oligopolistic Behavior. Imperfect Information.

AB This paper examines a model of post-product development market research that allows firms to improve their information about demand curves. The process does not allow perfect information at finite expenditure levels. The model examines oligopolistic behavior and social welfare in the heterogeneous product world. The basic results derived are that investment of this type bears no externality to other firms in the market and a negative externality to consumers in the market from the improved information of the firm. These results are robust across several extensions which are presented in the paper. Conclusions for policy toward firms engaging in postproduct market research are drawn for several different international market scenarios.

\section{Reinhart, Carmen M.}

TI Capital Inflows and Real Exchange Rate Appreciation in Latin America: The Role of External Factors. AU Calvo. Guillermo A.; Leiderman, Leonardo; Reinhart, Carmen M.

\section{Renault, E.}

TI Indirect Inference. AU Gourieroux, C.: Monfort. A.; Renault, E.

\section{Reny, Philip}

TI A Non-Cooperative View of Coalition Formation and the Core. AU Perry, Motty: Reny, Philip.

\section{Revesz, Richard L.}

TI Multi-Defendant Settlements: The Impact of Joint and Several Liability. AU Kornhauser, Lewis A.; Revesz, Richard L. 
Rice, Patricia

TI Output and Employment During the Interwar Period: The Case of the Ship-Building Industry. AU Gazeley, Ian; Rice, Patricia.

\section{Richardson, Matthew}

TI Testing Inequality Restrictions Implied from Conditional Asset Pricing Models. AU Boudoukh. Jacob; Richardson. Matthew; Smith, Tom.

TI The Equity Risk Premium and the Term Structure: Two Centuries of Evidence. AU Boudoukh, Jacob; Richardson, Matthew: Whitelaw, Robert F.

\section{Riddell, W. Craig}

TI The Economic Effects of Unemployment Insurance in Canada: An Empirical Analysis of UI Disentitlement. AU Green. David A.; Riddell. W. Craig.

\section{Rietz, Thomas A.}

PD July 1992. TI Implementing and Testing Risk Preference Induction Mechanisms in Experimental Sealed Bid Auctions. AA Northwestern University. SR Northwestern University Center for Mathematical Studies in Economics and Management Science Discussion Paper: 993; J.L. Kellogg Graduate School of Management. Northwestern University, 2001 Sheridan Road. 3-014 Leverone Hall. Evanston. Il 60208. PG 15. PR per copy: $\$ 3.00$ in the U.S.A. or Canada; $\$ 5.00$ via international mail. Make check payable to Northwestern University. JE B40, C14, C72, C92, D80. KW Sealed Bid Auctions. Risk Preference Induction. Experimental Design. Expected Utility Hypothesis.

AB Lottery procedures for inducing risk preferences can serve as valuable tool for experimental economists. However, questions about their effectiveness may make experimenters hesitate to use such procedures even when predictions and conclusions depend crucially on risk preferences. Here, I review attempts to induce risk preferences in sealed bid auction experiments. I discuss factors that promote or hinder success. Making the procedure as transparent as possible and allowing subjects to accustom themselves to it in simple environments promote success. Hysteresis effects resulting from switching between monetary payoffs and lottery procedures in a single environment hinder success. Thus, lottery procedures appear sensitive to how they are implemented. However, implemented carefully, they can generate behavior consistent with the intended risk preferences.

\section{Rob, Rafael}

TI Evolution of Equilibria in the Long Run: A General Theory and Applications. AU Kandori. Michihiro; Rob, Rafael.

Roberts, John M.

PD July 1992. TI Limited-Information Estimates of New Keynesian Price-Adjustment Models. AA Board of Governors of the Federal Reserve System. SR Board of Governors of the Federal Reserve System Economic Activity Section Working Paper: 127; Board of Governors of the Federal Reserve System Economic Activity Section. Stop \#80. Federal Reserve Board, Washington, D.C. 20551. PG 21. PR no charge. JE E31, C52, D84. KW Inflation. Expected Prices. AB In New Keynesian models, price adjustment does not occur immediately. As a result, expectations of future prices are an important part of the model. This paper presents limitedinformation estimates of such models using both surveys of inflation expectations and actual future values, which are a valid proxy under certain assumptions. The estimates using surveys are generally significant and consistent with theory. Estimates using actual outcomes, though, are less structurally stable over time. Thus, surveys may be better proxies than actual future values, introducing less error and requiring few econometric assumptions.

\section{Robinson, Sherman}

TI Labor Issues in a North American Free Trade Area.

AU Hinojosa-Ojeda, Raul; Robinson, Sherman.

\section{Roe, Terry}

TI Endogenous Growth. Health and the Environment. AU Mohtadi, Hamid; Roe, Terry.

\section{Roemer, John E.}

PD September 1992. TI A Proposal for Denationalizing the State Sector When Pollution is an Issue. AA University of California, Davis. SR University of California at Davis Economics Department Working Paper: 404; Department of Economics. University of California at Davis, Davis. CA 95616. PG 23. PR \$3.00 U.S. and Canada. $\$ 4.00$ international. JE D62, P51, D58. KW Property Rights Reform. Stock Market. Market Socialism.

AB This paper contrasts the general equilibrium welfare effects of "straight privatization," when the ownership of formerly state firms is distributed on a per capita basis and trading of shares on a stock market follows, with a "limited privatization" proposal. In the latter shares are also initially equally distributed to adult citizens in the form of coupons, and trade can take place on a coupon stock market, where prices of shares are quoted only in coupons, not roubles (the money currency). The welfare of the population is compared in the equilibrium of the economy with straight privatization to that in the equilibrium of the coupon economy: because of a public bad, it turns out that the coupon equilibrium can be better for the majority of the population. This is a consequence of the fact that concentration of the ownership of firms is precluded in the coupon stock market, which prevents the emergence of a class of citizens who have an economic interest in a high level of the public bad.

PD September 1992. TI The Use of Campaign Finance to Influence Voter's Beliefs. AA University of California, Davis. SR University of California at Davis Economics Department Working Paper: 405; Department of Economics, University of California at Davis, Davis, CA 95616. PG 12. PR \$3.00 U.S. and Canada. \$4.00 international. JE D72. KW Political Economy. Electoral Equilibrium.

AB Voters have preferences over economic outcomes, in which each consumes a private and a public good. They vote. however, over tax policies, not outcomes, where taxes finance the pubic good. Voters are uncertain about the mapping from policies to outcomes, that is, about how the economy works. In particular, they are uncertain about the efficiency with which the government converts tax revenue into the pubic good. There are three classes: rich, middle, and poor voters, with the same preferences over the private and pubic good. There are two parties. one representing the interests of the poor, the other of the rich. The electoral equilibrium is a Nash equilibrium 
between these parties, where a party's strategy is a triple consisting of (1) an amount of campaign spending, (2) an announcement about the government's efficiency, and (3) a tax rate it will enact if elected. It is shown. by use of simulation techniques that the equilibrium may well consist in both parties announcing a tax policy of the rich, who comprise only a very small fraction of the electorate.

PD September 1992. TI A Partial Theory of the Link Between Economic Development and Political Economy. AA University of California, Davis. SR University of California at Davis Economics Department Working Paper: 407; Department of Economics, University of California at Davis, Davis, CA 95616. PG 21. PR \$3.00 U.S. and Canada. \$4.00 international. JE D58. D72. D62. KW Political Economy. Voting Models.

AB A politico-economic model is defined, in which consumers, at date 0 , decide how much to invest in a firm. whose production possibilities are determined by the outcome of an election, to be held at date 1 . At date 1 , voters vote on the level of pollution the firm shall be allowed to emit. The main exercise of the paper is to examine to what extent the support for democracy, contra dictatorship, grows among the population as economic development occurs. Economic development is simulated in five different ways, and it is not unambiguously the case that development induces a growing social preference for democracy.

\section{Rogerson, Richard}

TI Income Distribution, Communities and the Quality of Public Education: A Policy Analysis. AU Fernandez, Raquel; Rogerson, Richard.

\section{Rogoff, Kenneth}

PD July 1992. TI Traded Goods Consumption Smoothing and the Random Walk Behavior of the Real Exchange Rate. AA University of California, Berkeley and National Bureau of Economic Research. SR National Bureau of Economic Research Working Paper: 4119; National Bureau of Economic Research, 1050 Massachusetts Avenue, Cambridge, MA 02138. PG 33. PR \$5.00. JE F31, E21. KW Exchange Rates. Consumption Smoothing.

AB Conventional explanations of the near random walk behavior of real exchange rates rely on near random walk behavior in the underlying fundamentals (e.g., tastes and technology). The present paper offers an alternative rationale. based on a fixed-factor neoclassical model with traded and non-traded goods. The basic idea is that with open capital markets. agents can smooth their consumption of tradeables in the face of transitory traded goods productivity shocks. Agents cannot smooth non-traded goods productivity shocks, but if these are relatively small (as is often argued to be the case) then traded goods consumption smoothing will lead to smoothing of the intra-temporal price of traded and non-traded goods. The (near) random walk implications of the model for the real exchange rate are in stark contrast to the empirical predictions of the classic Balassa-Samuelson model. The paper applies the model to the yen-dollar exchange rate over the floating rate period.

TI Global versus Country-Specific Productivity Shocks and the Current Account. AU Glick, Reuven; Rogoff, Kenneth.
Roller, Lars-Hendrik

TI Trade Liberalization. Transportation. and the Environment. AU Gabel, H. Landis; Roller, Lars-Hendrik.

PD June 1992. TI Preemptive Investment with Resalable Capacity. AU Roller, Lars-Hendrik; Krishnan, Murugappa. AA Roller: INSEAD. Krishnan: Purdue University. SR INSEAD Working Papers: 92/44/EP: INSEAD, Boulevard de Constance. Fontainebleau, 77305 Cedex. FRANCE. PG 23. PR not available. JE L11, E22. KW Entry. Limited Commitment.

AB We study an entry game under perfect information, with the salient feature that capacity is resalable. While entry itself is easier - entry deterrence is never even feasible with small fixed costs -- it may still be the incumbent, and not the entrant. who is better off. Only for large fixed costs can the incumbent be worse off with resalable capacity. Other analyses of limited commitment do not specify the sources of limits to commitment. By assuming that such limits arise from the resalable nature of capacity, we are led naturally to a consideration of additional strategic variables which can improve the incumbent's position in our model. Resalability increases the complexity of the incumbent's precommitment problem, but also furnishes her with an additional source of power -- in our model the price at which to resell capacity. The very existence of a resale market can generate an incentive for a much larger initial level of investment, to the point where the overall equilibrium outcome can be more competitive.

\section{Romer, Christina D.}

PD August 1992. TI Remeasuring Business Cycles. AA University of California, Berkeley and National Bureau of Economic Research. SR National Bureau of Economic Research Working Paper: 4150; National Bureau of Economic Research, 1050 Massachusetts Avenue. Cambridge. MA 02138. PG not available. PR \$5.00. JE E30, E32, E37. KW Business Cycles. Business Cycle History.

AB This paper evaluates the consistency of the NBER business cycle reference dates over time. Analysis of the NBER methods suggests that the early turning points are derived from detrended data, while the dates after 1927 are derived from data in levels. To evaluate the importance of this and other changes in technique, the paper derives a simple algorithm that matches the postwar NBER peaks and troughs closely. When this algorithm is applied to data for 1884-1940, the new dates systematically place peaks later and troughs earlier than do the NBER dates. Using the new business cycle chronology, recessions have not become shorter. less severe. or less persistent between the pre-World War I and the post-World War II eras. Expansions, however, have become longer.

\section{Romer, David}

PD July 1992. TI Rational Asset Price Movements Without News. AA University of California, Berkeley and National Bureau of Economic Research. SR National Bureau of Economic Research Working Paper: 4121; National Bureau of Economic Research, 1050 Massachusetts Avenue, Cambridge, MA 02138. PG 40. PR \$5.00. JE G12. G14. KW Asset Prices. Investor Information.

AB This paper argues that an important part of movements in asset prices may be caused by neither external news nor irrationality, but by the revelation of information by the trading process itself. Two models are developed that illustrate this general idea. One model is based on investor uncertainty about 
the quality of other investors' information; the other is based on widespread dispersion of information and small costs to trading. The analysis is used to suggest a possible rational explanation to the October 1987 crash.

\section{Rosen, Asa}

PD September 1992. TI An Equilibrium SearchMatching Model of Discrimination. AA London School of Economics and Institute for Economic Research. Sweden. SR London School of Economics Centre for Economic Performance Discussion Paper: 97; Centre for Economic Performance, London School of Economics, Houghton Street, London WC2A 2AE, ENGLAND. PG 18. PR no charge. JE J71. J31, D82. KW Incomplete Information. Employment.

AB A model in which firms have incomplete information about workers at the hiring stage is shown to entail discrimination as the unique stable equilibrium outcome, even if no agents have a taste for discrimination. Discriminated groups (e.g., blacks, women) earn lower wages, endure longer unemployment spells, and must satisfy stricter requirements in order to obtain work.

\section{Rosen, Harvey S.}

TI The Carnegie Conjecture: Some Empirical Evidence. AU Holtz-Eakin. Douglas; Joulfaian. David: Rosen. Harvey S.

Rosenwald, F.

TI Relations Verticales, Integration et Barrieres a l'Entree. AU Bayet. A.: Rosenwald. F.

Rotella, Elyce

TI The Savings of Ordinary Americans: The Philadelphia Saving Fund Society in the Mid-Nineteenth Century. AU Alter, Gearge; Rotella, Elyce; Goldin, Claudia.

\section{Rothman, Phillip}

TI A Reassessment of Dimension Calculation Using Some Monetary Data. AU Ramsey. James B.; Rothman, Phillip.

\section{Rubinstein, Ariel}

TI Finite Automata Play a Repeated Extensive Game. AU Piccione, Michele; Rubinstein, Ariel.

\section{Russell, Armistead}

TI Electric Vehicles and the Environment: Consequences for Emissions and Air Quality in Los Angeles and U.S. Regions. AU Dowlatabadi. Hadi; Krupnick, Alan J.: Russell. Armistead.

\section{Rust, John}

PD May 1992. TI Do People Behave According to Bellman's Principle of Optimality? AA University of Wisconsin. SR Hoover Institute Working Papers in Economics: E-92-10; Domestic Studies Program Working Paper Series, Hoover Institution. Stanford University, Stanford. CA 94305. PG 76. PR not available. JE C10, C60, D80. D90. KW Dynamic Programming. Maximum Likelihood. Method of Moments.

AB This paper investigates whether the main mathematical procedure for solving sequential decision problems under uncertainty, dynamic programming (DP), provides a good model of the way humans actually solve such problems. The theory implies that behavior is determined by a decision rule that satisfies Bellman' principle of optimality. In infinitehorizon Markovian decision problems (MDP), Bellman's principle implies Blackwell's theorem; an optimal decision rule is stationary and Markovian. I show that without further restrictions on an MDP problem, Blackwell's Theorem provides a necessary and sufficient characterization of optimal decision rules, implying that Bellman's principle per se has no empirically testable content. However if researchers are willing to impose a priori identifying restrictions on the functional forms of agents' preferences and beliefs, the theory does lead to strong testable restrictions.

\section{Rustichini, Aldo}

PD August 1992. TI Converge to Efficiency in a Simple Market with Incomplete Information. AU Rustichini. Aldo; Satterthwaite, Mark A.; Williams, Steven R. AA Rustichini: New York University. Satterthwaite: Northwestern University. Williams: University of Illinois, Urbana-Champaign. SR Northwestern University Center for Mathematical Studies in Economics and Management Science Discussion Paper: 995; J.L. Kellogg Graduate School of Management. Northwestern University, 2001 Sheridan Road, 3-014 Leverone Hall, Evanston, IL 60208. PG 43. PR per copy: $\$ 3.00$ in the U.S.A. or Canada: $\$ 5.00$ via international mail. Make check payable to Northwestern University. JE D82, D44. C72, C78. KW Incomplete Information. Double Auction.

AB An independent private values model of trade with $\mathrm{m}$ buyers and $\mathrm{m}$ sellers is considered in which a double auction sets price to equate revealed demand and supply. In a symmetric Bayesian Nash equilibrium, each trader acts not as a price-taker, but instead strategically misrepresents his true demand/supply to influence price in his favor. This causes inefficiency. We show that the amount by which a trader misreports is $O(1 / \mathrm{m})$ and the corresponding inefficiency is $0\left(1 /\left(m^{2}\right)\right)$. By comparison, inefficiency is $0(1 / m)$ for a dual price mechanism and $0\left(1 / \mathrm{m}^{\wedge} .5\right)$ ) for a fixed price mechanism. Price-taking behavior and its associated efficiency thus quickly emerge in the double auction despite the asymmetric information and the noncooperative behavior of traders.

\section{Ruud, Paul A.}

TI Simulation of Multivariate Normal Orthant Probabilities: Theoretical Computational Results. AU Hajivassiliou, Vassilis A.; McFadden. Daniel L.; Ruud, Paul A.

\section{Sabourian, Hamid}

TI Cooperation and Effective Computability. AU Anderlini, Luca; Sabourian. Hamid.

\section{Sadeghi, Mehidi}

PD August 1992. TI Stock Market Response to Unexpected Macroeconomic News: The Australian Evidence. AA University of Western Sydney and International Monetary Fund. SR International Monetary Fund Working Paper: 92/61; International Monetary Fund, Washington, DC 20431. PG 9. PR not available. JE G14. KW Stock Returns. Surprise News.

AB This paper provides empirical evidence on the relationship between unexpected changes in macroeconomic variables and Australian stock returns over the period 1980- 
1991. The results suggest that stock returns are positively correlated with any surprise news in the current account deficit. the exchange rate and growth rate of real GDP, and negatively correlated with surprise news about the inflation rate and interest rates. Stock returns are also positively correlated with the unexpected unemployment rate and negatively correlated to revisions in the expected unemployment rate. The results furthermore suggest that market portfolios can detect the impact of common economic shocks better than the portfolios of the two main subsectors of the market.

\section{Sadka, Efraim}

TI International Migration and International Trade. AU Razin, Assaf; Sadka, Efraim.

\section{Samuelson, Larry}

TI The Evolutionary Foundations of Backward and Forward Induction. AU Noldeke, Georg: Samuelson. Larry.

\section{Satchell, Stephen}

TI The Black and Scholes Option Price as a Random Variable. AU Ncube, Mthuli; Satchell. Stephen.

\section{Satterthwaite, Mark A.}

TI Converge to Efficiency in a Simple Market with Incomplete Information. AU Rustichini. Aldo: Satterthwaite. Mark A.; Williams. Steven R.

\section{Saunders, Anthony}

TI Excessive Gambling with Unfavorable Odds: Financial Institutions' Real Estate Investments. AU Mei, Jianping; Saunders. Anthony.

TI Universal Banking: Should Banks Hold Equity in Borrowing Firms? AU Berlin, Mitchell; John, Kose; Saunders, Anthony.

\section{Scarf, Herbert E.}

PD September 1992. TI Tjalling Charles Koopmans (August 28, 1910 - February 26, 1985). AA Yale University. SR Yale Cowles Foundation Discussion Paper: 1029; Yale University, Cowles Foundation, 30 Hillhouse Ave., Box 2125. Yale Station. New Haven CT 06520. PG 26. PR no charge. JE B31. KW Biography.

AB A biographical memoir of Tjalling Charles Koopmans.

TI The Complex of Maximal Lattice Free Simplices. AU Barany, Imre; Howe, Roger; Scarf, Herbert E.

\section{Schadler, Susan}

TI Interest Rate Policy in Central and Eastern Europe: The Influence of Monetary Overhangs and Weak Enterprise Discipline. AU Bennett, Adam; Schadler, Susan.

\section{Schmeidler, David}

TI A More Robust Definition of Subjective Probability. AU Machina. Mark J.; Schmeidler, David.

TI Case-Based Decision Theory. AU Gilboa, Itzhak; Schmeidler, David.

\section{Schmidt, Klaus M.}

TI Unverifiable Information, Incomplete Contracts, and Renegotiation. AU Noldeke, Georg; Schmidt, Klaus M.
PD June 1992. TI Privatization and Management Incentives in the Transition Period in Eastern Europe. AU Schmidt, Klaus M.; Schnitzer. Monika. AA University of Bonn and Massachussetts Institute of Technology. SR Universitat Bonn Sonderforschungsbereich 303Discussion Paper: A-374; Sonderforschungsbereich 303 an der Universitat Bonn Adenauerallee 24-42, D-5300 Bonn 1, GERMANY. PG 31. PR no charge. JE D82, P50, O52. KW Privatization. Principal-Agent Theory. Economic Reform. Eastern Europe.

AB Privatization and Restructuring of large industrial companies is one of the most important and most difficult elements in the current transformation process of the economies in Eastern Europe. This paper develops a simple theoretical framework in which the impact of different governance structures on management incentives, the efficiency of restructuring, and the social costs of the adjustment process can be analyzed. The model allows for a comparison of many of the privatization proposals that have been put forward in recent years. The model predicts that immediate privatization of the firms will lead to strong incentives for managers to restructure but also to high social costs of bankruptcies and layoffs. The model also gives some insights on which companies should be privatized first.

\section{Schmidt, Roland}

PD August 1992. TI On the Stationarity of the Real Exchange Rate and the Role of Transaction Costs. AA University of Bonn. SR Universitat Bonn Sonderforschungsbereich 303 - Discussion Paper: B-218; Sonderforschungsbereich 303 an der Universitat Bonn, Adenauerallee 24-42, D-5300 Bonn 1, DEUTSCHLAND. PG 29. PR no charge. JE F31. KW Purchasing Power Parity. Error Correction Model.

AB This paper investigates the real exchange rate between the German mark and the dollar for stationarity. The different tests we apply show conflicting evidence. The puzzle we resolve by introducing transaction costs that impose a range of real exchange rates to be compatible with purchasing power parity. This interpretation is finally successfully tested within an error correction model.

PD October 1992. TI An Empirical Evaluation of the Portfolio Model for the Dollar-Mark Exchange Rate. AA University of Bonn. SR Universitat Bonn Sonderforschungsbereich 303 - Discussion Paper: B-223; Sonderforschungsbereich 303 an der Universitat Bonn. Adenauerallee 24-42, D-5300 Bonn 1, DEUTSCHLAND. PG 32. PR no charge. JE F31, E43, G15. KW Risk Premium. U. S. Bonds. German Bonds.

AB This paper estimates the monetary and the portfolio model for the dollar-mark exchange rate. It turns out that German and U.S. bonds are imperfect substitutes and the observed exchange rate fluctuations are to a significant part due to a varying risk premium. The risk premium reflects relative indebtedness and inflation risk but not real exchange rate risk.

\section{Schmitz, James A., Jr}

TI Managerial Tenure, Business Age and Small Business Dynamics. AU Holmes, Thomas J.; Schmitz, James A., Jr.

\section{Schnitzer, Monika}

TI Privatization and Management Incentives in the Transition Period in Eastern Europe. AU Schmidt, Klaus M.; 
Schnitzer, Monika.

\section{Schwartz, Aba}

PD September 1992. TI Seniority, Tenure and the Efficiency Wage Paradigm. AA Tel-Aviv University. SR Tel-Aviv Sackler Institute of Economic Studies Working Paper: 12/92: Department of Economics. Tel-Aviv University. Ramat Aviv 69978, Tel-Aviv, ISRAEL. PG 20. PR no charge. JE J30. KW Efficiency Wage. Tenure. Seniority. AB Implicit and explicit contract arguments are typically made to justify the optimality of Tenure and Seniority from the point of view of the firm and its employees. This paper shows that the efficiency wage paradigm provides an alternative theory which implies the optimality of Tenure and/or Seniority for the firm. The efficiency wage model constructed in this paper generates implications (in addition to the optimality of Tenure and Seniority) that are consistent with the relevant stylized facts in the labor market.

\section{Schwartz, Gerd}

TI Currency Substitution: The Recent Experience of Bolivia. AU Clements. Benedict; Schwartz, Gerd.

\section{Schweizer, Martin}

TI Option Pricing under Incompleteness and Stochastic Volatility. AU Hofmann, Norbert; Platen, Eckhard; Schweizer, Martin.

\section{Schweizer, Urs}

PD July 1992. TI Politische Regeln als Unvollstaendige Vertraege: Ursache von Staatsversagen. AA University of Bonn. SR Universitat Bonn Sonderforschungsbereich 303 Discussion Paper: A-372; Sonderforschungsbereich 303 an der Universitat Bonn. Adenauerallee 24-42, D-5300 Bonn 1, DEUTSCHLAND. PG 14. PR no charge. JE E61, L14. KW Incomplete Contracts. Market Failure. Intervention. AB The neoclassical theory of market failure specialized in pointing out sources of market failure, thereby justifying government intervention. The preference of intervention depends implicitly on the assumption that selective intervention is possible. This paper offers the interpretation that the government cannot intervene directly, but rather must employ an agent. Conflicting interests of the principal and the agent create frictions which are responsible for the failure of selective intervention. These frictions are grounded in contract theory. The paper is written in German.

\section{Selten, Reinhard}

PD August 1992. TI Demand Commitment Bargaining in Three-Person Quota Game Experiments. AU Selten. Reinhard; Kuon, Bettina. AA University of Bonn. SR Universitat Bonn Sonderforschungsbereich 303 Discussion Paper: B-219; Sonderforschungsbereich 303 an der Universitat Bonn. Adenauerallee 24-42, D-5300 Bonn 1. DEUTSCHLAND. PG 17. PR no charge. JE C72, C92. KW Demand Commitment Model. Experiments.

AB It is the purpose of this paper to report on experiments with three-person quota games based on a finite laboratory procedure called the demand commitment model. Other computerized methods for playing characteristic function games are infinite extensive games. Strictly speaking, infinite horizon games cannot be played in the laboratory. Therefore it is desirable to develop finite procedures like the demand commitment model. The experiments reported here all concern three-person quota games without the grand coalition and with zero values for the one-person coalitions. The non-cooperative analysis of the demand commitment model applied to threeperson quota games yields quota agreements as neutral equilibrium outcomes. Here the term "neutral" characterizes equilibria with the property that in case of indifference all optimal choices are taken with equal probability.

\section{Serrano, Roberto}

PD October 1992. TI Information Revelation in a Market with Pairwise Meetings: The One Sided Information Case. AU Serrano, Roberto; Yosha, Oved. AA Brown University. SR Brown University Department of Economics Working Paper: 92-21; Department of Fconomics. Brown University. Providence, Rhode Island 02912. PG 29. PR no charge. JE D82. D83. KW Information Revelation. Learning.

AB We study a market with pairwise meetings of agents and with a one sided information asymmetry regarding the state of the world, which may be "low" or "high". We characterize the set of equilibria of the model, and study its behavior as the market becomes approximately frictionless. For any one sided economy there is an equilibrium where trade occurs at the right price (an ex-post individually rational price). Moreover. there is an open set of economies where in all the equilibria trade occurs at the right price.

\section{Shaffer, Sherrill}

PD July 1992. TI A Revenue-Restricted Cost Study of 100 Large Banks. AA Federal Reserve Bank of Philadelphia. SR Federal Reserve Bank of Philadelphia Research Working Paper: 92-11; Working Papers. Department of Research. Federal Reserve Bank of Philadelphia, 10 Independence Mall, Philadelphia. PA 19106. PG 15. PR no charge except overseas airmail, \$2.00; checks/money orders in U.S. funds payable to Federal Reserve Bank of Philadelphia. JE G21, L11. KW Cost Functions. Commercial Banks.

AB A revenue-restricted cost function, derived from duality theory assuming that firms optimize outputs as well as inputs, is estimated for a sample of large commercial banks. This form has the advantages of sidestepping the controversy over the role of deposits in the bank production function, measuring banks' output as a flow rather than a stock, and allowing flexible treatment of the expansion path of a multiproduct bank. The results indicate statistically significant and economically meaningful economies of scale out to large size ranges.

PD July 1992. TI Structure, Conduct, Performance, and Welfare. AA Federal Reserve Bank of Philadelphia. SR Federal Reserve Bank of Philadelphia Research Working Paper: 92-13; Working Papers, Department of Research, Federal Reserve Bank of Philadelphia, 10 Independence Mall, Philadelphia, PA 19106. PG 18. PR no charge except overseas airmail, \$2.00; checks/money orders in U.S. funds payable to Federal Reserve Bank of Philadelphia. JE L10. L22. KW Social Welfare. Structure. Performance.

AB This paper extends previous analysis of weaknesses of the structure-conduct performance paradigm of the price-cost margin as a measure of performance. Sufficient conditions are established under which monotonic-linkages may not exist between virtually any two of social welfare, its individual components, structure. conduct, or performance.

PD August 1992. TI Optimal Linear Taxation of 
Polluting Firms. AA Federal Reserve Bank of Philadelphia. SR Federal Reserve Bank of Philadelphia Research Working Paper: 92-17; Working Papers, Department of Research, Federal Reserve Bank of Philadelphia, 10 Independence Mall. Philadelphia. PA 19106. PG 18. PR no charge except overseas airmail, \$2.00; checks/money orders in U.S. funds payable to Federal Reserve Bank of Philadelphia. JE H21, L51, L13. D62. KW Oligopoly. Regulation. Entry.

AB This paper shows that a simple (linear) ad valorem tax can induce homogeneous firms to produce at socially optimal levels, thereby achieving the first-best allocation for general oligopoly, in the presence of external costs. The optimal tax rate is independent of private cost functions and thus reduces the informational requirements on the regulator. Alternatively, if the regulator knows marginal private costs but not the pattern of firms' conduct or the slope of the demand curve, an iterative implementation of the tax is possible. Both blockaded and endogenous entry are considered, as is strategic behavior by firms toward the regulator.

\section{Shahrokhi, Farhad}

PD January 1992. TI Uniform Concurrent Multicommodity Flow in Product Graphs. AU Shahrokhi, Farhad: Szekely, L. A. AA Shahrokhi: University of North Texas. Szekely: University of Bonn and Eotvos University, Budapest. SR Universitat Bonn Sonderforschungsbereich 303- Discussion Paper: C-92-744; Sonderforschungsbereich 303 an der Universitat Bonn Adenauerallee 24-42, D-5300 Bonn 1, GERMANY. PG 22. PR no charge. JE C60, C61. KW Graph Theory. Flow Problem. Product Graph. Mesh Product.

AB In this paper we continue our algebraic approach to the uniform concurrent multicommodity flow problem which was initiated in (SS91) and study this problem in product graphs. We define the mesh product of graphs and give an algorithm which constructs a uniform flow which is edge-, vertex-, and cost-optimal, provided that the group invariant flow for each factor is known. For the cartesian product graph, which is a special instance of the mesh product graph, we construct a flow which is edge optimal provided that for each factor an edgeoptimal solution is known. It is shown that this flow is vertexoptimal and cost-optimal under certain conditions. Different formulas are provided for the congestion and vertex utilization of the flows constructed in product graphs and some examples are given.

Shapley, Lloyd S.

T1 Long-Term Competition- A Game Theoretic Analysis. AU Aumann, Robert J.; Shapley, Lloyd S.

\section{Sharma, S.}

TI Uncertainty and Irreversible Investment: An Empirical Analysis of Development of Oilfields on the UKCS. AU Favero, Carlo A.; Pesaran. M. Hashem; Sharma. S.

\section{Shephard, Neil}

TI Exact Score for Time Series Models in State Space Form. AU Koopman, Siem Jan; Shephard, Neil.

\author{
Shubik, Martin \\ TI Is Gold an Efficient Store of Value? AU Dubey,
} Pradeep; Geanakoplos, John; Shubik, Martin.

\section{Sibert, Anne}

TI Strategic Capital Taxation in Large, Open Economies with Mobile Capital. AU Ha, Jiming: Sibert, Anne.

PD September 1992. TI Can Unconventional Preferences Explain Risk Premia in the Foreign Exchange Markets? AA Federal Reserve Bank of Kansas City and University of Kansas. SR Federal Reserve Bank of Kansas City Research Working Paper: 92-02; Research Division, Federal Reserve Bank of Kansas City, 925 Grand Ave.. Kansas City, MO 64198. PG 19. PR no charge. JE F31, D52. KW Incomplete Markets.

AB The purpose of this paper is to examine the impact of non-standard preferences in an incomplete-markets, generalequilibrium model of the forward foreign exchange market. We find that even extreme levels of habit persistence have almost no impact on the mean or standard deviation of either real or nominal risk premia. With ordinal-certainty-equivalent preferences, the mean and standard deviations of risk premia are sensitive to the intertemporal elasticity of substitution. however, even extreme values of this variable do not allow us to replicate actual data.

\section{Sichel, Daniel E.}

PD August 1992. TI Inventories and the Three Phases of the Business Cycle. AA Board of Governors of the Federal Reserve System. SR Board of Governors of the Federal Reserve System Economic Activity Section Working Paper: 128; Board of Governors of the Federal Reserve System Economic Activity Section. Stop \#80, Federal Reserve Board. Washington, D.C. 20551. PG 17. PR no charge. JE E32, E22. KW Recession. Recovery.

AB This paper makes a simple point: recessions typically are followed by a high-growth recovery phase that pushes output back to its pre-recession level and during which the growth rate is higher than later in the expansion. That is, postwar fluctuations in real output in the U.S. have consisted of three sequential phases rather than two: contractions, high-growth recoveries, and moderate-growth periods following recoveries. The existence of high-growth phases is supported by a battery of tests, some of which impose very little structure on the problem. Further. I show that the three-phase pattern reflects swings in inventory investment. The evidence in this paper supports the output gaps view of fluctuations put forward by DeLong and Summers (1988) and suggests that output fluctuations have an important transitory component.

\section{Sicherman, Nachum}

TI Maternal Age as an Indication for Amniocentesis: An Evaluation of the "35-Plus" Rule. AU Rappoport, Peter: Sicherman, Nachum.

\section{Sickles, Robin C.}

PD August 1992. TI The Structure of Technology, Substitution, and Productivity in the Interstate Natural Gas Transmission Industry under the NGPA of 1978. AU Sickles, Robin C.; Streitwieser, Mary L. AA Sickles: University of Michigan. Streitwieser: Bureau of the Census. SR Bureau of the Census Center for Economic Studies Discussion Paper: 92 9; Center for Economic Studies, Bureau of the Census. Washington, DC 20233. PG 18. PR no charge. JE L95, K23, L51, C21. KW Regulation. Price Discrimination. 
AB The structure of production in the natural gas transmission industry is estimated using the dual restricted cost function based on panel data for twenty four firms. A standard translog variable cost function with firm fixed effects is augmented with controls for capacity utilization, technical change, and shifting regulatory regimes. During the implementation of the Natural Gas Policy Act (NGPA), 19781985. the industry exhibited no significant increase in productivity, largely attributable to the decline in output for the industry. Regulatory efforts to promote voluntary non-contract transmission appear to have enabled some firms to mitigate the overall industry productivity stagnation. The NGPA and Federal Regulatory Commission oversight practices allow the transmission industry to price discriminate among customers.

\section{Sill, Keith}

PD July 1992. TI An Empirical Investigation of Money Demand in the Cash-In-Advance Model Framework. AA Federal Reserve Bank of Philadelphia. SR Federal Reserve Bank of Philadelphia Research Working Paper: 92-16; Working Papers, Department of Research, Federal Reserve Bank of Philadelphia. 10 Independence Mall, Philadelphia, PA 19106. PG 37. PR no charge except overseas airmail. $\$ 2.00$; checks/money orders in U.S. funds payable to Federal Reserve Bank of Philadelphia. JE E41, E51. KW Velocity of Money. Interest Elasticity.

AB The time series behavior of the income velocity of money is examined in the context of a cash-in-advance model developed by Lucas and Stokey (1987). The model is estimated by generalized method of moments with special attention paid to the issue of identification. Instruments exploited by the estimation procedure are chosen on the basis of whether they can reasonably be believed to be uncorrelated with preference shocks. The estimated interest elasticity of money demand is time varying as a consequence of how the trend in velocity is allowed for in the theoretical model. Dynamic multipliers are obtained by solving the stochastic model. We find that positive shocks to money growth and income growth increase velocity. with the effects largely dissipated after eight quarters. Temporary shocks to money growth have a much larger effect on velocity than do temporary shocks to income growth.

\section{Simoncini, Gabriele}

PD October 1992. TI Ethnic and Social Diversity in the Membership of the Communist Party of Poland: 1918-1938. AA St. John's University. SR Stanford Hoover Institute International Studies Working Paper: I-92-13: The Hoover Institution. Stanford University, Stanford. CA 94305. PG 16. PR no charge. JE D72, N44. KW Comintern. Interwar Period.

AB The interwar Communist Party of Poland is examined, including its membership, goals, and relationship to the Comintern.

\section{Sinclair-Desgagne, Bernard}

TI Corporate Responses to Environmental Concerns. AU Gabel, H. Landis; Sinclair-Desgagne, Bernard.

\section{Sindelar, Jody $L$.}

TI Health Capital, Risk Aversion, and the Variance of Income: Assessing Some Welfare Costs of Alcoholism and Poor Health. AU Mullahy, John; Sindelar, Jody L.
Singh, Ajit

PD December 1991. TI Corporate Takeovers: A Review. AA University of Cambridge. SR University of Cambridge Department of Applied Fconomics Working Paper: 9206; Department of Applied Economics, University of Cambridge, Sidgwick Avenue, Cambridge CB3 9DE. UNITED KINGDOM. PG 13. PR $\$ 5.00$ (L2.50), checks payable to University of Cambridge. JE G34. L12, L21, L22. KW Mergers. Takeover Mechanism.

AB In advanced capitalist economies, with well-developed capital markets, corporate takeovers constitute an important institutional device which can in principle promote efficient utilization of resources. Not only are takeovers empirically extremely important in countries like the UK and US, they also lie at the heart of current concerns in the theory of the firm, the theory of industrial organization, welfare economics, as well as in economics and industrial policy. This essay reviews the main theoretical, empirical and policy questions which the functioning of the takeover mechanism raises; and assess briefly what research on the subject has accomplished, and what has been left undone.

PD January 1992. TI Regulation of Mergers in the US and the UK: A New Agenda. AA University of Cambridge. SR University of Cambridge Department of Applied Economics Working Paper: 9207; Department of Applied Economics, University of Cambridge, Sidgwick Avenue, Cambridge CB3 9DE, UNITED KINGDOM. PG 12. PR $\$ 5.00$ (L2.50), checks payable to University of Cambridge. JE G34, G38, L51, D63. KW Takeovers. Income Redistribution.

AB The paper argues that the regulation of mergers needs to go beyond the traditional questions of monopoly and economies of scale to consider also the broader issues of corporate governance and the agency problem in the modern corporation, as well as the nature of the discipline which the takeover mechanism on the stock market actually represents. In view of the large redistributions of income and wealth which takeovers often involve between shareholders, the employees. and other stakeholders in the corporation, mergers policy also needs to pay close attention to distributional questions.

\section{Skinner, Jonathan}

TI The Risk and Duration of Catastrophic Health Care. AU Feenberg. Daniel; Skinner, Jonathan.

\section{Smith, Peter}

PD September 1992. TI Women in the Labour Force: Some Aspects of Gender Inequality in Human Development. AA University of Southampton. SR University of Southampton Discussion Paper in Economics and Econometrics: 9227: Department of Economics, University of Southampton, Southampton SO9 5NH. ENGLAND. PG 27. PR no charge. JE J16. O15. KW Southeast Asia. Gender Economics.

AB Women play a vital role in the process of human development, but often do not share fully in the benefits. This paper looks at the place of women in human development and uses a cross-section of 75 countries to analyze the factors which influence formal participation by women in the labor force. An exploration of the economies of South-East Asia serves to highlight the fact that formal participation is but one step towards enabling women to share in the fruits of development. 
Smith, Ron

TI Estimating Long-Run Relationships from Dynamic Heterogeneous Panels. AU Pesaran, M. Hashem; Smith, Ron.

Smith, Roy C.

TI Bank Industry Linkages: Models for Eastern European Economic Restructuring. AU Walter, Ingo; Smith, Roy C.

\section{Smith, Tom}

TI Testing Inequality Restrictions Implied from Conditional Asset Pricing Models. AU Boudoukh. Jacob; Richardson, Matthew: Smith. Tom.

\section{Smith, V. Kerry}

TI "Black Mayonnaise" and Marine Recreation: Methodological Issues in Valuing A Cleanup. AU Kaoru, Yoshiaki; Smith, V. Kerry.

PD March 1991. TI Natural Resource Damage Assessments and the Mineral Sector: Valuation in the Courts. AA North Carolina State University and Resources for the Future. SR Resources for the Future Quality of the Environment Division Discussion Paper: QE91-09; Quality of the Environment Division, Resources for the Future, $1616 \mathrm{P}$ Street, NW, Washington, D.C. 20036. PG 35. PR $\$ 2.25$ prepaid. U.S. funds. JE Q28, K13. KW Liability. Mining. Natural Resource Damage.

AB Because liability for natural resource damages is the only federal influence on the disposal of residuals from mining activities, understanding the source of that liability and the factors influencing its implementation is important. This paper describes the evolution of natural resource damage liability from the Trans Alaska Pipeline Authorization Act (1973) and the Deepwater Port Act (1974) to the Comprehensive Environmental Response. Compensation and Liability Act (1980) and its reauthorizing legislation, the Superfund Amendments and Reauthorization Act (1986), which extended this liability beyond the oil industry and defined a process for measuring environmental damages. The alternative economic perspectives that can be offered on these mandates' specific requirements are discussed, including Type $A$ and Type B damage assessments required by the Department of Interior. Following that background. examples are used to describe how both current litigation and the economic frameworks for defining the value of nonmarket environmental services affect the estimates produced by both direct and indirect frameworks for valuing them.

PD March 1991. TI On Separating Defensible Benefits Transfers from "Smoke and Mirrors". AA North Carolina State University and Resources for the Future. SR Resources for the Future Quality of the Environment Division Discussion Paper: QE91-10; Quality of the Environment Division, Resources for the Future, 1616 P Street, NW, Washington, D.C. 20036. PG 29. PR \$2.25 prepaid. U.S. funds. JE Q28. KW Benefits. Nonmarket Goods.

AB Benefits transfer methods increasingly are being applied to value nonmarket resources for both policy evaluation and natural resource damage litigation. This paper illustrates the need for guidelines for deciding when benefits transfer methods can be used to efficiently value changes in environmental resources. It begins by discussing applied economic modeling perspectives and transfers as tools for evaluating policy. It reviews the history of benefits transfers and summarizes how they are typically undertaken, including the influence of the analyst's judgments on their outcomes, by comparing the development of two different analyses that use benefits transfers to consider the same issue--estimating the benefits from limiting industrial effluents discharge into specific rivers. It proposes an agenda for future benefits transfer research: devising strategies for extending available benefits transfer theory. learning from existing research. and formulating transferable versus "portable" modeling strategies.

\section{Snower, Dennis J.}

TI Patterns of Unemployment: An Insider-Outsider Analysis. AU Lindbeck, Assar; Snower, Dennis J.

TI Price Inertia and Production Lags. AU Lindbeck. Assar; Snower, Dennis J.

\section{Snyder, Ralph D.}

TI Rationalization of Exponential Smoothing in Terms of a Statistical Framework with Multiplicative Disturbances. AU Kœehler, Anne; Ord, Keith; Snyder, Ralph D.

\section{Solomou, $\mathrm{S}$}

TI Quarterly National Income Accounts for Interwar Germany, 1925-1938. AU Ellam, Michael; Kitson, Michael; Solomou, S; Weale, $M$.

\section{Sorensen, Bent E.}

TI Multivariate Tests of a Continuous Time Equilibrium Arbitrage Pricing Theory with Conditional Heteroscedasticity and Jumps. AU Ho, Mun S.; Perraudin, W. R. M.; Sorensen, Bent E.

TI Multivariate Tests of a Continuous Time Equilibrium Arbitrage Pricing Theory With Conditional Heteroskedasticity and Jumps. AU Ho. Mun S.; Perraudin. W. R. M.; Sorensen. Bent E.

TI Asymptotic Distributions of the Least Squares Estimators and Test Statistics in the Near Unit Root Model with Non-Zero Initial Value and Local Drift and Trend. AU Nabeya, Seiji; Sorensen, Bent E.

PD October 1992. TI Testing the Equivalence of Unemployment and Leisure Time in the Aggregate Neoclassical Model. AA Brown University. SR Brown University Department of Economics Working Paper: 92-24; Department of Economics. Brown University. Providence. Rhode Island 02912. PG 31. PR no charge. JE C51, E24, E32. KW Real Business Cycles. Unemployment. GMM Estimation.

AB In the empirical neoclassical models of growth or business cycles it is usually assumed implicitly that time spent unemployed and leisure time are one-to-one substitutes. This paper attempts to test this assumption by econometric methods. A standard utility function for consumption of leisure is formulated with the extension that hours spent unemployed may have different weight in the utility function than does leisure time. This approach parallels earlier work (Christiano and Eichenbaum 1992) testing for the substitutability of government and private consumption. For a model resembling the one used by Christiano and Eichenbaum the empirical results indicate quite strongly that leisure and unemployment are not substitutes. When taxes and trends in the efficiency of production of leisure services are allowed for, the empirical 
results give somewhat mixed support for the hypothesis that leisure and unemployment are perfect substitutes.

\section{Spagat, Michael}

TI Learning. Experimentation and Monetary Policy. AU Bertocchi. Graziella: Spagat, Michael.

Spencer, Michael G.

TI The Dissolution of the Austro-Hungarian Empire: Lessons for Currency Reforms. AU Garber, Peter M.; Spencer, Michael G.

\section{Spiegel, Mark M.}

PD September 1992. TI "Burden Sharing" in Sovereign Debt Reduction. AA New York University. SR New York University Economic Research Reports: 92-41: New York University. Faculty of Arts and Science. Department of Economics, Washington Square, New York, N.Y. 10003. PG 16. PR no charge. JE F34, G21. KW Banks. Official Debt.

AB We examine a concerted debt reduction deal between a sovereign debtor, a private creditor, and an official creditor. who insures the deposits of the commercial bank. The results show that a weakening of the financial position of the commercial bank reduces the contribution of the commercial bank to the debt reduction program, while increasing those of the official creditor. However, the net terms faced by the debtor nation are independent of the strength of the commercial bank. This result is robust to changes in the assumed seniority of official and private debt. Our results also suggest that standard interpretations of the degree of "burden sharing" between official and private creditors may underestimate the contribution of the private creditor and overestimate that of the official creditor. We show that a debt reduction program which leaves both creditor values unchanged will typically have commercial banks retiring debt at "unfairly" high prices, and contain a net contribution by the official creditor.

TI The Role of Human Capital in Economic Development: Evidence from Aggregate Cross-Country and Regional U.S. Data. AU Benhabib, Jess; Spiegel, Mark M.

Spiegel, Matthew

TI Non-Temporal Components of Residential Real Estate Appreciation. AU Goetzmann, William N.; Spiegel. Matthew.

\section{Starr, Richard F.}

PD July 1992. TI The New Russian Armed Forces: Preparing for War or Peace? AA Stanford University. SR Stanford Hoover Institute International Studies Working Paper: I-92-9; International Studies Working Paper Series. Hoover Institution. Stanford University. Stanford, CA 94305. PG 29. PR not available. JE A12, H56. KW Military Coup. Russia.

AB The attempt to seize power in August 1991, supported by substantial numbers of regular army officers, resulted in a new military command structure and emergence of generals from elite branches (air force and airborne) in key positions. Most of them had fought in Afghanistan and subsequently became part of that network of war veterans.
Stavins, Robert N.

TI Evaluating the Relative Effectiveness of Economic Incentives and Direct Regulation for Environmental Protection: Impacts on the Diffusion of Technology. AU Jaffe. Adam B.; Stavins, Robert N.

\section{Steckel, Richard H.}

TI Tall but Poor: Nutrition, Health, and Living Standards in Pre-Famine Ireland. AU Nicholas, S.; Steckel, Richard H.

PD August 1992. TI Wealth Mobility in America: A View from the National Longitudinal Survey. AU Steckel, Richard H.; Krishnan, Jayanthi, AA Krishan: Ohio State University. Steckel: Ohio State University and National Bureau of Economic Research. SR National Bureau of Economic Research Working Paper: 4137; National Bureau of Economic Research, 1050 Massachusetts Avenue. Cambridge. MA 02138. PG not available. PR \$5.00. JE J30, J31. KW Wage Structure. Wealth Mobility.

AB We depict and analyze wealth mobility in a national sample of nearly 4,000 households interviewed by the National Longitudinal Survey over a ten year period from the mid 1960's to the mid 1970's. A transition matrix, the Shorrocks measure, average decile position for various subgroups, and wealth in period two compared with wealth in period one are used to describe patterns of wealth mobility. These results and regression models of change in percentile position. of persistence in the top. of movement into the top. of persistence into the bottom. and of movement into the bottom identify winners and losers. The losers include single people. blacks. and those who experienced marital disruption, while winners were the skilled and more educated. These findings have implications for the interpretation of cross-sectional measures of inequality, the explanation of long-term trends in wealth mobility, and the consequences of recent trends in the wage structure.

\section{Stein, Jerome L.}

TI The Dynamics of the Fundamental Determinants of the Natural Real Exchange Rate. AU Allen, Polly Reynolds; Stein, Jerome L.

PD September 1992. TI Balance of Payments Developments: A Review Article. AA Brown University. SR Brown University Department of Economics Working Paper: 92-17; Department of Economics, Brown University, Providence, Rhode Island 02912. PG 21. PR no charge. JE F10, A00. KW Balance of Payments. Developments. AB The Bank for International Settlements Economic Paper. written by P.S. Andersen (PSA), attempts to explain balance of payments developments by drawing upon the state of the art theories in international finance. This study is most welcome from several points of view. First: the countries experiencing persistent current account deficits have been concerned with the rising external debt. Questions asked in these countries are: what has produced these deficits, will they persist and are they sustainable, and what policies should be adopted to reverse the deficits? Second: there are many different theories in international finance literature. Their rate of growth is not diminishing because there is dissatisfaction with the explanatory power of existing models. However, unless one knows why the existing theories have failed to explain the empirical phenomena, there is no way to know the desirable direction for theoretical research. 


\section{Stiglitz, Joseph E.}

PD August 1992. TI Discouraging Rivals: Managerial Rent Seeking and Economic Insufficiencies. AU Stiglitz, Joseph E.: Edlin. Aaron S. AA Stiglitz: Stanford University and National Bureau of Economic Research. Edlin: Stanford University. SR National Bureau of Economic Research Working Paper: 4145; National Bureau of Economic Research, 1050 Massachusetts Avenue. Cambridge. MA 02138. PG not available. PR \$5.00. JE M10, M19, L21, G31. KW Management. Investment. Managerial Entrenchment.

AB Management has enormous discretion in choosing the form of a firm's investment. We ask: what sort of investments will management make in order to entrench itself. minimizing the probability of being ousted and maximizing its rents? The paper analyzes a number of managerial entrenchment activities. In our main model we explain how investing in risky investments - and particularly those whose risks are sooner or more fully resolved for insiders than for outsiders - - leads to managerial entrenchment. We identify a number of complementary reasons that such investments will be favored by management that seeks its own rents over firm value. The model is adapted to rationalize management touting itself, independent of other egoistic explanations. Finally, we present a simple model which illustrates the entrenching value of idiosyncratic investments and organizational structure which can provide motivation for the creation of standard operating procedures.

\section{Stock, James $H$.}

PD June 1992. TI Deciding Between I(1) and I(0). AA Harvard University and National Bureau of Economic Research. SR National Bureau of Economic Research Technical Paper: 121; National Bureau of Economic Research. 1050 Massachusetts Avenue. Cambridge MA 02138. PG not available. PR \$3.00. JE C10, C11, C40. KW Integrated Processes. Detrending.

AB This paper proposes a class of procedures that consistently classify the stochastic component of a time series as being integrated either of order zero [I(0)] or one [I(1)] for general $I(0)$ and $I(1)$ processes. These procedures entail the evaluation of the asymptotic likelihoods of certain statistics under the $\mathrm{I}(0)$ and $\mathrm{I}(1)$ hypotheses. These likelihoods do not depend on nuisance parameters describing short-run dynamics and diverge asymptotically. so their ratio provides a consistent basis for clarifying a process as $I(1)$ or $I(0)$. Bayesian inference can be performed by placing prior mass only on the point hypotheses "I(0)" and "I(1)" without needing to specify parametric priors within the classes of $\mathrm{I}(0)$ and $\mathrm{I}(1)$ processes; the result is posterior odds ratios for the $I(0)$ and $I(1)$ hypotheses. These procedures are developed for general polynomial and piecewise linear detrending.

TI Inference in Time Series Regression when the Order of Integration of a Regressor is Unknown. AU Elliot. Graham; Stock, James H.

\section{Stockman, Alan C.}

PD July 1992. TI International Transmission Under Bretton Woods. AA Stockman: University of Rochester and National Bureau of Economic Research. SR National Bureau of Economic Research Working Paper: 4127; National Bureau of Economic Research, 1050 Massachusetts Avenue. Cambridge, MA 02138. PG 39. PR \$5.00. JE F31.
F33. KW Bretton Woods. International Transmission Mechanism.

AB This paper explores the main channels of international transmission of economic disturbances under the Bretton Woods System and presents evidence on the short-run international transmission of inflation under that system. There appears to have been little short-run international transmission of inflation. Countries with one-percent higher money-growth rates subsequently had one-fourth to one-half percent higher inflation and a (predictably) lower real interest rate. This probably reflects effects of money growth on inflation and interest rates rather than reverse causation: the natural interpretation of the evidence is that countries had some scope for monetary-policy independence under Bretton Woods. despite pegged exchange rates and exercised that independence in ways that limited international transmission.

\section{Streitwieser, Mary L.}

TI The Structure of Technology, Substitution, and Productivity in the Interstate Natural Gas Transmission Industry under the NGPA of 1978. AU Sickles, Robin C.: Streitwieser, Mary L.

\section{Sturzenegger, Federico}

TI Recurrent High Inflation and Stabilization. A Dynamic Game. AU Mondino. Guillermo; Sturzenegger. Federico: Tommasi, Mariano.

\section{Swinkels, Jeroen M.}

PD September 1992. TI Adjustment Dynamics and Rational Play in Games. AA Northwestern University and Stanford University. SR Northwestern University Center for Mathematical Studies in Economics and Management Science Discussion Paper: 1001; J.L. Kellogg Graduate School of Management, Northwestern University, 2001 Sheridan Road. 3-014 Leverone Hall Evanston, II 60208. PG not available. PR per copy: $\$ 3.00$ in the U.S.A. or Canada; $\$ 5.00$ via international mail. Make check payable to Northwestern University. JE C72. KW Game Theory. Evolution. Learning. Adjustment Dynamics.

AB When a given strategic situation arises repeatedly, the possibility arises that equilibrium prediction can be justified by a dynamic adjustment process. We examine myopic adjustment dynamics, a class that includes replicator dynamics from evolutionary game theory, simple models of imitation models of experimentation and adjustment, and some simple learning dynamics. We present a series of theorems showing conditions under which behavior that is asymptotically stable under some such dynamic is strategically stable (Kohlberg and Mertens (1986)). This behavior is thus as if the agents in the economy satisfied the extremely stringent assumptions that game theory traditionally makes about rationality and beliefs.

Szekely, L. A.

TI Uniform Concurrent Multicommodity Flow in Product Graphs. AU Shahrokhi, Farhad; Szekely, L. A.

\section{Tagaras, George}

PD July 1992. TI Economic Acceptance Sampling by Variables with Quadratic Quality Costs. AA July 1992. SR INSEAD Working Papers: 92/39/TM: INSEAD. INSEAD. Boulevard de Constance, Fontainebleau, 77305 Cedex, FRANCE. PG 21. PR not available. JE L15, 
L23. KW Product Cost. Product Quality. Sampling Plans. Technology Management.

AB An economic model is developed, to assist in the selection of minimum cost acceptance sampling plans by variables. The quadratic Taguchi loss function is adopted to model the cost of accepting items, with quality characteristics deviating from the target value. The case of a normally distributed quality characteristic with known variance is examined, and a simple and efficient optimization algorithm is proposed. Comparisons with other methods of deriving sampling plans reveal that the cost penalties for using an inappropriate plan may be very large.

PD July 1992. TI Economic Models For Vendor Evaluation with Quality Cost Analysis. AU Tagaras, George; Lee, Hau L. AA Tagaras: INSEAD. Lee: Stanford University. SR INSEAD Working Papers: 92/40/TM:INSEAD. Boulevard de Constance. Fontainebleau, 77305 Cedex. FRANCE. PG 19. PR not available. JE L15, L23, L14. KW Product Cost. Product Quality. Technology Management.

AB Successful vendor-vendee partnership is viewed as an important ingredient for maintaining competitiveness in the current market place. This calls for a careful and comprehensive approach in selecting vendors. The cost of quality (or better phrased as the cost of "unquality") resulted from imperfections of a vendor's incoming input materials is one component of the total costs in the evaluation of vendors. In this paper. we explore the relationship between the vendor's quality cost. the vendor's input quality, and the imperfections of the manufacturing process. We analyze the properties of the resulting quality cost model. and draw managerial implications in the selection of vendors.

Tan, Guofu

TI The Economics of Hubs: The Case of Monopoly. AU Hendricks. Ken: Piccione, Michele: Tan, Guofu.

TI An Analysis of Dr. Sun Yat-Sen's Self-Assessment Scheme for Land Taxation. AU Niou, Emerson M. S.; Tan, Guofu.

Taylor, Alan D.

TI An Envy-Free Cake Division Algorithm. AU Brams, Steven J.; Taylor, Alan D.

Thisse, J. - F.

TI Technological Linkages and Efficient Location of Indivisible Activities: Koopmans-Beckmann and Von Thunen Unified. AU Fujita, Masahisa; Thisse, J. - F.

TI Probabilistic Voting and Platform Selection in MultiParty Elections. AU Anderson, S. P.; Kats, A.; Thisse, J. - F.

\section{Thomas, Charles P.}

TI War and Peace: Recovering the Market's Probability Distribution of Crude Oil Futures Prices During the Persian Gulf Crisis. AU Melick. William R.; Thomas, Charles P.

\section{Thomas, Jonathan}

PD October 1991. TI Main Search Methods and Outcomes. AA University of Cambridge. SR University of Cambridge Department of Applied Economics Working Paper: 9119; Department of Applied Economics, University of
Cambridge. Sidgwick Avenue. Cambridge CB3 9DE, UNTTED KINGDOM. PG 30. PR $\$ 5.00$ (L2.50), checks payable to University of Cambridge. JE J64. KW Job Search. Unemployment.

AB Users of a public employment agency have consistently been found to suffer longer spells of unemployment than jobseekers who use other job-search methods. In order to investigate this relationship empirically this paper integrates the choice of search method into a model of multi-sector jobsearch developed by Thomas and Bernhardt (1991). Using Canadian data, the implications for the model are examined. Our findings suggest that this observed positive relationship is driven by a minority of workers with a priori good employment histories who have relatively long spells of joblessness if they leave employment via a public employment agency and change sector of employment.

\section{Timmermann, A.}

TI Forecasting Stock Returns. AU Pesaran, M. Hashem; Timmermann, A.

\section{Tobin, James}

PD August 1992. TI Poverty in Relation to Macroeconomic Trends. Cycles, and Policies. AA Yale University. SR Yale Cowles Foundation Discussion Paper: 1030; Yale University, Cowles Foundation, 30 Hillhouse Ave., Box 2125, Yale Station, New Haven CT 06520. PG 31. PR no charge. JE I32, E32, E24. KW Unemployment. Labor Market. Macroeconomic Policy.

AB This survey concludes that general prosperity and economic growth have been considerably less powerful engines of progress against poverty in the U.S. than they were before 1973. Macroeconomic performance has deteriorated, and its relation to poverty has weakened 100 . It is shown that the incidence of poverty can be fairly well explained by regressions on unemployment rates and real wages, both in national time series and in state cross-sections. Recent downward deviations from these regressions appear to reflect structural labor market changes that make poverty less treatable by macro medicine.

PD September 1992. TI Price Flexibility and OutputStability: An Old Keynesian View. AA Yale University. SR Yale Cowles Foundation Discussion Paper: 994R; Yale University. Cowles Foundation, 30 Hillhouse Ave., Box 2125. Yale Station. New Haven CT 06520. PG 31. PR no charge. JE E12, E31, E63. KW Aggregate Demand. Sticky Prices.

AB The central macroeconomic issue is the same as ever. How reliable are automatic market adjustments in maintaining full employment equilibrium in the face of aggregate demand shocks? Many modern theorists assume that nominal prices. including wages, jump instantaneously to keep supply and demand equal in all markets. No excess supply, no involuntary unemployment, can ever arise. However, since actual price adjustments take real time. greater flexibility can be destabilizing. "Real balance" effects are overrated, and the demand effects of nominal price changes are perverse. Activist macro policies are necessary, as Keynes argued, even though nominal prices are far from rigid.

Todd, $\mathbf{R}$.

TI Real Effects of Monetary Policy in a World Economy.

AU Miller, P.: Todd, $\mathbf{R}$. 
Toman, Michael A.

TI The Cost-Effectiveness and Energy Security Benefits of Methanol Vehicles. AU Krupnick, Alan J.; Walls, Margaret A.: Toman, Michael A.

\section{Tommasi, Mariano}

TI Recurrent High Inflation and Stabilization. A Dynamic Game. AU Mondino, Guillermo; Sturzenegger, Federico; Tommasi. Mariano.

\section{Trajtenberg, Manuel}

PD August 1992. TI Ivory Tower versus Corporate Lab: An Empirical Study of Basic Research and Appropriability. AU Trajtenberg. Manuel: Henderson, Rebecca: Jaffe, Adam B. AA Trajtenberg: Tel Aviv University and National Bureau of Economic Research. Henderson: Massachusetts Institute of Technology and National Bureau of Economic Research. Jaffe: Harvard University and National Bureau of Economic Research. SR National Bureau of Economic Research Working Paper: 4146; National Bureau of Economic Research. 1050 Massachusetts Avenue. Cambridge. MA 02138. PG not available. PR \$5.00. JE O31, O32, O33. KW Patents. Invention. Patent Citations.

AB We explore the use of patent citations to measure the "basicness" and appropriability of inventions. We propose that the basicness of research underlying invention can be characterized by the nature of the previous patents cited by an invention; that the basicness of research outcomes relates to the subsequent patents that cite an invention; and that the fraction of citing patents that are assigned to the same organization as the original invention is a measure of appropriability. We test the validity of these presumptions by comparing the value of our measures for university and corporate patents, and find that many of the measures do conform to our prior that university research and research outcomes are more basic and harder to appropriate than those of corporations. We also find some evidence that basicness of outcomes is correlated with basicness of research, and that appropriability is lower for basic outcomes.

TI General Purpose Technologies: "Engines of Growth?" AU Bresnahan, Timothy F.; Trajtenberg. Manuel.

\section{Troske, Kenneth R.}

PD September 1992. TI The Time-Series Pattern of Firm Growth in Two Industries. AA Bureau of the Census. SR Bureau of the Census Center for Economic Studies Discussion Paper: 92-10; Center for Economic Studies, Bureau of the Census. Washington. DC 20233. PG 26. PR no charge. JE C32, G22, L85, L60. KW Entry. Exit.

AB Using a unique firm-level longitudinal data set that covers both the manufacturing and finance. insurance and real estate (FIRE) industries, this paper examines the time-series pattern of firm growth both immediately after entry and immediately prior to exit, and compares these patterns across the two industries. While previous research has examined the post-entry time-series behavior of firms, this research has focused exclusively on manufacturing firms. The main finding of this paper are: (1) relative to FIRE firms, manufacturing firms experience more periods of above average growth immediately after entry; (2) relative to FIRE firms, manufacturing firms experience more periods of below average growth immediately prior to exit: and (3) relative to the growth of manufacturing firms, the growth of the typical FIRE firm is much more responsive to transitory shocks.

\section{Tsybakov, A. B.}

TI Minimax Linewise Algorithm for Image Reconstruction. AU Korostelev, A. P.; Tsybakov, A. B.

\section{Tulkens, $\mathrm{H}$.}

TI The Acid Rain Game as a Resource Allocation Process with an Application to the Cooperation Among Finland, Russia, and Estonia. AU Kaitala. V.; Maler. K.- G.; Tulkens, H.

\section{Tuma, Elias H.}

PD September 1992. TI Economic Discrimination in Europe: Race and Ethnicity. AA University of California, Davis. SR University of California at Davis Economics Department Working Paper: 410; Department of Economics. University of California at Davis, Davis, CA 95616. PG 32. PR \$3.00 U.S. and Canada. $\$ 4.00$ international. JE J15, N13, N14. KW Economic Discrimination. Race. Ethnicity. European History.

AB Economic discrimination against racial and ethnic minorities in Europe (and other regions) has been historically ubiquitous, wasteful, and sticky. Attempts for systematic solutions have been recent and limited. International concern for minorities has been mostly political, focused on national minorities and their treatment by the national majority, mainly in the form of international conventions, charters, treaties, and political and moral suasion. Domestic legislation, administrative measures, and court actions which have dominated national approaches to discrimination have boen imprecise, vague. difficult to enforce, and therefore insufficient to remove discrimination. Seen in this light, taming discrimination may be the next best alternative, which is the recommendation of this analysis. Taming discrimination involves four major approaches: guaranteed equality before the law: affirmative action as an integral part of public policy; guaranteed full employment; and equality of opportunity at birth.

PD September 1992. TI Restitution for Slavery: Africa and the West. AA University of California, at Davis. SR University of California at Davis Economics Department Working Paper: 412; Department of Economics, University of California at Davis, Davis, CA 95616. PG 24. PR $\$ 3.00$ U.S. and Canada. \$4.00 international. JE J15. N31. N33. N37. KW Slavery. Restitution. Economic Effects.

AB The claim for restitution for African enslavement is still barely heard, but it is being raised in spite of complications. such as the relevant system of justice, the legalistic aspects of slavery, and the humanistic, moral, and ethical grounds which may be invoked to justify or deny restitution. What may be considered right or wrong owes much to the system of distribution of power in each time and place. My conclusion is that restitution is justifiable mainly on pragmatic grounds. as less costly than noncompensation. The guiding principle is to let those who benefited compensate those who were injured.

\section{Turlach, Berwin A.}

TI Nonparametric Approaches to Generalized Linear Models. AU Hardle, Wolfgang K.; Turlach. Berwin A. 
Turner, Matt

TI Industrial Development in Cities. AU Henderson. Vernon; Kuncoro. Ari: Turner, Matt.

\section{Van Cleave, William R.}

PD July 1992. TI Assertive Disarmament in the New World Order. AA Stanford University and Southwest Missouri State University. SR Stanford Hoover Institute International Studies Working Paper: I-92-10; International Studies Working Paper Series, Hoover Institution. Stanford University. Stanford. CA 94305. PG 10. PR not available. JE A12, F01. KW Disarmament. World Peace.

AB On Sunday, June 7, 1981, Israel's air force, operating with surgical precision, destroyed Iraq's nuclear reactor complex, thus preventing Saddam Hussein from producing nuclear weapons. The Israeli government announced to the world that it had "decided to act without further delay, to ensure our people's existence," after all diplomatic efforts had failed. This was the first exercise of "Assertive Disarmament," the use of military force specifically to stop a threatening nuclear weapons program. A decade later, during Desert Storm, the United States also bombed Iraq's nuclear facilities, which were once again intended to produce nuclear weapons. The question which we are dealing is simply how civilized nations. and a stable world order, can deal with the acquisition of nuclear weapons by dangerous or unstable regimes, and prevent their proliferation.

\section{Van Wassenhove, Luk}

PD 1992. TI Strategic Marketing. Production, and Distribution Planning of an Integrated Manufacturing System. AU Van Wassenhove, Luk; Ashayeri, Jalal; Pourbabai, Behnam. AA Van Wassenhove: INSEAD. Ashayeri: Tilburg University. Pourbabai: University of Maryland. SR INSEAD Working Papers: 92/47/TM; INSEAD, Boulevard de Constance, Fontainebleau, 77305 Cedex. FRANCE. PG 16. PR not available. JE L23, C61. KW Loading Strategy. Aggregate Scheduling.

AB This paper extends Pourbabai's (1991) results for generating a strategic marketing and production plan for an Integrated Manufacturing System (IMS) to include distribution decisions. The paper introduces additional distribution decision variables and constraints for both of the loading models proposed by Pourbabai (1991). The new models optimize the utilization of the processing capabilities of an IMS consisting of a set of heterogeneous workstations. The objective to be maximized includes the fixed and variable market values of each job. the fixed and variable processing costs of each job, the setup costs, and the fixed and variable distribution costs. Each job requires a single aggregated stage of operation; job splitting is also allowed; and the processing priorities of all jobs during the planning time horizon are given. Setup times collapsings is also allowed, to shorten the completion times of some jobs. The proposed models are fixed charge problems which can be solved by a mixed integer programming algorithm.

\section{Vanhonacker, Wilfried R.}

TI Recursive Least-Squares Approach to Data Transferability: Exposition and Numerical Results. AU Price, Lydia J.; Vanhonacker, Wilfried R.

\section{Velasco, Andres}

PD September 1992. TI Animal Spirits, Capital Repatriation and Investment. AA New York University. SR New York University Economic Research Reports: 9243: New York University. Faculty of Arts and Science. Department of Economics, Washington Square, New York, N.Y. 10003. PG 18. PR no charge. JE F21, F32. KW Capital Movements. Multiple Equilibria.

AB In the aftermath of the debt crisis. developing countries are endeavoring to repatriate flight capital and to resume domestic private investment. Yet investment and the associated capital inflows continue to be disappointing and highly uneven over time in many cases. This paper provides a model of investment and capital movements in and out of such countries. Central to the paper is the introduction of fiscal increasing returns to domestic capital into a standard dynamic optimizing model. The resulting system may display multiple steady states and surprising dynamic behavior. A limit cycle may occur around one of the welfare-inferior equilibria. Along that cycle. capital stocks and relative prices display endogenous fluctuations. Moreover, initial conditions and expectations both matter in selecting the equilibrium on which the economy converges. For some initial conditions, "animal spirits" can determine the course of investment and capital flows.

PD September 1992. TI A Model of Cyclical International Capital Movements. AA New York University. SR New York University Economic Research Reports: 92 44: New York University. Faculty of Arts and Science. Department of Economics. Washington Square. New York. N.Y. 10003. PG 11. PR no charge. JE F21, F32, E32. KW Cycles. Animal Spirits.

AB This paper introduces fiscal increasing returns to domestic capital into a standard optimizing model of international portfolio selection. The resulting system displays surprising dynamic behavior. Endogenous cycles of any length may occur around the steady state equilibrium, with both capital flows and asset prices displaying regular fluctuations. Initial conditions and expectations both matter in selecting the cycle on which the economy converges. Herce, "animal spirits" may determine the course of asset prices and capital flows.

\section{Vincent, Daniel R.}

TI Optimal Procurement Mechanisms. AU Manelli, Alejandro M.: Vincent, Daniel R.

Vohra, Rajiv

TI Equilibrium Binding Agreements. AU Ray, Debraj; Vohra, Rajiv.

\section{Wadsworth, Jonathan}

TI Do Strikes Pay? AU Metcalf, David; Wadsworth, Jonathan; Ingram. Peter.

\section{Walls, Margaret A.}

TI The Cost-Effectiveness and Energy Security Benefits of Methanol Vehicles. AU Krupnick, Alan J.; Walls, Margaret A.; Toman, Michael A.

\section{Walter, Ingo}

PD October 1992. TI Bank Industry Linkages: Models for Eastern European Economic Restructuring. AU Walter, Ingo; Smith, Roy C. AA Walter: INSEAD. Smith: New York 
University. SR INSEAD Working Papers: 92/46/EP; INSEAD, Boulevard de Constance, Fontainebleau, 77305 Cedex. FRANCE. PG 28. PR not available. JE O16, G10, P41. KW Financial Institutions. Institutional Design. AB Among the critical issues facing the emerging economies of Eastern Europe is the choice of linkages between financial institutions and a privatized industrial sector. This is especially important during the initial process of economic restructuring. Replacing state ownership of enterprise with private equity holders must be accompanied by appropriate sources of financing. and a corporate governance structure that imposes discipline on managers to work consistently in the interests of the shareholders. Governments in Eastern Europe have a choice of models for the important relationship between the financial and real economies, i.e., between banks and industry. This paper considers three of these models: The Japanese keiretsu approach, the Anglo-American capital markets approach, and the German universal banking approach. We examine the strengths and weaknesses of each, and assess its potential as an appropriate transplant to Eastern Europe.

\section{Wang, Zhenyu}

TI Portfolio Characterization of Risk Aversion. AU Werner, Jan; Wang. Zhenyu.

\section{Watson, Mark W.}

TI Testing Long Run Neutrality. AU King. Robert; Watson, Mark W.

\section{Weale, $M$.}

TI Quarterly National Income Accounts for Interwar Germany, 1925-1938. AU Ellam, Michael; Kitson, Michael; Solomou. S; Weale. M.

\section{Weiss, Yoram}

PD August 1992. TI The Formation and Dissolution of Families: Why Marry? Who Marries Whom? And What Happens Upon Marriage and Divorce? AA Tel-Aviv University and Economics Research Center/NORC. SR Economics Research Center/NORC Discussion Paper: 92-7; Economics Research Center/NORC, $6030 \mathrm{~S}$. Ellis, Chicago. Illinois 60637. PG 62. PR \$2.00; send requests to Librarian, NORC. JE J12. KW Marriage. Divorce.

AB This survey summarizes the main ideas that economists bring to the analysis of marriage and divorce. The new perspective of economists is that marriage. when viewed as a voluntary union of rational individuals, is subject to the same tools of analysis as other economic phenomena. In particular. economists rely heavily on the similarity between the job market, where workers and firms combine to produce marketable goods, and the marriage market where husbands and wives combine to produce non marketable household goods. In both cases the forces of competition determine the assignment and the associated division of the proceeds between the partners. This survey does not enumerate individual contributions and does not summarize empirical findings. Instead, the reader is exposed to the main ideas in an integrated fashion, using simple models. The survey covers the following topics: gains from marriage, resource allocation within the family and the role of altruism, assortive matching. search for a mate and divorce.
Welch, Finis

TI Labor Force Transitions of Older Workers. AU Peracchi, Franco; Welch. Finis.

\section{Werner, Jan}

PD June 1992. TI Portfolio Characterization of Risk Aversion. AU Werner, Jan; Wang. Zhenyu. AA University of Minnesota. SR Universitat Bonn Sonderforschungsbereich 303 - Discussion Paper: A-373; Sonderforschungsbereich 303 an der Universitat Bonn, Adenauerallee 24-42. D-5300 Bonn 1, DEUTSCHLAND. PG 5. PR no charge. JE D81, GIl. KW Portfolio Choice. Risky Asset.

AB The classical theorem of the theory of risk aversion establishes the equivalence of several measures of risk aversion: the Arrow-Pratt measure, concavity of utility function, risk premium, and certainty equivalent. Another measure of risk aversion that has been asserted to be equivalent to the others is the demand for risky asset in a portfolio choice situation with one risky and a riskless asset. The portfolio choice problem requires a specification of short-sales restrictions for both assets, and thus can take one of several forms depending on whether riskless borrowing and/or short selling of the risky asset is permitted. The purpose of this note is to clarify the nature of the equivalence of the Arrow-Pratt measure of risk aversion and the demand for risky asset. We shall state and prove three theorems and provide examples which illustrate necessity of the assumptions.

\section{West, Michael}

TI On Elephants and Blind Researchers: Methods for Accessing Culture in Organizations AU Locatelli, Veronica; West, Michael.

TI Management Consultancy: Dimensions of ClientConsultant Relationships. AU Fullerton, Johanna; West. Michael.

TI Collective Climates: A Test of Their Socio-Psychological Significance. AU Patterson. Malcolm; West, Michael: Payne, Roy.

Whitelaw, Robert F.

TI The Equity Risk Premium and the Term Structure: Two Centuries of Evidence. AU Boudoukh. Jacob; Richardson, Matthew; Whitelaw, Robert F.

\section{Williams, Nicolas}

TI The Effects of Labor Market Experience, Job Seniority, and Job Mobility on Wage Growth. AU Altonji. Joseph G.; Williams, Nicolas.

\section{Williams, Steven R.}

TI Converge to Efficiency in a Simple Market with Incomplete Information. AU Rustichini, Aldo; Satterthwaite. Mark A.; Williams, Steven R.

\section{Williamson, Jeffirey $\mathbf{G}$.}

TI Were Heckscher and Ohlin Right? Putting History Back into the Factor-Price-Equalization Theorem. AU O'Rourke, Kevin; Williamson, Jeffrey $G$. 
Willis, Robert J.

TI Daughters. Education, and Family Budgets: Taiwan Experiences. AU Parish, William L.; Willis, Robert J.

\section{Wolfe, Barbara}

TI The "Window Problem" In Studies of Children's Attainments: A Methodological Exploration. AU An. Chong-Bum; Haveman, Robert: Wolfe, Barbara.

\section{Wolff, Edward N.}

TI Factors Behind Cross-Industry Differences in Technical Progress. AU Nelson, Richard R.; Wolff, Edward N.

Wolsey, Laurence A.

TI Optimizing Constrained Subtrees of Trees. AU Aghezzaf. El Houssaine; Magnanti. Thomas L.: Wolsey, Laurence A.

\section{Woo, Wing Thye}

TI Decentralized Socialism and Macroeconomic Stability: Lessons from China. AU Fan, Gang; Woo, Wing Thye.

TI Saving Behavior Under Imperfect Financial Markets and the Current Account Consequences. AU Liu, Liang-Yn; Woo, Wing Thye.

\section{Wooders, Myrna Holtz}

PD August 1992. TI Large Games and Economies with Effective Small Groups. AA University of Toronto. SR Universitat Bonn Sonderforschungsbereich 303 Discussion Paper: B-215: Sonderforschungsbereich 303 an der Universitat Bonn. Adenauerallee 24-42, D-5300 Bonn 1 , DEUTSCHLAND. PG 45. PR no charge. JE C72. D51. KW Core. Large Games.

AB A model of large games in characteristic form is introduced and a number of results are reported. The gametheoretic results and techniques are related to economic models and results. For the main results, two properties are required: most players have many substitutes and small groups are effective - all or almost all gains to collective activities can be realized by groups bounded in absolute size of membership. From these two properties it follows that: approximate cores of large games are nonempty; approximate cores of large games are typically small, and converge to Walrasian payoffs; asymptotically, the approximate core correspondence is monotonic, that is, a vector of changes in population composition and a corresponding vector of changes in core payoffs point in opposite directions; the core of a continuum limit game with small (finite) groups is nonempty; and when all gains to group formation can be realized by groups bounded in absolute size then the convergence of the core occurs at finite group sizes and the monotonicity of the core correspondence is exact.

\section{Wooton, Ian}

TI Cross-Border Externalities and Trade Liberalization: The Strategic Control of Pollution. AU Ludema, Rodney D.; Wooton, Ian.

\section{Yamanaka, Ju-ichi}

PD June 1992. TI Institutional Behavior of Japanese Commercial Banks--An Empirical Perspective. AA Nomura Research Institute. Japan. SR Hoover Institute Working
Papers in Economics: E-92-15: Domestic Studies Program Working Paper Series, Hoover Institution, Stanford University. Stanford, CA 94305. PG 32. PR not available. JE G21. KW Institutional Behavior. Commercial Banks. Risk Mangement.

AB In 1993 interest rates on all time deposits will be deregulated, and segmentation of the financial businesses will be relaxed. As this critically important year draws closer, many Japanese commercial banks are struggling with unprecedented problems. One problem is a surge in the number of bad loans and another is the institutional behavior of commercial banks now under question. In the following pages, we shall examine the institutional behavior of the Japanese commercial banks. the process of its formation, and its ripple effect in light of the experience gained during the 1980's.

\section{Yosha, Oved}

TI Regulation by Entry: The Case of Monopolistic Insurance Market with Adverse Selection. AU Cornelli. Francesca; Yosha, Oved.

TI Information Revelation in a Market with Pairwise Meetings: The One Sided Information Case. AU Serrano. Roberto; Yosha, Oved.

PD October 1992. TI Disclosure Regulations and the Decision to Issue Securities Publicly. AA Brown University. SR Brown University Department of Economics Working Paper: 92-22: Department of Economics. Brown University, Providence. Rhode Island 02912. PG 21. PR no charge. JE G19, G21, G32. KW Disclosure. Banks. Stock Market. AB Firms wishing to issue securities on the stock market are required to disclose private information which might be beneficial to competitors. Issuing securities publicly is more costly than doing so privately. As a result, in equilibrium. firms with sensitive information issue securities privately, while competitors cannot unambiguously infer that the information withheld is very sensitive. This suggest that one special role of banks and venture capital in financial markets is to provide debt and equity financing, respectively, confidentially.

\section{You, Jong-il}

TI Growth and Structural Change in the Swedish Model. AU Ramaswamy, Ramana; You, Jong-il.

\section{Zang, Hyoungsoo}

TI Family Size. Income Distribution and Economic Growth: Theory and Cross-Country Evidence. AU Galor, Oded; Zang, Hyoungsoo.

\section{Zeckhauser, Richard}

PD July 1992. TI Robin-Hooding Rents: Exploiting the Pecuniary Effects of In-Kind Programs. AU Zeckhauser. Richard: Coate. Steve; Johnson, Stephen. AA Zeckhauser: Harvard University and National Bureau of Economic Research. Coate: University of Pennsylvania. Johnson: Harvard University. SR National Bureau of Economic Research Working Paper: 4125; National Bureau of Economic Research, 1050 Massachusetts Avenue, Cambridge, MA 02138. PG 22. PR \$5.00. JE R31. H23. H53. KW Transfers. Rent. Housing.

AB The pecuniary effects of cash and in-kind programs differ. A program that builds housing for the poor, for example, is likely to result in a lower price of existing low-income housing 
than would an equally costly cash transfer program. Lowincome renters in general would benefit; landlords would lose. The process we label Robin-Hooding rents employs in-kind programs to transfer rents from one group in society to another. Direct taxation of "donor" groups may be infeasible because their incomes can't be monitored. they are engaged in illegal activities, they are foreign, on the government's administrative apparatus is ineffective. A general equilibrium analysis reveals that absent the ability to target taxation, Robin-Hooding may be a valuable second-best transfer instrument. Robin-Hooding also has drawbacks. The real world use of Robin-Hooding in both developed and developing nations is discussed.

\section{Zejan, Mario}

TI Host Country Competition and Technology Transfer by Multinationals. AU Blomstrom, Magnus; Zejan, Mario; Kokko, Ari.

TI What Explains Developing Country Growth? AU Blomstrom, Magnus; Zejan, Mario; Lipsey, Robert E.

\section{Zilberman, David}

TI Not Just Another Paper Showing Violations of the Expected Utility Model: The Effects of Alternative Similarity on Risky Choice. AU Buschena. David E.: Zilberman. David.

\section{Zusman, Pinhas}

PD August 1992. TI Intraorganizational Influence Relations and the Optimality of Collective Action. AU Zusman, Pinhas; Rausser, Gordon C. AA Zusman: The Hebrew University of Jerusalem. Rausser: University of California, Berkeley. SR University of California at Berkeley, Department of Agricultural and Resource Economics (CUDARE) Working Paper: 528(Revision 2); Department of Agricultural and Resource Economics, 313 Giannini Hall. UC Berkeley, Berkeley, CA 94720. PG 22. PR \$6.75. JE D50, L00. KW Intraorganizational Influence. Collective Action.

AB Collective action, though often superior to anarchy, tends to be socially suboptimal even when the proclivity of free riders to defect is fully controlled and an organization for collective action is set up. An effective organization for collective action involving many participants will likely feature a coordinating center and peripheral participants. Even if the overall group objective is fully internalized by the center, the organizational equilibrium is suboptimal as it reflects the influence of narrowly rational peripheral participants. The efficiency loss is particularly evident in collective action over time, where group choices even within a single generation are likely to be myopic-a propensity further exacerbated by the center's short planning horizon. 